University of Louisville

ThinkIR: The University of Louisville's Institutional Repository

Electronic Theses and Dissertations

8-2009

\title{
Correlates of intake and disposition decisions by child protective services professionals.
}

Lisa Michele Johnson

University of Louisville

Follow this and additional works at: https://ir.library.louisville.edu/etd

\section{Recommended Citation}

Johnson, Lisa Michele, "Correlates of intake and disposition decisions by child protective services professionals." (2009). Electronic Theses and Dissertations. Paper 700.

https://doi.org/10.18297/etd/700

This Doctoral Dissertation is brought to you for free and open access by ThinkIR: The University of Louisville's Institutional Repository. It has been accepted for inclusion in Electronic Theses and Dissertations by an authorized administrator of ThinkIR: The University of Louisville's Institutional Repository. This title appears here courtesy of the author, who has retained all other copyrights. For more information, please contact thinkir@louisville.edu. 


\title{
CORRELATES OF INTAKE AND DISPOSITION DECISIONS BY CHILD PROTECTIVE SERVICES PROFESSIONALS
}

\author{
by
}

Lisa Michele Johnson

B.S., University of North Carolina at Greensboro, 1999

M.S.W., University of Illinois at Urbana-Champaign, 2001

\author{
A Dissertation \\ Submitted to the Faculty of the \\ Graduate School of the University of Louisville \\ in Partial Fulfillment of the Requirements \\ for the Degree of
}

Doctor of Philosophy

Kent School of Social Work

University of Louisville

Louisville, KY

August 2009 

Copyright 2009 by Lisa M. Johnson

All rights reserved 
CORRELATES OF INTAKE AND DISPOSITION DECISIONS BY CHILD

PROTECTIVE SERVICES PROFESSIONALS

by

Lisa Michele Johnson

B.S., University of North Carolina at Greensboro, 1999

M.S.W., University of Illinois at Urbana-Champaign, 2001

A Dissertation Approved on

July 23,2009

by the following Dissertation Committee:

\footnotetext{
Bibhuti K. Sar, Ph.D., Chair

Becky F. Ahtiø, Ph.D.

Anita P. Barbee, Ph.D.

Christopher W. Flaherty, Ph.D.

Armon R. Perry, Ph.D.
} 


\section{ACKNOWLEDGEMENTS}

I would like to thank my parents, Allan and Jean Johnson for encouraging and supporting me throughout my life. Their belief in my potential planted the seed that grew into the completion of this endeavor. I am grateful to my dissertation committee members for helping me complete this project. Many thanks to Dr. Sar for patiently discussing all of the approaches to this project; to Dr. Barbee for making connections with state administrators; to Dr. Antle for guiding me through the statistical analyses; and to Drs. Perry and Flaherty for their helpful feedback and words of encouragement at each step of the process. I appreciate the participation of the child protection professionals who took time to complete the survey for this project and the help of the state administrators who facilitated the survey process and provided helpful information. I am also thankful for my time spent among the child welfare community in Louisville. I have learned so much from the dedication of these professionals to the well-being of all children and families. I would like to also thank my friends and family who have cheered me on along the way, especially Andria who cheered the loudest. 


\title{
ABSTRACT \\ CORRELATES OF INTAKE AND DISPOSITION DECISIONS BY CHILD PROTECTIVE SERVICES PROFESSIONALS
}

\author{
Lisa M. Johnson
}

July 23, 2009

This study examined intake and post-investigative disposition decision making among professionals engaged in child protective services to understand disproportionality and disparities in the child welfare system. Using child welfare, decision making, and attribution theories as a framework, a multivariate $2 \times 2 \times 2$ factorial vignette design was used to examine intake and post-investigative disposition decision making among 400 child protective caseworkers and supervisors employed in a Midwestern state. Data were gathered through an online self-administered survey. Among the key variables of interest-race, socio-economic status, and family structure--only the family's socio-economic status was found to influence the intake decision but none were associated with the disposition decision. As expected, participants in this study who endorsed the child's removal were more likely to attribute the cause of the maltreatment to a parent's internal characteristics rather than any external circumstances; and this was more so when the family was described as either two-parent or middle socio-economic status. Plus, prior involvement of a family with CPS was found to be a key predictor of both screen-in and removal. Implications of these findings 
for practice and future research to understand disproportionality and disparities in the child welfare system are discussed. 


\section{TABLE OF CONTENTS}

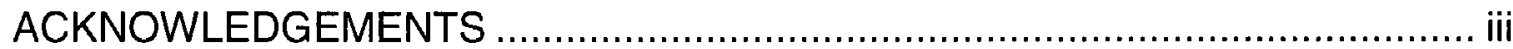

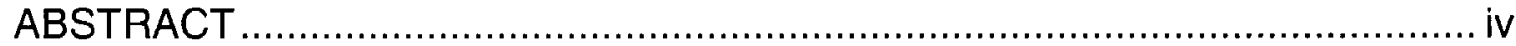

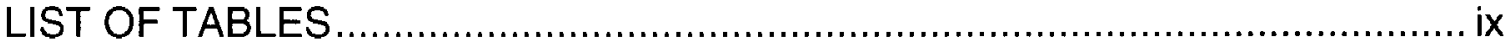

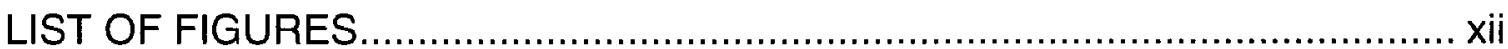

CHAPTER I: STATEMENT OF THE PROBLEM ...........................................

Child Welfare and Child Maltreatment ....................................................

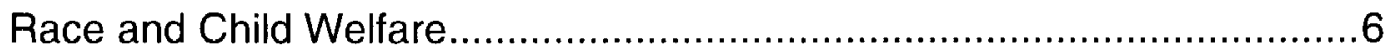

Decision Making in Child Protection .....................................................32

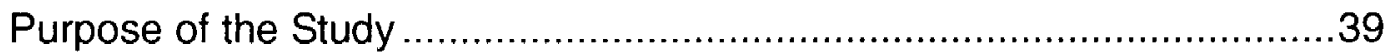

CHAPTER II: REVIEW OF THE LITERATURE ........................................4 41

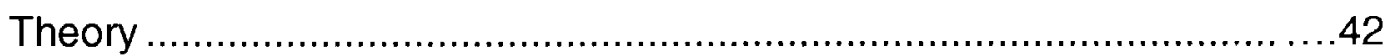

Decision Making in Child Protection .....................................................64

Development of an Integrated Framework for Problem Consideration.....88

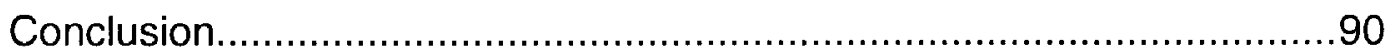

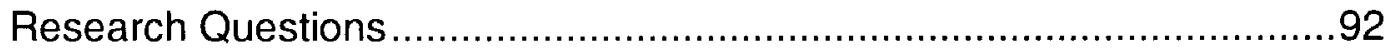

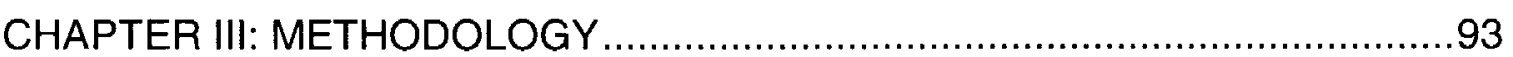

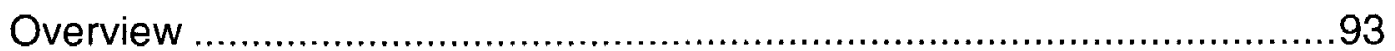

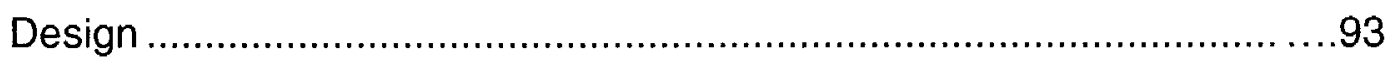

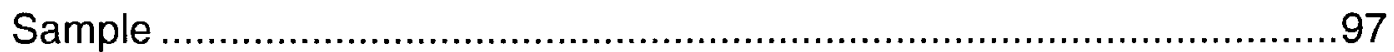

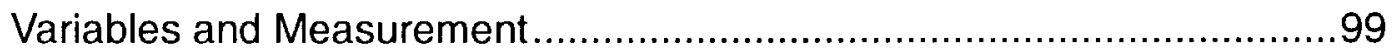

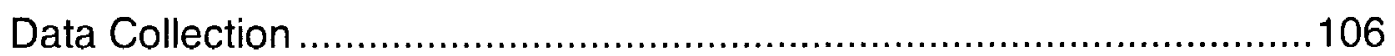




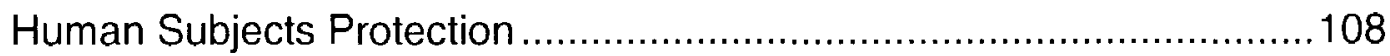

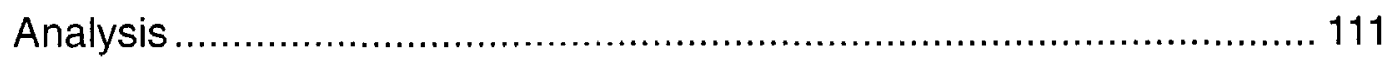

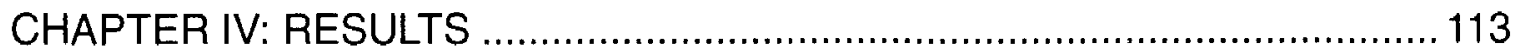

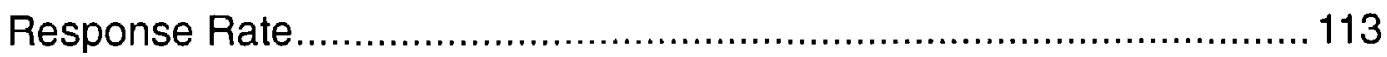

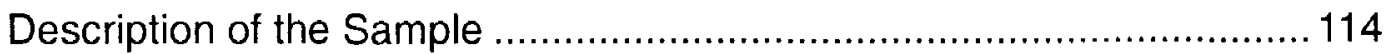

Correlates of Decision Making in Child Protection Cases .....................123

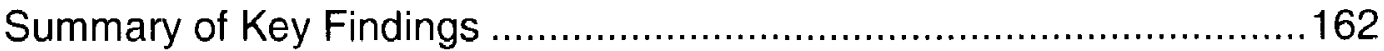

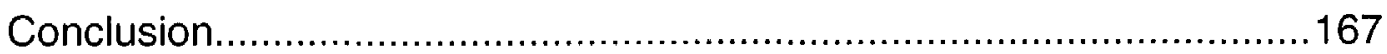

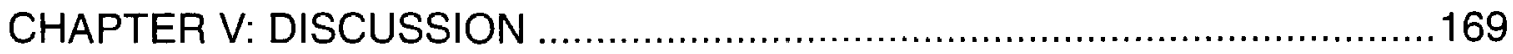

Summary of Methods and Demographics …...................................170

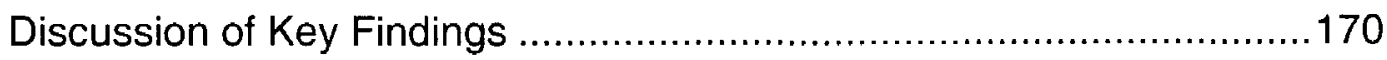

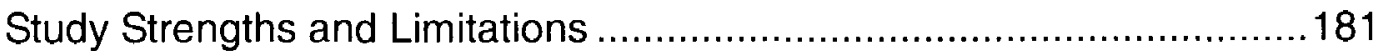

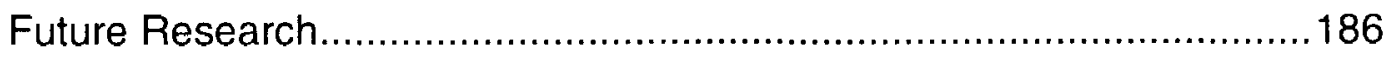

Implications for Child Protection Practice and Policy..........................188

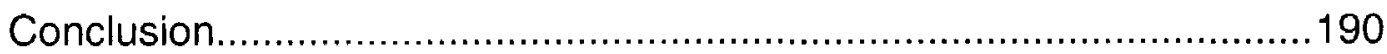

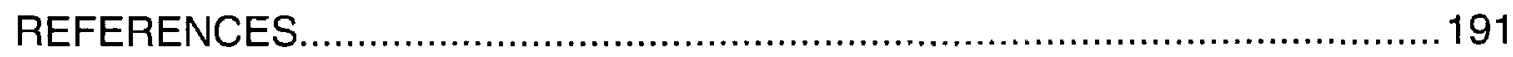

Appendix A: Professional Decision Making Survey Questionnaire and Preamble

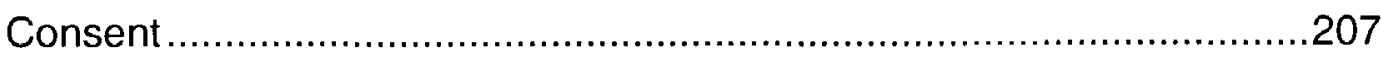

Appendix B: Vignettes Randomly Assigned in Survey ...............................228

Appendix C: Factorial Vignette Matrices ……….......................................239

Appendix D: Participant Communications …….........................................243

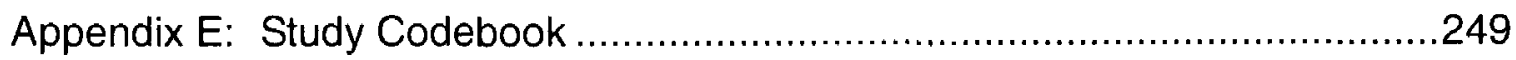

Appendix F: Informal Name Survey Questionnaire ...................................258 
Appendix G: Demographics for Total and Final Samples 259

Appendix H: Results of Qualitative Analysis .............................................262

Appendix 1: Test Statistics for Logistic Regression Models Based on

Theoretical Constructs. 264

Appendix J: Summary of Research Regarding Factors Contributing to Disproportionality and Disparity 266

Appendix K: Summary of Decision Making Literature 275

Appendix L: Factors Impacting Decision Making in Child Protection by Design 282

Appendix M: Factors Impacting Decision Making in Child Protection Checklist. 286

CURRICULUM VITAE 289 


\section{LIST OF TABLES}

TABLE

PAGE

1. Developmental-Ecological Framework of Child Maltreatment and Related

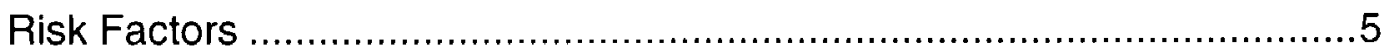

2. Categorization of Factors Influencing Decision Making in Child Welfare...43

3. Target State Child Welfare Demographics..........................................98

4. Comparison of Study Samples and Response Rates..........................115

5. Transformation of Scores from Six-point to Five-point Response Set ....122

6. Test Statistics for Individual Decision Making Factors Related to Decision

Outcome (Decision B) 129

7. Test Statistics for Individual Decision Making Factors Related to SES of

Family (Decision B) 130

8. Groupings of Parental Attribution Items into Factors ..........................132

9. Test Statistics for Individual Parental Attribution Items Related to Decision Outcome (Decision B) 134

10. Test Statistics for Individual Parental Attribution Items Related to SES of Family (Decision B) 135

11. Test Statistics for Individual Parental Attribution Items Related to Family

Structure (Decision B) 136

12. Logistic Regression Model: Variables Predicting Disposition Decision (B) Based on Bivariate Analysis 
13. Logistic Regression Model: Variables Predicting Disposition Decision (B) Based on Theoretical Constructs. 140

14. Test Statistics for Individual Decision Making Factors Related to Decision Outcome (Decision A2) 143

15. Test Statistics for Individual Parental Attributions Related to Decision Outcome (Decision A2). 146

16. Test Statistics for Individual Parental Attributions Related to SES of Family (Decision A2)

17. Logistic Regression Model: Variables Predicting Intake Decision (A2)

Based on Bivariate Analysis

18. Logistic Regression Model: Variables Predicting Intake Decision (A2)

Based on Theoretical Constructs

19. Percentages of Respondents in Various Practice Areas by Decision

Outcome (Decision B2) 153

20. Test Statistics for Individual Decision Making Factors Related to Decision Outcome (Decision B2) 155

21. Test Statistics for Individual Parental Attributions Related to Decision Outcome (Decision B2) 158

22. Logistic Regression Model: Variables Predicting Disposition Decision (B2) Based on Bivariate Analysis 160

23. Logistic Regression Model: Variables Predicting Disposition Decision (B2) Based on Theoretical Constructs. 162 
24. Responses to Open-ended Questions Regarding Respondents'

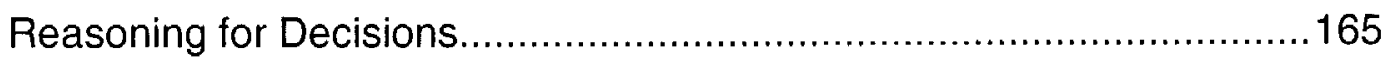

25. Comparison of Screen-In and Removal Percentages: Study Sample and

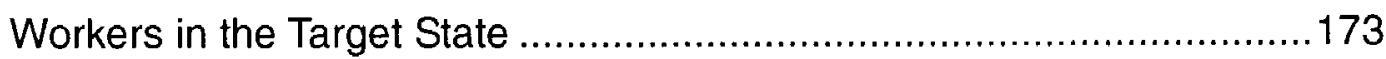




\section{LIST OF FIGURES}

FIGURE

PAGE

1. Simplified model of caseload flow of children ........................................26

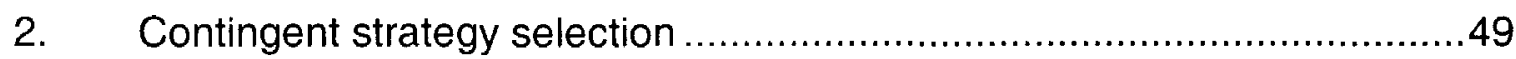

3. Jones and Davis' contributions to Heider's attribution theory ..................52

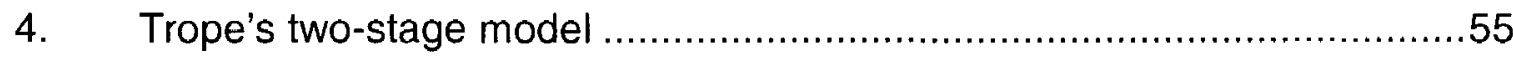

5. Outline of decision making in child protective services ..........................89

6. From theoretical frameworks to research study..................................90

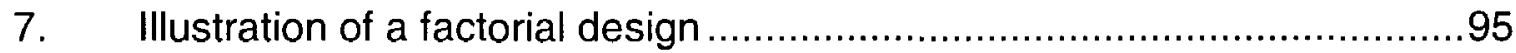

8. Initial reassignment of responses from six-point to five-point response

set 


\section{CHAPTER ONE: STATEMENT OF THE PROBLEM}

Joseph and Sam are similar in many ways. Both boys are in the fourth grade. They both live in a working-class neighborhood on the south side of town. Their parents are employed in similar positions and have comparable household incomes. They even make the same grades in school. Because of their similarities and parallel life circumstances, it seems reasonable to believe that if both of these boys came into contact with the child welfare system, their experiences and outcomes would probably be very much alike. Yet there is one characteristic that the boys do not share and it is this difference that may send them and their families on very different journeys through the system. Joseph is Black and Sam is White, and despite their many similarities, this one difference may have a variety of consequences.

\section{Child Welfare and Child Maltreatment}

On any given day in any given city in the United States, a child and his/her family will be brought to the attention of the local child protection agency. Usually, a neighbor, a teacher, a doctor, or a police officer will call the child protection intake hotline to report suspicions or evidence of risk to the child due to the actions or inactions of the child's parent(s) or guardian(s). This phone call is the beginning of a process - known as the child welfare system - that may last hours or years for the family, depending upon decisions made not only by the child and family, but also by a multitude of others, including professionals, who are tasked with guiding children and families through this process. The professionals may be child protection investigators, family court judges, school counselors, or individuals in a number of other positions who come into contact with children and families during their journey through the child welfare system. In a perfect 
world, there would be no need for this system to exist and in a more equitable world than this one, there would be no disparity between the experiences of children and families in this system based on characteristics such as race or social status. Unfortunately, the world is not perfect and our child welfare system is not equitable.

It has been said that the child welfare system is a reflection of society's views about the value of children and families, and the rights of parents in relation to the rights of children (Downs, Costin, \& McFadden, 1996). If this is the case, then the child welfare system, like most, if not all, other social systems in the United States, is a product of our collective history and continues to be influenced by our current practices and future goals.

Although there have been enormous changes in American child welfare from colonial to current times, the current system continues to rely heavily on principles originating in the distant past. According to Billingsley and Giovannoni (1972), three factors rooted in the philosophy and beliefs of the Anglo-American settlers strongly influenced the development and current state of child welfare: (1) poverty was linked with indolence and moral depravity; (2) religious autonomy and sectarianism favored private over public provision; and (3) the demographic homogeneity of the early settlers created the probability for intensely ethnocentric policies and practices.

In colonial times, children who could not be adequately cared for by their families were considered the responsibility of the local township. Young children were cared for by individual families in return for a small, regular sum of money 
or goods. Some children were sent to live in almshouses with adults considered deviant or deficient. Able-bodied, older children were indentured to tradesmen. In some cases, the local poor law authority would provide "outdoor relief"-aid to children in their own homes. This form of protection was nominal and poorly managed (Downs, Costin, \& McFadden, 1996).

Gradually, society realized that children needed more specialized services. Efforts were spearheaded by groups of citizens who formed voluntary agencies. Orphanages were a result of such efforts. It is important to note, however, that these early forms of child services were for White children. During slavery, the family was essentially the only source of support for Black children. In the North where slavery had been abolished, Black children were often excluded from the services of orphanages (Downs et al., 1996).

As states began to take responsibility for social services that localities were unwilling or unable to provide, specialized state institutions (e.g., reform and training schools) were established for children who were blind, deaf, or mentally disabled. This caused the need for a centralized state-level agency to coordinate the administration of state programs. In 1863, Massachusetts was the first to establish a State Board of Charities for the supervision of all state charities (Downs et al., 1996).

The federal government was slow to become involved in child welfare due to concerns about states' rights and family rights. However, concerns about invading family rights were not present in the federal government's role in breaking up Native American families by sending their children to boarding 
school far away from their homes. The Children's Bureau, which was created in 1912 , focused its efforts on widespread distribution of information and not on delivery of children's services. The Social Security Act of 1935 established AFDC and a federal role in child welfare services through Title IV-B. The focus on social reform during the 1960s sparked an explosion of federal programs for families and children. Although ideological conflicts continued to persist (and are still present) regarding the role of government in family affairs, the federal government took a major step in addressing child maltreatment and child welfare by enacting the Child Abuse Prevention and Treatment Act (CAPTA) of 1974. This legislation established the National Center on Child Abuse and Neglect as well as regulations for states that receive federal child welfare funding. CAPTA has been reauthorized and other pieces of federal legislation that addressed child welfare issues were enacted in the 1980s and 1990s.

\section{Maltreatment and Risk Factors}

Entry into and involvement with the child welfare system is based on occurrence or risk of maltreatment-abuse and neglect. There is no single cause of child maltreatment, but multiple risk factors have been identified (Asawa, Hansen, \& Flood, 2008). These risk factors have been organized under the developmental-ecological framework into four interrelated groups: parent factors, child factors, factors in the immediate interactional context, and factors in the broader environmental context (Asawa et al.). Table 1 provides examples of risk factors from Asawa and colleagues that are encompassed by each of the four categories. 
Table 1

Developmental-Ecological Framework of Child Maltreatment and Related Risk

Factors

\begin{tabular}{|c|c|c|c|}
\hline Parent & Child & Interactional & Environmental \\
\hline $\begin{array}{l}\text { - } \begin{array}{l}\text { mental illness } \\
\text { low self- } \\
\text { esteem } \\
\text { - poor impulse } \\
\text { control } \\
\text { - maltreated as } \\
\text { a child } \\
\text { - substance } \\
\text { abuse }\end{array}\end{array}$ & $\begin{array}{l}\text { - } \begin{array}{l}\text { prenatal drug } \\
\text { exposure: low } \\
\text { birth weight, } \\
\text { developmental } \\
\text { disabilities, } \\
\text { prematurity }\end{array} \\
\text { - age (younger = } \\
\text { higher risk) } \\
\text { behavior } \\
\text { problems } \\
\text { low self } \\
\text { esteem, lack of } \\
\text { social support, } \\
\text { increase risk of } \\
\text { sexual abuse }\end{array}$ & $\begin{array}{l}\text { - lack of } \\
\text { parenting skills } \\
\text { - } \begin{array}{l}\text { poor } \\
\text { knowledge of } \\
\text { child } \\
\text { development }\end{array} \\
\text { - parental } \\
\text { relationship } \\
\text { discord } \\
\text { - intimate } \\
\text { partner } \\
\text { violence }\end{array}$ & $\begin{array}{l}\text { - } \begin{array}{l}\text { poverty } \\
\text { - } \\
\text { neigh crime } \\
\text { - } \quad \begin{array}{l}\text { family social } \\
\text { isolation }\end{array} \\
\text { - lack of societal } \\
\text { awareness } \\
\text { about child } \\
\text { maltreatment } \\
\text { - } \begin{array}{l}\text { acceptance of } \\
\text { corporal } \\
\text { punishment as } \\
\text { a form of } \\
\text { discipline }\end{array} \\
\text { general } \\
\text { acceptance of } \\
\text { violence }\end{array}\end{array}$ \\
\hline
\end{tabular}

Statistics

The most recent national statistics available on the incidence and prevalence of children's involvement in the child welfare system is from FY 2006. This is due to the inherent delay in the system of states gathering the data and then reporting it to the federal government. According to the US DHHS (2008a), between October 1, 2005 and September, 30 2006, 3.6 million children received 
investigation by CPS agencies. Approximately 905,000 (or $25 \%$ ) of these children were found to be maltreated. The data regarding types of maltreatment is as follows: $64 \%$ of maltreated children were neglected, $16 \%$ experienced physical abuse, $9 \%$ were sexually abused, $7 \%$ were psychologically maltreated, $2 \%$ were victims of medical neglect, and $15 \%$ experienced some "other" form of maltreatment such as "abandonment," "threats of harm to the child," or "congenital drug addiction"1 (US DHHS, 2008a). The US DHHS (2008a) notes that states may code any type of maltreatment that does not fall into one of the main categories as "other." The vast majority of these children were new to the child welfare system. Nearly three-quarters of maltreated children had no history of prior victimization (US DHHS, 2008a). According to the US DHHS (2008b) on September $30,2006,510,000$ children were in foster care and 129,000 children were awaiting adoption.

\section{Race and Child Welfare}

The overrepresentation of African American children in the child welfare system has been identified as a problem for over thirty years (see Billingsley \& Giovannoni, 1972). Multiple authors have addressed this problem in child welfare (for example, Garland \& Besinger, 1997; Harris \& Courtney, 2003; Morton, 1999; Roberts, 2002) and interest in studying this issues has grown steadily (Hill, 2006).

In 1999, Westat, the research firm that conducted the National Incidence Studies, and the Children and Family Research Center within the School of

\footnotetext{
${ }^{1}$ These maltreatment type percentages total more than 100 percent because children who were victims of more than one type of maltreatment were counted for each type of maltreatment (US DHHS, 2008a).
} 
Social work at the University of Illinois at Urbana-Champaign began to jointly examine the factors contributing to overrepresentation of African American children in the child welfare system (Race Matters Consortium, 2005). Casey Family Programs, a national non-profit foundation that had also been exploring the issues of race and child welfare, joined the collaboration in 2001. "Race Matters" forums, which brought together child welfare researchers and experts from across the U.S. were held in 2001 and 2002 (Race Matters Consortium). Since that time, research on children's disproportionate representation by race and other child/family characteristics has progressed and local, state, and federal government agencies have become more involved in addressing this problem.

\section{Disproportionality and Disparity}

Differences in representation of children and families of various races in the child welfare system are known as disproportionality and disparity (Hill, 2006). Disproportionality refers to the difference in the percentage of a group of children in the child welfare system as compared to that group's percentage in the general population (Hill, 2006). This is illustrated by the fact that in $2006,15 \%$ of children in this country were Black, while $32 \%$ of the children in foster care were Black (United States Government Accountability Office [U.S. GAO], 2008). This is known specifically as overrepresentation because the percentage of Black children in the child welfare system far exceeds the percentage of the same group of children in the general population. If Black children were proportionally represented, based simply on race, we would expect to see Black children make up about 15 percent of children in the child welfare system. The disproportionality 
rate for Black children in foster care is 2.13 , which means that these children are represented in the system at more than twice their proportions in the general population (Hill, 2006).

Disparity means that one group of children experiences inequitable treatment or outcomes as compared to another group of children (Hill, 2006). Such disparity is present throughout the child welfare system, including key decision points (reporting, investigation, substantiation, out-of-home placement, and exit), treatment, services, and resources. Research in this area indicates that children of color and their families who are involved with the child welfare system often experience different treatment and more negative trajectories than White children and families (for example, Garland \& Besinger, 1997; Derezotes, 2002; Harris \& Courtney, 2003; Rodenberg, 2004). For example; according to Hill (2006), fewer Black children receive mental health services than White children, even though Black children have been identified as having greater need for such services.

Although Black children are not the only group affected by disproportionality and disparity (Native American, Latino, and Asian children are often overrepresented in the child welfare system and Caucasian children are most often underrepresented), this discussion will focus on Black children, as they are overrepresented at the greatest rates throughout the country and often experience the greatest levels of disparity during their involvement with the child welfare system (Hill, 2006). 
The Overrepresentation of Black children in the Child Welfare System

An important and interesting point is that overrepresentation in the child welfare system is a fairly recent occurrence for Black children. In fact, these children were totally excluded from the orphanages established during the $19^{\text {th }}$ century to rescue poor and orphaned children from the appalling conditions of almshouses. This exclusion from mainstream provisions for child welfare continued through the first half of the $20^{\text {th }}$ century and the creation of charitable organizations, mutual aid societies, and settlement houses intended to aid poor White immigrants. "The only alternative for Black children at that time was the small number of segregated orphanages that had been established by White or Black religious groups" (Hill, 2006, p. 7).

Black self-help efforts have been largely ignored in the child welfare literature, but services provided to Black children by their own communities were integral to the welfare of these children. Churches, schools, secret organizations, women's clubs, and individual philanthropy in the Black community were integral in providing for needy Black children "in the face of an inadequate and discriminatory child welfare system" (Billingsley and Giovannoni, 1972, p. 58).

Before the modern civil rights era, segregation existed in the child welfare system, as in the majority of other social welfare systems in America. Black children were increasingly, though still only partially, included in mainstream child welfare services between WWII and the early 1970s (Billingsley and Giovannoni, 1972). Reasons for this increase include: (1) a population shift from the rural South to the urban North, which increased the presence of Black children; (2) 
child welfare services were increasingly directed at poor children and families, and as White wealth increased, Black children became disproportionately poor; and (3) integration became a national goal (Billingsley and Giovannoni, 1972). More recently, in an effort to determine the incidence of reported and unreported child abuse and neglect, the federal government funded National Incidence Studies in 1980,1986, and 1993. These are the most comprehensive and informative studies available, which provide national figures on children who are abused and neglected and those who never receive services (Derezotes, 2002). Findings from the National Incidence Studies support existing hypotheses about risks for child maltreatment. For example, significant differences were found among different income groups. Children in families with lower annual incomes (below $\$ 15,000$ ) had abuse and neglect rates that were 22 times the rates for children in families with higher incomes $(\$ 30,000$ or more; Hill, 2006). Race, however, was not supported as influencing incidences of maltreatment. In fact, all three studies revealed no statistically significant differences in the overall maltreatment rates between Black and White families (Hill, 2006).

In contrast, there have been studies that have shown racial differences in maltreatment rates, but differences that do not support the overrepresentation of Black children in the child welfare system. For example, Korbin, Coulton, Chard, Platt-Houston, \& Su (1998) studied four neighborhoods in Ohio, two predominately White and two predominately Black, and found lower rates of maltreatment among families in the Black neighborhoods, even when poverty was greater in these communities. According to these authors, community 
protective factors such as social cohesion and extended family ties may serve as mediators of maltreatment, even in the presence of environmental risk factors such as poverty.

A national study of children who received in-home or out-of-home child welfare services showed that Black children were less likely than White children to have certain advantaged characteristics (e.g., living in two-parent families, neither parent abusing drugs, the family relying on earnings and not welfare, and the family living in low-crime neighborhoods), which were correlated with receiving in-home services. In other words, the less advantaged Black children were more likely to be placed in out-of-home care than White children (U.S. DHHS, 1997). A reanalysis of the data from this study revealed that even when Black children were in advantaged circumstances, they were still more likely to be placed in out-of-home care than their White counterparts (Hill, 2005).

Possible Causes of Disproportionality/Disparity in Child Welfare

Disproportionality in child welfare has been attributed to a myriad of interrelated factors, both systemic and individual. Although some of these factors are more responsible for the overrepresentation of Black children in the child welfare system than others, there is no one factor that has been identified as causing this problem.

The U.S. GAO (2007) recently conducted a comprehensive analysis of the social problem of differences among children and families of different races in the child welfare system. This study included a national survey of public child welfare agency leadership and staff. The results point to several factors that may affect 
Black children's disproportional representation in foster care, including (a) higher rates of poverty among Black families, (b) families' difficulties in accessing services that are instrumental in creating safe home environments and preventing removal of children, and (c) racial bias and cultural misunderstanding among child welfare decision makers. These and other factors will be explored in the proceeding sections in an effort to highlight some of the arguments posed by practitioners and researchers as to how these factors influence disproportionality and disparity in child welfare.

Racism

In his report Synthesis of Research on Disproportionality in Child Welfare: an Update, Hill (2006) concludes that although race is a factor in child protective services decision making and that there are disparities in the treatment of Black children and families, the causes of disproportionality cannot be identified based on research done in this area, which has almost completely focused on the existence of disproportionality and disparities, and not directly on their causes. Hill's final thought is that racial differences cannot be convincingly linked to a presence or absence of intentional or unintentional bias, and that future research should address causal factors of disproportionality and disparity.

Other authors have gone further to hypothesize that institutional racism and individual bias form the roots of disproportional representation of and disparate outcomes for Black children in the child welfare system. Although the authors provide compelling arguments for this hypothesis, as Hill (2006) points out, there has been negligible empirical evidence to support racism and bias as 
causes of disproportionality and disparity in the child welfare system. Despite this lack of empirical evidence, practice wisdom has led some professionals to create programs to address disproportionality and disparity in child welfare that focus on curtailing or eliminating systemic/institutional racism and/or individual bias.

Several of these programs have been shown to affect more positive outcomes for children and families of color in the child welfare system. For example, the U.S. GAO (2007) reported that an evaluation of a comprehensive cultural competency training program for child protection staff in Washington state showed that staff who participated in the training had higher rates of Black children being reunited with their families than staff who did not participate in the training. Also, a study by Johnson, Antle, and Barbee (2009) found that child welfare professionals engaged in an anti-racism training increased their knowledge about racial issues and reported more awareness of institutional racism, White privilege, and racial dynamics. Furthermore, these professionals indicated a willingness and ability to engage in more culturally competent practice as a result of this training.

\section{Poverty}

Closely linked to the issue of race in child welfare is that of class. Class is often operationalized by level of poverty experienced in the literature. Poverty is the most important predictor of foster care placement and length of time in care (Lindsey, 1992). Researchers have put forth three types of associations between poverty and child maltreatment: maltreatment may be indirectly caused by parental poverty, detected because of parental poverty, or defined by parental poverty (Roberts, 2002). As Black children and families are disproportionately 
poor, race and class are intricately connected in the child welfare system.

Therefore, the decisions and actions of individuals in the child welfare system may be influenced by a combination of attitudes about both race and class.

McRoy (2002) points out that poverty is often cited in the literature as a root cause of disproportionality. In 2006, an estimated $24 \%$ of Black Americans lived below the poverty level compared to only $8 \%$ of White Americans (U.S. Census Bureau, 2007). In fact poverty is linked to entry into the child welfare system for children, regardless of race (Sedlack \& Broadhurst, 1996). However, since Black families are disproportionately poor, it follows that this would translate into disproportional representation in the child welfare system. According to the U.S. GAO (2007), in 2003, the top three sources of child protection reports were educational staff, law enforcement officials, and social services personnel, of which the latter two disproportionately interact with lowincome individuals. This interaction of public welfare professionals and Black families is related to the hypothesis of visibility as a cause of disproportionality. This hypothesis suggests that Black children are more likely to become involved with the child welfare system because Black families are more visible to those who make referrals to child protective services (McRoy, 2002). Poverty and visibility may be viewed as interrelated causes of racial differences in the child welfare system. The depressed sociopolitical and economic positions of many Black families lead them to be involved with government systems, such as welfare and criminal justice, which exposes them to greater scrutiny. 
It must be acknowledged, however, that this logic is complicated by the complex relationship between race and poverty. As mentioned above, Korbin and colleagues (1998) found that protective factors such as extended family networks played a role in mitigating the effects of poverty and the risk of maltreatment for Black families. Furthermore, Hill (2005) found that even when Black children possessed protective factors such as two-parent families, education, and higher income, they were still more likely to be placed in out-of-home care than White children who were more likely to receive in-home services.

While the majority of low-income families do not maltreat their children, poverty is prominent among families in the child welfare system. According to the NIS-3 (Sedlack \& Broadhurst, 1996), family income is significantly related to incidence rates in nearly every category of maltreatment. For example, compared to children in homes with higher incomes $(\$ 30,000$ or more per year), children in families with annual incomes below $\$ 15,000$ were over 22 times more likely to experience some form of maltreatment, over 44 times more likely to be neglected, almost 18 times more likely to be sexually abused, and sixty times more likely to die from maltreatment. The authors of the NIS-3 study point out a number of problems associated with poverty that may contribute to maltreatment. These problems include more transient residence, poorer education, higher rates of substance abuse, mental illness, cognitive impairment, and less adequate social support systems.

The National Survey of Child and Adolescent Well Being (NSCAW), conducted by the U.S. Department of Health and Human Services (U.S. DHHS, 
ACF, OPRE, 2006b) found that approximately one-quarter of households who have been investigated for child maltreatment had a total household income under $\$ 10,000$, and $65 \%$ had a total income under $\$ 25,000$. In the general population, however, $20 \%$ of families including children have incomes under $\$ 25,000$ (U.S. Census Bureau, 2008b). This reveals an overrepresentation of poor families in the child welfare system.

The effects of poverty may be mitigated by factors such as geography (e.g., rural vs. urban; Barth, Wildfire, and Green, 2006), amount of danger in the home, characteristics of the caregivers, and social environments (Scannapieco \& Carrick, 2003). As Hines, Lemon, Wyatt, and Merdinger (2004) point out, the relationship between poverty and child well-being outcomes, such as maltreatment rates and entry into the child welfare system, is blurred by several family and neighborhood conditions that co-occur with poverty. For example, poor families are more likely to be headed by young, single mothers who have low levels of educational attainment and are unemployed or underemployed. Furthermore, neighborhoods in which the rate of poverty exceeds $40 \%$ often suffer from high crime rates, inadequate systems of education, violence, and inadequate housing (Hines et al., 2004). The idea that poverty should be separated from the effects that poverty has on individual and family functioning when considering the role of poverty in child welfare (McDaniel, 2006) is highlighted in the literature. Examples of studies that support this point follow. Scannapieco and Carrick (2003) studied differences among poor families who maltreat their children and those who do not maltreat their children. These 
authors found that poor families who were substantiated were more likely to expose children to unsanitary conditions within the home, as well as hazards and other dangers. Maltreating caregivers had fewer parenting skills and a decreased capacity as a parent due to substance abuse and mental illness.

Berger (2005) analyzed data from the 1985 National Family Violence Survey (NFVS) in an effort to estimate the effects of income and other factors on physical violence toward children. Although Berger suggests that findings regarding income should be viewed cautiously due to limited income data, lack of information on sources of income, and small sample size, these findings are relevant, as they suggest that income likely has a more substantial impact on parental violence in single-parent families than two-parent families. As Waldfogel (2005) points out, this finding suggests that "the care of children may be more sensitive to economic conditions in families where only one parent is present" ( $p$. 102).

Carter and Meyers (2007) used data from the National Study of Protective, Preventive, and Reunification Services Delivered to Children and Their Families, 1994 to consider the influence of poverty indicators and parental characteristics on physical neglect. Although these authors found a high correlation between substantiated physical neglect and indicators of poverty such as unemployment and receipt of social welfare assistance, these indicators were not found to be predictive of substantiated physical neglect. The factors that were strong predictors of physical neglect were substance abuse problems and mental illness among primary caretakers. The authors draw from Berger (2006) to hypothesize 
that low-income families who benefit from economic resources provided by social assistance programs such as WIC and Medicaid, are less likely to come into contact with child protective services, thereby having less of a chance of being substantiated for physical neglect.

Like race and family structure, considerations of the impact of poverty on child welfare involvement and outcomes are clouded by the interrelatedness of poverty and other factors such as geography, as well as the effects of poverty on family functioning. The literature continues to call for more research that teases out these interwoven factors.

Visibility

The visibility hypothesis states that Black children are more likely to become involved in the child welfare system if they are more visible in the population. In other words, there is a higher probability of Black children entering the child welfare system in a geographic area where they comprise a small number of the population (Jenkins \& Diamond, 1985). In their reanalysis of data from public welfare departments in 94 counties, Jenkins and Diamond found support for this hypothesis. Results showed that Black children were two times more likely to enter foster care when the Black community comprised only $5-10 \%$ of the local population than when the Black community was $30-50 \%$ of the population. Jenkins and Diamond suggested that this may mean the visibility of Black children could set them apart and propel them into care or the smaller Black population could mean a thinner kin support network and fewer buffers between children and placement. 
Family structure

The past several decades have witnessed a shift in types of family structure from a predominance of two biological parents and their children to a variety of parental living arrangements such as single biological mothers and fathers, unmarried biological parents who are cohabitating, unrelated surrogate parents, and kinship care arrangements with an array of extended family members (Oliver, Kuhns, \& Pomeranz, 2006). The children and families who populate the child welfare system represent a variety of non-traditional family structures; therefore, it is important to consider how the issue of family structure has been addressed in the child welfare literature.

One method of exploring the connection between disproportionality and differential family structure is to consider the family structures of those involved in the child welfare system versus families in the general population. The National Survey of Child and Adolescent Well Being (NSCAW), conducted by the United States Department of Health and Human Services (USDHHS), gathered data from 6,231 children and their families who had contact with the child welfare system between October 1999 and December 2000 (U.S. DHHS, ACF, OPRE, 2006b). The purpose of this national, longitudinal study was to describe the characteristics and trajectories of children and families who are involved in the child welfare system. According to the NSCAW, approximately one-third of children involved in the child welfare system live at home live with two parents, and for the majority of these children, there is no other adult in the household. However, the majority of children in the child welfare system (56\%) live in single- 
mother households, and nearly half of these children experience another adult living in the household. Furthermore, approximately one-quarter of children in the child welfare system live with their mother and an unrelated male (USDSSH, ACF, OPRE). In contrast to the figures above, the majority of children $(68 \%)$ in the general population live with married parents, and only $3 \%$ live in unmarried, two-parent homes. Approximately $23 \%$ of children in the general population live with their mothers (US Census Bureau, 2008a). Given this data, it is clear that in the child welfare system, children in single-parent homes are more frequently represented. Furthermore, when race is introduced, differences in family structure also appear. In the general population, $74 \%$ of White children live with married parents versus $36 \%$ of Black children. Moreover, only $20 \%$ of White children live in single-parent families, while over half of Black children live with their mothers or fathers only (US Census Bureau, 2008a).

Regarding child maltreatment and family structure, Nobes and Smith (2002) compared the extent of physical punishment of children in one-parent (lone mother) and two-parent (mother and father) families. Such a study is relevant to child welfare concerns given the likelihood that physical punishment may lead to abuse and/or neglect. The authors interviewed a total of 498 parents from 399 families in the U.K., asking them about the nature, severity, and frequency of their punishment of their children. Findings indicated that the frequency of lone mothers' and partnered mothers' use of physical punishment did not differ significantly. However, inclusion of fathers showed that children in two-parent families were punished more frequently than children in one-parent 
families. The authors also explored confounding factors that might influence associations between family structure and use of physical punishment. They found that regarding measures of social deprivation, including poverty, lone parents were, on average, worse off than partnered parents. However, facing such social disadvantages did not lead to a more significant presence of punishment among single-parent families. Among families with higher incomes, Ione parents were more likely to have used severe punishments, but this difference among one- and two-parent families was not significant among those in lower income groups. Ultimately, the authors found that lone mothers were no more punitive than partnered mothers, despite (or maybe because of) their exposure to social disadvantages such as poverty, and that their children experience less frequent and less severe physical punishment than do those in two-parent families. These findings indicate that risk of abuse and/or neglect as a result of physical punishment is not necessarily associated with a single-parent family structure. The authors provide an interpretation of these findings that highlights the role that fathers in two-parent families may play in exacerbating stressful social situations, which may lead to physical punishment of children.

Although children in single-mother families may experience less punishment than those in two-parent families, the presence of an unrelated male may increase the risk of harm to children. In contrast to the results shared by Nobes and Smith (2002), findings from the Third National Incidence Study of Child Abuse and Neglect (NIS-3; Sedlack \& Broadhurst, 1996) indicate that children in single-parent families are at higher risk of physical abuse and severe 
neglect than children in two-parent families. For example, compared with children living with two parents, children in single-parent families had a $77 \%$ greater risk of being harmed by physical abuse, an $87 \%$ greater risk of being harmed by physical neglect, and a $120 \%$ greater risk of being endangered by some type of abuse or neglect. Furthermore, among children in single-parent families, those living with their fathers were over 1.5 times more likely to be physically abused than those children living with their mothers. The researchers concluded that the relationship between family structure and maltreatment incidence is understandable, given the "added responsibilities and stresses of singleparenting, together with the likelihood that surrounding social and practical support may be inadequate" (n.p.) These findings are supported by the research of Daly and Wilson (1994), which indicates that stepfathers and mothers' paramours are more likely to be perpetrators of fatal child abuse than genetically related fathers. Daly and Wilson hypothesize that this may be due to the stepfather's or paramour's antipathy toward or lack of concern for the child.

In a national survey of 1,000 children aged 10 to 17 , Turner, Finkelhor, and Ormrod (2007) examined differences in victimization among those living in biological or adoptive, two-parent households, stepfamily households, and singleparent households. These researchers found that youth in single-parent families and stepfamilies experience greater victimization than youth living with two biological or adoptive parents. However, youth in stepfamilies reported the greatest exposure to individual forms of victimization, such as child maltreatment. Turner and colleagues hypothesize that this is due to family-generated risks such 
as family problems and parent-child conflict. Youth in single-parent families were more likely to be exposed to victimization outside of the family context, as a result of lower socio-economic status and residence in more violent neighborhoods and schools.

Dufour, Lavergne, Larrivée, \& Trocmé (2007) explored the differences between fathers and mothers with regard to family structure and child neglect. Data from 1266 neglecting families represented in the 2003 Canadian Incidence Study of Reported Child Abuse and Neglect (CIS) suggest great variations in parental situations according to gender and family structures. Researchers found that almost half of the cases studied were single-parent families. Furthermore, many of these were families whose female heads were extremely vulnerable, due to issues such as little education, mental illness, and no employment income. The data also indicated that situations of neglect often include men, whether they reside with their children in a two-parent family ( $38 \%$ of neglectful families) or they maintain a link with their children, but live outside the home (approximately $35 \%$ of child neglect situations).

Harris and Courtney (2003) considered a key point in the child welfare process, family reunification, and its association with race/ethnicity and family structure. As these authors point out, given the fact that research has examined the relationship between race/ethnicity and family reunification as well as the relationship between family structure and reunification, and given the fact that demographic research has found distinctions between the family structures among various racial/ethnic groups, the lack of research exploring the interaction 
of these factors is conspicuous. Harris and Courtney analyzed data from 9,162 White, Black, and Hispanic children placed in out-of-home care in California. Findings were consistent with earlier analyses, and suggested that children from two-parent families were returned home faster than children from single-parent homes, regardless of the parent's gender. Reunification for African-American children from single-parent families was the slowest and Hispanic children in twoparent families were reunified at the fastest rates. The authors note that twoparent families were not the most representative family structure of any of the racial/ethnic groups in the study.

The research literature discussed above offers a revealing glimpse into the relationship between family structure and child welfare issues. Families in the child welfare system are often headed by single mothers who experience a variety of social and personal difficulties such as lack of education and mental illness. While the research literature offers differing viewpoints regarding the risk of maltreatment associated with single-parent families, issues such as poverty that often plague vulnerable families in the child welfare system, tip the scales in the direction of increased risk for the children in these families.

\section{Limited or Lack of Access to Supports and Services}

Poverty and related risk factors such as substance abuse prevent families from accessing services necessary to avoid involvement with the child welfare system. Furthermore, even after families are referred to child protective services, they may continue to have difficulty accessing services that would allow children to remain in the home (US GAO, 2007). Research has shown that Black families, 
in particular, are not able to access the same level of services when they become involved in the child welfare system. In a study of mental health service utilization among children in foster care, Garland and colleagues (2000) found a significant difference in utilization rates across racial and ethnic groups. Even when controlling for the confounding effects of age, severity of behavior problems, and type of maltreatment, Black children were still significantly less likely to receive mental health services than White children. This indicates that Black children who are in the care of state agencies are not exposed to the same level of therapeutic services as their White counterparts.

Professionals' Biased Decision Making

Figure 1 details the caseload flow of children through the child welfare system. Beginning with a report of child maltreatment, each step in this flowchart represents a point at which an individual service provider or a group of providers makes decisions that will influence the experiences of the children and families about whom the decisions are made. 


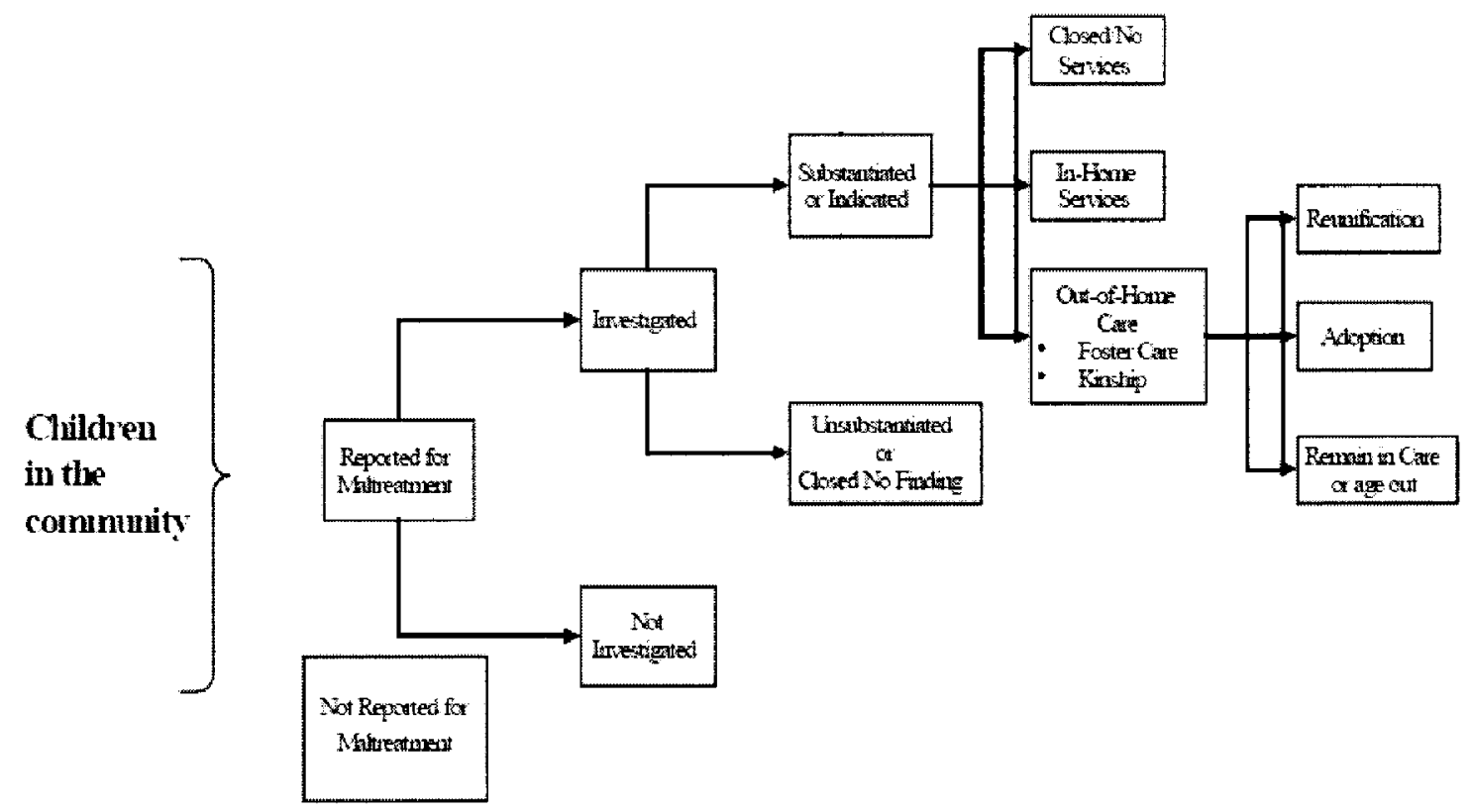

Figure 1. Simplified model of caseload flow of children. Barth, 2005, p. 26.

Hill's (2006) review of research shows that most studies of disproportionality focused on the following decision stages: reporting, investigation, substantiation, placement into foster care, exit from care, and reentry into care. The majority of these studies indicate that race is an important factor at each of the aforementioned decision points (Hill).

Even more detrimental than the overrepresentation of Black children in the child welfare system are the increasingly negative trajectories that these children experience as they move through the various parts of the system. Black children are more likely to be referred to child protective services, to have their cases substantiated, to be placed in out-of-home care, and to spend longer periods of time in state care without achieving permanency (Hill, 2006). 
Although disproportionality and disparity are different concepts, each with its own set of defining properties, they are nonetheless intimately connected. In a review of child welfare research, Courtney and Barth (1996) conclude that there is "a pattern of inequity, if not discrimination, based on race and ethnicity in the provision of child welfare services" (p. 112). Most recently, Hill's (2006) review of research found support for racial disparities in the following: "fewer and lower quality services, fewer foster parent support services, fewer contacts by caseworkers, less access to mental health services, less access to drug treatment services, and higher placement in detention or correctional facilities" (p. 28).

In a study of institutional discrimination in child welfare, Rodenborg (2004) considered outcomes for African American children and children in poverty. Findings from this study indicate racial disparity in service provision, as African American clients exhibited higher levels of unmet need than Caucasian clients. In general, this study found a lack of service to all poor children. The child welfare system's inadequate response to conditions of poverty disproportionately impacts African American children. As Rodenborg points out, given the strong link between child maltreatment and poverty, it is vital that the child welfare system do more to address conditions of poverty among its clients.

The disproportional representation of Black children at each level of the system (intake, investigation, case management, out-of-home placement, and adoption) indicates increased state intervention in the lives of these children and their families. Such intervention is necessary in many cases to ensure the safety 
and well-being of these children, but lack of permanency is sometimes the result. Lu and colleagues (2004) reviewed the records of nearly 4000 children who were referred to a public receiving home for suspected maltreatment. Findings indicated that "African American children are overrepresented in the child protective system, are most likely to be placed out-of-home, and are less likely to be reunited with their family of origin" than any other racial group in the study ( $p$. 457). Such overrepresentation in foster care is a form of disparate treatment for Black children.

In a review of the medical records of Black and White toddlers who were seen for bone injuries, Lane, Rubin, Monteith, and Christian (2002) found that Black children were more likely to have skeletal surveys ordered and to be reported to child protective services than White children. Other research has found that medical professionals are more likely to attribute Black children's injuries to "abuse," while White children's injuries were more likely to be attributed to "accidental" causes (Hill, 2006).

Garland and Besinger (1997) studied court-ordered mental health services and found that Black children were less likely to receive court orders for services than White children. Furthermore, Garland and colleagues (2000) found that even when services were ordered, Black children had lower levels of service provision and utilization than White children.

Rodenborg (2004) examined provision of services, such as housing assistance, to address the poverty-related needs of families involved in the child welfare system. This author found that Black children and families' poverty- 
related needs were more likely to go unmet than White children and families' needs. ${ }^{2}$

The dual effects of Black parents' distrust of the child welfare system and racial bias or cultural misunderstanding among decision makers, such as mandated reporters, child welfare caseworkers, and family court judges, may also contribute to disproportionality and disparity (U.S. GAO, 2007). In fact, issues of race and ethnicity, cultural competence, inherent systemic bias, and individual bias are among the key issues discussed in the literature regarding disproportionality and disparate outcomes in child welfare (see Rodenborg, 2004; Smith \& Devore, 2004; Derezotes, Poertner, \& Testa, 2005; Elliott \& Urquiza, 2006).

The understandings of race and culture on which child welfare professionals base their decisions are very important. In a review of research in the area of disproportionality, Hill (2006) found that race was a significant factor in decisions made by professionals at all points of transition in the child welfare system. Therefore, in decisions to report, investigate, substantiate, place in foster care, and reunify with biological family, race was the only common factor. Even so, there exists very little empirical evidence indicating a causal relationship between bias among individual professionals and disproportionality or disparity.

There is, however, some anecdotal consensus about the role of bias in decision-making. The U.S. GAO found that nearly half of the state child welfare directors surveyed reported that they considered racial bias or cultural

\footnotetext{
${ }^{2}$ The remainder of this section was written previously by this author and published in Johnson, Antle, and Barbee (2009).
} 
misunderstanding among those reporting abuse or neglect to have at least a moderate influence on disproportionality. For example, in a retrospective chart file review, Lane and colleagues (2002) found a significant difference in evaluation of skull and long-bone fractures for abusive injury between children of color and White children, even after adjustment for likelihood of abuse. When the researchers controlled for socioeconomic status, there remained a statistically significant difference in ordering skeletal surveys and reporting to CPS among children of color and White children with accidental or indeterminate injuries. Specifically, more than $65 \%$ of children of color had skeletal surveys performed, while only $31 \%$ of White children underwent this same test. Furthermore, CPS reports were filed for $22.5 \%$ of White children versus $52.9 \%$ of children of color.

Berger, McDaniel, and Paxon (2006) explored the presence of racial bias in judgments about parenting. In observations of home visits by professional human service providers, the researchers found that Black parents were judged more harshly by the professionals on subjective measures of parenting such as annoyance, criticism, and hostility. There was no racial bias found, however, in judgments of more objective measures such as spanking. These authors concluded that in this study, the professionals' judgments were likely biased due to negative characteristics attributed to low-income parents. As Berger and colleagues explain, in the absence of information, professionals rely on stereotypes and biases to make judgments about clients. In this study, the professionals were not aware of the class status of the parents, so race was used as a proxy measure, as people of color are usually assumed to be poor. 
Research has shown that professional judgments may also be biased in the opposite direction. For example, in a study of the influence of case and professional variables in the identification and reporting of child maltreatment, Hansen, Bumby, Lundquist, Chandler, Le, and Futa (1997) found that race had the most impact on psychologists' and social workers' ratings of severity of maltreatment and the need to report. These professionals were more likely to rate vignettes describing possible maltreatment among African American families as less severe and less likely to be reported than similar vignettes including White families. Interestingly, Hansen and colleagues found in the literature evidence of similar response patterns for race among law enforcement officials, day care providers, and teachers. The authors postulated that these differences in reporting by race could be due to views of maltreatment among African American families as more normative and less extreme than maltreatment among White families. However, while this hypothesis has been generated through the findings in other studies (e.g., Landsman \& Hartley, 2007; Rivaux et al., 2008), there has been no research that directly addresses this issue.

Green, Kiernan-Stern, and Baskind (2005) studied agency-based social workers' attitudes about ethnic and cultural diversity. Although most of the social workers included in the study had positive attitudes toward people of color and the concept of cultural diversity, these social workers expressed some ambivalence regarding a desire for more interaction with people of color. Furthermore, $12 \%$ of those surveyed believed that racism is no longer a major 
problem in the U.S. These authors concluded that this finding indicated a lack of racial awareness among the social workers surveyed.

As shown, the literature provides useful information about the issues of cultural awareness and racial attitudes among social workers and other professionals. However, with specific regard to the child welfare system, research on disproportionality points to a need for further examination of the link between professionals' cultural attitudes and awareness and possible resolutions to the problem of overrepresentation of children of color in the child welfare system (Hill, 2006).

\section{Decision Making in Child Protection}

An integral part of a child protection worker's job is making decisions. In fact, Cohen (2003) asserts that child welfare workers act more as decision makers than service providers. Much of the mandate of CPS workers is to make decisions regarding the safety of and risk to children. These workers do not operate in a vacuum and their decisions are influenced by more than their own judgment. In fact, this judgment itself is influenced by complex cognitive and emotional processes that are fed by individual and societal norms.

\section{Decision Making in Naturalistic Settings}

Orasanu and Connolly (1993) have identified factors that characterize decision making in realistic settings. These factors provide a useful lens through which to view issues of decision making in child welfare generally and child protection specifically. These factors are as follows: ill-structured problems; uncertain dynamic environments; shifting, ill-defined, or competing goals; 
action/feedback loops; time stress; high stakes; multiple players; and organizational goals and norms. Each of these factors will be considered as it relates to child welfare and, specifically, child protection.

\section{III-structured Problems}

Orasanu and Connolly (1993) argue that in naturalistic, or realistic, decision settings, problems rarely present themselves in an orderly, complete form. Decision makers usually must make a substantial effort to "generate hypotheses about what is happening, to develop options that might be appropriate responses, or even to recognize that the situation is one in which

choice is required or allowed" (p. 7). For example, although the various types of child maltreatment are defined by state statute, professionals must determine if the unique circumstances of individuals and families meet the levels of maltreatment as defined by the statutes. As the authors point out, ill-structured problems are frequently made more unclear by uncertain, dynamic information and by multiple interacting goals (see below).

\section{Uncertain, Dynamic Environments}

The waters of child protective services (and child welfare in general) are often murky. Child protection workers often have limited information or are given incorrect information during the course of a case. Furthermore, a family's situation may change dramatically while they are involved in child protective services. Workers must continually assess the needs and risks of the children and families as new information arises or even in the absence of some 
information. As Orasanu and Connolly (1993) point out, "decision making typically takes place in a world of incomplete and imperfect information" (p. 8). Shifting, III-defined, or Competing Goals

Orasanu and Connolly (1993) state that it is rare for a real-world decision to be driven by a single, well-understood goal or value. Decision makers are usually influenced by a variety of purposes, many of which may be vague and in opposition to one another. This is often the case for child protection workers, who are guided by a variety of mandates that are not always clearly defined and may even seem to be conflicting at times. Their own personal beliefs, agency policy, and state/federal requirements all play roles in their decision making regarding children and families. An issue that highlights this concept of competing goals is concurrent planning in child welfare. Some authors have questioned the impact of this practice on outcomes for biological parents (see Stein, 2000). Workers are compelled to simultaneously prepare for termination of parental rights and reunification of children with their biological parents.

\section{Action/Feedback Loops}

While consideration of decisions through research may occur in a crosssectional manner (snapshot in time), in naturalistic decision settings, such as the life of a child protective services (CPS) case, decisions and actions are intermingled and often inform each other. Orasanu and Connolly (1993) contend that instead of a single decision event, it is much more common to find a series of decisions and actions that are designed to gather more information about the problem, deal with it, or both. While a child protection investigator is considering 
the safety of a child's environment, he may also make decisions, such as which interim services to offer, that may impact his final disposition decision.

\section{Time Stress}

Child welfare workers are often expected to make decisions in relatively short amounts of time given the information that must be considered. Time constraints on these workers may include having only minutes to decide whether to remove a child from a situation of immediate risk to having only 30 days to make an investigation decision based on limited information. Orasanu and Connolly (1993) point out that (1) decision makers in such situations often experience high levels of personal stress, with the potential for fatigue and loss of vigilance and (2) their cognitive reasoning strategies will become characteristically less complicated. While these issues will be discussed in more detail in the second chapter of this paper, it can be said at this point that time pressures and related stressors often have a considerable impact on professional decision making in child protection and child welfare. High Stakes

Child welfare workers are responsible for the safety, wellbeing, and permanency of children (and their families). There are outcomes of real significance at stake when families come into contact with the child welfare system.

\section{Multiple Players}

While an individual child protection worker makes many decisions in the life of a case, decisions such as whether to accept a case for investigation, 
whether to substantiate the allegations, and whether to remove a child from the home are made by at least two individuals--the worker and the immediate supervisor. Often such decisions are made by groups including professionals from outside CPS as well as family members.

\section{Organizational Goals and Norms}

The settings in which professionals make decisions impact the decision making process as well. As previously stated, CPS workers do not practice in a vacuum and are significantly guided by the policies and culture of their organizational settings. Orasanu and Connolly (1993) highlight two ways in which the organizational setting is relevant to the decision making process. First, the values and goals that are applied to solving the problem are not simply those of the individual decision maker, but also include the values and goals of the agency and/or system in which the individual works. A child protection intake worker's individual values may influence her judgment, but she is also mandated to abide by agency regulations, which are based on a set of values derived from the external sources, such as society-at-large. Second, the organization may be responsive to its workers' decision making difficulties. More adaptive goals, rules, or procedures may be instituted by the organization in an effort to help workers make decisions more simply or efficiently.

As discussed, the characteristics of decision making in realistic settings proposed by Orasanu and Connolly (1993) serve well as a framework for consideration of decision making in child protection and child welfare. Each of the 
components of naturalistic decision making speaks to a feature of the decision problems and environments faced by child protection workers.

\section{Context-Contingent Decision Making}

Another framework that may be useful in reflecting on decision making in child protection is context-contingent decision making, proposed by McConnell, Llewellyn, and Ferronato (2006) based on their research on how child protection workers make decisions to take court action, especially in cases of parents with an intellectual disability. These authors conducted a thorough literature review of decision making in child welfare and studied the decision making processes of 155 social workers.

Based on this research, McConnell and colleagues (2006) have identified three factors present in the child welfare literature that appear to characterize decision-making in the child protection process: narrowness of scope in child protection investigations, parental compliance, and system imperatives embedded in the nature and function of the child protection process. The narrow scope of child protection investigations refers to the tendency of workers to focus on the family unit (particularly the mother) and attribute parenting problems to individual difficulties without taking into account the role of social and environmental stressors.

Regarding parental compliance, McConnell and colleagues (2006) point out that this issue appears to be a significant factor in workers' assessment of risk to children. Parental cooperation may lead to workers viewing the family more favorably and being more willing to support family maintenance or 
reunification. On the other hand, parental non-compliance may cause workers to impose their own interpretations of the case evidence and family situation.

Finally, McConnell and colleagues (2006) define system imperatives as integral components of the functioning of the child protection process. The first such imperative is the desire to win the court case. This desire often causes child protection workers to question the sufficiency of the evidence and second-guess a judge's likely decision before choosing to remove a child. The second system imperative is the desire to avoid public criticism. Child protection workers fear errors that may lead to the agency failing to protect children from harm, and are therefore likely to respond to perceived public criticism by deciding to remove children in situations where there is doubt about which action should be taken. The final imperative is the increasing pressure to ration available resources. Such pressure may result in child protection workers focusing the majority of their attention and time on high risk cases, causing them to overlook supporting families in lower risk cases, which could lead to a decreased likelihood of future crisis.

\section{Summary}

Viewing decision making in child protection through the lenses offered by Oransu and Connolly (1993) and McConnell and colleagues (2006), we see that workers are often responsible for engaging in a complex, weighty decision process. As will be discussed later in the review of the literature, there are many influences on and outcomes of such decisions that are ultimately responsible for impacting the lives of children and families in our society. 


\section{Purpose of the Study}

The present study will focus on racial bias, poverty, and family structure in its consideration of the possible connection between these factors and disproportionality and disparity in child welfare. As discussed above, these factors appear to be interrelated and may have a compound effect on decision making and child outcomes, but how they interact to influence decision making in child protection has yet to be empirically investigated.

The outcomes of children in the child welfare system are based largely on decisions made by professionals involved in this system. From a teacher deciding to report a child to protective services to a social worker deciding to remove a child from his/her home, the experiences of children and families are managed and influenced by the actions of professionals. It is important to consider how these professionals make decisions, what factors impact their decisions, and in what ways these decisions can be shaped to lead to better outcomes for not only Black children, but all children in the child welfare system.

As McConnell and colleagues (2006) point out,

Historically, research efforts in the child protection field have focused on the 'parent as the problem.' Numerous studies have endeavored to develop a predictive profile of a child maltreatment perpetrator. Less attention has been given to the systematic processes developed to assess parenting efforts and required to fulfill the legal responsibility of protecting children from abuse and/or neglect. (231)

This research project will examine an aspect of these "processes" by studying how decisions regarding children are made by a select group of child protection workers and supervisors, and how these decisions may differ based on the race, 
class, and family structure of the child, as well as characteristics of the professionals themselves. 


\section{CHAPTER TWO: REVIEW OF THE LITERATURE}

A young caseworker stands at the doorway of a small house. As she looks at her surroundings, she sees a home in some disrepair and a neighborhood that has seen better times. From her drive down the block, she recalls cracked sidewalks and streets, broken and boarded windows on homes, graffiti, and groups of African American youth standing on corners. She needs to make several decisions soon that will affect the safety of the child she is about to see. The intake call sounded serious. Aside from deciding whether or not to substantiate the case, she must determine whether the risk of future harm is sufficient to provide services or regrettably, if high enough, to place the child in foster care. How will she make this decision? How will the poverty she has seen affect this judgment? Will race play a role? Will she confuse these factors with risk? (Rivaux et al., 2008, p. 152)

Ruvaux and colleagues (2008) point out the importance of knowing the answers to the questions posed above. Specifically, if we recognize that the caseworker's judgment is improperly influenced by these external factors, steps may be taken to improve the uniformity, consistency, and equity of caseworkers' decisions.

This chapter begins with a review of theories and constructs related to decision making and then proceeds with a discussion of research studies in decision making in the provision of child protection services. A useful method of exploring decision making in child protection and factors that influence these decisions is through consideration of theoretical frameworks. These frameworks offer explanations of the decision making process and outcomes. 


\section{Theory}

The focus of this project, decision making among child protection professionals, is informed by several theoretical constructs. These constructs are then interwoven to create a model that will guide consideration of factors that influence decision making in child protective services. The theoretical constructs considered are Cohen's (2003) model of factors influencing decision making in child welfare, the Adaptive Decision Model (Payne, Bettman, and Johnson, 1993), attribution theory, and the concept of heuristics.

\section{Factors Influencing Decision Making in Child Welfare}

Cohen (2003) offers a framework that includes specific child welfarerelated factors that influence decision-making. According to Cohen, the professional decision-making process in child protection is influenced by multiple and interrelated factors such as the policy context, environmental factors, organizational culture, individual provider attributes, and family characteristics (see Table 2). Such a model speaks to the person-in-environment framework that is an underlying principle of social work practice. This framework states that individual issues and needs are most effectively addressed in the context of that individual's environment. This environment may consist of social, political, community, and family factors. Cohen's model takes this into account by showing that such multiple, interrelated factors should come to bear on how child welfare professionals process information, interact with clients, and make decisions.

Professionals working with families in the child welfare system must be aware of government policies such as the Child Abuse Prevention and Treatment 
Act (CAPTA) of 1974, environmental mediators such as poverty, the goals and policies of the agencies through which they provide services, their personal experiences and biases, as well as their views about the families with whom they work. This constitutes a great deal of information and influence thrust upon professionals in their day-to-day work.

Table 2

Categorization of Factors Influencing Decision Making in Child Welfare

Factor Examples

Policy - Various governmental policies such as the Indian Child Welfare Act, Child Abuse Prevention and Treatment Act, and the Multi-Ethnic Placement Act

Environment - Various "isms" such as racism, sexism, and classism

- Attitudes and expectations of child welfare staff

- Interrelated challenges such as poverty, substandard housing, and unemployment

Organization - Different definitions of abuse among states and agencies

- Agency mission, goals, and policies, service delivery patterns

Practitioner - Personal experiences and background

- Professional training and culture

- Biases

Family - Own perceptions of what constitutes child abuse/neglect

- Immigration history

- Relationships and individual experiences

- Culture shapes family's response to intervention 
Cohen (2003), along with other researchers, postulates that one way to improve the experiences of African American children and their families in the child welfare system is to promote a more culturally competent process of decision-making among professionals. Navigating the path between cultural values and beliefs of diverse families and mandates of the child protection agency is a very complex process. Cohen (2003) offers a framework that can be used to guide the decision-making processes of child welfare agencies and practitioners, with the goal of improving services for ethnically and racially diverse children and families, as well as all children and families. This framework suggests questions that practitioners should ask in their work with children and families, which emphasize an understanding of the structural, cultural, and ecological forces that influence the decision-making process (Cohen). For example, critical considerations for intake include: "Whose criteria have been used to determine that the child's basic needs have not been met?" and "What are the family's expectations of child safety and well-being?" (Cohen, p. 150). Critical considerations for case planning and implementation include: "Has the family been involved in developing the plan?" and "Are services accessible, available, and culturally appropriate?" (Cohen, p. 153). As Cohen (2003) points out, child welfare agencies and social workers rarely account for the potential effects of decisions on children and families from different backgrounds. At each step of the system (intake, investigation, treatment, foster care/adoption) there are goals for child safety, permanency, and well-being; there are also key 
decisions to be made, which must include critical considerations for working with diverse families (Cohen).

\section{Heuristics}

While the factors described by Cohen (2003) should be considered, the concept of heuristics informs us that often decisions are made based on a method of mental shortcuts that does not leave room or time for such a comprehensive assessment. The use of heuristics, however, is not simply a random trial and error process (Poulter, 2006). A heuristic is a problem-solving strategy that seems likely to lead to relevant and reliable information (Heineman Pieper, 1989). Its goal is utility rather than certainty due to the complex, dynamic, and fast-paced real life situations in which it is often employed by decision makers. Ultimately these decision makers rely on heuristics to make problems manageable and produce helpful information (Heineman Pieper).

In the high-stakes field of child protective services, making problems manageable and gathering useful information are key problem-solving skills. Poulter (2006) states:

The utility and economy of the heuristic approach arises out of its inductive nature. In [social workers'] case interventions, the data we gather are cognitively manipulated for possible temporal, spatial or functional relationship to other data. Sometimes the sheer contiguity of two factors will produce an insight or suggest a hypothetical way of organizing the data to extract meaning. Thus, the heuristic processes aim at working with complex data in time-efficient inductive ways such as in our case interventions. (p. 335)

Given the job-related pressures faced by child protection workers, the use of heuristics as problem-solving strategies may be especially prominent. 


\section{Child Protection and Worker Stress}

Child protection workers and supervisors are under a great deal of stress related to their job duties. This is often a result of "low pay and long hours at potentially hazardous work, agency and community resources inadequate to client needs, the threat of legal liability, and investigator versus helper role conflict" (Anderson, 2000, p. 840). Many workers also attribute high stress levels to the knowledge that a child may be seriously injured or even die if the worker misjudges risk to the child at any given time (Davoren as cited in Anderson, 2000).

Although less research exists regarding the amount of work-related stress endured by child protection supervisors, some exploratory research has examined this issue (Dill, 2007). Supervisors have reported lower levels of job satisfaction than their front-line colleagues, likely due to many more years of employment in a chronically stressful work environment (Silver, Poulin, \& Manning, 1997). Furthermore, child protection supervisors were found to be more likely to have experienced the death of a child and to have encountered internal reviews on cases than front-line child workers (Regehr, Chau, Leslie, \& Howe, 2002).

\section{The Adaptive Decision Model}

Payne, Bettman, and Johnson (1993) include heuristics in their discussion of decision making strategies. They hold that such strategies are a part of decision makers' adaptation to the decision task at hand. These authors developed the Adaptive Decision Model as a theoretical construct that addresses 
decision making processes and strategies. Like Cohen, Payne and colleagues' model highlights the importance of including individual and contextual factors in consideration of decision making processes (and outcomes). Such a model is highly suited to a discussion of decision making in child protective services due to the complexity of the decision environment and the person-in-environment focus of the social work profession that informs child protection work. Overview of the Adaptive Decision Model

Payne and colleagues (1993) promote their Adaptive Decision Model as offering a "framework for understanding the contingent nature of human decision behavior" (p. 9). In their opinion, one of the most intriguing features of human decision making is individuals' flexibility in responding to many different task conditions. Because the variety of task conditions is great, decision makers are often faced with complex problems involving several alternatives. In these situations, people frequently use heuristics, or simplifying strategies, that do not utilize all of the relevant information available (Payne et al.) These authors provide the following definition for decision strategy: "a sequence of mental and effector (actions on the environment) operations used to transform an initial state of knowledge into a final goal state of knowledge where the decision maker views the particular decision problem as solved" (Payne et al., p. 9).

Payne and colleagues' (1993) major thesis is that "an individual's use of multiple decision strategies in different situations, including various simplifying methods or choice heuristics, is an adaptive response of a limited-capacity information processor to the demands of complex decision tasks" (p. 2). 
Furthermore, two primary considerations underlying decision making are the "desire to achieve a good decision and the desire to minimize the cognitive effort needed to reach a decision" (Payne et al., p. 9). In other words decision makers face a variety of complex problems for which they cannot have all the relevant information. Therefore, they utilize strategies to make the decision making process as efficient and effective as possible given the information they do have. Factors Affecting Decision Strategy

Payne and colleagues (1993) identified three factors that influence how a decision maker chooses to solve a particular decision problem. The factors are: properties of the decision task, individual characteristics (including prior knowledge and expertise regarding a problem area), and social factors (including feelings of accountability). These factors, illustrated in Figure 2, are similar to the factors proposed by Cohen (2003) as being relevant to decision making in child welfare (policy, environment, organization, practitioner, and family). Both frameworks stress the importance of considering the role of individual/internal and social/external factors in decision making. Payne and colleagues go further to suggest that decision makers will utilize different decision processes, or strategies, given the specific blend of factors. 


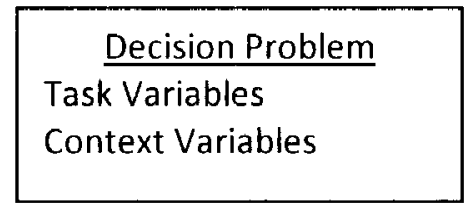

$\frac{\text { Social Context }}{\text { Accountability }}$
Group Membership

\begin{tabular}{|l|}
\hline \multicolumn{1}{|l|}{$\frac{\text { Individual }}{\text { Cognitive Ability }}$} \\
Prior Knowledge \\
\hline
\end{tabular}

Figure 2. Contingent strategy selection.

\section{Assumptions of the Adaptive Decision Model}

The Adaptive Decision Model (Payne et al., 1993) is based on several assumptions. To begin with, decision strategies are "sequences of mental operations" (p. 11). Some decision problems simply require the strategy of memory retrieval. For example, if a child protection worker is asked about her most difficult case, her answer-the Gripps family-is likely not the result of processing information about the characteristics of the alternatives being considered, but instead it is simply based on prior evaluations of the alternatives (Payne et al.). The Adaptive Decision Model focuses on the strategies people use to solve problems for which simple memory retrieval does not provide an acceptable solution. The Model is useful for examining decision making regarding novel or complex problems (Payne et al.).

Another assumption is that the amount of cognitive effort needed (and used) in reaching a decision using a particular strategy is dependent upon a variety of factors determined by the environment in which the decision task is taking place. Furthermore, the various strategies that may be used involved 
different levels of accuracy. As in the case of cognitive effort, the task environment influences the level of accuracy of each decision strategy (Payne et al., 1993).

A decision maker's collection of strategies is related to his/her level of prior experiences and training. In other words, greater experience and training is assumed to indicate a larger strategic arsenal. The decision maker may also consider issues such as justification of the decision or minimization of inherent conflict in a decision problem as he selects decision strategies (Payne et al., 1993).

Choosing a particular decision strategy or set of strategies is not always a conscious or deliberate process. Sometimes it is a learned, instinctive process relating to the elements of the task and the relative effort and accuracy of decision strategies. Finally, strategy selection is assumed to be generally adaptive and intelligent, even if it is not optimal (Payne et al., 1993).

\section{Theories of Attribution}

An aspect of the individual decision making process that must be considered is the impact of attributions on decisions and the strategies that are selected to make decisions. The underlying assumption behind theories of attribution is that the observer's primary task is to interpret or infer the causes of an action or behavior (Gilbert, 1998). Heider's (1958) ideas about how people explain events and understand the causes of behavior form the basis of theories of attribution. According to Heider (1958), attribution is a form of causal analysis (Gilbert, 1998). A person may attribute his or other's behavior to internal causes 
such as attitude, character, or personality—or external causes—such as the situation or environment (Gilbert, 1998; Hewstone, 1983). Heider (1958) acknowledged that attribution is an important way of categorizing the multitude of information received from the world, yet it is often an unconscious process (Gilbert, 1998).

Jones and Davis (1965) amended Heider's theory by focusing on the rules used by attributional systems to identify the specific intentions that form the base of specific decisions (see Figure 3; Gilbert, 1998). Jones and Davis (1965) argued that an observer's goal is make correspondent inferences about another's behavior. In other words, the observer attempts to determine to what extent he/she may infer a stable psychological disposition or internal characteristic of the other person as the cause of a specific behavior (Gilbert, 1998; Taylor, 1998). Jones and Davis' theory of correspondent inferences takes into account the observer's inferences about what the actor is trying to achieve in a particular situation (Jones and Davis as cited in Gilbert, 1998). Specifically, the observer's knowledge about what is socially desirable (what most people want) helps explain actions (Gilbert, 1998). Socially undesirable behavior is likely to be attributed to personal dispositions, while socially desirable behavior is likely to be attributed to external factors such as social norms (Taylor, 1998). Jones and Davis (1965) also proposed the analysis of noncommon effects occurs when an observer asks, "What is this action producing that other actions would not have produced" (Taylor, 1998, p. 71). The more distinctive the consequences of the 
action, the more likely the observer will assume that dispositions reflecting these consequences are the cause of the action (Taylor, 1998).

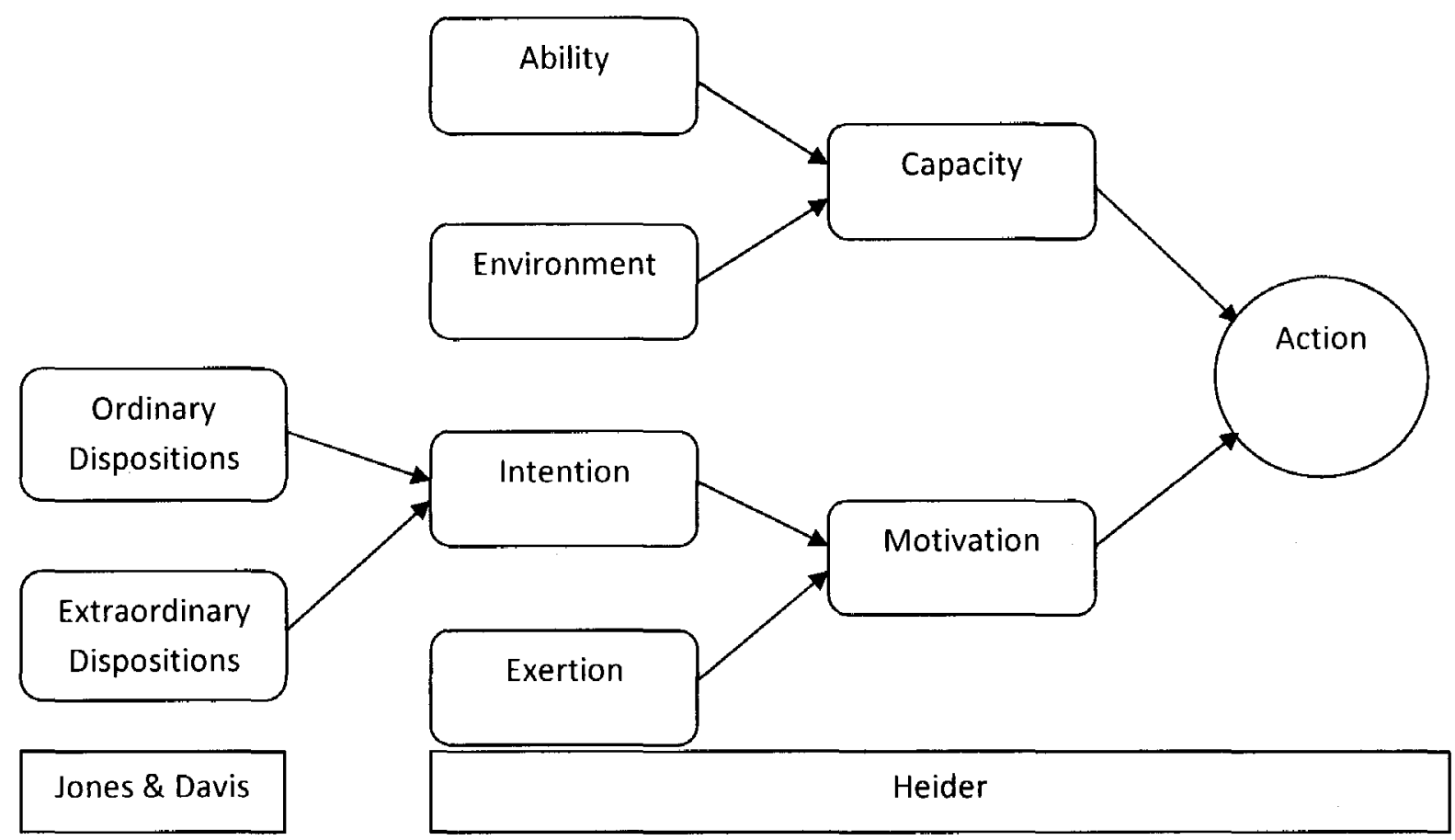

Figure 3. Jones and Davis' contributions to Heider's attribution theory.

Kelley (1967) introduced the covariation principle to attribution theory. He suggested that people test for, or consider, covariation in behavior based on the behaviors of other actions, stimuli (situation type), and time (Gilbert, 1998). Actually, Kelley's (1967) propositions were similar to Jones and Davis's (1965) proposal in that both theories suppose that observers make inferences about an actor's dispositions by (1) considering how an actor's behavior differs based on the type of situation (distinctiveness test) and (2) considering how an actor's 
behavior is different from other actors with the same attributes (principle of social desirability or consensus test) (Gilbert, 1998). Kelley (1967) added the idea that observers also consider differences or similarities in an actor's behavior over time given similar situations (consistency test) (Gilbert, 1998).

Quattrone's (1982) contribution to attribution theory is based on the work of Tversky and Kahnernan (1974) who posited that due to time constraints and the usual need for rapid problem-solving, people tend to provide an immediate response in the form of an initial rough estimate, and then revisit and revise this initial approximation as time and circumstances allow (Gilbert, 1998). Quattrone used this idea of an anchoring-adjustment mechanism to describe the mental process of behavioral attributions (Gilbert, 1998). He argued that rather than first weighing the options of dispositional or situational explanations, observers first assume a correspondence between the action and the actor's disposition. Observers then adjust or correct this initial assumption as needed based on further consideration (Gilbert, 1998). Essentially, the dispositional inference is followed by situational adjustment (Gilbert, 1998).

Trope (1986) moved attribution theory forward by suggesting that identification of actions and attribution of a disposition could be described in a common language that allows their interactions to be examined (Gilbert, 1998). Trope noted that two factors enable the observer's identification of the actor's behavior and the same two factors allow the observer to attribute the behavior to the actor's situation or dispositions: (1) observers often have knowledge of the 
actor's prior behaviors and (2) observers often have knowledge of the actor's current situation (Gilbert, 1998).

As illustrated in Figure 4, although knowledge of prior behaviors and of the current situation have additive effects at the identification stage, Trope suggested that they have very different effects at the attribution stage. For example, knowing that a person behaved nervously in the past should encourage the observer to identify the person's nail biting as nervousness (Effect A) and to attribute that nervous behavior to the person's dispositions (Effect $B$ ) because such behavior is, apparently, typical of the person, and dispositions are enduring tendencies to behave in certain ways. Conversely, knowing that the person is waiting to see a doctor should encourage the observer to identify the person's nail biting as nervousness (Effect $C$ ), but should discourage the observer from attributing the person's nervous behavior to her enduring dispositions (Effect $D$ ) because the upcoming physical exam provides a plausible situational explanation for her behavior (Gilbert, 1998). 


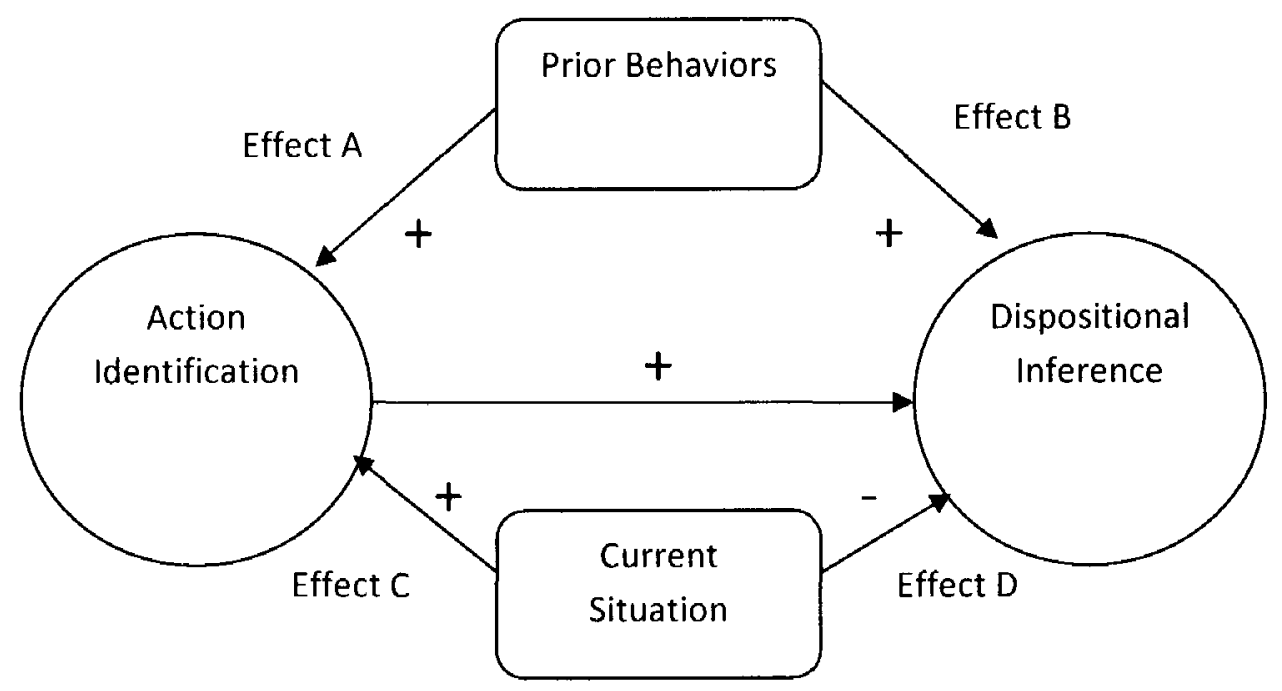

Figure 4. Trope's two-stage model.

Trope's model incorporated the work of other classic attribution theorists (Gilbert, 1998). Specifically, Effect B is a simple way of describing Kelly's consistency and distinctiveness tests. Furthermore, Effect $D$ essentially describes Kelly's discounting principle and Jones and Davis' social desirability principle. Finally, Trope's model proposes that the factors that determine how actions are identified also determine how they will be attributed, but knowledge of the actor's current situation affects these processes in opposite ways (Gilbert).

Gilbert, Pelham, and Krull (1988) developed an integrated model of three sequential operations of attribution: (1) the behavioral identification stage (categorization), (2) a dispositional influence stage (characterization), and (3) a situational adjustment stage (correction). The first two stages occur relatively automatically, but the last stage requires conscious, controlled deliberation 
(Gilbert, 1998). Essentially, "attributional principles are used to repudiate dispositional inferences rather than construct them" (Gilbert, 1998, p. 113).

As discussed, there are a variety of theories that may be covered by the mantle of "attribution theory." Kelley's theory, however, is widely considered to be the most holistic representation of theories of attribution because it included a handful of smaller models under one conceptual umbrella (Gilbert, 1998).

\section{Attribution Errors}

The piece of attribution theory that may have the most relevance to a discussion of how race, family structure, and income influence decision making in child protective services is the concept of attributional bias. As the poet Alexander Pope declared, to err is human. People often make mistakes in their thinking and as Allport (as cited in Gilbert, 1998) explains:

Almost every conceivable way of committing an error in thinking is at the same time a way of misjudging people. Superficial observation, faulty memory, erroneous premises, mistaken inferences, superstitions, prejudice, rationalization, projection-the number of possible missteps is too great to classify. (p. 121)

Even before Heider articulated his theory of attribution, Gustav Ichheiser argued that an actor's dispositions may or may not manifest as behavior (the process of expression) and an observer's attempts to infer those dispositions from the actor's behaviors (the process of impression) generally result in a mix of success and failure (Gilbert, 1998). In other words, individuals' attempts to infer realities from appearances are very likely to fall short of the truth (Gilbert, 1998). Ichheiser thought that many of people's mistakes in thinking were a result of a single, fundamental error: the tendency to attribute the behaviors and actions (or 
inactions) of others to the presence (or absence) of specific personal qualities rather than attributing these behaviors to the social situation in which the actors are placed (Ichheiser as cited in Gilbert, 1998). For instance, in child protection, an incident of child maltreatment might be wholly attributed to the parent's anger, while the parent's circumstances (e.g., unemployment, poverty, lack of education) are not taken into account.

Ichheiser offered three reasons for the pervasiveness of the fundamental attribution error: it originates in ideology, it is maintained by invisibility, and it occurs automatically (Gilbert, 1998). Regarding ideology, Ichheiser argued that attributional misinterpretations are not based on individual ignorance, but on the western philosophy that our social fate depends mainly on our personal characteristics and not on prevailing social conditions or circumstances surrounding individual actors (Gilbert, 1998). This concept is related to Cohen's (2003) urge for child protection workers to take into account policy, environment, and other factors that may influence the behaviors of parents alleged to have maltreated their children.

Ichheiser's second reason for the persistence of the fundamental error is that even if an individual attempts to take into account the situational antecedents of another's behavior, the factors are very difficult to detect (Gilbert, 1998). Ichheiser (as cited in Gilbert, 1998) writes:

In perceiving and observing other people we do see the spatial situation in which they act, but, as a rule, we are not in the position to see and evaluate correctly the dynamic meaning of the social, invisible factors in the total situation controlling the behavior of those people. (p. 128) 
Situational forces such as poverty and racism were described by Ichheiser as "invisible social chains" that were often undetectable and easily overlooked by observers (Gilbert, 1998). As described in the previous chapter, there is a plethora of child welfare literature that explores the impact of these situational forces on the experiences and outcomes of children and families. This issue is ever-present for child protection workers who must serve children and families who have been overwhelmed by social maladies such as poverty. This does not guarantee, however, that individual workers will easily pinpoint the impact of poverty or racism on the lives or behaviors of families in the child welfare system. Ichheiser's final explanation for the existence of the fundamental error is that it occurs automatically. Although we work diligently to be aware of this error in thinking, it is difficult to prevent dispositional inferences from being automatically drawn, and despite our awareness, these initial inferences impact our reasoned thinking. Ichheiser explains that "conscious interpretations operate on the basis of an image of personality which was already performed by the unconscious mechanisms" (as cited in Gilbert, 1998, p. 129). Like Heider, Ichheiser believed that attribution is largely implicit, but Ichheiser also believed that implicit attributions were dispositional and that they occurred in spite of and often formed the basis of one's better insights into the matter (Gilbert, 1998).

This aspect of the fundamental attribution error is demonstrated in the findings of a study by Munro (1999) in which she performed a content analysis on all available child fatality reports $(N=45)$ published in Britain between 1973 and 1994. Particular to decision making and risk assessment in child protection, 
Munro found that in many instances, once a decision had been made regarding a case, social workers were slow to revise their judgment, even in the presence of new information. Essentially, the initial risk assessment had a significant influence on responses to new information. If the workers' initial assessments of risk were accurate, they exhibited adequate to good practice. If their original assessments were inaccurate, their practice was hindered by failure to collect and take note of counter evidence that was available.

Munro (1999) points out several reasons for workers not accounting for information or evidence. First, some evidence may be technically difficult to obtain due to issues of confidentiality or impediments to inter-agency communication. Second, psychological issues may be involved. Munro found multiple instances of workers overlooking past information and focusing only on the present family situation. Also, written information was less likely to be noticed by workers than information gathered verbally. Finally, the workers' first impressions regarding the family seemed to endure (perhaps due to a primacy effect). The third reason involves unreliable evidence. Workers were found to be skeptical about evidence that conflicted with their view of the family and uncritical when new evidence supported their view. Workers must also rely on information from sources such as neighbors and relatives who may have motives to distort information.

The vast majority of cases in which child protection workers revised their initial judgments were due to injuries being seen on a child. However, it seemed that serious injuries reported by professionals caused workers to reassess the 
family. Injuries reported by neighbors and relatives had little effect on altering the workers' judgments. In general, Munro (1999) found that social workers were making decisions without the benefit of extensive information about the families they were serving.

Ichheiser's notion of the fundamental attribution error contributed greatly to attribution theory. The idea that observers follow attributional rules when they make inferences was identified as "observer bias" by Jones and Harris. However, these inferences may reflect a bias that occurs in addition to and not instead of the prescribed rule-following behavior (Gilbert, 1998). Other authors have referred to this as "correspondence bias" (Gilbert).

\section{From Bias to Stereotyping}

Fiske (1998) reports that in the late 1970s and 1980s, researchers generated a number of theories that explained stereotyping as an unavoidable result of categorization and other normal cognitive processes, including attributions and heuristics. These theorists assumed that "people are cognitive misers, overwhelmed by the complexity of the social environment and forced to conserve scarce mental resources" through grouping and other cognitive shortcuts (Fiske, 1998, p. 362). Categorization relates to stereotyping in that it increases the perceived homogeneity of group members and causes their behavior to be interpreted stereotypically (Fiske). Essentially, in an effort to reason efficiently, an observer may misperceive another's action because he assumes that the actor's category membership covaries with certain behaviors. This is a phenomenon known as "illusory correlation" (Fiske, p. 362). 
Illusory correlation can be seen as an example of the fundamental attribution error, or correspondence bias. When an observer attributes stereotype-confirming information to the disposition or personal characteristics of an actor, the observer is effectively deciding that the stereotypic material resides in the nature of the actor (Fiske, 1998). Pettigrew (as cited in Fiske, 1998) identified the "ultimate attribution error" (p. 369) as the tendency to explain the good behaviors of those in the in-group and the bad behaviors of those in the out-group (e.g., people of color, single mothers, poor families) as personal and dispositional, while attributing bad in-group and good out-group behaviors to situational or social factors.

Fiske (1998) points out that an especially interesting intergroup attributional bias emerges in language use. People tend to perceive and communicate positive in-group and negative out-group behavior more abstractly than behavior that contradicts stereotypes. For instance, an out-group member may be described as hostile, while an in-group member exhibiting the same behavior is described as assertive. The power of language is seen in the tendency of people to use these initial abstract depictions (e.g., "hostile") as the basis for future inferences and interactions instead of returning to the data on which the summaries were based (Fiske, 1998). In child protection, written and verbal communication serves as the basis for interactions between everyone involved in this system. The workers' case notes become a formal and lasting description of the family, their behaviors, and their circumstances. The language that workers use to describe the parents and children are incredibly important 
and, based on the theoretical framework just described, set the stage for future interpretations of the family's behaviors by others.

The relationship between categorization, stereotyping, and attributions can be seen in the three types of explanations for poverty that are regularly found in research literature: individualistic, structural, and fatalistic (Bullock, 1995). Individualistic explanations are essentially based on dispositional attributions. The poor are perceived as having certain personal characteristics (e.g., laziness, lack of thrift, lack of interest in self-improvement) that cause certain behaviors and, thereby, poverty. Alternately, middle-class or wealthy individuals are assumed to possess more positive characteristics (e.g., personal drive, willingness to take risks, hard working), which serve as explanations for their social and economic success (Bullock, 1995). The other two types of explanations for poverty, structural and fatalistic, focus on socio-economic factors and unfortunate circumstances, respectively. In the United States, individualistic explanations or attributions regarding class status are more frequently and strongly endorsed than structural or fatalistic explanations (Bullock, 1995). However, these attributions may be related to characteristics of the observer. This is highlighted by the following research example.

In a study of Mississippi social workers' attitudes toward poverty and the poor, Rehner, Ishee, Salloum, and Velasues (1997), using the Attitudes Toward Poverty (ATP) scale, found that these social workers had a relatively positive attitude toward the poor overall. However, age and years of social work experience were found to be correlated with ATP scores. Essentially, older social 
workers, and those workers who had more practice experience, tended to have more favorable attitudes toward the poor.

\section{Summary}

Like Cohen's (2003) factors that influence decision making in child welfare and Payne and colleagues' (1993) factors that affect decision strategies, attributions and heuristics play a role in shaping child protection workers' decisions. As discussed earlier, heuristics are often used as a shortcut method of decision making given workers' demanding, time-limited work environments. In the case of attributions, such a stressful environment may lead to attributional bias. Worker stress lowers cognitive capacity, which allows for bias to enter more easily. This, in turn, may result in differential outcomes based on certain child and family characteristics such as race, socio-economic status, and family structure due to stigma and social differences associated with these characteristics. Furthermore, as Cohen (2003) points out, failure to consider the entire situation may cause errors and differential outcomes for children and families.

\section{Appraisal of Theoretical Frameworks}

None of the theoretical frameworks used to inform this study are specific to child protective services. Cohen's (2003) framework for decision making in child welfare comes closest in its original form to addressing issues of decision making in child protection. The Adaptive Decision Model (Payne et al., 1993) is a general framework for exploring decision strategies in many different environments. While it lends itself well to a study of decision making in child 
protective services, it was not developed for this task or necessarily intended to serve a study of this particular issue. Both Cohen's framework and the Adaptive Decision Model highlight the fact that the individual decision maker's characteristics and experiences influence the decision process. They do not, however, emphasize the key role that attribution theory, specifically observer or correspondence bias, plays in the individual's influence on the decision process.

Theories of attribution and related concepts such as correspondence bias have been utilized in child welfare and child protection decision making research (see Berger et al., 2006; Hansen et al., 1997; Landsman \& Hartley, 2007;

McConnell and colleagues, 2006; Rivaux et al., 2008; Williams \& Soydan, 2005). However, the specific relationships between these concepts and those of the two other frameworks highlighted in this study have not been explored.

The aforementioned theoretical frameworks provide a basis for consideration of the factors that influence decision making among intake, investigative, and ongoing workers and supervisors in child protective services. The following review of the literature highlights the theoretical argument made above in that it presents an empirical demonstration of the theoretical assumptions. The literature also highlights factors that have consistently been found to impact decisions in child protection.

\section{Decision Making in Child Protection}

This section provides an overview of research that has explored decisions made by professionals at key stages of the child welfare system. Given the focus of the proposed research study on decision making by child protection workers, 
this review will concentrate on research which considers three key decision points: decisions regarding intake/screening, decisions based on investigation, and decisions regarding disposition/intervention (e.g., in-home services, removal to foster/kinship care). Specific consideration will be given to factors that influence decisions and variables that predict outcomes.

The literature offers some conflicting information about the factors that impact professional decision making in child protection. For instance, while several studies found that the race of the child influences social workers' professional decisions (see English, Marshall, Coghlan, Brummel, \& Orme, 2002; Galante, 1999; Landsman \& Hartley, 2007; Rivaux et al., 2008; Stevens, 1998), other studies found that race played little or no role in these decisions (see Britner \& Mossler, 2002; Forslund, Jergeby, Soydan, and Williams, 2002; Gammon, 2000). These apparent conflicts in findings among the decision making literature will be discussed in greater detail after the literature is reviewed.

Despite some differences, findings from these research studies do provide an understanding of the case, professional, and contextual characteristics that do and do not play a role in social workers' child protection decisions. In the following review of literature pertaining to professional decision-making in child protection, factors affecting decisions will be considered in the context of the child protection decision point that was the primary focus of the study.

Intake/Screening

There are fewer research studies that have examined decision making at the intake/screening phase of child protection than at the investigation and 
placement decision stages. As Hill (2006) points out, this is an underdeveloped area in research on child welfare decision-making. Findings from a review of the literature are discussed below.

Karski (1999) conducted a chart file review and interviews in an effort to examine a public child welfare agency's response to child maltreatment allegations. The author gathered data from a file review of 557 child protection reports and interviews of the 23 assessment workers in the county in question. The case files were stratified and a random sample of cases was drawn for each type of service decision: reports screened out at intake, reports investigated and closed, and reports assessed and referred for court services. Findings indicated that case characteristics influence workers' screening decisions. Specifically, Karski found that reports in which parental drug use was alleged, there was a female primary victim, or sexual abuse was alleged were more likely to be referred for investigation by the intake worker. Parents who were cooperative with the agency were less likely to be referred for court intervention than uncooperative parents. Poverty also played a role, as reports involving families who received AFDC were more likely to be screened in for investigation.

Gryzlak, Wells, and Johnson (2005) attempted to build on previous work conducted on the role of race in screening decisions. For the study, these researchers considered 2,504 intake cases from 12 sites in five states. The data collected for each case included report characteristics (time of report, source of report, type of maltreatment alleged), child characteristics (age, race, gender), family structure, the decision made by the worker, and the reason given for 
making the decision. Caseworkers and their supervisors were also surveyed. After excluding sites that had less than 100 cases, had screened in more than $94 \%$ of study cases, or had greater than $90 \%$ of data on race missing or unknown, the researchers retained 960 cases from five sites in four states for analysis. Findings indicated that there were several predictors of screening decisions: the CPS site, allegation, type of injury, source of the report, completeness of the data recording form, gender of child, age of youngest child, and type of parental problems. While race or ethnicity of the child alone was not found to have an overall effect on the decision to screen in a case for investigation, the interaction of race/ethnicity and type of maltreatment alleged was found to be significant. Of cases involving allegations of sexual abuse, $76 \%$ of cases involving White children were screened in and $57 \%$ of cases involving children of color were screened in. In cases involving allegations of maltreatment other than sexual abuse, the cases of children of color were more likely to be screened in than cases involving White children (55.7\% versus $49.5 \%)$. Finally, in considering the association between the worker's and child's race or ethnicity, the researchers focused on 342 cases for which data were available on the race/ethnicity of both the worker and the child. Cases in which the worker and child were of the same race were similar in screening decisions. Workers of color screened in $46.2 \%$ of cases involving children of color and $76 \%$ of cases involving White children. White workers screened in $49.1 \%$ of cases involving White children and $40.4 \%$ of cases involving children of color. Gryzlak and colleagues (2005) acknowledge that this last finding should be considered 
cautiously, as it may be influenced by other factors such as within-site trends or severity of reports.

In a qualitative study of the ways in which social workers in England made screening decisions and the strategies they used to decipher the limited information reported, Platt (2006) conducted a chart file review of 23 cases and interviews with 14 social workers and parents involved in these cases. The author concluded that social workers evaluated CPS referrals on the basis of five key factors: severity of the alleged maltreatment, specificity of the allegations, perceived risk to the child, parental accountability, and corroboration of the alleged situation.

Parada, Barnoff, and Coleman (2007) explored the role of professional agency in decision-making through interviews with 10 Canadian social workers as well as review of documents related to child welfare practice in Ontario. The authors define professional agency as social workers' capacity to exercise their social work knowledge, skills, and clinical judgment when making practice decisions. Findings from this study indicate that the social workers interviewed utilized professional agency in adapting the system's tools, such as standardized assessment protocols, to bring in additional decision-making factors

While the factors found to influence intake/screening decisions include case and professional characteristics, none of the studies detailed above considered family structure and only Karski (1999) found evidence supporting poverty as a decision factor. Gryzlak and colleagues (2005) explored the role of race in screening decisions and found a significant interaction between race and 
type of maltreatment alleged, but no impact of race on the screening decisions overall.

\section{Investigation/Assessment}

Much more information exists in the literature regarding decision making in the investigation/assessment stage of child protection. This may be due to the fact that families interact directly with workers in this phase and for longer periods of time. Furthermore, this is often the point in child protection at which decisions are made regarding in-home services and placement. The following discussion highlights research within the investigation phase. The next section will focus on removal and placement decisions.

Stevens (1998) attempted to identify factors that influence CPS workers' case disposition decisions following investigation. This researcher used stratified, purposive sampling to select 336 cases from those reported to a New Jersey public child welfare agency in 1988 and 1989. Along with this secondary data analysis, Stevens administered questionnaires to $180 \mathrm{CPS}$ workers. The study considered organizational factors, case characteristics, individual traits, worker activities, and case disposition. Findings indicated that case characteristics (i.e., parental cooperation, parental problems, and child problems) and individual worker traits and activities (i.e., contact with the child, judged severity of maltreatment, and education level) had a significant influence on the decision to refer the case for in-home services. The race of the child also impacted the case decision. Specifically, in-home services were less likely to be recommended in cases involving Black children than in cases involving White children. 
In a study of investigative decision-making by child protection professionals in Washington State, English, Marshall, Coghlan, Brummel, and Orme (2002) analyzed secondary data from 12,871 CPS referrals and interviewed 200 CP.S workers about the factors they utilized in making decisions generally and related to specific referrals they had investigated. Variables noted in review of the case records included 37 variables (for example, history of domestic violence, disability, hazardous home, cooperation with the agency) from the Washington Risk Model that were defined on a six-point ordinal scale from zero (no risk) to five (high risk), as well as case demographics, contextual factors (region, office size, area population), and worker assessment of risk. The authors used neural network analysis to explore the quantitative data. Information from worker interviews was analyzed using a content analysis method. The authors found that the only risk factor used in consistent manner by workers in their decision making was chronicity of child maltreatment. In this study, chronicity increased the probability of an allegation being substantiated, slightly increased the probability of an allegation being declared inconclusive, and decreased the probability of an allegation being unfounded. The vast majority (84\%) of workers interviewed indicated that chronicity was of either moderate or high importance in their decision-making processes. Regarding the influence of case characteristics on outcomes of decisions, results indicated that race and gender were significant factors. Cases involving Native American children were substantiated at a significantly higher rate than children of other ethnic backgrounds. This was due in large part to the high rate of substantiation of physical neglect for Native 
American children. Caucasian children had a significantly lower rate of physical neglect substantiation than children from all other ethnic backgrounds combined. There were no differences in rates of abuse substantiation by ethnicity. Results also revealed a higher rate of substantiation for females in cases of sexual abuse and a higher rate of substantiation for males in cases of physical neglect. Results of the qualitative interviews revealed that workers indicated a great diversity of reasons for making a decision regarding substantiation. English and colleagues (2002) conclude that

this range of responses indicates that the substantiation decision, which is intended by law and policy to be based on the evidence surrounding particular allegations, is instead mixed with risk assessment and a wide variety of other features of the child protection workers' environment, including fear of liability and workload management. (p. 830)

Furthermore, $60 \%$ of workers reported that risk factors influenced their decision to substantiate. These and other results indicated that workers considered the combined effect of risk factors in making decisions instead of basing decisions on consideration of isolated risk factors.

In a cross-national study of the use of ethnicity as a variable in social workers' assessments and interventions, Williams and Soydan (2005) surveyed 713 child protection workers in Sweden, Denmark, Germany, and the UK who reported working with ethnic minorities. The cities chosen for the study were comparable in their total and ethnic minority populations. The authors utilized self-administered questionnaires, which were either distributed by mail or during small group meetings with the workers. The questionnaire included a case vignette, which developed in three stages. Each stage was followed by a set of 
standardized and open-ended questions focused on assessment, intervention, and decision-making processes. A between-subjects design was used, and only the ethnicity of the child and family was manipulated, leaving half of the respondents to consider a majority-population family and the other half to consider an ethnic minority family. The quantitative portion of the analysis, which is explained in detail by Forslund and colleagues (2002), focused mainly on explicit or implicit references to ethnic background in the workers' responses to the case vignettes. The results of this quantitative analysis showed no significant differences in the overall decision-making pattern of the workers between the majority-population and ethnic minority families. However, responses to the third stage of the vignette indicated that more social workers would start a formal investigation for the family with a foreign-sounding surname (the ethnic minority family). In Denmark, the social workers were more likely to work alone with, seek more information about, and propose more swift intervention for the family with the Danish-sounding surname (majority-population family). Furthermore, more Danish social workers referred the ethnic minority family to a physician or the police. In Germany, social workers were more likely to act in the case of the majority-population family, but more likely to seek further information on the ethnic-minority family. As Williams and Soydan point out, such findings indicate that the ethnic minority family was subjected to the more punitive end of the care/control axis.

Williams and Soydan (2005) reasoned that while there was no significant difference in the general responses of social workers to ethnicity, further review 
of responses to the ethnic minority family described in one of the study vignettes may reveal important information about the nature of references to ethnicity. The authors conducted qualitative analysis of the open-ended responses, focusing on explicit references to ethnic background. Words such as culture, race, ethnicity, immigrant, foreigner, and use of interpreter were specifically noted. Statements that indicated an assumption of a different color or national origin were also considered. Within the open-ended participant responses, the authors found examples of stereotyping based on culture, ethnocentrism, and the tendency of workers to engage in psychological and behavioral explanations over social/structural factors. The authors also noted that participants' explanations at the level of culture included phrases that exemplified the use of cultural deficit models. These findings indicated that in considering the minority family's situation, workers leaned more toward the use of individual/cultural deficit models rather than a broader ecological consideration of how poverty, neighborhood and housing conditions, support networks, racism, and other social issues may impact family functioning. Finally, Williams and Soydan reported that the most remarkable aspect of workers responses to the vignettes was their similar reactions at each stage regardless of the background of the family. This indicates that the vast majority of social workers in the study were using color-blind and universalist approaches to practice.

McConnell, Llewellyn, and Ferronato (2006) reviewed court files and conducted group interviews in their exploration of how child protection workers in Sydney, Australia made removal and court action decisions regarding cases 
involving parents with intellectual disability. These researchers reviewed 285 court files and conducted 17 focus groups involving 155 workers. The group discussions were semi-structured and focused on the decision making process and influences on the decision to take court action. The majority (85\%) of the group participants were frontline child protection workers. The study's results were based on a content analysis of the court files and a thematic analysis of the transcripts from the group interviews. McConnell and colleagues reported that in determining to take court action, child protection workers assessed several issues: 1) the child's present situation; 2) the likelihood of effecting change and improving the child's situation; 3) the seriousness of the case relative to other cases being managed at the time; and 4) the strength of the evidence.

McConnell and colleagues (2006) found parental compliance to be the "bottom line" for the child protection workers in the study (p. 235). If parents were not perceived as being cooperative, workers saw little hope of improving a child's situation. The authors found that for the workers, parental compliance meant appreciating the seriousness of the allegation or situation, being willing to cooperate, and being committed to change. Furthermore, parental compliance was found to be a significant determinant of court action. The workers identified a range of factors that influenced parental compliance such as the parents' intellectual capacity and history of abuse. This indicates that workers acknowledged the external factors that may play a role in parents' ability to cooperate with child protective services. 
Landsman and Hartley (2007) examined the factors influencing how assessment and ongoing services workers attribute responsibility for child maltreatment and safety in cases involving domestic violence. A factorial survey approach was utilized and case vignettes were constructed by randomly including characteristics believed to be related to assessments of responsibility for child maltreatment. Surveys, which included five unique vignettes and followup questions, were mailed to a random sample of child welfare assessment workers. The final sample consisted of 87 workers. Findings indicated that the presence of domestic violence had a significant impact on workers' assessments of responsibility for child maltreatment and concerns for child safety. The respondents' degree of concern for safety was predicted by seven variables including race and prior referrals. Specifically, the presence of cases in which the family was Black and had more than one prior referral to CPS decreased concerns for child safety. Landsman and Hartley point out that this result is similar to that of Hansen and colleagues (1997) who found that professionals were less likely to report Black families than White families with the same situations and maltreatment allegations.

Each of the studies discussed in this section (except for McConnell and colleagues, 2006) considers the role of race or ethnicity in professionals' decision making. However, none of these studies takes into account family structure or socio-economic status. There was support presented for differential outcomes for children of different races. Black children and families were found to receive fewer in-home services (Stevens, 1998), have less concern for their safety 
(Landsman \& Hartley, 2007), and experience more punitive treatment (Williams \& Soydan, 2005) than White children and families. Also, both English and colleagues (2002) and McConnell and colleagues found support for the influence parental factors such as previous child protection involvement and compliance on workers' decisions. Together, these studies highlight the concurrent and interrelated influences of case, professional, and external factors on decision making.

\section{Removal/Placement}

Although the previous section considers a decision phase that often produces removal and placement decisions, the following research studies focus on the actual decisions regarding placement of children outside of their homes. Findings from the literature are outlined below.

In a study of the degree of agreement between experts and front-line workers on decisions to place children in out-of-home care or refer them to family preservation services, Rossi, Scheurman, and Budde (1999) surveyed 27 child welfare experts and 103 child protection investigators from urban sites in Michigan, New York, and Texas. The experts received a booklet containing 70 case summaries and were asked to record two judgments on each case: whether to place the child in the presence and absence of family preservation services. The resulting data set from the experts consisted of 1,890 case decisions in addition to demographic variables. The workers, all of whom had investigated abuse and neglect cases for more than one year in an urban setting, were given one of four sets of 18 cases randomly selected from the 70 cases given to the 
experts. Four cases were identical across sets, and the other 14 cases appeared in only one set. The workers' data set consisted of 1,854 decisions and demographic information regarding the workers.

Rossi and colleagues (1999) report that in an effort to capture the substantive content of cases, the case summaries were coded independently by two members of the research team. The more than 70 variables in the coding scheme included factors such as household composition, the nature of the complaint, demographic characteristics of the victims, and the reactions of the caretakers and other adults to child protective services investigation. These authors found that in making removal decisions, workers and experts consistently placed the greatest weight on the prior complaint record of families. Families who were previously involved with child protective services were much more likely to have their children taken into custody. Overall, workers and experts of varying degrees of experience or from various backgrounds appeared to make decisions about cases no differently. Also, workers' and experts' characteristics had far less influence on their decisions than case characteristics.

Galante's (1999) examination of social workers' removal decisions after substantiation considered how such decisions were influenced by degree of ambiguity in aspects of the case presented, race of the child, maltreatment type, and degree of modern racism exhibited by the respondents. The study design included vignettes in which level of ambiguity, race, and maltreatment type were manipulated, resulting in 12 versions, or conditions. A stratified random sample of NASW members who worked in child welfare were randomly assigned to each 
condition and mailed a self-administered questionnaire, which included a vignette and a series of open-ended questions related to the vignette. The final sample consisted of 903 social workers. Results showed that social workers' decisions about removal differed significantly by maltreatment type and race. In particular, a greater variety of service recommendations were given for physical abuse cases than neglect cases, and cases in which physical abuse occurred were associated with longer stays in out-of-home care. White children were more likely to be removed from high-risk situations than Black children, which indicated that White children were afforded more protection from such situations. This finding is similar to findings reported by Hansen and colleagues (1997) and Landsman and Hartley (2007), which indicate that in some instances, professionals are less inclined to intervene on behalf of or have as many safety concerns about Black children in maltreatment situations. Galante also reported that respondents considered lack of cultural understanding to be a greater barrier for treatment for Black families than White families and that White children were more adoptable than Black children. This author surmised that these particular results could reflect an acknowledgement of bias in American culture rather than individual bias in professionals' decision making. Finally, in addressing the findings of differences in decisions by race, Galante concluded that:

Race may have been used as a heuristic, a way to categorize information, rather than in a manner that promoted unconscious discrimination. Therefore, while this study found that race matters in child welfare decision making, information about this child/family characteristic is not being used in a discriminatory manner. (p. 93) 
Gammon (2000) examined the impact of professional and case characteristics on social workers' decision processes regarding family reunification. This study utilized vignettes in which race of the child (BlackWhite) and socioeconomic status of the family (mid-SES/low-SES) were manipulated. A questionnaire including one vignette, questions regarding the vignette, and demographic questions were mailed to randomly selected NASW members who listed child welfare as their primary area of practice. Gammon found no statistically significant difference in the reunification decisions of the 534 respondent social workers by race or SES. However, professional characteristics-sex of the social worker and years of practice experience-were found to impact case decisions. Specifically, male social workers were more likely to have the child remain in foster care, and more experienced workers were more likely to reunify the child and family.

Britner and Mossler (2002) examined the role that professionals' experiences play in their decision-making processes regarding foster care placement. This study utilized vignettes in a mixed between- and within-subjects design, which included manipulating the following variables: race of the child (Black/White; between factor), age of the child (2 years/6 years; within factor); and pattern of abuse (chronic/first offense; within factor). Other variables, such as gender, type of abuse, and family structure, were held constant. Selfadministered questionnaires including four vignettes and follow-up open-ended questions were mailed to individuals from several professional groups, resulting in a final sample of 90 professionals. These authors found that race and 
chronicity of maltreatment did not influence professionals' ratings of the importance of various kinds of information used in decision-making. Instead, the importance of types of information varies by profession. In other words, different professional groups assign different weights to various child/family characteristics (individual, social, environmental) when making decisions. Social workers and mental health providers rely most heavily on information about the severity and pattern of abuse as well as the parents' responses to services provided in the past. Judges and guardians ad litem focus more attention on information about the likelihood of recurrence of abuse and the child's ability to recount the abuse. Child Appoint Special Advocates (CASAs) rely on information about the stability of the family (Britner \& Mossler). According to these authors, these findings underscore the need to assess and evaluate the multiple perspectives of decision-makers from different professional groups, as a variety of professionals are involved in and responsible for decisions about children and families involved in the child welfare system.

Lazar (2006) studied the effects of professional characteristics such as demographic and personality variables on Israeli child protection workers' decisions in emergency situations. A survey questionnaire containing one of four vignettes describing emergency situations related to boys and girls were randomly mailed to 154 licensed social workers and registered child protection workers employed in departments of welfare services throughout Israel. The questionnaires also gathered the professionals' socio-demographic information regarding including age, gender, ethnicity, family status, and authoritarianism. 
This last variable was measured using a 16-item authoritarianism scale. Each respondent received a randomly chosen vignette that described a situation for a runaway girl, battered girl, molested boy, or beaten boy. Lazar's findings indicated that the severity of the intervention was associated with the child's gender, the worker's gender, and the worker's authoritarianism. Generally, the workers who were more authoritarian tended to choose more severe intervening decisions than their less authoritarian counterparts. In addition, these more authoritarian workers tended to choose less severe intervening decisions for boys than for girls. Regarding the worker's gender, female child protection workers were found to choose less severe courses of action than male workers, but only in the situation of the battered girl.

In a study of how assumptions about race, poverty, and risk factor into the professional decision-making process in child protection, Rivaux and colleagues (2008) analyzed a sample of cases from the Texas child welfare database ( $N=$ $123,621)$. The family, or "case," was used as the unit of analysis, so families who had more than one investigation in the study time frame (September, 2003 through February, 2005). The overall sample included cases in which a decision was made to (1) take no action and close the case, (2) provide in-home services, and (3) remove the child and place him/her in out-of-home care. The sample was approximately one-third African American and two-thirds Caucasian. Single parent households comprised nearly $72 \%$ of cases, and $40 \%$ of these households were headed by mothers. Nearly one-third of the families had a household income of less than $\$ 10,150$ per year. The majority of cases (87\%) 
were closed after investigation. Only $8 \%$ of cases resulted in removal and only $5 \%$ of cases involved provision of in-home services.

Rivaux and colleague's (2008) study included the following main variables: race/ethnicity, household income, and the caseworker's risk assessment score after investigation. This risk assessment score was constructed by summing the scores for seven risk areas of concern reported by caseworkers after a maltreatment investigation. The areas included child vulnerability, caregiver capability, quality of care, maltreatment pattern, home environment, social environment, and response to intervention. Rivaux and colleagues found that risk scores for White families were significantly higher than risk scores for African American families, even within comparable case decision categories.

Furthermore, families with lower incomes were generally rated as being at higher risk than their counterparts with higher incomes. Race not only contributed to the decision to take action, but also to the decision about what actions would be taken. Specifically, African Americans were $20 \%$ more likely to have their case acted upon (versus being closed), and $77 \%$ more likely to be removed. Other variables that contributed significantly to removal were child age, marital status of parents, income level, number of children in the family, whether the parents were teens, report source, allegation type, and state region of the report. Finally, while an interaction of race, risk, and income seemed to predict decision regarding services and removal, when the effects of risk, poverty, and other relevant factors were controlled, race alone continued to be a predictor of worker decisions. Since the risk scores of White families were higher than the scores of African 
American families, Rivaux and colleagues suggest that direct racial bias may not have been present. This author concludes that the study's findings suggest that, rather than racial bias impacting the risk score itself, disproportionality in this instance may be better explained by racial/ethnic differences in the risk threshold workers used to make case decisions. In other words, more evidence of risk is required to take action in cases involving White families than in cases involving African American families.

Not all of the studies in this section considered race as a factor in decision making, yet those that did had mixed results. While Galante (1999) found that White children were more likely to be removed from their homes, Rivaux (2008) found that Black children were more likely to face out-of-home placement. Gammon (2000) found no racial differences, but did conclude that professional characteristics influenced decision making in the study. Lazar's (2006) findings support the idea of professional characteristics being influential, specifically the gender and level of authoritarianism of the worker. One of Rossi and colleagues' (1999) conclusions was that case characteristics such as prior complaints were

more influential in removal decisions than professional characteristics. Regarding socio-economic status, Rossi and colleagues found poverty to be a factor in that almost all of the cases involving homelessness resulted in higher relative risk and removal of the child.

Multiple Decision Points

While the research studies discussed above focus primarily on a single decision point within the child protective services process, a study by Harris and 
Hackett (2008) had a broader focus. These authors considered professional decision-making at several key decision points in the child welfare system. These authors conducted a quantitative analysis of administrative data to determine the trajectories of African American, Caucasian, and Native American children ( $N=$ 6,518 ) through reporting, referral for investigation, reunification services, out-ofhome placement or termination of parental rights, and exiting the system. Findings indicated that children of color had a different set of experiences at each stage of the system than White children. To provide a context for the quantitative findings, Harris and Hackett qualitatively analyzed secondary data from focus groups including 66 professionals, community stakeholders, youth, and families involved in decision-making at each stage of the child welfare system in King County, Washington. The intention of the focus groups was to seek information about the mechanisms of decision-making at each decision point that might suggest sources of racial disproportionality. Analysis of data from focus groups including a variety of individuals involved in the child welfare system yielded some findings regarding individual bias that have not been widely explored or reported in the literature. Particularly, some decision makers in the study felt that the system was objective and without bias. Others believed that subjective crosscultural decisions could be made accurately, without concern. Decision-makers with these viewpoints are unlikely to "acknowledge the need for checks and balances for bias in their own decision-making and those of others they supervise or manage" (p. 212). 
Based on their findings, Harris and Hackett (2008) contend that decisions made in the child welfare system seem to be the results of interdependent processes from multiple systems. Furthermore, decision outcomes are influenced by both attitudinal and structural factors. Specifically, these authors found that:

Subjective factors in the risk assessment processes may open the door for racial bias in assigning cases for investigation, and a lack of culturally specific remedial services (family preservation, mental health, substance abuse) or differences in perception regarding the value of these services may result in fewer in-home services to support the preservation of families of color and could play a role in differences between in-home placement versus out-of-home services. (p. 212)

\section{Relevance to Attribution Theories}

Concepts related to attribution theories, specifically attributional bias, are present in several of the research studies discussed above. Although attributions were not directly measured in these studies, researchers noted the role played by issues of attribution in the discussions of their findings.

In studies by Rivaux and colleagues (2008), Landsman and Hartley (2007), McConnell and colleagues (2006), and Williams and Soydan (2005), there were indications that child protection workers' decisions were influenced by the fundamental attribution error. Rivaux and colleagues concluded that "poverty, risk, and race may be related due to the fundamental attribution error through which decisions may be based on an underestimation of situational forces such as poverty" (p. 165). Like Landsman and Hartley and Hansen and colleagues (1997), Rivaux and colleagues' findings indicate that workers inferred more negative personal characteristics for Black families. Specifically, the inference was that Black families should receive CPS intervention because the risk to 
Black children is predominately grounded in the parents'/family's internal deficits (Rivaux). In other instances, the inference was that maltreatment is more normative for Black families and, therefore, Black children are at less risk of harm if they remain in such situations (Hansen et al.; Landsman and Hartley). The findings of McConnell and colleagues and Williams and Soydan also indicate the presence of correspondence bias. These researchers report that the workers surveyed tended to attribute maltreatment or risk of maltreatment to the personal dispositions of the families, while giving little or no attention to external factors such as the families' circumstances or the social environment

\section{Summary}

The literature provides a great deal of information about the various factors (i.e., case, professional, and environmental characteristics) that are influential in child protection workers' decisions about child maltreatment cases. As mentioned earlier, however, at first look, there appear to be some inconsistencies in the findings within the literature. In an effort to consider the findings more closely, the decision making studies are grouped according to design—secondary data collection, primary qualitative data collection, and primary quantitative data collection (see Appendix I).

Regarding secondary data collection, Gryzlak and colleagues (2005) and English and colleagues (2002) found that while the race of the child alone did not influence professional decision making, the interaction of race and maltreatment type impacted decisions. None of the qualitative studies considered family structure or socio-economic status as variables influencing decision making and 
only Williams and Soydan (2005) considered race/ethnicity. These authors did find differences in decision making based on ethnicity. Both studies by Platt (2006) and McConnell and colleagues (2006) found that parental compliance played a part in professionals' decision making.

Among the studies in which primary data collection occurred, family structure was not considered. Gammon (2000) considered the family's socioeconomic status, but did not find it or race to influence reunification decisions. Britner and Mossler (2002) did not find evidence of race impacting professionals' ratings of the importance of various kinds of information. Galante (1999) found race to be a factor in removal decisions and Landsman and Hartley (2007) found that race influenced professionals' safety concerns. Interestingly, both studies found that White children experienced higher levels of concern and protection from professionals than Black children.

Taking into account all of the studies in this review, only two did not find support for race and socio-economic status as influential factors in professional decision making. All of the other studies that considered race, family structure, and socio-economic status did find that they influenced professionals' decisions.

It is clear from this review of the literature that the theoretical constructs discussed at the beginning of this chapter are helpful in explaining these factors and the decision process as well as predicting outcomes of workers' decisions. The person-in-environment concept promoted by Cohen's (2006) decision making framework, the theory of strategy selection put forth by Payne and 
colleagues (1993), and the related ideas expressed by theories of attribution are evident in the literature on decision making in child protection.

Development of an Integrated Framework for Problem Consideration

The theoretical constructs discussed at the beginning of this chapter are highly complementary, as the decision making frameworks may be interconnected and informed by attribution theory. Drawing from these constructs and previous research, a model has been developed that will serve as a guide for this project's consideration of decision making in child protective services. The proposed model emphasizes the role of attribution theory in the decision process and integrates relevant decision making factors from the literature into its structure. Once a strategy is selected, attribution and other factors influence how the decision process is carried out. The model borrows concepts from other disciplines such as social psychology to create a framework for understanding decision making in child protective services.

Figure 5 and Figure 6 illustrate the connection between the aforementioned constructs and factors. Also, the use of this model in development of the survey questionnaire for this research project is shown through indication of the questionnaire items that relate to the various aspects of the model. 


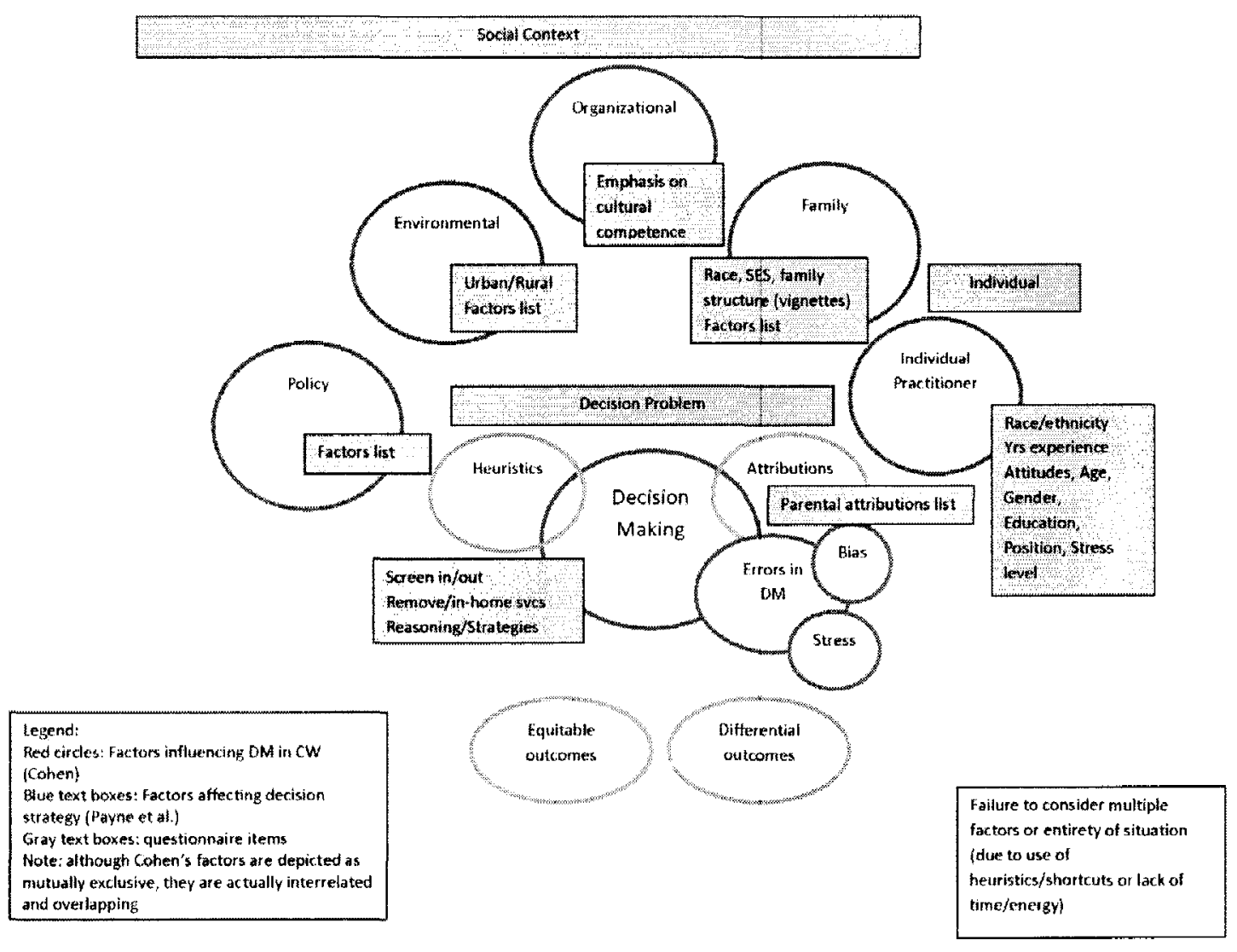

Figure 5. Outline of decision making in child protective services. 


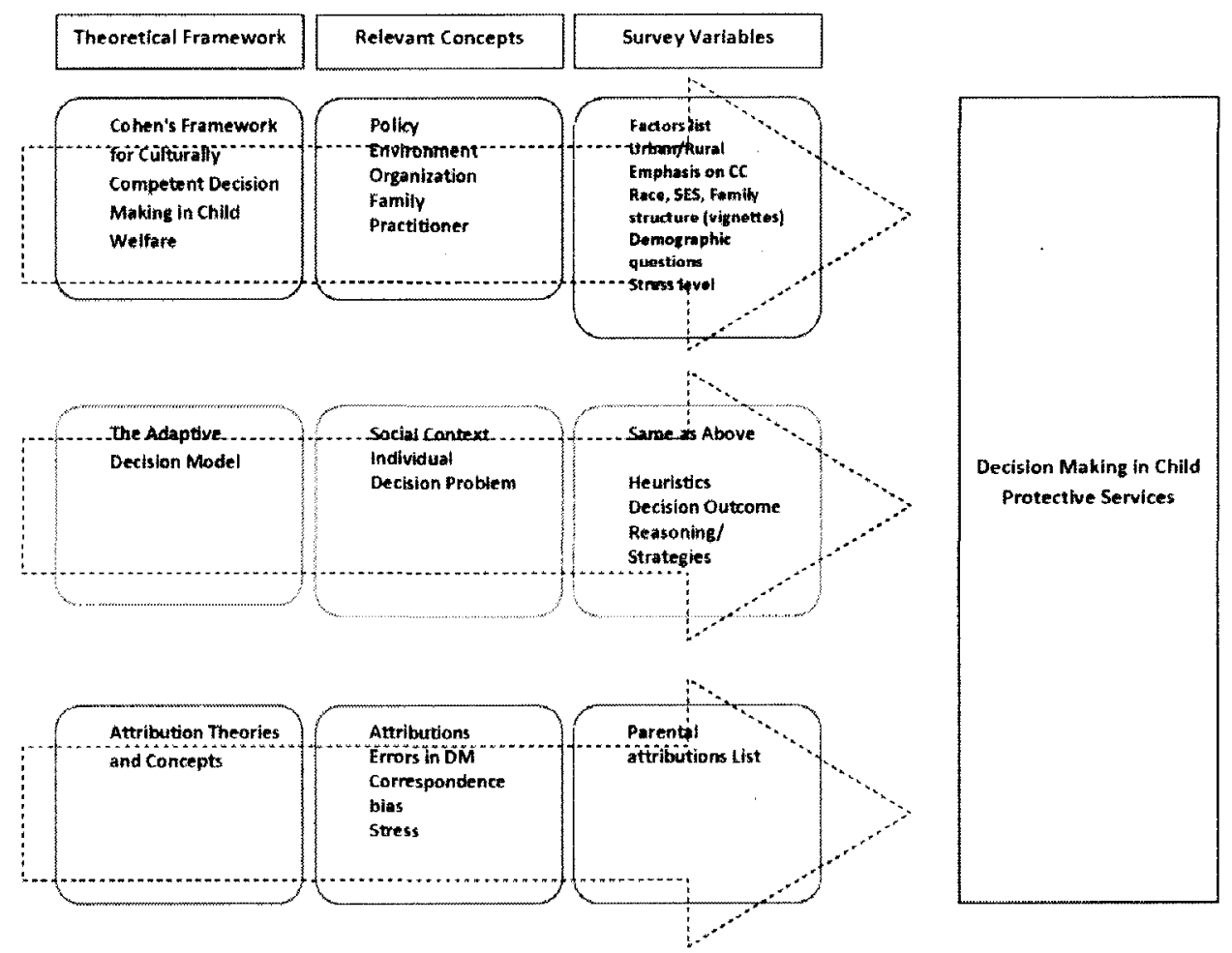

Figure 6. From theoretical frameworks to research study.

Conclusion

The literature and theoretical constructs provide a good foundation for a study of decision making in child protective services and factors that influence professionals' decisions. It has been shown, however, that more exploration of this subject is needed, specifically as it relates to race, poverty, and family structure. Although these factors are often discussed in the literature as impacting professional decision making and, possibly, creating disproportionate and disparate outcomes for children and families, they have yet to be considered concomitantly. Furthermore, the theoretical frameworks that will inform the 
present study have not been utilized for this express purpose. Ultimately, the hope is that exploring these foundational concepts in a different way will provide a more in-depth view of decision making in child protection.

Appendix $\mathrm{K}$ offers a summary of the reviewed studies' methods, findings, and limitations. The present research study addresses several limitations and gaps present in previous child protection decision making research. First, while many of the other studies were exploratory or descriptive, this study endeavors to explain at least part of the decision making processes and factors associated with professionals' assessments of child protection intake and investigation cases. Second, the present study gathers primary data directly from child protection workers and supervisors who are engaging in direct service provision in the areas of intake, investigation, and ongoing services. Respondents are given an opportunity to communicate the reasons driving their decisions and the factors that they believe influence their decision making. Respondents were also asked to provide information about their attitudes and beliefs related to race, family structure, and poverty. Third, many of the studies reviewed relied on analyses of information gathered in the 1980 s or 1990s. The present research offers an up-to-date and current examination of decision making in child protective services. Fourth, the factorial vignette within-subjects design of the present study is an improvement over designs of previous studies. This study examines the additive and individual effects of race, family structure, and poverty on professional decision making in child protection. Finally, this study includes an intentional focus on the role of attributional bias in decision making. While 
previous studies have noted this issue in their findings, the present study asks specific questions of workers and supervisors that are intended to provide information about attributions made during the decision making process.

\section{Research Questions}

The present research study addressed an underexplored area of the literature by providing more insight into decision-making among current child protection and permanency workers, including those involved in screening decisions. This study attempted to answer the following questions:

- What personal, professional, and environmental characteristics (e.g., race/ethnicity, years of experience, geographic location, stress level, attitudes toward race, and case composition) influence child protection workers' screening and disposition decisions?

- What child and family (case) factors influence child protection workers' intake and post-investigation disposition decisions?

- To what extent do parental attributions influence child protection workers' screening and disposition decisions?

- What is the impact of race, family structure, and socio-economic status on decisions by child protection workers regarding intake and postinvestigation disposition decisions? 


\section{CHAPTER THREE: METHODOLOGY}

\section{Overview}

The major goal of this research study was to add to the understanding of the mechanisms that cause disproportionate representation of and differential outcomes for children in the child welfare system by race (class, and family structure). This study employed a cross-sectional, factorial, descriptive/explanatory research design. Child protection workers and supervisors were surveyed regarding their decision making at a single point in time using an Internet-based, self-administered survey questionnaire. This study utilized a mixed methods approach in that quantitative and qualitative data were gathered and analyzed.

\section{Design}

A multivariate $2 \times 2 \times 2$ (race $\times$ family structure $\times$ SES) withingroups/between-groups factorial design was utilized. Child and family characteristics that were manipulated in the scenarios were race (White versus Black), socio-economic status (middle Class versus poor), and family structure (two-parent versus single-parent). Consideration of professional characteristics included race, gender, years of experience, practice area, rank, work environment, perceived stress, and attitudes. The interaction of these variables was also explored. Respondents were randomly assigned to two of 16 child maltreatment scenarios. The 16 maltreatment scenarios consisted of eight 
scenarios involving a six-year-old boy whose teacher discovered bruises on his leg and eight scenarios involving a seven-year-old boy who was taken to a doctor's office due to injuries alleged to be due to a bicycle accident. Within each of the two sets of eight scenarios, the stories varied in terms of race, SES, and structure of the family [1) Black, low-SES, two-parent; 2) Black, low-SES, singleparent; 3) Black, mid-SES, two-parent; 4) Black, mid-SES, single-parent; 5) White, low-SES, two-parent; 6) White, low-SES, single-parent; 7) White, midiSES, two-parent; 8) White, mid-SES, single-parent]. Each scenario involved two stages-intake and investigation-after which the respondent was asked to make a decision and discuss factors involved in the decision.

According to Taylor (2006), the factorial survey design has several features that make it a particularly rigorous and ethical design for exploration of factors that influence decision making. This is because it offers the experimental design strength of teasing out the influence of individual factors in the decision, as well as the validity of a survey method that is closely linked to real practice. Specifically, the factorial survey uses realistic vignettes, or case scenarios, that are presented to a decision maker for judgment (Finch, 1987; Taylor, 2006). These vignettes, which are constructed from practice wisdom, a review of relevant literature, or preliminary qualitative study, consist of "a series of sentences in a fixed order that contain factors relevant to the decision. The level or presence of the factors within the sentences is randomly varied among the vignettes" (Taylor, 2006, p. 1191). These factors are independent variables that may be categorical, ordinal, or interval level. The dependent variables in the 
factorial vignette method are the participants' responses to questions at the end of each vignette. These dependent variables may also be at various levels of measurement (Taylor, 2006).

The experimental nature of the factorial vignette method is apparent in the deliberate construction of multifaceted vignettes and the random assignment of these vignettes to study participants (Taylor, 2006). The general principle of factorial designs is that the dependent variable is measured in relation to combinations of the various factors (independent variables) in the vignette (Taylor, 2006). This is illustrated in Figure 7, which represents the factorial design of the present study. The letters in the cells represent the dependent variables.

\begin{tabular}{|l|c|c|}
\hline & White child & Black child \\
\hline $\begin{array}{l}\text { low-SES } \\
\text { single-parent }\end{array}$ & $\mathrm{A}^{\mathrm{a}}{ }^{\mathrm{A}}{ }^{\mathrm{a}}$ & $\mathrm{B} 1 \mathrm{~B} 2$ \\
\hline $\begin{array}{l}\text { low-SES } \\
\text { two-parent }\end{array}$ & $\mathrm{C} 1 \mathrm{C} 2$ & $\mathrm{D} 1 \mathrm{D} 2$ \\
\hline $\begin{array}{l}\text { mid-SES } \\
\text { single-parent }\end{array}$ & $\mathrm{E} 1 \mathrm{E} 2$ & $\mathrm{~F} 1 \mathrm{~F} 2$ \\
\hline $\begin{array}{l}\text { mid-SES } \\
\text { two-parent }\end{array}$ & $\mathrm{G} 1 \mathrm{G} 2$ & $\mathrm{H} 1 \mathrm{H} 2$ \\
\hline
\end{tabular}

Figure 7. Illustration of a factorial design. $\left({ }^{2}\right.$ The numbers 1 and 2 indicate the first and second case situations; therefore, each cell contains two randomly assigned case situations.)

Taylor (2006) asserts that the use of factorial vignettes is a valuable method for descriptive studies, such as the current study, that consider how 
professionals make real world practice decisions. This method, which was first articulated by Rossi and Nock (as cited in Taylor), has been used in a variety of fields, but has yet to be widely used in social work research (only six of the studies reviewed for this project utilized the vignette method). The ability of the factorial survey design to deal with the complexity of situations faced by social workers in everyday practice promotes this design's external validity. Another valuable feature of the factorial survey design is that it may be used to determine the decision practices and processes of groups of decision makers. Furthermore, it informs an understanding of how social workers (and other types of decision makers) view the comparative importance of factors or issues and how these factors are combined in decision making (Hammond, 1996).

As Taylor (2006) states, the factorial survey design is "suited to almost any topic where we wish to know how client, family, and context factors affect professional judgments" (p. 1201). As this was the focus of the present research study, the use of this method, including realistic vignettes, was highly appropriate. Although Taylor (2006) encourages the use of random sampling of respondents, which will allow for greater external validity, this study did not attain that aspect of the factorial survey design.

\section{Proposed Study Vignette Design}

Three independent variables were manipulated: (1) race (Black/White), (2) family structure (single-parent/two-parent), and (3) socio-economic status (lowSES/mid-SES). The age of the child was only varied by one year and all other variables were held constant. Vignettes were divided into two stages-intake and 
investigation/disposition. Manipulated variables were identified at both stages. Individuals with knowledge of child protection cases and processes were asked to assess the realism and clarity of the vignettes before data collection begins.

As mentioned above, the dependent variables are measured in relation to combinations of the independent variables (Taylor, 2006). In the present study, decision making processes and outcomes, including the presence of bias, were measured according to whether differential rates of investigation referrals and out-of-home placements were observed by race, family structure, and/or socioeconomic status. The detailed factorial vignette design of this study is illustrated in Appendix C.

\section{Sample}

The population of interest was comprised of current protection and permanency workers in public child welfare agencies. Initial plans for the study involved including professionals from three states, but only two states approved the study and one of the states that approved the study did not follow through with administration of the survey.

Therefore, the population for the present study consisted of supervisors and front-line workers who practiced in the areas of intake, investigations, and ongoing in-home service provision in a Midwestern state. The purpose of focusing on this group of workers and supervisors was to address an apparent gap that exists in the literature regarding an empirical understanding of decisionmaking regarding screening, investigation, and treatment by the professionals who are currently working in these areas of child protection. 
As of July 2009, there were 1805 intake, investigation, and ongoing workers (including 244 supervisors) employed in the target state (R. James, personal communication, July 10,2009$)$. This number comprised the target population for the proposed study. Given the $2 \times 2 \times 2$ design of the study and a desire to have at least 30 participants respond to each combination of independent variables, the minimum desired sample for this study was 240 participants.

The public child welfare system in the target state is centralized and stateadministered. Population demographics and the severity of Black-White disparity in foster care population of the target state (Child Welfare League of America [CWLA], 2009) is illustrated in Table 3.

Table 3

Target State Child Welfare Demographics

\begin{tabular}{|c|c|c|c|c|c|c|}
\hline $\begin{array}{l}\text { State } \\
\text { Population/ } \\
\text { Children } \\
\text { Under } 18 \\
\text { (2007) }\end{array}$ & $\begin{array}{c}\text { Children } \\
\text { Referred } \\
(2006)\end{array}$ & $\begin{array}{l}\text { Investigated } \\
\quad(2006)\end{array}$ & $\begin{array}{l}\text { Substantiated } \\
\text { (2006) }\end{array}$ & $\begin{array}{c}\text { Out of } \\
\text { Home } \\
\text { Care } \\
(2006)\end{array}$ & $\begin{array}{l}\text { Disproportionality } \\
\text { (Foster Care) }\end{array}$ & $\begin{array}{c}\text { Poverty } \\
\text { Rate } \\
\text { for } \\
\text { children } \\
\text { under } \\
18 \\
(2007) \\
\end{array}$ \\
\hline $6,345,289 /$ & 67,290 & 44,051 & 20,925 & 11,384 & Extreme $^{a}$ & $18.8 \%$ \\
\hline $1,586,518$ & & & & & & \\
\hline
\end{tabular}

${ }^{\mathrm{a}}$ Center for the Study of Social Policy (2004)

The sampling frame included a list of office e-mail addresses for protection and permanency workers and supervisors in the target state, through the e-mail system. The final sample consisted of those who completed and submitted the 
questionnaire. Given that the questionnaire asked respondents to answer questions about personal attitudes and professional practice, it was believed that a higher response rate would be achieved if the survey process allowed for the workers and supervisors to maintain anonymity. To this end, participants were asked to register for the survey using a self-determined nickname and password. This allowed participants to remain anonymous as well as stop, save their progress, and resume the survey at a later time if needed.

As this study relied on a sample of convenience, no attempts (such as stratification or randomization) were made to secure a representative sample in data collection. The survey was sent electronically to all child protection intake, investigative, and ongoing workers and supervisors in the target state who had active e-mail accounts at the time of survey administration.

\section{Variables and Measurement}

The key variables of interest in this study were as follows: professionals' demographic characteristics; professionals' attitudes toward race, poverty, and family structure; professionals' case decisions; professionals' attributions for causation of maltreatment, professionals' feeling about the parents actions, and child and family demographic characteristics. These variables were operationalized through the various items found in the survey instrument. These items are discussed in detail below. 


\section{Case Characteristics in Vignettes}

Race

The race of the child and family was manipulated in each vignette, so that half of the vignettes described a situation concerning a Black family and the other half described a situation concerning a White family. Instead of explicitly stating the race of the child and family, implicit cues about race were provided through the use of names that are commonly associated with a certain racial category. The method for selecting such names included a brief informal paper survey of 25 social work students, practitioners, and educators (see Appendix F). These individuals were asked to indicate their opinions about whether each of 20 names would be associated with a Black or White child. If the individual was of the opinion that a name could easily be associated with either racial category, s/he was encouraged to indicate this by checking "neutral." The two names that were most frequently associated with a Black child were Tyrone and Jamal. The two names most frequently associated with a White child were Garth and Dustin. Therefore, these four names were chosen to represent children from these two racial categories in the vignettes. No manipulation checks were conducted in the study itself in order to reduce response bias and to keep the questionnaire as brief as possible.

Class

The socio-economic status of the children and families described in the vignettes was also manipulated to be either low-SES or mid-SES. The socioeconomic status was indicated through descriptions of the family's housing 
environment and the employment type of the parent(s). Specifically, families in low-SES situations were described as living in a public housing project with parents employed as fast food restaurant workers. Families in mid-SES situations were described as living in a middle-class neighborhood just outside of town. The mid-SES parents were described as grocery store managers, occupational therapists, or accountants.

\section{Family Structure}

Vignettes depicted either two-parent or single-parent family situations. In two-parent families, the child was described as living with his mother and father. In single-parent families, the child was described as living with only his mother and having an estranged father.

\section{Case Characteristics Controlled}

As indicated in the literature, there are several child and family variables that often influence professional decision making. In an effort to address this issue and place greater emphasis on the variables of interest, the following case characteristics remained static throughout the various iterations of the case vignettes: gender, age, type of maltreatment, perpetrator, reporter type, history of maltreatment, and service history. Each of the vignettes described a professional (teacher or nurse) reporting that a six- or seven-year-old male child had been physically abused by his mother. The family had a history of child protective services involvement due to maltreatment, as well as a history of service

- provision and parental compliance with services. While attempting to control for the possible influence of the aforementioned variables was deemed necessary 
for this study, it may also be considered a limitation in that only a select group of three variables was considered.

\section{Professional Characteristics}

\section{Demographics}

Background and descriptive information was gathered from the professionals who completed the questionnaires through individual questions that were measured at the nominal and ratio levels. Professionals were asked to report their race, gender, level of education, practice area, position, years of experience, and geographic location. In this study, geographic location was categorized as either urban (population of 50,000 or more) or rural (population of less than 50,000$)$.

Decisions Made Regarding Vignettes

Professionals were asked to respond to two sets of questions after reviewing the vignettes. The first question in each set referred to the screening and placement decision and the professional was asked to report his/her choice of one of two options-screen in/screen out or remove to out-of-home care/set up in-home services-depending upon whether the vignette presented was an intake or investigative situation. This variable was measured on the nominal level. The second question in each set was an open-ended question and referred to the professional's reasoning. The responses to this question were analyzed qualitatively. 
Work Environment

Participants were asked to respond to questions about their caseloads, level agency emphasis on cultural competence, and level of work-related stress. These variables were measured at the ratio and ordinal levels.

\section{Attitudes toward Race}

Participants' attitudes toward race were measured using the Color-Blind Racial Attitudes Scale (COBRAS), developed by Neville, Lilly, Duran, Lee, and Browne (2000). The COBRAS assesses the extent to which individuals deny or are unaware of racial dynamics. This scale is composed of three factors: Racial Privilege, which refers to blindness to the existence of White privilege; Institutional Discrimination, which involves a limited awareness of implications of institutional forms of racial discrimination and exclusion; and Blatant Racia! Issues, which concerns unawareness to general, pervasive racial discrimination. The COBRAS' 20 items are rated on a Likert-type scale from 1 (strongly disagree) to 6 (strongly agree). A lower score indicates greater awareness of racial dynamics. In five studies of college students and some community members $(\mathrm{N}=1188)$, the COBRAS demonstrated acceptable validity and an overall Cronbach's alpha of 0.86 (Neville et al., 2000). The combined sample from these studies was approximately one-half female and three-quarters White. The authors point out that the COBRAS was positively related to other racial attitudes scales (i.e., the Quick Discrimination Index and the Modern Racism Scale) as well as two measures of belief in a just world, indicating that color-blind 
racial attitudes were related to racial prejudice and belief that society is just and fair.

\section{Attitudes toward Poverty}

The Modified Economic Belief Scale (MEBS), developed by Aosved and Long (2006), was included in the survey to measure participants' attitudes toward poverty and the economically disadvantaged. This fifteen-item scale was based on an earlier, eight-item version of the Economic Belief Scale (EBS) developed by Stevenson and Medler (1995) to measure attitudes toward the economically disadvantaged in their larger study of homophobia and sexism. The fifteen MEBS items are rated on a Likert-type scale from 1 (strongly agree) to 5 (strongly disagree) and scores range from 15 to 75 , with lower scores indicating higher levels of classism. The original EBS was administered to a sample of 155, primarily Caucasian, college students, ranging in age from 16 to 45 , with a mean age of 20 . The internal consistency reliability coefficients for this sample were .77. Aosved and Long's (2006) sample was demographically similar to that of Stevenson and Medler, but included many more students $(N=998)$. The internal consistency reliability coefficient of the MEBS, as reported by Aosved and Long, was 0.85 . No information regarding validity was provided by the authors of either study.

For the purposes of the proposed study, the ordinal scale ratings were reversed (for example, 1 = strongly disagree, $5=$ strongly agree) to allow for consistency between the format of the MEBS and the COBRAS. Therefore, higher scores on the MEBS among the present sample indicate higher levels of 
classism. Furthermore, items from both scales were intermingled and combined under one Likert-type rating scale ( 1 = strongly disagree, $6=$ strongly agree) and five additional items related to family structure were included in the combined list. The purpose of this action was to reduce the likelihood of respondent social desirability bias, as similar items in separate scales may have been more easily recognized as pertaining to a specific social issue.

\section{Attitudes toward Family Structure}

In addition to the use of the aforementioned standardized instruments, five items related to attitudes about traditional and non-traditional (single-parent) family structures were intermingled with the race and poverty attitude scales. These items were adapted from the Attitudes toward Working Single Parents scale developed by Noble, Eby, Lockwood, and Allen (2004). The complete scale, which includes 15 items, is designed to measure perceptions individuals have about single parents in the workplace. As employment was not the focus of

this study, only items deemed appropriate for this study were used. Therefore, no reliability or validity data are available for these particular items.

Workers' Attributions for Parental Behaviors and Causation of Maltreatment

Respondents were asked to rate, on a 5-point Likert-type scale, their level of agreement with eight statements about the parents. The purpose of this line of questioning was to gather information on the attributions professionals made, and emotions they had, regarding the actions and circumstances of the parents in the vignette situations. Some of the items in this set were adapted from Barbee (1988) and others were developed for the proposed study. The following are 
examples from the list of statements: it is the parent's fault that the family is in this situation, the parents had control over their behavior, and the parent's behavior angered me. Respondents were asked to respond to these statements after each situation presented. Responses were measured at the ordinal level. Factors Influencing Decision Making

Respondents were asked to rate, on a 5-point Likert-type scale, the importance of 10 different specific pieces of information in their decision making. The list included items such as family history of CPS involvement, family's financial situation, and quality of the parent/child relationship. Some of these items were adapted from Britner and Mossler (2002), and some were developed for the proposed study. As in Britner and Mossler's study, respondents were asked to respond to this item set regarding each vignette situation presented. Therefore, the wording of these items and the parental attribution items was adjusted to represent a single- or two-parent family. Responses were measured at the ordinal level.

\section{Data Collection}

\section{Structure of the Survey Questionnaire}

Factors influencing professionals' decision-making and other variables of interest were measured using a self-administered questionnaire (see Appendix A), which included four sections. The first section consisted of demographic questions regarding the professional's position, experience, and geographic location. The vignettes and related questions were in the second section. The 
third section was comprised of attitude scales and the fourth section contained questions related to the respondent's work environment and stress level.

Specifically, the survey instrument solicited respondents' demographic information and included scales designed to examine their attitudes and beliefs about race (the Color-blind Racial Attitudes Scale) and poverty (Modified Economic Beliefs Scale) as well as items to measure their attitudes toward alternative family structures. They were randomly assigned two of 16 possible vignettes that consisted of two parts each (See Appendix B). The first part described an intake situation and the second part described a related investigation situation. After each vignette, respondents were asked to make a case decision, describe their reasoning, rate their reactions to the parents, and rate the importance of several factors in their decision making processes.

The professional practice-related variables included in the instrument focused on professional role, demographics, and work environment. The caserelated variables were located within the vignettes, which presented situations varying by race, socio-economic status, and family structure. Data on variables encompassing all levels of measurement was gathered through this survey instrument.

\section{Pre-testing of the Questionnaire}

Before being finalized, the instrument was administered to several professionals with former child welfare experience. It was determined from this pre-testing that the instrument would take approximately 20 minutes to complete. Modifications to some of the items were made based on feedback from the 
professionals. However, correct identification of the case demographics (race, SES, and family structure) was not assessed.

\section{Survey Administration and Data Collection}

Data were collected through professionals' completion of an Internetbased questionnaire housed in PsychData ${ }^{\top \mathrm{M}}$, an online survey service provider. Interaction with the sample population in this study was informed by the Tailored Design Method (Dillman, 2000). Recruitment of participants began with sending a brief pre-notice letter (see Appendix $D$ for participant communications) to all front-line workers and supervisors in the sampling frame via e-mail. This prenotice letter informed prospective participants that a link to an important survey would be mailed in a few days and their participation would be greatly appreciated. Four days later, a cover letter was e-mailed, which further explained the study and provided a link to the electronic Internet-based questionnaire. Three weeks after the survey e-mail, a follow-up e-mail was sent to thank those who completed the questionnaire and ask those who had not to also consider completing the questionnaire. The data collection period lasted six weeks.

$$
\text { Human Subjects Protection }
$$

The proposed research study was reviewed by the University of Louisville Human Subjects Protection Program Office and Institutional Review Board (IRB) of the target state. The design of this study was intended to allow participants to remain anonymous. 


\section{Informed Consent Process}

Potential participants were e-mailed a pre-notice letter informing them that they would soon be invited to participate in a research study regarding decision making in child protective services. The background and purpose of the study were briefly explained and individuals were provided with contact information for the researchers. The second e-mail message was the actual invitation to participate in the study. This message was more comprehensive in its explanation of the purpose of the study, the survey process, and the incentive. This second e-mail also included the entire informed consent statement.

Consent was discussed with participants in the second e-mail, which contained the link to the survey instrument. Potential participants had received a brief pre-notice e-mail one week prior to this survey e-mail. A comprehensive preamble consent statement was included in the body of this second e-mail as well as at the beginning of the on-line survey itself. Respondents were able to access the survey at their convenience and at any time during the data collection period. Therefore, they had ample time to consider participation in the study.

Given that this is an Internet-based research study, there was no method for assessing the respondents' understanding of the informed consent. The target population for this research study consisted of adults who were employed by a public child welfare agency and held at least a Bachelor's degree. The FleschKincaid grade level for the readability of the informed consent letter is 12 .

Therefore, it was expected that the child protection workers and supervisors who 
were the intended participants would be able to understand the consent information.

\section{Participant Incentive}

Due to the ethics regulations of the target state, which do not allow payment of employees for participation in research studies during paid work time, the planned incentive for this study was removed from the research design. Lack of an incentive may have impacted the response rate, but the impact was not deemed severe enough to require changing the design of the study. The brevity and ease of completion of the online survey likely assisted in creating a desire among the target sample to complete the survey.

\section{Risks and Benefits}

There was no direct benefit to the respondents who completed the survey. However, it is expected that this study will have societal benefits such as an increased understanding of how child protection workers make decisions, what case and professional characteristics factor into these decisions, and how bias may impact these decisions. Such understanding will allow for improvements to worker training and child protection practice. An ultimate goal of this research is to address the overrepresentation of children of color, particularly Black children, in the child welfare system, as well as the negative experiences that these children often have in relation to their White counterparts. In summary, the hope is that this study will lead to a better understanding of decision-makers processes, attitudes, and possible biases. This, in turn, may lead to the development of methods to impact attitudes, addresses biases, and make the 
decision process more transparent, which will result in a more equitable system of decision making in child protection.

Although respondents did not receive direct benefits from participating in this study, risk to participants was determined to be extremely minimal. The benefits of this study, specifically the possibility of improved outcomes for children and families involved in the child welfare system, outweighed the potential risks.

Analysis

\section{Quantitative Data Analysis}

Analyses of quantitative data included the use of Mann-Whitney tests, independent samples $t$-tests and ANOVAs to measure group differences (various professional characteristics) in attitudes/beliefs and factors influencing decisionmaking. Bivariate correlations (Pearson and chi square analyses) were used to measure the strength of relationships between variables. Binary logistic regression analysis was used to determine the extent to which groups of variables predicted intake and post-investigation disposition decisions. Standard univariate analyses were also completed.

\section{Qualitative Data Analysis}

A random sample of 45 cases ( $11.25 \%$ of study sample) was obtained using a function in SPSS. Univariate analyses revealed that this sample was comparable to the larger sample regarding demographic information, types of vignettes answered, and decision outcomes. Content analysis was used to examine this qualitative data. Each of the reason statements was reviewed within 
each of the four decisions (two intake and two disposition) and explanatory phrases were highlighted. Similar phrases/reasons were grouped under an exemplar phrase, which led to the development of a list of reasons for each of the four decisions. The presence of each of the phrases in the response set was then counted to determine frequencies of the types of reasons given for making the particular decisions. Qualitative and quantitative analysis methods will be discussed further in the next chapter. 


\section{CHAPTER FOUR: RESULTS}

In this chapter I provide detailed results of quantitative and qualitative analyses of the data gathered from surveys completed by child protection professionals. The study's research questions are restated and answered according to the findings of the analyses. Finally, a summary of the results is presented.

\section{Response Rate}

Individuals in the target state who provided child protection services $(N=$ $1805)$ were invited to complete an online self-administered survey. Data collection from April 15 to May 25, 2009 resulted in 533 of cases, $429(80 \%)$ of which contained responses to at least the first of two scenarios. Although the focus of this study is on decisions made by professionals engaged in child protective service provision, the online survey was accessed and responded to by some professionals outside this role $(N=29)$. These outside professionals represent a very small portion ( $7 \%$ ) of the total number of respondents and do not differ significantly from the child protection service providers regarding demographics or responses. However, because the purpose of this study is to explore decision making among professionals who are currently providing child protective services, respondents who indicated another child welfare role (e.g., adoptions) were not included in the current analysis. Therefore, 400 is the total sample size used for analysis. 
The response rate for the present study was $22 \%$. Although this response rate is much lower than the $80 \%$ response rate encouraged by Dillman (2000), the study's goal of 240 respondents was surpassed. Furthermore, the target population was comprised of child protective services providers who have very demanding schedules. The fact that nearly a quarter of professionals in the target state took the time to complete the survey is heartening.

Description of the Sample

\section{Demographic Characteristics ${ }^{3}$}

Women constituted $86 \%(N=312)$ of respondents and men $14 \%(N=52)$. The vast majority $(88 \%, N=320)$ of them were White. Six percent $(N=21)$ of respondents identified themselves as Black, while the remaining $6 \%(N=21)$ identified themselves as another race or ethnicity. One respondent identified herself as Latino/Hispanic. They ranged in age from 23 years to 63 years, with an average age of 36 years $(S D=10.82)$. Furthermore, they had an average of four $(S D=5.23)$ years of experience in their current areas of practice, with a range of between zero and 40 years, and reported an average of seven $(S D=6.89)$ years of child welfare practice experience, with a range of 0 to 40 years. The majority of respondents $(65 \%, N=234)$ held a Bachelor's Degree in a field other than social work. A much smaller percentage $(14 \%, N=51)$ reported having a Bachelor's Degree in Social Work (BSW), while $19 \%(N=68)$ held a Graduate Degree, and only $1 \%(N=5)$ had less than a four-year degree.

\footnotetext{
${ }^{3}$ Some respondents chose not to answer the demographic questions, which resulted in group numbers totaling less than 400. Percentages discussed are based on numbers of respondents who provided demographic information.
} 
Information about the demographic make-up of the child protection providers in the target state was not made available as of this writing. Therefore, the study sample cannot be compared to the larger population of child protection service providers in the target state. However, the sample and response rate of this study may be compared to those of similar studies. As shown in Table 4, the present study's sample is comparable to the samples of other studies regarding race and gender. Other demographics such as years of experience and education vary.

Table 4

Comparison of Study Samples and Response Rates

\begin{tabular}{|c|c|c|c|c|c|c|}
\hline Study & Location & $\begin{array}{c}\text { Response } \\
\text { Rate }\end{array}$ & Race & Gender & Education & $\begin{array}{c}\text { Mean } \\
\text { Years of } \\
\text { Experience }\end{array}$ \\
\hline $\begin{array}{l}\text { Present } \\
\text { Study }\end{array}$ & $\begin{array}{l}\text { Midwestern } \\
\text { state }\end{array}$ & $\begin{array}{c}22 \% \\
400 / 1805\end{array}$ & $88 \%$ white & $\begin{array}{c}86 \% \\
\text { female }\end{array}$ & $\begin{array}{c}64 \% \text { BS } \\
14 \% \text { BSW }\end{array}$ & $\begin{array}{l}6.5 \text { yrs CW } \\
4 \text { yrs current }\end{array}$ \\
\hline $\begin{array}{l}\text { Landsman } \\
\text { \& Hartley } \\
(2007)\end{array}$ & lowa & $\begin{array}{c}44 \% \\
87 / 200\end{array}$ & $\begin{array}{l}\text { not asked } \\
\text { (population } \\
94 \% \text { white) }\end{array}$ & $\begin{array}{l}85 \% \\
\text { female }\end{array}$ & $\begin{array}{c}89 \% \text { BS } \\
54 \% \text { SW } \\
\text { degree }\end{array}$ & $\begin{array}{l}11 \text { yrs CW } \\
7 \text { yrs current }\end{array}$ \\
\hline $\begin{array}{l}\text { Britner \& } \\
\text { Mossler } \\
\text { (2002) }\end{array}$ & Virginia & $\begin{array}{c}60 \% \\
90 / 150\end{array}$ & $83 \%$ white & $\begin{array}{c}70 \% \\
\text { female }\end{array}$ & $\begin{array}{l}\text { average } 17 \\
\text { years of } \\
\text { education }\end{array}$ & 6 yrs exp \\
\hline $\begin{array}{l}\text { Gammon } \\
(2000)\end{array}$ & $\begin{array}{l}\text { National } \\
\text { (NASW) }\end{array}$ & $\begin{array}{c}45 \% \\
534 / 1200\end{array}$ & $84 \%$ white & $\begin{array}{c}75 \% \\
\text { female }\end{array}$ & $90 \% \mathrm{MSW}$ & 20 yrs exp \\
\hline $\begin{array}{l}\text { Galante } \\
\text { (1999) }\end{array}$ & $\begin{array}{l}\text { National } \\
\text { (NASW) }\end{array}$ & $\begin{array}{c}30 \% \\
903 / 3036\end{array}$ & $87 \%$ white & $\begin{array}{c}\text { not } \\
\text { reported }\end{array}$ & $\begin{array}{c}79 \% \\
\text { graduate } \\
\text { degree }\end{array}$ & not reported \\
\hline
\end{tabular}

\section{Setting}

This study was completed in a Midwestern state, which is described as having a state-administered child welfare system with strong county discretion 
regarding child protective services (U.S. DHHS, 2003). A local CPS agency is located in each of its 92 counties and there are 18 regional offices, each managing several of the county-based CPS agencies. Respondents completed the online survey for the present study at their respective county office locations.

\section{Current Position and Practice Area}

Only $18 \%(N=73)$ of respondents were supervisors, while the vast majority $(75 \%, N=297)$ were direct service providers. Some $(7 \%, N=27)$ respondents held administrative or liaison roles. Their current practice areas were reported as follows: Intake, $1 \%(N=5)$; Investigation, $11 \%(N=45)$; Ongoing, $45 \%(N=178)$; Combination of CPS duties, $37 \%(N=148)$; and CPS duties and other duties, $6 \%(N=24)$.

\section{Work Environment}

Respondents were evenly distributed between urban $(49 \%, N=195)$ and rural $(51 \%, N=202)$ work environments. The median caseload for the group was $11(M=24$, range $0-1047)$. Only $83(21 \%)$ respondents reported having children of color on their caseloads. The average percentage of White children on a caseload was $71 \%$ and the average percentage of children of color on a caseload was $22 \%$. Overall, respondents reported moderate to high levels of stress. With a score of 1 being the lowest stress level and 7 being the highest, the group's median stress level was $5.00(M=5.13, S D=1.35)$. Finally, respondents reported a moderate level of agency emphasis on cultural competence, median $=5.00(M=4.81$ of 7 possible, $S D=1.56)$. 
Attitudes about Race, Socio-economic Status, and Family Structure Respondents completed two standardized scales pertaining to attitudes toward racism and poverty and one brief non-standardized scale related to attitudes about single-parent families. Numeric responses to these scale items were totaled and these total scores for each scale were included in analyses of correlations and group differences. Results are described below.

Color-Blind Racial Attitude Scale (COBRAS; Neville et al., 2000)

The COBRAS measures the extent to which individuals deny or are unaware of racial dynamics, and possible COBRAS scores range from 20 to 120 . A lower score indicates greater racial awareness. The COBRAS includes three factors: Racial Privilege, which refers to blindness to the existence of White privilege; Institutional Discrimination, which involves a limited awareness of implications of institutional forms of racial discrimination and exclusion; and Blatant Racial Issues, which concerns unawareness to general, pervasive racial discrimination. In the present sample of child protection workers $(N=400)$, the range of respondents' scores for the COBRAS was between 27 and 114, and the average score for the group was $68(S D=14)$, which indicates a moderate level of racial awareness.

Independent samples $t$ tests revealed significant differences in COBRAS scores as related to geographic location and position of respondents. Respondents working in urban settings had lower COBRAS scores $(M=65.69$, $S D=14.92)$ than respondents working in rural settings $(M=69.82, S D=12.93)$, $t(317)=-2.73, p<.01$. Supervisors had lower COBRAS scores $(M=63.38, S D=$ 
15.17) than frontline/direct services workers $(M=69.20, S D=13.70), t(321)=$ $2.96, p<.01$. Finally, respondents of color demonstrated lower COBRAS scores $(M=60.71, S D=15.93)$ than Caucasian respondents $(M=69.01, S D=$ $13.47), t(345)=-3.65, p<.001$. There were no significant differences in COBRAS score by respondents' gender, program area, education, or years of experience in current practice area.

Bivariate correlations revealed significant, negative relationships between COBRAS score, age, and years of child welfare experience. Older $(r=-.14, p<$ $.01)$, more experienced $(r=-.15, p<.01)$ respondents had lower COBRAS scores than their younger, less experienced counterparts. No significant correlation was found between percentage of children of color on a caseload and the COBRAS score or percentage of Caucasian children on a caseload and the COBRAS score.

Economic Belief Scale (EBS; Stevenson \& Medler, 1995)

Initially, respondents' attitudes toward the poor were to be measured using the 15-item Modified Economic Belief Scale (MEBS; Asoved \& Long, 2006), which is an extended version of the EBS. However, an item (People living in poverty would rather commit crimes for financial gain than work for a living) was inadvertently omitted from the final survey. In an effort to gather information based on a whole standardized scale, the eight items from the MEBS that constitute the original EBS were used in data analysis for the present study. The EBS measures attitudes toward poverty and the economically disadvantaged. The EBS is a single-factor scale. 
As discussed in the previous chapter, the response set for the Economic Belief Scale (EBS) was increased from five points to six points so that this scale could be interspersed with the other two attitude scales. The EBS response choices were also switched so that 1 indicated a strong disagreement with the statement and 6 indicated a strong agreement with the statement. The range of respondents' scores for the six-point response Economic Beliefs Scale (EBS) was between 8 and 43 (possible EBS scores for the six-point response ranged from 8 to 48$)$, and the average score for the group was $22(S D=7.14)$, which indicates moderate level of classism. [Since the value (1 to 6$)$ attached to the responses were reversed (i.e., $1=6,6=1$ ), in this study a higher EBS score indicates a higher level of classism.]

Data from the six-point response EBS were used for bivariate analyses. A one-way ANOVA revealed significant differences in the EBS scores of respondents of different education levels, $F(3,347)=6.96, p<.001$. Specifically, respondents with BSW degrees displayed the lowest EBS scores $(M=19.69, S D$ $=6.04)$ and respondents with other types of Bachelor's degrees displayed the highest EBS scores $(M=23.55, S D=7.04)$. Respondents with graduate degrees had slightly higher EBS scores $(M=20.15, S D=6.98)$ than respondents with BSW degrees. These findings indicate that among this sample, those with BSW degrees presented the most tolerant attitudes toward the economically disadvantaged.

An independent samples $t$ test revealed significant differences in the EBS scores of frontline workers and supervisors, $t(328)=4.42, p<.001$. Supervisors 
demonstrated lower EBS scores $(M=18.81, S D=7.57)$ than frontline workers $(M=23.10, S D=6.82)$, suggesting that in this sample supervisors' attitudes toward poverty and the economically disadvantaged were more tolerant. No significant differences were found in EBS scores by respondents' gender, race, program area, or geographic location.

Bivariate correlations revealed significant, negative relationships between EBS score and age, years of experience in current position, and years of child welfare experience. Essentially, younger $(r=-.26, p<.001)$ respondents with fewer years of experience in their current positions $(r=-.13, p<.05)$ and less general child welfare experience $(r=-.27, p<.001)$ had higher EBS scores than their counterparts. This finding supports the previous result regarding the more tolerant attitudes of supervisors toward the economically disadvantaged since these professionals are usually older and have more experience.

\section{Score Transformation for Outside Comparison}

Possible EBS scores for the original five-point response set range from 8 to 40 . A running mean formula was used to transform the total score mean for the six-point EBS to a mean for a five-point EBS so that the average scale score from respondents in this study may be compared to findings from other studies.

The transformation process is illustrated in Figure \#. Essentially, respondents who marked 1 or 6 on a six-point scale would be likely to mark 1 or 5 , respectively, on a five-point scale. However, of the respondents who marked 2 on a six-point scale some will mark 1 , while others will mark 2. (This is similar for 3,4 , and 5 as illustrated in Figure 8.) The initial step of the scale transformation 
assumes that an equal number (half) of respondents will mark 1 and 2 on the five-point scale.

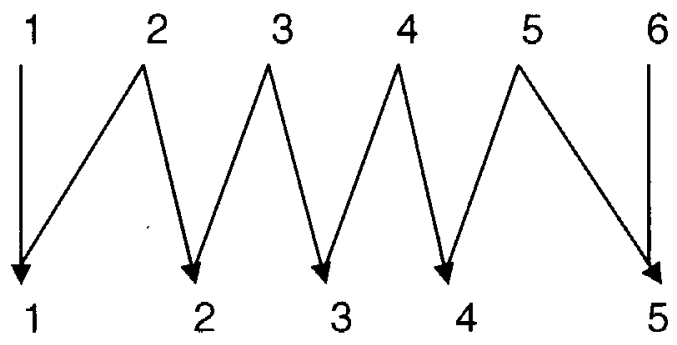

Figure 8. Initial reassignment of responses from six-point to five-point response set. $^{4}$

It is unlikely that respondents who chose 2 on a six-point scale would be equally as likely to choose 1 or 2 on a five-point scale. Therefore, the next step of the scale transformation involved a series of calculations which accounted for the error in the initial step. Table 5 illustrates the transformation of data from a sixpoint response scale to a five-point scale. The percentages, average ratings, and average totals scores were very similar for both versions.

\footnotetext{
${ }^{4}$ Personal communication, M. A. van Zyl, September 9, 2009.
} 
Table 5

Transformation of Scores from Six-point to Five-point Response Set ${ }^{1}$

\begin{tabular}{lcc}
\hline & Six-point & Five-point \\
\hline$N$ & 2889 & 2889 \\
Maximum score & 17334 & 14445 \\
Actual Score & 8025 & 6687.5 \\
Percentage & 46.296 & 46.296 \\
Average rating & 2.778 & 2.315 \\
Average total score & 22 & 19 \\
\hline
\end{tabular}

\section{Attitudes about Family Structure}

Because the group of items used to measure attitudes toward family structure were not previously analyzed regarding reliability and validity, exploratory factor and reliability analyses were completed for these five items.

The factor analysis yielded two components, but one component contained only one item (Single parents and their children develop closer relationships than children with two parents). An initial reliability analysis including all five items resulted in a Cronbach's alpha of .55. The Cronbach's alpha was increased to .697 when the aforementioned item was deleted. While this is not a high reliability score, deletion of the item resulted in a more reliable scale. Therefore, bivariate and multivariate analyses were completed using the four-item attitudes toward family structure scale. 
The range of respondents' scores for the items designed to indicate attitudes toward single-parent families was between 4 and 22 (possible scores ranged from 4 to 24$)$, and the average score for the group was $9.8(S D=3.82)$, which indicates that respondents were relatively supportive of a single-parent family structure. [A higher score indicates more support for a traditional nuclear family structure.] An independent $t$ test indicated that male and female respondents differed significantly in their attitudes toward family structure, $t(359)$ $=-3.66, p<.001$. Men $(M=11.56, S D=4.42)$ displayed a higher total score for family structure items than women $(M=9.49, S D=3.65)$. A significant correlation was found between family structure and age, $r=.15, p<.01$. Older respondents indicated more support for a traditional nuclear family structure.

There were no significant differences in the total score of family structure items by position, program area, geographic location, race, or education, and no correlation between years of experience and total score of the family structure items.

\section{Correlates of Decision Making in Child Protective Cases}

Respondents were asked to make four decisions including one intake and one follow-up disposition decision in each of two scenarios (Decisions $A, B, A 2$, and B2). Because the research questions for this study focused on factors influencing professional decision making in child protection, these results will be grouped by decision and framed by the following research questions:

- What personal, professional, and environmental characteristics (e.g., race/ethnicity, years of experience, geographic location, stress level, 
attitudes toward race, and case composition) influence child protection workers' screening and disposition decisions?

- What child and family (case) factors influence child protection workers' intake and post-investigation disposition decisions?

- To what extent do parental attributions influence child protection workers' screening and disposition decisions?

- What is the impact of race, family structure, and socio-economic status on decisions by child protection workers regarding intake and postinvestigation disposition decisions?

\section{Decision A}

Respondents were asked to make an intake decision regarding a 6-yearold boy whose teacher reported suspected maltreatment due to a bruise on the child's leg. Respondents were prompted to either screen the report in for investigation or screen the report out and take no further action.

\section{Decision Outcomes}

A total of 400 respondents indicated a decision and 391 provided a written reason for the decision. Approximately $99 \%(N=395)$ of respondents decided to screen the report in for investigation. Therefore, further quantitative analyses were not completed regarding this particular decision due to lack of variability in response. This homogeneous decision pattern indicates that the variables of interest did not appear to matter when respondents were focused on the content of the scenario. 
Reasons Provided by Respondents for Their Decisions

Method of qualitative analysis. A random sample of 40 cases was

obtained using a function in SPSS. Univariate analyses revealed that this sample was comparable to the larger sample regarding demographic information, types of vignettes answered, and decision outcomes. Since the five respondents who chose to screen the case out in Decision A were not included in this random sample, they were added to the 40 randomly selected cases. Therefore, the decision reasons in a total of 45 cases $(11.25 \%$ of study sample) were reviewed. Content analysis was used to examine this qualitative data. Each of the reason statements was reviewed within each decision (A, B, A2, B2) and explanatory phrases were highlighted. Similar phrases/reasons were grouped under an exemplar phrase, which led to the development of a list of reasons for each of the four decisions. The presence of each of the phrases in the response set was then counted to determine frequencies of the types of reasons given for making the particular decisions. A complete list of responses to each of the decision reasoning questions may be found in Appendix $\mathrm{H}$.

Respondents' reasoning. Regarding Decision A, the content analysis revealed that the vast majority of the randomly sampled respondents $(N=38)$ indicated that the bruising/marks found on the child was a key reason for their decision to screen the case in for further investigation. Other frequent reasons were the child's statement $(N=14)$, past CPS involvement $(N=16)$, and the assumption that "trouble at home" meant punishment, specifically physical discipline $(N=14)$. Of the few respondents who screened the case out, four of 
them reported their reason for this decision being due to no disclosure from the child of hitting, spanking, or how he was injured. Three of the respondents reasoned that there could be other plausible explanations for the child's injury. A complete list of responses to each of the decision reasoning questions may be found in Appendix $\mathrm{H}$.

\section{Decision B}

Respondents were asked to make a disposition decision after receiving information about the findings of an investigation into the 6-year-old boy's injury. They were prompted to either remove the child from the home or leave the child in the care of his parent(s) and provide in-home services.

\section{Decision Outcomes}

A total of 398 respondents indicated a decision and 383 provided a written reason for the decision. A little more than half $(57 \%, N=226)$ of respondents chose to provide in-home services.

Influence of Personal, Professional, and Environmental Characteristics on Decision Making

Demographic characteristics. Chi square analyses found no significant relationships between respondents' race, gender, or level of education and their decision groups. An independent samples $t$ test indicated that the decision groups differed significantly regarding years of child welfare practice experience, $t(386)=-2.56, p=<.05$. Although this difference is significant, it represents a very small effect size $r=.02$. The respondents who removed the child from his home were less experienced $(M=5.52, S D=5.86)$ than those who provided in- 
home services $(M=7.26, S D=7.51)$. No significant difference was found in decision groups related to respondents' years of experience in their current positions.

Position and practice area. A $2 \times 4$ chi square test revealed a significant relationship between this first disposition decision and practice area, $X^{2}(3)=8.67$, $p<.05, V=.15$. Respondents providing intake/investigation services only or performing duties in addition to CPS were relatively equally represented in the two decision groups, indicating no differences in decision outcomes among these groups. However, those providing a combination of CPS services were more likely to set up in-home services (43\%) than remove the child from his home $(30 \%)$ and ongoing workers were more likely to remove the child $(52 \%)$ than set up in-home services (38\%).

Work environment. Results of chi square analyses showed no significant correlation between position or geographic location and the outcome of Decision B. An independent samples $t$ test revealed no significant differences in decision group by percentages of children of color or Caucasian children being served by the respondents.

Mann-Whitney $U$ analyses revealed significant differences between decision groups in their reported levels of work-related stress. The sum of the average ranking of stress level was significantly higher for those who recommended removal $(M$ rank $=194.37, N=154)$ than for those who recommended in-home services $(M$ rank $=171.97, N=208) z=-2.08, p<.05$. An exploration of group differences through a Mann-Whitney $U$ analysis revealed 
no significant differences between the decision groups regarding the ranking of the agency's emphasis on cultural competence. [The $z$ value is reported instead of $U$ because all of the groups contain more than 20 respondents.]

Attitudes. Independent samples $t$ tests showed no significant differences between the decision groups regarding the respondents' attitudes toward race, poverty, and family structure. This indicates that respondents' decisions in this case were not influenced by their attitudes or beliefs about these larger social issues.

Influence of Case Factors on Decision Making

A Mann-Whitney $U$ analysis was used to determine the differences between decision groups regarding the importance of certain factors in making this disposition decision. Results indicated that the importance of social supports, history of CPS involvement, the family's financial situation, and neighborhood safety/risks were ranked significantly differently among decision groups. Social supports, financial situation, and neighborhood safety were ranked as significantly more important by respondents who chose to provide in-home services. Family history of CPS involvement was ranked as significantly more important by respondents who chose to remove the child from his home. Although not significant, a trend toward significance regarding family's ethnic background indicated that respondents who chose to provide in-home services found this factor more important than respondents who removed the child. Test statistics are provided in Table 6. 
Table 6

Test Statistics for Individual Decision Making Factors Related to Decision

Outcome (Decision B)

\begin{tabular}{|c|c|c|c|}
\hline \multirow{2}{*}{$\begin{array}{l}\text { Decision Making } \\
\text { Factors }\end{array}$} & \multicolumn{2}{|c|}{$M \operatorname{rank}(N)$} & \multirow[t]{2}{*}{$z, p$} \\
\hline & $\begin{array}{l}\text { Remove from } \\
\text { home }\end{array}$ & $\begin{array}{c}\text { Provide in-home } \\
\text { services }\end{array}$ & \\
\hline Parent risk factors & $188.86(170)$ & $205.75(226)$ & $-1.52, .128$ \\
\hline $\begin{array}{l}\text { Social supports } \\
\text { available }\end{array}$ & $181.56(171)$ & $212.20(226)$ & $-2.76, .006^{\star}$ \\
\hline $\begin{array}{l}\text { Family history of CPS } \\
\text { involvement }\end{array}$ & $228.04(171)$ & $177.03(226)$ & $-4.90, .000^{\star \star}$ \\
\hline $\begin{array}{l}\text { Parental compliance } \\
\text { with past services }\end{array}$ & $194.42(171)$ & $202.47(226)$ & $-.77, .454$ \\
\hline $\begin{array}{l}\text { Who is living in the } \\
\text { home at the time of } \\
\text { the incident }\end{array}$ & $195.21(171)$ & $201.87(226)$ & $-.60, .550$ \\
\hline $\begin{array}{l}\text { Family's financial } \\
\text { situation }\end{array}$ & $175.89(171)$ & $216.48(226)$ & $-3.63, .000^{* \star}$ \\
\hline $\begin{array}{l}\text { Neighborhood } \\
\text { safety/risks }\end{array}$ & $175.48(170)$ & $214.21(224)$ & $-3.49, .000^{\star \star}$ \\
\hline Policy guidelines & $209.98(171)$ & $190.69(226)$ & $-1.75, .080$ \\
\hline $\begin{array}{l}\text { Family's ethnic } \\
\text { background }\end{array}$ & $185.84(170)$ & $207.18(225)$ & $-1.96, .050$ \\
\hline $\begin{array}{l}\text { Quality of the } \\
\text { parent/child } \\
\text { relationship }\end{array}$ & $191.90(171)$ & $204.37(226)$ & $-1.13, .259$ \\
\hline
\end{tabular}


A Mann-Whitney $U$ analysis revealed a significant difference in respondents' ratings of the importance of some case factors based on the SES case characteristic they experienced in their vignettes. Specifically, respondents who made decisions about low-SES families rated parent risk factors, availability of social supports, and the family's financial situation as more important in their decision making than those who made decisions about mid-SES families.

Related test statistics are provided in Table 7.

Table 7

Test Statistics for Individual Decision Making Factors Related to SES of Family (Decision B)

\begin{tabular}{lccc}
\hline $\begin{array}{l}\text { Decision Making } \\
\text { Factors }\end{array}$ & \multicolumn{2}{c}{$M$ rank $(N)$} & $z, p$ \\
\cline { 2 - 3 } & Low-SES & Mid-SES & \\
\hline Parent risk factors & $212.61(217)$ & $183.78(181)$ & $-2.61, .009^{\star \star}$ \\
$\begin{array}{l}\text { Social supports } \\
\text { available }\end{array}$ & $210.28(218)$ & $187.62(181)$ & $-2.05, .041^{\star}$ \\
$\begin{array}{l}\text { Family's financial } \\
\text { situation }\end{array}$ & $211.79(218)$ & $185.80(181)$ & $-2.33, .020^{\star}$ \\
\hline
\end{tabular}

${ }^{*} p<.05,{ }^{* *} p<.01$

Reasons Provided by Respondents for Their Decisions

Child safety/protection ( $N=11$ ) was most frequently listed by respondents who removed the child from his home as a key reason for their decision. Other reasons given by several respondents were: failure of previous interventions ( $N=$ 7), history of CPS involvement $(N=5)$, and numerous incidents of maltreatment $(N=5)$. Four respondents also mentioned the consistency of the child's report to 
the injury and the fact that the parents did not display remorse. The majority of respondents who recommended in-home services reported doing so because the parents had complied in the past $(N=10)$ and because services would be beneficial to the parent/family in terms of skill-building $(N=10)$. Respondents who decided on in-home services also felt this would give the parent(s) an opportunity to utilize services this time $(N=5)$ and would provide for monitoring and further assessment of the family's needs $(N=5)$. Influence of Attributions for Parental Behaviors on Decision Making Attribution items were considered separately and in groups during analysis. Based on face validity, the attribution items were grouped by the researcher into the following categories: internal attributions, external attributions, and feeling attributions. ${ }^{5}$ This is illustrated in Table 8. Ratings for each item were combined to create a total score for each factor.

\footnotetext{
${ }^{5}$ An exploratory principle components factor analysis using Varimax rotation was completed to further test the validity of these groupings. Results indicated that the items loaded on factors based on the researcher's original grouping except in Decision A2. In this case, an "internal" item (The parents had control over their behavior.) loaded on the external factor and an "external" item (The parents' circumstances were to blame for potential risk to the child.) loaded on the internal factor. Although the information obtained from the factor analysis was helpful, it was determined that the most legitimate factor analysis would need to be done based on the scenario groupings since respondents were exposed to different scenarios. This would not be possible because at least 10 cases per item would be needed to maintain enough power for a valid analysis.
} 
Table 8

Groupings of Parental Attribution Items into Factors

Internal

External

Feeling

- It is the parents' fault that the family is in this situation.

- The parents alone were responsible for causing a potentially negative situation.

- The parents had control over their behavior.
- Other factors, besides the parents' actions, caused a potentially negative situation.

- The parents' circumstances were to blame for potential risk to the child.
- The parents' behavior angered me.

- This situation makes me feel sympathetic toward the parents.

- The parents' situation makes me feel distressed.

Independent samples $t$ tests showed that in Decision B, only group disposition decisions for the internal attribution subscale were significantly different, $t(395)=2.44, p<.05$. Respondents who decided to remove the child from his home $(M=10.50, S D=2.24)$ indicated higher internal attributions than those who made the decision to provide in-home services $(M=9.96, S D=2.16)$. Furthermore, the internal attribution subscale score was significantly different for the scenario groups of SES, $t(397)=-3.63, p<.001$, and family structure, $t(397)$ $=2.87, p<.01$. Respondents who made decisions about low-SES families had a lower internal attribution score $(M=9.83, S D=2.18)$ than those who made decisions about mid-SES families $(M=10.62, S D=2.16)$. Similarly, those considering two-parent families rated internal attributions higher $(M=10.48, S D$ 
$=2.15)$ than those considering single-parent families $(M=9.85, S D=2.22)$. No significant group differences were found regarding the race scenario groups.

Regarding individual attribution items, the results of Mann-Whitney $U$ analyses indicated that ratings of attributions regarding the fault and sole responsibility of the parents as well as respondents' anger toward the parents' behavior were higher among those who chose to remove the child than those who chose to provide in-home services. Respondents who provided in-home services indicated that they felt more sympathy toward the parents than respondents who removed the child from his home. Furthermore, respondents who reviewed mid-SES cases ranked parental fault and sole responsibility for the situation more highly than those who reviewed low-SES cases. Alternately, respondents making decisions about low-SES cases expressed more sympathy toward the parents than their counterparts. Finally, while respondents deciding about two-parent families ranked parental fault more highly, respondents making decisions about single-parent families indicated that other factors, besides the parents actions, were to blame for the situation. Test statistics for each of these findings are presented in Tables 9,10 , and 11. 
Table 9

Test Statistics for Individual Parental Attribution Items Related to Decision

Outcome (Decision B)

\begin{tabular}{lccc}
\hline Parental Attributions & \multicolumn{2}{c}{$M$ rank $(N)$} & \multirow{2}{*}{$z, p$} \\
\cline { 2 - 3 } & Remove & In-home services & \\
\hline $\begin{array}{l}\text { It is the parents' fault } \\
\text { that the family is in } \\
\text { this situation. }\end{array}$ & $215.33(171)$ & $186.65(226)$ & $-2.61, .009^{\star \star}$ \\
$\begin{array}{l}\text { The parents alone } \\
\text { were responsible for } \\
\text { causing a potentially } \\
\text { negative situation. }\end{array}$ & $212.26(170)$ & $188.15(226)$ & $-2.20, .028^{\star}$ \\
$\begin{array}{l}\text { The parents' } \\
\text { behavior angered } \\
\text { me. }\end{array}$ & $214.72(171)$ & $187.11(226)$ & $-2.46, .014^{\star}$ \\
$\begin{array}{l}\text { This situation makes } \\
\text { me feel sympathetic } \\
\text { toward the parents. }\end{array}$ & $174.41(171)$ & $217.61(226)$ & $-3.92, .000^{\star \star \star}$ \\
\hline${ }^{*} p<.05,{ }^{\star \star} p<.01,{ }^{\star \star \star} p<.001$ & \\
\hline
\end{tabular}


Table 10

Test Statistics for Individual Parental Attribution Items Related to SES of Family (Decision B)

\begin{tabular}{lccc}
\hline Parental Attributions & \multicolumn{2}{c}{$M$ Mrank $(N)$} & $z, p$ \\
\cline { 2 - 3 } & Low-SES & Mid-SES & \\
\hline $\begin{array}{l}\text { It is the parents' fault } \\
\text { that the family is in } \\
\text { this situation. }\end{array}$ & $172.95(217)$ & $232.25(182)$ & $-5.41, .000^{\star \star *}$ \\
$\begin{array}{l}\text { The parents alone } \\
\text { were responsible for } \\
\text { causing a potentially } \\
\text { negative situation. }\end{array}$ & $186.62(216)$ & $214.79(182)$ & $-2.58, .010^{\star *}$ \\
$\begin{array}{l}\text { This situation makes } \\
\text { me feel sympathetic } \\
\text { toward the parents. }\end{array}$ & $210.05(217)$ & \\
\hline
\end{tabular}

${ }^{\star} p<.05,{ }^{\star \star} p<.01,{ }^{\star \star \star} p<.001$ 
Table 11

Test Statistics for Individual Parental Attribution Items Related to Family

Structure (Decision B)

\begin{tabular}{lccc}
\hline Parental Attributions & \multicolumn{2}{c}{ M rank $(N)$} & \\
\cline { 2 - 3 } & Two-parent & Single-parent & \\
\hline $\begin{array}{l}\text { It is the parents' fault } \\
\text { that the family is in } \\
\text { this situation. }\end{array}$ & $216.65(213)$ & $180.93(186)$ & $-3.27, .001^{\star *}$ \\
$\begin{array}{l}\text { Other factors, } \\
\text { besides the parents' } \\
\text { actions, caused a } \\
\text { potentially negative } \\
\text { situation. }\end{array}$ & $187.96(212)$ & $212.66(186)$ & $-2.30, .021^{*}$ \\
\end{tabular}

${ }^{\star} p<.05,{ }^{* \star} p<.01$

Influence of Race, Family Structure, and Socio-economic Status on Decision

Making

With respect to Decision $B$, chi square analyses indicated no significant correlations between the decision group (remove vs. in-home services) and the scenario group (race, SES, or family structure). No significant correlations were found between the decision group and the randomly assigned vignette (various combinations of race, SES, and family structure).

Variables that Predict Disposition Decisions

Binary logistic regression was chosen over discriminate analysis because the goal was to simultaneously evaluate the effects of variables of different measurement levels on the dichotomous dependent variable, decision outcome. This type of logistic regression allows the prediction of the outcome of a 
dichotomous dependent variable from a set of independent variables that may be continuous, discrete, dichotomous, or a mix (Tabachnick \& Fidell, 2001). Logistic regression is related to, but more flexible than other multivariate techniques because it has no assumptions about the distributions of the predictor variables, the predictor variables do not need to be discrete, and this analysis cannot produce negative predicted probabilities. Logistic regression emphasizes the probability of a particular outcome for each case (Tabachnick \& Fidell). In this case, it is used to predict the probability that a given professional will make a decision based on that professional's pattern of responses to questions from the survey.

Logistic regression analysis was employed to predict the probability that a respondent would remove the child from the home. The predictor variables were ongoing service provider only (yes/no), level of internal parental attributions, and rating of importance of CPS history as a decision factor. These variables were selected based on findings from bivariate analyses, which indicated they were significantly correlated with the outcome variable. Variables were then added or deleted to balance goodness-of-fit in the model, statistical significance of the variables themselves, and the percentage of variance predicted. Addition and deletion of variables was also based on theoretical constructs that inform decision making in child protection. Therefore, a model was also tested that included not only significant variables from bivariate analyses, but also variables drawn from each domain (e.g., professional characteristics, demographics, attributions, and attitudes). 
Model based on bivariate analyses. A test of the full model versus a model with intercept only was statistically significant, $\chi^{2}(3, N=396)=32.85, p<.001$. The model was able to correctly classify $38 \%$ of those who decided on removal and $81 \%$ of those who provided in-home services, with an overall success rate of $62 \%$. Table 12 outlines the logistic regression coefficient, Wald test statistic, and odds ratio for each of the predictors. Practice area (ongoing only) and history of CPS involvement had significant partial effects. The odds ratio for these variables indicates that when holding other variables constant, an ongoing service provider or professional who places great importance on history of CPS involvement will be nearly two times more likely to remove the child than their counterparts.

Table 12

Logistic Regression Model: Variables Predicting Disposition Decision (B) Based on Bivariate Analysis

\begin{tabular}{|c|c|c|c|c|c|c|c|c|}
\hline \multirow[b]{2}{*}{ Predictors } & \multirow[b]{2}{*}{$\beta$} & \multirow[b]{2}{*}{ S.E. } & \multirow[b]{2}{*}{ Wald $x^{2}$} & \multirow[b]{2}{*}{$d f$} & \multirow[b]{2}{*}{$p$} & \multirow[b]{2}{*}{$\begin{array}{l}\text { Odds } \\
\text { Ratio }\end{array}$} & \multicolumn{2}{|c|}{$\begin{array}{l}95 \% \mathrm{Cl} \text { for } \\
\text { Odds Ratio }\end{array}$} \\
\hline & & & & & & & Lower & Upper \\
\hline Ongoing only & .586 & .212 & 7.604 & 1 & $.006^{\star}$ & 1.796 & 1.185 & 2.724 \\
\hline CPS history & .689 & .167 & 16.987 & 1 & $.000^{\star \star}$ & 1.991 & 1.435 & 2.762 \\
\hline $\begin{array}{l}\text { Internal } \\
\text { attribution }\end{array}$ & .088 & .049 & 3.298 & 1 & .069 & 1.093 & .993 & 1.202 \\
\hline Constant & -4.514 & .884 & 26.094 & 1 & $.000^{\star \star}$ & .011 & & \\
\hline
\end{tabular}


Model based on theoretical constructs. Binary logistic regression analysis was utilized to consider the relevance of the theoretical frameworks discussed in Chapter Two to decision making among respondents in the present study. Survey variables based on Cohen's (2003) Framework for Child Welfare Decision Making, the Adaptive Decision Model (Payne et al., 1993), and attribution theories, respectively, were entered into logistic regression models in blocks using the enter method to determine the prediction value of these variables. ${ }^{6}$ The first block included personal, professional, case, and work environment factors as well as scores for the attitudes scales. The second block added the ranked decision making factors. The third and final block added parental attribution items. Therefore, the final model included all of the independent variables. This process was completed for each of the decisions ( $\mathrm{B}$, A2, B2).

For Decision B, a test of the full model versus a model with intercept only was statistically significant, $X^{2}(35, N=309)=67.05, p<.01$. The model was able to correctly classify $60 \%$ of those who decided on removal and $80 \%$ of those who provided in-home services, with an overall success rate of $72 \%$. Table 13 outlines the logistic regression coefficient, Wald test statistic, and odds ratio for each of the predictors that had significant partial effects. (Appendix I provides test statistics for the stepwise progression of the logistic regression models for each of the decisions.)

A family history of CPS involvement is an even greater predictor of removal among this sample than in the previous model based on bivariate

\footnotetext{
${ }^{6}$ See Figure 5 for a list of survey variables related to each theoretical framework.
} 
analyses. Holding all other variables constant, a respondent who ranked the importance of CPS history in decision making highly was over four times more likely to recommend removal than his/her counterparts who did not feel CPS history was important in decision making.

Table 13

Logistic Regression Model: Variables Predicting Disposition Decision (B) Based on Theoretical Constructs

\begin{tabular}{|c|c|c|c|c|c|c|c|c|}
\hline \multirow[b]{2}{*}{ Predictors } & \multirow[b]{2}{*}{$\beta$} & \multirow[b]{2}{*}{ S.E. } & \multirow[b]{2}{*}{$\begin{array}{c}\text { Wald } \\
x^{2}\end{array}$} & \multirow[b]{2}{*}{$d f$} & \multirow[b]{2}{*}{$P$} & \multirow[b]{2}{*}{$\begin{array}{l}\text { Odds } \\
\text { Ratio }\end{array}$} & \multicolumn{2}{|c|}{$\begin{array}{l}95 \% \mathrm{Cl} \text { for } \\
\text { Odds Ratio } \\
\end{array}$} \\
\hline & & & & & & & Lower & Upper \\
\hline $\begin{array}{l}\text { Agency } \\
\text { emphasis } \\
\text { on cultural } \\
\text { competence }\end{array}$ & .243 & .094 & 6.722 & 1 & $.010^{\star}$ & 1.276 & 1.061 & 1.533 \\
\hline CPS history & .913 & .268 & 11.615 & 1 & $.001^{\star \star}$ & 2.491 & 1.474 & 4.210 \\
\hline Constant & -4.646 & 2.628 & 3.125 & 1 & .077 & .010 & & \\
\hline
\end{tabular}

Decision A2

Respondents were asked to make an intake decision regarding a report made by a nurse who treated a 7-year-old boy brought to a doctor's office with a sprained wrist and bruised elbow. Respondents were asked to screen the report in for investigation or screen the report out and take no further action. 


\section{Decision Outcomes}

A total of 400 respondents indicated a decision and 381 provided a written reason for the decision. The majority of respondents $(62 \%, N=247)$ chose to screen in and refer the case for investigation. Influence of Personal, Professional, and Environmental Characteristics on Decision

Demographic characteristics. Chi square analyses found no significant relationships between respondents' race, gender, or level of education and their decision groups. Independent samples $t$ tests also revealed no significant differences in decision group by years of child welfare experience or years of experience in current position.

Position and practice area. Results of chi square analyses showed no significant correlation between position and the outcome of Decision A2. Similar analyses found no significant correlation between respondents' stated practice areas and their intake decisions for the second scenario.

Work environment. An independent samples $t$ test revealed no significant differences in decision group by percentages of children of color or Caucasian children being served by the respondents. A chi square analysis showed no significant association between geographic location and the decision outcome. An exploration of group differences through Mann-Whitney $U$ analyses revealed no significant differences between the decision groups regarding the ranking of the agency's emphasis on cultural competence or the ranking of work-related stress levels. 
Attitudes. Independent samples $t$ tests showed no significant differences between the decision groups regarding the respondents' attitudes toward race, poverty, and family structure. Again, attitudes had no effect on decision making. Influence of Case Factors on Decision Making

Results of a Mann-Whitney $U$ analysis indicated that the importance of all of the decision factors except for policy guidelines were ranked significantly differently between the two decision groups. The respondents who chose to screen the case in and refer the family for investigation found parent risk factors, availability of social supports, CPS history, past compliance, the family's financial situation, neighborhood safety risks, the family's ethnic background, and the quality of the parent-child relationship to be more important in the decision than those who screened the case out and took no further action. Test statistics are provided in Table 14. 
Table 14

Test Statistics for Individual Decision Making Factors Related to Decision

Outcome (Decision A2)

\begin{tabular}{|c|c|c|c|}
\hline \multirow{2}{*}{$\begin{array}{l}\text { Decision Making } \\
\text { Factors }\end{array}$} & \multicolumn{2}{|c|}{$M \operatorname{rank}(N)$} & \multirow[t]{2}{*}{$z, p$} \\
\hline & Screen in & Screen out & \\
\hline Parent risk factors & $216.41(240)$ & $158.97(148)$ & $-5.05, .000^{\star \star}$ \\
\hline $\begin{array}{l}\text { Social supports } \\
\text { available }\end{array}$ & $215.01(240)$ & $162.77(149)$ & $-4.63, .000^{\star \star}$ \\
\hline $\begin{array}{l}\text { Family history of CPS } \\
\text { involvement }\end{array}$ & $226.78(241)$ & $144.90(149)$ & $-7.27, .000^{\star \star}$ \\
\hline $\begin{array}{l}\text { Parental compliance } \\
\text { with past services }\end{array}$ & $216.34(241)$ & $160.24(148)$ & $-4.96, .000^{* *}$ \\
\hline $\begin{array}{l}\text { Who is living in the } \\
\text { home at the time of } \\
\text { the incident }\end{array}$ & $222.14(240)$ & $151.29(149)$ & $-6.24, .000^{\star \star}$ \\
\hline $\begin{array}{l}\text { Family's financial } \\
\text { situation }\end{array}$ & $211.28(240)$ & $167.28(148)$ & $-3.93, .000^{\star *}$ \\
\hline $\begin{array}{l}\text { Neighborhood } \\
\text { safety/risks }\end{array}$ & $206.42(241)$ & $176.41(148)$ & $-2.68, .007^{\star}$ \\
\hline Policy guidelines & $194.77(239)$ & $194.07(149)$ & $-.06, .950$ \\
\hline $\begin{array}{l}\text { Family's ethnic } \\
\text { background }\end{array}$ & $206.76(240)$ & $176.06(149)$ & $-2.80, .005^{\star}$ \\
\hline $\begin{array}{l}\text { Quality of the } \\
\text { parent/child } \\
\text { relationship }\end{array}$ & $211.96(240)$ & $166.18(148)$ & $-4.07, .000^{\star \star}$ \\
\hline
\end{tabular}

${ }^{\star} p<.01,{ }^{\star \star} p<.001$

A Mann-Whitney $U$ analysis revealed that respondents' ratings of the importance of the history of CPS involvement differed significantly based on the 
family structure presented in the vignette, $z=-2.54, p<.05$. Respondents who made decisions regarding two parent families indicated that CPS history was a more important factor in their decision making $(M$ rank $=209.77, N=190)$ than respondents who made decisions about single-parent families $(M$ rank $=181.95$, $N=200)$.

Reasons Provided by Respondents for Their Decisions

Many of the respondents who chose to screen the case in for investigation indicated that the child not being willing to talk and/or his sullen behavior $(N=11)$ was a key factor in their decision. Several respondents also reported that the seriousness of the injury $(N=5)$, the need for more information $(N=5)$, and questions about the explanation for the injury $(N=5)$ played a part in their decision to screen in for investigation. Respondents who screened the case out reasoned that the injury seemed to be consistent with the explanation $(N=4)$ and that there was no reason to question the mother's story regarding the injury ( $N=$ 3).

Influence of Attributions for Parental Behaviors on Decision Making Independent samples $t$ tests were employed to determine if differences existed among those who screened the case in and those who screened the case out regarding attribution subscale scores. Results indicated that in Decision A2, group responses for each of the attribution factors were significantly different. Respondents who screened the case in $(M=8.53, S D=1.95)$ indicated higher internal attributions than those who screened the case out $(M=7.09, S D=2.03)$, $t(389)=7.00, p<.001$. Similarly, higher external attributions were indicated, 
$t(293)=5.92, p<.001$, by those who screened the case in $(M=5.71, S D=1.35)$ than those who screened the case out $(M=4.83, S D=1.48)$. Finally, those who screened the case in $(M=6.60, S D=2.40)$ indicated greater levels of feelings about the parents than those who screened the case out $(M=5.93, S D=2.16)$, $t(339)=2.85, p<.01$. No significant differences were found, however, regarding the subscale scores of scenario groups (race, SES, and family structure).

A Mann-Whitney $U$ analysis of individual attribution items revealed that decision groups differed significantly in their ratings of several of these attributions. Respondents who screened the case in for investigation felt the situation was the parents' fault alone, were angered or distressed by the parents' situation or behavior, or felt the parents' circumstances were to blame at greater levels than their counterparts who screened the case out. Test statistics are displayed in Table 15. Regarding scenario groups, a Mann-Whitney $U$ analysis showed that respondents who considered mid-SES families rated parental fault and responsibility, as well as their own feelings of anger and distress at the parents' behavior more highly than respondents who made decisions about lowSES cases. Relevant test statistics for these findings are displayed in Table 16. 
Table 15

Test Statistics for Individual Parental Attributions Related to Decision Outcome (Decision A2)

\begin{tabular}{|c|c|c|c|}
\hline \multirow[t]{2}{*}{ Parental Attributions } & \multicolumn{2}{|c|}{$M \operatorname{rank}(N)$} & \multirow[t]{2}{*}{$z, p$} \\
\hline & Screen in & Screen out & \\
\hline $\begin{array}{l}\text { It is the parents' fault } \\
\text { that the family is in } \\
\text { this situation. }\end{array}$ & $231.20(242)$ & $138.83(149)$ & $-8.44, .000^{* *}$ \\
\hline $\begin{array}{l}\text { The parents alone } \\
\text { were responsible for } \\
\text { causing a potentially } \\
\text { negative situation. }\end{array}$ & $227.34(241)$ & $144.00(149)$ & $-7.60, .000^{\star \star}$ \\
\hline $\begin{array}{l}\text { The parents' } \\
\text { circumstances were } \\
\text { to blame for potential } \\
\text { risk to the child. }\end{array}$ & $226.87(242)$ & $144.21(148)$ & $-7.64, .000^{\star \star}$ \\
\hline $\begin{array}{l}\text { The parents' behavior } \\
\text { angered me. }\end{array}$ & $216.09(241)$ & $160.66(148)$ & $-5.02, .000^{\star \star}$ \\
\hline $\begin{array}{l}\text { The parents' situation } \\
\text { makes me feel } \\
\text { distressed. }\end{array}$ & $208.24(241)$ & $174.89(149)$ & $-3.01, .003^{\star}$ \\
\hline
\end{tabular}

${ }^{\star} p<.01,{ }^{* *} p<.001$ 
Table 16

Test Statistics for Individual Parental Attributions Related to SES of Family (Decision A2)

\begin{tabular}{|c|c|c|c|}
\hline \multirow[t]{2}{*}{ Parental Attributions } & \multicolumn{2}{|c|}{$M \operatorname{rank}(N)$} & \multirow[t]{2}{*}{$z, p$} \\
\hline & LoW-SES & Mid-SES & \\
\hline $\begin{array}{l}\text { It is the parents' fault } \\
\text { that the family is in } \\
\text { this situation. }\end{array}$ & $185.48(207)$ & $207.83(184)$ & $-2.10, .036^{\star}$ \\
\hline $\begin{array}{l}\text { The parents alone } \\
\text { were responsible for } \\
\text { causing a potentially } \\
\text { negative situation. }\end{array}$ & $182.25(206)$ & $210.33(184)$ & $-2.63, .009^{* \star}$ \\
\hline $\begin{array}{l}\text { The parents' behavior } \\
\text { angered me. }\end{array}$ & $183.82(206)$ & $207.58(183)$ & $-2.21, .027^{\star}$ \\
\hline $\begin{array}{l}\text { The parents' situation } \\
\text { makes me feel } \\
\text { distressed. }\end{array}$ & $182.65(207)$ & $210.03(183)$ & $-2.54, .011^{\star}$ \\
\hline
\end{tabular}

${ }^{\star} p<.05,{ }^{\star \star} p<.01$

Influence of Race, Family Structure, and Socio-economic Status on Decision Making

A $2 \times 2$ chi square test indicated a significant relationship between this screening decision (Decision A2) and SES of the family, $x^{2}(1)=10.94, p<.01, \varphi$ $=-.17$. Respondents considering the cases of low-SES families screened the case in only $46 \%$ of the time and screened the case out $63 \%$ of the time.

However, those considering mid-SES families were more likely to screen the case in for investigation (54\%) than screen the case out (37\%). No significant relationships were found between the screening decision and the race or 
structure of the family. Regarding combined scenario factors, a $2 \times 8$ chi square analysis revealed a significant relationship between this screening decision and the randomly assigned vignette (combination of race, SES, and family structure), $X^{2}(1)=17.34, p<.05, V=-.15$. Two vignettes were particularly noticeable in the analysis. The case involving the White, low-SES, single-parent family was screened out $(20 \%)$ much more often than it was screened in (10\%), while the case of the Black, mid-SES, single-parent family was screened in (17\%) more often than it was screened out $(9 \%)$. This supports the previous analysis which showed that low-SES families were more likely to be screened out and race does not appear to impact this decision since race was not found to be a significant factor in the decision outcome.

\section{Variables that Predict Intake Decisions}

Model based on bivariate analyses. Logistic regression analysis was used to predict the probability that a respondent would screen a case in for investigation. The predictor variables were mid-SES family (yes/no), level of parental attributions, and rating of importance of CPS history as a decision factor. These variables were based on findings from bivariate analyses. A test of the full model versus a model with intercept only was statistically significant, $x^{2}(5, N=$ $390)=93.37, p<.001$. The model was able to correctly classify $49 \%$ of those who decided to screen the case out and $87 \%$ of those who screened the case in, with an overall success rate of $73 \%$. Table 17 outlines the logistic regression coefficient, Wald test statistic, and odds ratio for each of the predictors. Socioeconomic status of the family, parental attributions, and rating of CPS history 
importance had significant partial effects. The odds ratio for these variables indicates that when holding other variables constant, a professional who rates previous CPS involvement as a highly important factor in decision making will be nearly two times more likely to screen the case in for investigation than their counterparts.

Table 17

Logistic Regression Model: Variables Predicting Intake Decision (A2) Based on Bivariate Analysis

\begin{tabular}{|c|c|c|c|c|c|c|c|c|}
\hline \multirow[b]{2}{*}{ Predictors } & \multirow[b]{2}{*}{$\beta$} & \multirow[b]{2}{*}{ S.E. } & \multirow[b]{2}{*}{$\begin{array}{c}\text { Wald } \\
x^{2}\end{array}$} & \multirow[b]{2}{*}{$d f$} & \multirow[b]{2}{*}{$p$} & \multirow[b]{2}{*}{$\begin{array}{l}\text { Odds } \\
\text { Ratio }\end{array}$} & \multicolumn{2}{|c|}{$\begin{array}{l}95 \% \mathrm{Cl} \text { for } \\
\text { Odds Ratio }\end{array}$} \\
\hline & & & & & & & Lower & Upper \\
\hline Mid-SES & -.688 & .240 & 8.229 & 1 & $.004^{\star \star}$ & .503 & .314 & .804 \\
\hline $\begin{array}{l}\text { External } \\
\text { attribution }\end{array}$ & .260 & .106 & 5.972 & 1 & $.015^{\star}$ & 1.297 & 1.053 & 1.597 \\
\hline $\begin{array}{l}\text { Internal } \\
\text { attribution }\end{array}$ & .226 & .074 & 9.385 & 1 & $.002^{\star \star}$ & 1.254 & 1.085 & 1.449 \\
\hline $\begin{array}{l}\text { Feelings } \\
\text { toward } \\
\text { parents }\end{array}$ & -.047 & .058 & .658 & 1 & .417 & .954 & .852 & 1.069 \\
\hline CPS history & .629 & 118 & 28.158 & 1 & $.000^{\star \star \star}$ & 1.875 & 1.487 & 2.366 \\
\hline Constant & -4.292 & .717 & 35.799 & 1 & $.000^{\star \star \star}$ & .014 & & \\
\hline
\end{tabular}

Note: $R^{2}=.91$ (Hosmer \& Lemeshow), .21 (Cox \& Snell), .29 (Nagelkerke); ${ }^{*} p<$ $.05,{ }^{\star \star} p<.01,{ }^{\star \star \star} p<.001$

Model based on theoretical constructs. A test of the full model versus a model with intercept only was statistically significant, $X^{2}(35, N=308)=97.77, p$ $<.001$. The model was able to correctly classify $86 \%$ of those who decided to 
screen the case in and $60 \%$ of those who screened the case out, with an overall success rate of $76 \%$. Table 18 outlines the logistic regression coefficient, Wald test statistic, and odds ratio for each of the predictors that had significant partial effects.

Again, CPS involvement is a predictor of a more restrictive decision, with respondents being twice as likely to screen in a case in which the family had prior CPS involvement. In this second intake decision, the rated importance of family structure was also a significant predictor, as respondents who felt this was important were twice as likely to screen in the case than their counterparts. As in the model based on bivarate analyses, low-SES families were less likely to be screened in than mid-SES families. 
Table 18

Logistic Regression Model: Variables Predicting Intake Decision (A2) Based on Theoretical Constructs

\begin{tabular}{|c|c|c|c|c|c|c|c|c|}
\hline \multirow[b]{2}{*}{ Predictors } & \multirow[b]{2}{*}{$\beta$} & \multirow[b]{2}{*}{ S.E. } & \multirow[b]{2}{*}{$\begin{array}{c}\text { Wald } \\
x^{2}\end{array}$} & \multirow[b]{2}{*}{$d f$} & \multirow[b]{2}{*}{$p$} & \multirow[b]{2}{*}{$\begin{array}{l}\text { Odds } \\
\text { Ratio }\end{array}$} & \multicolumn{2}{|c|}{$\begin{array}{l}95 \% \mathrm{Cl} \text { for } \\
\text { Odds Ratio }\end{array}$} \\
\hline & & & & & & & Lower & Upper \\
\hline Low-SES & -.641 & .301 & 4.554 & 1 & $.033^{*}$ & .527 & .292 & .949 \\
\hline CPS history & .783 & .217 & 13.018 & 1 & $.000^{\star \star \star}$ & 2.188 & 1.430 & 3.348 \\
\hline $\begin{array}{l}\text { Importance } \\
\text { of family } \\
\text { structure in } \\
\text { DM }\end{array}$ & .562 & .195 & 8.339 & 1 & $.004^{\star \star}$ & 1.755 & 1.198 & 2.571 \\
\hline $\begin{array}{l}\text { Internal } \\
\text { parental } \\
\text { attributions }\end{array}$ & .332 & .098 & 11.432 & 1 & $.001^{\star \star}$ & 1.393 & 1.150 & 1.688 \\
\hline Constant & -5.405 & 2.801 & 3.724 & 1 & .054 & .004 & & \\
\hline
\end{tabular}

\section{Decision B2}

Respondents were asked to make a disposition decision after receiving investigation information regarding the case of the 7-year-old. Specifically, respondents were asked to remove the child from the home or set up in-home services. 


\section{Decision Outcomes}

A total of 382 respondents indicated a decision and 355 provided a written reason for the decision. The vast majority of respondents $(72 \%, N=274)$ chose to provide in-home services for the child and family. Influence of Personal, Professional, and Environmental Characteristics on Decision Making

Demographic characteristics. Chi square analyses found no significant relationships between respondents' race, gender, or level of education and their decision groups. Independent samples $t$ tests also revealed no significant differences in decision group by years of child welfare experience or years of experience in current position.

Position and practice area. Results of a chi square analysis showed no correlation between position and the outcome of Decision B2. A $2 \times 4$ chi square test revealed a significant relationship between this second disposition decision and practice area, $x^{2}(3)=9.97, p<.05, V=.16$. As illustrated in Table 19, the group differences appear to be most prevalent among intake/investigation and ongoing workers. While intake/investigation workers were more likely to recommend in-home services, ongoing workers were more likely to recommend removal of the child from the home. 
Table 19

Percentages of Respondents in Various Practice Areas by Decision Outcome (Decision B2)

\begin{tabular}{lcccc}
\hline Decision B2 & $\begin{array}{c}\text { Intake/ } \\
\text { Investigation }\end{array}$ & Ongoing & Combination & $\begin{array}{c}\text { CPS + } \\
\text { Other Duties }\end{array}$ \\
\hline Remove & $6 \%$ & $56 \%$ & $32 \%$ & $7 \%$ \\
In-home & $14 \%$ & $41 \%$ & $39 \%$ & $6 \%$ \\
services & & & & \\
\hline
\end{tabular}

Work environment. Results of a chi square analysis showed no significant correlation between geographic location and the outcome of Decision B2. An independent samples $t$ test revealed no significant differences in decision group by percentages of children of color or Caucasian children being served by the respondents. An exploration of group differences through Mann-Whitney $U$ analyses revealed no significant differences between the decision groups regarding the ranking of the agency's emphasis on cultural competence or the ranking of work-related stress levels.

Attitudes. Finally, independent samples $t$ tests showed no significant differences between the decision groups regarding the respondents' attitudes toward race, poverty, and family structure. Similar to the other case decisions, the respondents' attitudes did not play a role.

Influence of Case Factors on Decision Making

A Mann-Whitney $U$ analysis revealed a significant difference between the decision groups' ratings of the importance of two factors in their decision 
making —availability of social supports and family history of CPS involvement. Respondents who decided to provide in-home services rated the availability of social supports as significantly more important in their decisions than their counterparts. Those who decided to remove the child from the home rated family history of CPS involvement as being more important than those who recommended in-home services. Test statistics are provided in Table 20. 
Table 20

Test Statistics for Individual Decision Making Factors Related to Decision

Outcome (Decision B2)

\begin{tabular}{|c|c|c|c|}
\hline \multirow{2}{*}{$\begin{array}{l}\text { Decision Making } \\
\text { Factors }\end{array}$} & \multicolumn{2}{|c|}{$M \operatorname{rank}(N)$} & \multirow[t]{2}{*}{$z, p$} \\
\hline & $\begin{array}{l}\text { Remove from } \\
\text { home }\end{array}$ & $\begin{array}{l}\text { Provide in-home } \\
\text { services }\end{array}$ & \\
\hline Parent risk factors & $172.15(104)$ & $192.07(268)$ & $-1.68, .094$ \\
\hline $\begin{array}{l}\text { Social supports } \\
\text { available }\end{array}$ & $164.83(105)$ & $195.68(268)$ & $-2.62, .009^{\star}$ \\
\hline $\begin{array}{l}\text { Family history of CPS } \\
\text { involvement }\end{array}$ & $214.90(105)$ & $176.81(269)$ & $-3.34, .001^{*}$ \\
\hline $\begin{array}{l}\text { Parental compliance } \\
\text { with past services }\end{array}$ & $178.37(105)$ & $191.06(269)$ & $-1.11, .269$ \\
\hline $\begin{array}{l}\text { Who is living in the } \\
\text { home at the time of } \\
\text { the incident }\end{array}$ & $182.23(105)$ & $187.49(266)$ & $-.44, .657$ \\
\hline $\begin{array}{l}\text { Family's financial } \\
\text { situation }\end{array}$ & $177.98(105)$ & $191.22(269)$ & $-1.12, .264$ \\
\hline $\begin{array}{l}\text { Neighborhood } \\
\text { safety/risks }\end{array}$ & $177.63(105)$ & $191.35(269)$ & $-1.15, .249$ \\
\hline Policy guidelines & $192.55(105)$ & $185.53(269)$ & $-.59, .552$ \\
\hline $\begin{array}{l}\text { Family's ethnic } \\
\text { background }\end{array}$ & $184.66(104)$ & $187.21(268)$ & $-.22, .827$ \\
\hline $\begin{array}{l}\text { Quality of the } \\
\text { parent/child } \\
\text { relationship }\end{array}$ & $181.62(105)$ & $189.79(269)$ & $-.69, .492$ \\
\hline
\end{tabular}

Findings from a Mann-Whitney $U$ analysis showed that respondents' ratings of the importance of parent risk factors in decision making differed 
significantly based on the race of the child/family, $z=-2.54, p<.05$. Furthermore, their ratings of the importance of the family's financial situation differed significantly based on SES, $z=-2.12, p<.01$, and their ratings of the importance of the history of CPS involvement differed significantly based on family structure, $z=-2.17, p<.05$. Specifically, their ratings indicated that parent risk factors were more important in their decision making regarding Black families $(M$ rank $=$ 199.55, $N=201$ ) than White families ( $M$ rank $=172.34, N=172$ ); the family's financial situation was a more important decision making factor in low-SES families $(M$ rank $=202.44, N=195)$ than mid-SES families $(M$ rank $=172.36, N$ $=180$ ); and that a history of CPS involvement was more important in decisions regarding two-parent families ( $M$ rank $=199.39, N=183$ ) than single-parent families $(M$ rank $=177.14, N=192)$.

Reasons Provided by Respondents for Their Decisions

Child safety $(N=4)$, lack of success of past services $(N=4)$ and history of CPS involvement $(N=4)$ were key reasons listed by respondents for their decision to remove the child in this case. A few respondents who removed also indicated that the serious nature of the injury $(N=3)$ factored into their decision. Many of those who chose to provide in-home services cited the benefits of such services $(N=18)$ (e.g., parenting supports, professionals in the home for further assessment, prevention of removal) in their reasoning. Several respondents also felt that the parent's previous compliance with services $(N=6)$ and the fact that the child was not in immediate danger $(N=5)$ were reasons to provide in-home services instead of removing the child from the home. 
Influence of Attributions for Parental Behaviors on Decision Making

An independent samples $t$ test showed that in Decision B2, those who removed the child $(M=10.88, S D=2.39)$ indicated higher internal parental attributions than those who provided in-home services $(M=10.17, S D=2.07)$, $t(372)=2.82, p<.01$. Regarding scenario group differences, an independent samples $t$ test revealed that respondents who considered low-SES families rated external attributions higher $(M=6.20, S D=1.31)$ than those who considered mid-SES families $(M=5.78, S D=1.42), t(373)=2.96, p<.01$. No significant group differences were found pertaining to race or family structure scenario groups.

An exploration of group differences regarding individual attribution items using Mann-Whitney $U$ analyses yielded the results displayed in Table 21 . Respondents who chose to remove the child from the home indicated higher ratings for the situation being the parents' fault, the responsibility being the parents' alone, and anger toward the parents' behavior, while respondents who recommended in-home services gave higher ratings for sympathy toward the parents. 
Table 21

Test Statistics for Individual Parental Attributions Related to Decision Outcome (Decision B2)

Parental Attributions $M \operatorname{mrank}(N) \quad z, p$

Remove In-home services

It is the parents' fault

$215.40(105)$

$176.61(269)$

$-3.30, .001^{* *}$ that the family is in this situation.

The parents alone were responsible for $215.94(105)$ $176.40(269)$ $-3.40, .001^{\star \star}$ causing a potentially negative situation.

The parents' behavior $206.18(105)$ $180.21(269)$ $-2.16, .031^{*}$ angered me.

This situation makes $166.77(105)$ 194.05 (269) $-2.32, .020^{\star}$ me feel sympathetic toward the parents.

${ }^{*} p<.05,{ }^{* *} p<.01$

A Mann-Whitney $U$ analysis showed significant differences in the ratings of one attribution item (Other factors, besides the parents' actions, caused a potentially negative situation) by SES of the family, $z=-3.68, p<.001$. The sum of the average ranking of this item by respondents who made a decision about a low-SES family ( $M$ rank $=205.69, N=195)$ was significantly higher than that of respondents who made a decision about a mid-SES family $(M$ rank $=167.69, N=$ 179). 
Influence of Race, Family Structure, and Socio-economic Status on Decision Making

Regarding Decision B2, chi square analyses indicated no significant correlations between the decision group (remove vs. in-home services) and the scenario group (race, SES, or family structure). No significant correlations were found between the decision group and the randomly assigned vignette (various combinations of race, SES, and family structure).

\section{Variables that Predict Disposition Decisions}

Model based on bivariate analyses. Logistic regression analysis was applied to the question of how a group of variables predict the probability that a respondent would remove the child from the home. Similar to the first disposition decision, the predictor variables were ongoing service provider only (yes/no), level of internal parental attributions, and rating of importance of CPS history as a decision factor. These variables were based on findings from bivariate analyses. A test of the full model versus a model with intercept only was statistically significant, $\mathrm{X}^{2}(3, N=374)=25.01, p<.001$. The model was able to correctly classify $10 \%$ of those who decided on removal and $97 \%$ of those who provided in-home services, with an overall success rate of $72 \%$. Table 22 outlines the logistic regression coefficient, Wald test statistic, and odds ratio for each of the predictors. Practice area (ongoing only), internal attribution, and rating of the importance of CPS history had significant partial effects. The odds ratio for these variables indicates that when holding other variables constant, an ongoing service provider or professional who believes previous CPS involvement is an 
important decision factor will be nearly two times more likely to remove the child than their counterparts.

Table 22

Logistic Regression Model: Variables Predicting Disposition Decision (B2) Based on Bivariate Analysis

\begin{tabular}{|c|c|c|c|c|c|c|c|c|}
\hline \multirow[b]{2}{*}{ Predictors } & \multirow[b]{2}{*}{$\beta$} & \multirow[b]{2}{*}{ S.E. } & \multirow[b]{2}{*}{$\begin{array}{c}\text { Wald } \\
x^{2}\end{array}$} & \multirow[b]{2}{*}{$d f$} & \multirow[b]{2}{*}{$p$} & \multirow[b]{2}{*}{$\begin{array}{l}\text { Odds } \\
\text { Ratio }\end{array}$} & \multicolumn{2}{|c|}{$\begin{array}{l}95 \% \mathrm{Cl} \text { for } \\
\text { Odds Ratio }\end{array}$} \\
\hline & & & & & & & Lower & Upper \\
\hline $\begin{array}{l}\text { Ongoing } \\
\text { only }\end{array}$ & .645 & .240 & 7.247 & 1 & $.007^{\star \star}$ & 1.907 & 1.192 & 3.050 \\
\hline CPS history & .551 & .172 & 10.259 & 1 & $.001^{\star \star}$ & 1.735 & 1.238 & 2.430 \\
\hline $\begin{array}{l}\text { Internal } \\
\text { attribution }\end{array}$ & .131 & .054 & 5.794 & 1 & $.016^{\star}$ & 1.140 & 1.025 & 1.268 \\
\hline Constant & -4.953 & .941 & 27.738 & 1 & $.000^{* * *}$ & .007 & & \\
\hline
\end{tabular}

Note: $R^{2}=.87$ (Hosmer \& Lemeshow), .07 (Cox \& Snell), .09 (Nagelkerke); ${ }^{*} p<$ $.05,{ }^{\star *} p<.01,{ }^{* \star *} p<.001$

Model based on theoretical constructs. A test of the full model versus a model with intercept only was statistically significant, $\mathrm{X}^{2}(35, N=309)=73.83, p$ $<.001$. The model was able to correctly classify $42 \%$ of respondents who removed the child from the home and $92 \%$ of those who provided in-home services, with an overall success rate of $77 \%$.

As in the first disposition decision, CPS history factored heavily into respondents' decision making. Those who felt this issue was important were nearly five times more likely to remove the child from his home than those who did not believe this was an important decision making issue. Findings also 
indicate that women and those who held less than a four-year degree were much less likely to recommend removal than their counterparts. Furthermore, when respondents felt families had available social supports and had complied with past services, they were less likely to recommend removal. Table 23 outlines the logistic regression coefficient, Wald test statistic, and odds ratio for each of the predictors that had significant partial effects. 
Table 23

Logistic Regression Model: Variables Predicting Disposition Decision (B2) Based on Theoretical Constructs

\begin{tabular}{|c|c|c|c|c|c|c|c|c|}
\hline \multirow[b]{2}{*}{ Predictors } & \multirow[b]{2}{*}{$\beta$} & \multirow[b]{2}{*}{ S.E. } & \multirow[b]{2}{*}{$\begin{array}{c}\text { Wald } \\
x^{2}\end{array}$} & \multirow[b]{2}{*}{$d f$} & \multirow[b]{2}{*}{$p$} & \multirow[b]{2}{*}{$\begin{array}{l}\text { Odds } \\
\text { Ratio }\end{array}$} & \multicolumn{2}{|c|}{$\begin{array}{l}95 \% \mathrm{Cl} \text { for } \\
\text { Odds Ratio }\end{array}$} \\
\hline & & & & & & & Lower & Upper \\
\hline Female & -.899 & .438 & 4.206 & 1 & $.040^{\star}$ & .407 & .172 & .961 \\
\hline $\begin{array}{l}\text { Less than } \\
4 \text {-year } \\
\text { degree }\end{array}$ & -3.082 & 1.290 & 5.704 & 1 & $.017^{\star}$ & .046 & .004 & .575 \\
\hline $\begin{array}{l}\text { Importance } \\
\text { of social } \\
\text { supports for } \\
\text { family }\end{array}$ & -.498 & .239 & 4.340 & 1 & $.037^{*}$ & .608 & .381 & .971 \\
\hline CPS history & 1.558 & .315 & 24.391 & 1 & $.000^{\star \star \star}$ & 4.748 & 2.559 & 8.810 \\
\hline $\begin{array}{l}\text { Importance } \\
\text { of } \\
\text { compliance } \\
\text { with past } \\
\text { services }\end{array}$ & -.910 & .271 & 11.254 & 1 & $.001^{\star \star}$ & .402 & .236 & .685 \\
\hline $\begin{array}{l}\text { Feeling } \\
\text { attributions }\end{array}$ & .141 & .070 & .114 & 1 & $.043^{*}$ & 1.152 & 1.004 & 1.320 \\
\hline Constant & -.910 & 2.700 & .114 & 1 & .736 & .403 & & \\
\hline
\end{tabular}

Note: $R^{2}=.55$ (Hosmer \& Lemeshow), .21 (Cox \& Snell), .30 (Nagelkerke); ${ }^{*} p<$ $.05,{ }^{\star \star} p<.01,{ }^{\star \star \star} p<.001$

Summary of Key Findings

Personal, Professional, and Environmental Characteristics

In the first disposition decision (B), program area, years of child welfare experience, and level of work-related stress influenced the decision outcome. 
Specifically, respondents providing a combination of CPS services were more likely to recommend in-home services, while those providing ongoing services only were more likely to recommend removal. Also, more experienced respondents tended to decide on provision of in-home services while respondents indicating higher levels of work-related stress were more likely to decide upon removal. Program area had a significant influence on the outcome of the second disposition decision (B2) as well. Respondents providing ongoing services only were again more likely to decide upon removal, while those in intake/investigations were more apt to recommend in-home services.

\section{Case Factors}

Regarding the second intake decision (A2), respondents indicated that all of the proposed factors except for policy were important in their decision to screen the case in for investigation. These factors are as follows: parent risk factors, social supports available, family history of CPS involvement, parents' compliance with past services, persons living in the home at the time of the incident, family's financial situation, neighborhood safety/risks, family's ethnic background, and quality of parent/child relationship.

Important decision factors in the post-intake disposition decision to provide in-home services were social supports available, family financial situation, and neighborhood safety. A history of CPS involvement was reported as an important factor in removal for both disposition scenarios. 


\section{Decision Reasoning}

In addition to closed-ended responses to a list of factors for each decision, respondents were also given the opportunity to provide their own reasons for making a particular decision. Table 24 offers a summary of factors respondents felt were important in their decision making. In screening decisions, the type of injury and past CPS involvement were key factors. Disposition decisions were often based on child safety, evidence of parental compliance, previous CPS involvement, and the possible benefits of services to the family. 
Table 24

Responses to Open-ended Questions Regarding Respondents' Reasoning for Decisions

\begin{tabular}{|c|c|c|c|}
\hline Screen In & Screen Out & Remove & $\begin{array}{c}\text { Provide In-home } \\
\text { Services }\end{array}$ \\
\hline $\begin{array}{l}\text { - } \begin{array}{l}\text { Bruising/marks } \\
\text { (seriousness of } \\
\text { injury)* }\end{array} \\
\text { - Past CPS } \\
\text { involvement }^{\star} \\
\text { - Statement of } \\
\text { "trouble at } \\
\text { home" indicates } \\
\text { punishment (A) } \\
\text { - Child not willing } \\
\text { to talk (A2) } \\
\text { - Need more } \\
\text { information } \\
\text { (obtained } \\
\text { through } \\
\text { investigation) } \\
\text { (A2) }\end{array}$ & $\begin{array}{l}\text { - } \begin{array}{l}\text { No disclosure } \\
\text { of } \\
\text { maltreatment } \\
\text { (A) }\end{array} \\
\text { - Other possible } \\
\text { explanation for } \\
\text { injury (A) } \\
\text { - Injury } \\
\text { consistent with } \\
\text { explanation } \\
\text { (A2) } \\
\text { - No reason not } \\
\text { to believe } \\
\text { child's story } \\
\text { (A2) }\end{array}$ & $\begin{array}{l}\text { - } \begin{array}{l}\text { Child's safety* } \\
\text { - History of CPS } \\
\text { involvement }^{\star} \\
\text { - } \begin{array}{l}\text { Pattern of } \\
\text { abuse (B) }\end{array} \\
\text { - Past services } \\
\text { not successful } \\
\text { (B2) }\end{array}\end{array}$ & $\begin{array}{l}\text { - Evidence of } \\
\text { parental } \\
\text { compliance* } \\
\text { - Benefits of } \\
\text { services to } \\
\text { family } \\
\text { (including } \\
\text { monitoring) } \\
\text { - Child is not in } \\
\text { immediate } \\
\text { danger (B2) }\end{array}$ \\
\hline
\end{tabular}

${ }^{*}$ Reason given for both scenarios (A/A2 and B/B2)

Attributions for Parental Behaviors

In the second intake decision (A2), respondents who screened the case in indicated high levels of each sub-group of parental attribution (internal, external, and feeling). However, regarding disposition (B and B2), internal parental attributions were rated higher for cases in which the child was removed. The case characteristic of socio-economic status was significant, as mid-SES families were given higher internal attributions than low-SES families. In the first 
disposition decision (B), family structure was also significant. Two-parent families received higher internal parental attributions than single-parent families.

Race, Family Structure, and Socio-economic Status

. Only in the second intake decision (A2) was a significant relationship found between the decision outcome and one of the variables of interest, namely socio-economic status. Specifically, the cases of mid-SES families were more likely to be screened in for investigation, while low-SES families were more likely to have their cases screened out. When the combination of variables was considered, Black, mid-SES, single-parent families were screened in more often and White, low-SES, single-parent families were screened in less often than their counterparts. The absence of significance in decision outcome by race of the family indicates that the different outcomes for these two variable combinations were due to socio-economic status and not race.

As mentioned above, quantitative and qualitative findings revealed that previous CPS involvement was a key factor in decisions to screen the case in for investigation and remove the child from his parents' care. This seemed to be an even more important factor in decision-making regarding two-parent families in both the intake and disposition decisions of the second scenario (A2 and B2). In the disposition decisions, parental risk factors, social supports available, and family financial situation were rated by respondents as more important in decisions about low-SES families. Respondents indicated that parental risk factors were more important in their consideration of Black families. 


\section{Variables Predicting Decision Outcomes}

Binary logistic regression models were created for the intake and postinvestigation disposition decisions to consider variables that predicted the outcomes of these decisions. Results from models creating using findings from bivariate analyses as well as theoretical constructs supported other quantitative and qualitative outcomes. Although race of the child/family was not a predictor of any of the decision outcomes, SES and family structure did have significant partial effects in the second intake decision (A2). Parental attributions were key in the second scenario decisions (A2 and B2), but CPS history was a major predictor of more restrictive decision making outcomes in the second intake and both post-investigation disposition decisions.

The second set of final logistic regression models based on the theoretical constructs utilized all of the independent variables (professional, personal, case, and work environment factors; attitudes; decision making factors; and parental attributions). However, only $37 \%$ of the variance was explained for Decision $A 2$, $27 \%$ for Decision B, and $32 \%$ for Decision B2. The fact that only around one-third of the variance was explained by all of these variables indicates that there are more variables to be considered.

Conclusion

Due to variations in the findings among the literature, and the somewhat exploratory nature of this research study, no formal hypotheses were put forth.

However, based on the literature review and theoretical notions, it was expected that respondents would differ significantly in their intake and post-investigation 
disposition decisions based on race, family structure, and socio-economic status of the family. This outcome only occurred in the second intake decision regarding socio-economic status.

Significant group differences among respondents regarding decision outcomes were also expected. Specifically, it was anticipated that respondents would differ in intake and post-investigation disposition decisions based on the professional characteristics of years of experience, practice area, and caseload composition as well as the personal characteristics of race, age, gender. No such differences were found in the intake decisions and only program area, years of child welfare experience, and level of work-related stress yielded differences in outcomes of the disposition decisions.

Finally, respondents were expected to differ in their decision outcomes based on attitudes toward race, poverty, and family structure as well as their attributions about the parents. Although there were some differences in attitudes based on professional characteristics, no associations were found between attitudes and decision outcomes. Parental attributions did correspond with differences in intake and disposition decisions. While the intake decision was significantly different based on all types of parental attributions, removal was associated with internal parental attributions, as expected. Another finding indicated that parents in mid-SES and two-parent families were ascribed higher levels of internal attributions for the situation. These results and their implications will be discussed in the following chapter. 


\section{CHAPTER FIVE: DISCUSSION AND IMPLICATIONS}

The caseworker who visited the family who lived in the neighborhood with cracked sidewalks, graffiti, and African American youth on street corners needed to make a decision regarding the safety of the child in the home. Her task was difficult. After speaking with the child and mother, examining the home, consulting her supervisor, and considering the information she had gathered during her visit, she decided upon provision of in-home services for the child and family. ${ }^{7}$

Rivaux and colleagues (2008) argue that knowing how the caseworker faced with this situation made her decision and what factors influenced this decision will help us determine the most effective course of action for ensuring consistency and equity in her decisions and those of her colleagues. Armed with a greater knowledge of how various internal and external components factor into child protection decision making will allow us to identify if and where bias exists in the process. These authors also maintain that if caseworker decisions are based on attributional biases, we can inoculate workers against susceptibility to such intrinsic errors through training or other strategies.

In this chapter, I will review and critique the methods and findings of this study. I will also expand on the ideas discussed above regarding the importance of these findings and their implications for child welfare practice and research.

\footnotetext{
${ }^{7}$ This scenario was created by the author based on the excerpt from Rivaux et al. (2008) used in Chapter Two.
} 


\section{Summary of Method and Demographics}

The study participants were CPS providers in a Midwestern state $(N=$ 400). E-mails containing a link to the online survey were sent to a state administrator who then forwarded them to CPS employees all across the target state. Those interested completed the survey which contained vignettes, demographic questions, and attitude scales. SPSS was used to conduct univariate, bivariate, and multivariate analyses of the survey data. The response rate was $22 \%$.

The respondents were primarily Caucasians (88\%) and women (86\%). Their average age was 36 years and the average time of practice experience they had in child welfare was seven years. Well over half of them $(65 \%)$ held a Bachelor's degree, with $14 \%$ reporting having a BSW. Three fourths $(75 \%)$ were direct service providers and less than one-fourth (18\%) were supervisors. Most of the respondents either provided only ongoing services (45\%) or held a combination of CPS duties (37\%), while only $1 \%$ provided investigation services only.

\section{Discussion of Key Findings}

Professionals' Attitudes toward Race, Poverty, and Family Structure

Obviously, it is improbable that social workers will admit to bias. They may even be more sensitive to questions of bias when completing a survey such as the one in this study. A social desirability scale was not included in an effort to keep the survey as brief and focused as possible. Some attempt to address social desirability bias was made by intermingling the attitude scales and 
soliciting responses to these scales after the case decisions had been made. There were some differences in attitudes toward race, poverty, and family structure by professional characteristics (i.e., years of practice experience, age, gender, and position) but these differences did not extend to the decision outcomes. It was interesting that respondents' answers to the attitude scales indicated moderate levels of color-blindness and classism and low levels of support for single-parent families. There was some expectation that CPS providers would exhibit even more open and tolerant attitudes, but again, the professionals' attitudes did not translate to differences in decision outcomes by race, SES, or family structure.

An attempt was made to assess whether those participating in the present study were more or less biased towards people based on their economic status than participants in other related studies; however, no mean score information for the Economic Belief Scale could be found in previous literature. The mean COBRAS score over four studies including college students and some community members $(N=1143$ ) was 64.25 (Neville et al., 2000), which is several points lower than the mean score for the present study (67.97). This indicates a somewhat lower level of racial awareness among the professionals in the present study. In an evaluation of an anti-racism training targeting service providers $(\mathrm{N}=$ 565) representing various child welfare-associated systems (child protection, health care, education, law enforcement, mental health, etc.), the participants' mean COBRAS score before the training was 57 (Johnson, Antle, \& Barbee, 2009). Those who identified themselves as child protective services providers 
had an average COBRAS score of $64(N=62)$ before the training and $58(N=$ 44) after the training. Therefore, the child welfare professionals in Johnson and colleague's study also demonstrated greater racial awareness than respondents in the current study. It must be noted, however, that individuals often selfselected to participate in the anti-racism training, which could indicate previous interest in and awareness of issues of race and racism that would impact scores on the COBRAS. Although respondents self-selected for the current study as well, there was no stated focus on issues of race or racism that may have drawn more racially aware respondents.

\section{Decision Outcomes}

Overall, univariate analyses of the decision outcomes indicate that respondents readily accepted the reports for investigation (screen in: $A=99 \%$, A2 $=62 \%$ ), but were less likely to remove the children from their homes (provide in-home services: $\mathrm{B}=57 \%, \mathrm{~B} 2=72 \%$ ). Regarding the actual practices of CPS providers in the target state, in $200765 \%$ of cases referred to CPS were screened in for investigation and $17 \%$ of children in the child protection system were placed in out-of-home care (CWLA, 2009). The mean percentages of cases in the study that experienced screening in for investigation or removal were much higher than the percentages of these decisions that occurred in the target state (see Table 25). As will be discussed below, this may be due to the hypothetical nature of the vignettes in the study that allow for decisions without actual consequences. 
Table 25

Comparison of Screen-In and Removal Percentages: Study Sample and Workers in the Target State

\begin{tabular}{lcc}
\hline & Present Study $^{\mathrm{a}}$ & Target State (2007) \\
\hline Screen In & $81 \%$ & $65 \%$ \\
Remove & $35 \%$ & $17 \%$ \\
\hline
\end{tabular}

${ }^{a}$ Average for both scenarios ( $A$ \& A2, B \& B2)

In the first disposition decision (B), the percentages of those who recommend removal or provision of in-home services were relatively equal ( $43 \%$ and $57 \%$, respectively), though as in the second disposition decision (B2), the majority $(72 \%)$ provided in-home services. Considering the face validity of the decision prompts (vignettes), it seems that the first case (B) may have appeared more ambiguous to study participants than the second case (B2). In other words, the information provided for Decision B leaves more room for the plausibility of either immediate risk or safety with in-home services. This may indicate that decision situations that are not as clear or allow for more subjective interpretation may result in more disparate outcomes by case characteristics. A similar point was made by Berger and colleagues (2006) regarding their findings about how professionals judged parenting behaviors.

\section{Case Characteristics}

There were no differences found in decision outcomes by the variables of interest (race, SES, family structure) at the disposition stage. Only the second intake decision, which involved a report from a nurse about a child who 
reportedly fell off of his bicycle, (A2) differed by socio-economic status. Mid-SES families were more likely to be screened in than low-SES families. This seems counterintuitive based on the higher proportion of poor families in the CPS system than in the general population (U.S. Census Bureau, 2008b; U.S. DHHS, ACF, OPRE, 2006), but some research regarding race has indicated that although this outcome is not expected, it may still be an indication of bias or different responses by case characteristics. For instance, Hansen and colleagues (1997) and Landsman and Hartley (2007) found that professionals rated maltreatment among Black families as less severe and they had fewer concerns about the safety of Black children compared to White children. These authors point out that in their study, respondents may have viewed maltreatment as more normative in Black families or they may have had a higher risk threshold for Black families. In the present study, it is possible that maltreatment was seen by respondents as more normative among poor families, poor children were perceived as being in less need of protection, or respondents placed more responsibility on families with more resources.

It was expected that the present study would reveal significant differences in decision outcomes by the race of the child and family. There are at least four possible explanations for a lack of differences in decision outcomes by race.

First, although the names used as racial cues in the vignettes were obtained from surveys of social work students and practitioners ${ }^{8}$, it is possible that these cues were not explicit enough to solicit specific racial or ethnic perceptions about the children and families from the respondents. Second, respondents may have been

\footnotetext{
${ }^{8}$ See Chapter Three for a description of this process.
} 
aware of these racial cues, but were particularly conscious of race in their decision making and, therefore, avoided the appearance of bias in this area. Third, respondents' decision making regarding the cases presented in the study could have been free of racial bias.

The fourth possible explanation for racial similarities in the decision outcomes is that socio-economic status may have subconsciously used as a proxy for race. ${ }^{9}$ However, the absence of differences in decision by race of the family indicates this may not be so. Race of the child was not a significant factor in any of the findings except for Decision B2 when those who considered Black families (as designated by the researcher) rated parental risk factors as more important in their decision making than did those who considered White families (as designated by the researcher). Socio-economic status and family structure were among the findings that correlated significantly with decision outcomes. Furthermore, the fact that there were no differences in decision outcomes based on the randomly assigned scenarios (combination of variables of interest in the vignettes) indicates that race was not associated with other case characteristics. In other words, it does not appear that stereotyping occurred in that Black families were not assumed to be poor or headed by a single parent and White families were not assumed to be middle class and have two parents. Therefore, findings related to SES and family structure are not necessarily proxy outcomes for race.

\footnotetext{
${ }^{9}$ Berger, McDaniel, and Paxon (2006) concluded from their study of professionals' judgments of parenting behavior that race was used as a proxy measure for socio-economic status, as people of color are sometimes assumed to be poor.
} 
Although more significant differences in decision outcomes by the child's race, SES, and family structure were expected, the fact that such differences were not found is encouraging. Although children of different backgrounds continue to be represented differently in the child welfare system, the findings of this study may indicate that the professionals who serve these children do so with less bias than in the past. These findings may also suggest that other factors beyond or in addition to race, SES, and family structure are involved in disproportionate or disparate outcomes for children, and these factors may be more amenable to intervention.

A key finding in the present study was the significance of the family's history of CPS involvement in both intake and disposition decision making. This particular finding is supported by previous research by English and colleagues (2002) in which $84 \%$ of respondents indicated chronicity of maltreatment was of moderate or high importance in their decision making. Furthermore, families with prior CPS involvement have a higher likelihood of a maltreatment allegation being founded (English et al., 2002) or their children being taking into custody (Rossi et al., 1999). Conversely, Landsman and Hartley (2007) actually found that history of prior CPS referrals decreased concerns about child safety among workers, but they explain that this finding may be due to their inclusion of domestic violence as an explanatory variable in their study.

Considering that some research has found previous CPS involvement to be a predictor of recurrence of maltreatment (English, Marshall, Bummel, \& Orme, 1999; Fluke, Shusterman, Hollinshead, \& Yuan, 2005; Sledjeski, Dierker, 
Brigham, \& Breslin, 2008; The Consultation Center of the Yale University School of Medicine, 2004), it is possible that CPS history is a valid reason for perception of increased risk and more restrictive intervention. Utilizing prior CPS involvement as a tool for assessing risk or need for intervention at the point of intake is often key due to the new allegation and possible lack of information. In this study, however, CPS history was a major predictor of removal in postinvestigation disposition decisions even when more information was known about the family's current situation. This indicates that respondents continued to rely on understandings of risk of recurrence of maltreatment related to previous CPS involvement beyond the intake phase.

The issue of parental compliance has also been found to be an integral factor in CPS decision making. Karski (1999) found that families who were cooperative or neutral with the child protection agency were far less likely than uncooperative parents to be referred to the court unit. Similarly, Rossi and colleagues (1999) found that families who exhibited interest in changing were less likely to have their children placed in out-of-home care and more likely to be referred for services. Stevens (1998), however, found that parental cooperation increased the probability of worker intervention. McConnell and colleagues (2006) suggest that a similar pattern in their study indicates that parental compliance gives workers hope for improving the child's situation; therefore, services are more likely to be suggested with this in mind. In the current study, previous compliance with services was often cited by respondents in their reasoning for recommending in-home services instead of removal. 


\section{Professional Characteristics}

The difference in disposition decision outcomes among respondents of different practice areas was another key finding. Respondents who reported providing ongoing services only were more likely to recommend removal and outof-home placement, while respondents who provided intake, investigative, or a combination of CPS services were more likely to recommend in-home services for the children in the case scenarios. No previous research on CPS decision making was found that has focused or reported on differences in decisions based on practice area. A possible explanation for the findings of the current study is that since ongoing workers provide and coordinate services, they may possess the most knowledge about the effectiveness of the types of services provided to families in which children are at risk. Therefore, ongoing workers may be more aware of when services are not likely to significantly reduce risk. to the children in a particular situation. In such cases, they could be more willing to recommend removal as the safest course of action. Also, since the cases presented were not as severe or extreme as cases often seen by intake and investigative workers, the cases in this study may have appeared to encompass relatively low levels of risk and, therefore, not be considered to warrant removal. Given these possibilities, it may have been helpful to include a measure of risk level for each of the scenarios.

Work-related stress was a significant variable in the first disposition decision (B) only. Respondents who indicated higher stress levels were more likely to decide upon removal of the child with bruises on his leg. This finding, 
however, was not associated with disproportionate removal based on case characteristics (race, family structure, SES). Therefore, the supposition that increased stress causes cognitive changes which allow for bias to have a greater influence on decision making, resulting in disparate outcomes for children of different backgrounds was not supported by the findings of this study.

Although previous studies (Gammon, 2000; Lazar, 2006) found gender to be a professional characteristic that influenced decision outcomes, the current study did not produce this result. However, similar to past research findings (Gammon, 2000; Parada et al. 2007), decision outcomes did differ based on the respondents' years of practice experience. Regarding the second disposition decision, those who reported more overall child welfare experience chose the less restrictive course of action (in-home service provision).

\section{Attributions for Parental Behaviors}

The fact that decisions to screen cases in for investigation and remove the children from their homes were associated with respondents attributing the parents' behavior to internal personality traits was not surprising. If a CPS worker perceives that risk to a child is heavily influenced by the nature of his parents, it follows that the worker will recommend further investigation into the child's circumstances or remove the child from his parents' care while services are provided to the parents to meet their specific needs. The surprising findings related to attributions were that respondents indicated higher internal attributions for parents' behavior in mid-SES and two-parent families when making disposition decisions. The theoretical framework of attribution bias supposes that 
stereotyping of non-typical individuals leads to attribution of their negative behaviors to personal flaws, while negative behaviors by individuals who fit more normative social constructions are thought to be caused by external factors (Fiske, 1998). This greater scrutiny of mid-SES and two-parent families regarding attribution may be associated with the greater responsibility placed on these families by respondents [screen in, remove]. It may have been the case that respondents believed that because mid-SES and two-parent families are usually not plagued by environmental factors that could result in risk or maltreatment their negative situations were likely a result of parental characteristics.

\section{Predictors of Decision Outcomes}

Logistic regression analysis was used to examine which variables were most informative in predicting the decision outcomes. In all of the decisions (B, A2, B2), respondents who felt prior CPS involvement was important were 2.2 to 4.7 times more likely to recommend the more restrictive intervention (screen in, removal). Therefore, the findings of this study echo others that found CPS history to be a major predictor of decision outcomes (English et al., 1999; Fluke et al., 2005; Sledjeski et al., 2008; The Consultation Center of the Yale University School of Medicine, 2004). Findings also showed that SES and family structure had significant partial effects in the second intake decision (A2) and that parental attributions were key in the second scenario decisions (A2 and B2).

Interestingly, when all of the independent variables were included in the models, none of the models explained more than roughly one-third of the variance in the decision outcomes. This likely means that there are other 
variables to be considered that were not included in the present study. However, this finding could also indicate that existing models for explaining decision making in child protective services may need to be re-examined and amended.

Study Strengths and Limitations

Strengths

A major strength of this study is its large sample size $(N=400)$, which allowed for robust statistical analysis to be performed. The large sample size also offered broader information about the population of CPS decision makers in the target state. Furthermore, unlike many previous CPS decision making studies, the present design includes primary data collection, factorial vignette design, the use of several standardized scales, and simultaneous consideration of intake and post-investigation disposition decisions. It was also a strength of the study design that vignettes were randomly assigned.

The present study also addressed several key issues that had not been previously focused on in the literature. First, intake decisions were expressly considered. Although a few previous studies explored CPS intake decisions, this remains an understudied aspect of CPS decision making. Second, this study took into account the individual and combined influences of the following case variables: race, SES, and family structure. These variables have been shown to be individually related to outcomes for children and families, but no previous studies were found that considered these variables together. Finally, the present study directly explored how professionals' emotions about and attributions for parental behavior influence their decision making. 


\section{Limitations}

Despite the strength of the study overall, there are several weaknesses which must also be acknowledged. First, although attempts were made to include responses from CPS professionals in several states, only professionals from one state participated in the study. This was due to lack of administrative approval and facilitation of survey distribution in the other states within the timeframe of this research project. However, the possibility exists for future participation in another round of this study by professionals in these states.

Second, as in many studies, there is an issue of generalizability within and beyond the target sample. Again, this is partially due to respondents representing only one state. Also, the sampling design was based on convenience and did not include random sampling methods that would allow for generalizations beyond the study sample.

Third, the vignette method and the specific vignettes presented in the survey may have had drawbacks. As Gammon (2000) pointed out, vignettes are hypothetical and, therefore, may not provide the most reliable picture of decision making. Although respondents were asked to make decisions using the reasoning they normally use for practice, it is accepted that the outcomes of these decisions have no real-world impact and no consequences for actual children, families, communities, or the professionals themselves. Furthermore, only two vignettes (encompassing four decisions) were used in the present study and these vignettes may not have been detailed enough to allow for variations in responses. Essentially, because the vignettes were brief and did not provide 
much of the information respondents are likely used to receiving (e.g., details of previous history, information from collateral sources, knowledge of local communities/neighborhoods in which the families may live), they may have "played it safe" in recommending removal at higher levels than usual.

Fourth, the survey did not effectively reach a key group of CPS providers. Due to the lack of research on intake decisions by intake workers, a major focus of this study was gathering such information. While two intake scenarios were offered to respondents in general, only five intake workers responded to the survey.

Fifth, as in most survey research, self-selection bias may have been at play. The survey was distributed via e-mail to all employees of the target state's child welfare department. Respondents included those professionals who had the time and inclination to complete the survey. It is likely that among very busy child protection professionals, only those who were expressly interested in decision making issues chose to complete the survey.

Sixth, although some standardized attitude scales were used, other measures, such as those for family structure, parental attributions, and workrelated stress, were not standardized and had not been previously tested. Therefore, reliability and validity had not been established for these measures. Seventh, the repetitive structure of the survey instrument may have contributed to response fatigue. The respondents were asked to make four decisions, two related to an intake scenario and two related to an investigation scenario. After each of these four decisions, they were asked to provide their 
reasoning for the decision and respond to a list of parental attribution and decision making items. The fact that response rates for the second scenario $(95.5 \%)$ were less than for the first scenario $(99.5 \%)$ indicates that respondents became weary with this portion of the survey, and this response fatigue could have not only impacted whether they completed the survey but also how they answered subsequent questions.

Finally, the survey did not include items that would gather demographic information from respondents regarding the structures of their own families of origin or their socio-economic statuses. While the research questions were answered despite not having this information, it would have been helpful in providing a more complete picture, along with attitude scale responses, of the impact of respondents' characteristics on their decision making.

\section{Internet-based Research}

This research project was heavily influenced by the use of the Internet as a survey creation and distribution tool. Therefore, this section includes some discussion of the strengths and limitations of Internet-based research.

The Internet is a rapidly growing form of communication. According to the Nielsen Company (2008), the Internet was accessed by over 160 million people in the U.S. between July and September, 2008 , which was a $4.2 \%$ increase from the previous year. The use of the Internet for professional communication has also increased. In an exploratory study of e-mail use by agency-based direct services social workers $(N=384)$, Finn $(2006)$ found that $75 \%$ of workers surveyed used e-mail regularly to communicate within their agencies and 
externally with other professionals. Most of the social workers surveyed indicated they were "experienced" (46.3\%) or "intermediate" (38.5\%) e-mail users. Only $2.6 \%$ of workers reported that they had never used e-mail.

Researchers have utilized the internet to survey and gather data from study participants for over a decade (Cook, Heath, \& Thompson, 2000; Dillman, 2000). As time has passed, Internet-based research methods have benefited from increased savvy among the general population and technological advances that allow for more complex online survey designs, while making surveys more accessible and visually appealing to participants (Cook et al., 2000; Finn, 2006). Strengths of Internet-based Research

There are many reasons to use the Internet as a vehicle for survey research. The Internet may allow for more cost-effective survey administration because paper copying and traditional mailing fees are avoided. This is especially helpful when using a method in which reminders or surveys may need to be sent to participants multiple times. (However, a reliable survey creation and hosting site, such as the one used in this study may be relatively expensive.) Data collection may take less time because there is no wait for participants to receive and return the survey through traditional mail. Also, during the data collection period, participants may complete the survey at their convenience and are less likely to misplace the survey because it can be accessed by simply clicking a link in the body of the e-mail message notifying or reminding them of the survey (Cook et al., 2000; Simsek \& Veiga, 2001). Although researchers have found that Internet-based surveys may not yield higher response rates than 
traditional mail surveys (Cook et al., 2000), there are methods that may increase response rates when using Internet-based surveys. In a review of research in this area, Cook and colleagues (2000) found that certain factors such as number of contacts, personalized contacts, and pre-contacts are the factors most associated with higher response rates in Internet-based studies.

Historically, there have been supposed racial, class, and generational differences between Internet users and non-users (Gosling, Vazire, Srivastava, \& John, 2004). However, in a review of research, Gosling and colleagues (2004) found that although Internet samples are not necessarily representative of the general population of the United States, they are generally more diverse than, or at least as diverse as, samples from traditional mail surveys.

\section{Limitations of Internet-based Research}

Although the child protection workers and supervisors targeted for this study have access to e-mail, there may have been some e-mail addresses that were incorrect or missing or potential respondents may not have chosen to use e-mail. Therefore, the design of this study resulted in those individuals not being reached. Also, in using Internet-based surveys that were intended to be anonymous, it was not possible to completely protect against multiple survey submissions from an individual.

\section{Future Research}

An ultimate goal of this research was to shed some light on factors related to disproportionality and disparity in child welfare. The assumption was that bias in decision making would lead to differential outcomes for children and families of 
different races, socio-economic statuses, and family structures. Although differences were only noted in one intake decision outcome regarding socioeconomic status, other findings from this study indicate that SES is not an isolated factor. This provides some support for further exploration of the interplay between race, SES, and family structure in real-world CPS decision making environments. Sub-group analyses would also be useful in this endeavor as more information could be gathered about how professionals of various circumstances (e.g., urban-based workers, those from single-parent households, and male workers) make decisions within their groups.

This study highlighted the difficulties in obtaining information from hypothetical scenarios. In future research that uses the hypothetical vignette method to examine professionals' reactions to a variety of family characteristics, it will be helpful to ensure that the respondents recognize implicit cues about, for instance, the family's race or socio-economic status. The presence of previous CPS involvement and specific behaviors exhibited by the parents regarding noncompliance may also be useful variables to manipulate, given the importance of these variables in the present study.

Despite the shortcomings of hypothetical scenarios, future research may draw from the findings of studies such as this. Utilizing the information about the importance of practice area, attributions, and workers associations of risk with CPS history, researchers may design questions that prompt workers to share their thoughts about these issues as they make decisions in actual cases. Also, the impact of the agency climate on these decisions may be further considered. 
A specific area of focus may be intake. Given that this study was one of only a few that focused on intake decisions, and intake workers were not successfully reached in the present study, there remains a need for further examination of this area of decision making in CPS.

Finally, future research should endeavor to amplify the voices of the children and families served by the child protection system. Their perspectives on how their backgrounds, interactions with professionals, and environmental circumstances will provide extremely valuable information that will be helpful in better understanding the complex issues of decision making and disproportionality.

Implications for Child Protection Practice and Policy

It was determined that among this sample, prior CPS involvement by a family, practice area, and attributions for causation of parental behaviors were key factors in removal decisions. Although differences in decisions based on attributions were found, these findings indicated that instead of bias against or stereotyping of Black, poor, or single-parent families, risk among mid-SES and two-parent families was identified as being caused by the these parents' internal characteristics. Based on the findings, it appears that attributional bias played some role in the decisions made by the respondents. Rivaux and colleagues' (2008) proposal to help CPS professionals be more aware of attributions in an effort to inoculate them against decisions made on faulty attributions may still be applicable despite the unexpected findings of this study. Knowing that CPS workers may base decisions heavily on how the parents are expected to behave, 
regardless of race, SES, or family structure, suggests that it may be helpful to educate workers about the role of environmental and social factors in the experiences and outcomes of families in the child welfare system.

Even though attitudes were not found to influence decision outcomes in the current study, respondents' scores on the attitude scales indicated only moderate awareness of racial dynamics, average support for the economically disadvantaged, and very little support for single-parent families. This suggests that providing workers with more information on racism, poverty, and nontraditional family structures may be useful in increasing their understanding of the impact of these issues on families in the child welfare system. This could be accomplished through the incorporation of this material in existing diversity training. Johnson and colleagues (2009) found support for the use of an antiracism training to influence child welfare system professionals' attitudes about race and racism. A similar method could be employed regarding poverty and family structure.

The findings of this study highlight the importance of a family's prior CPS involvement in decision making among child protection professionals. It is understandable to use such information in assessing and making a decision regarding a family, especially since research (e.g., Sledjeski et al., 2008) and practice wisdom support CPS history as a predictor of future maltreatment. However, it may be helpful to consider the extent to which this information is used to make decisions about families' current needs. 
Finally, the present study found more tolerant attitudes toward the economically disadvantaged among professionals with a Bachelor's degree in Social Work (BSW) and more years of experience. Furthermore, respondents with more practice experience demonstrated greater levels of awareness of racial dynamics. These findings provide some support for employing trained social workers in child protection and retaining professionals with ample practice experience.

\section{Conclusion}

The goal of this study was to determine what factors influence professionals' decision making in child protection cases and how these factors impact decision outcomes. While the main variables of interest-the case characteristics of race, family structure, and socio-economic status-were found to have little to no influence on decision outcomes, there were some interesting findings. Based on the findings of this study, there is some support for SES as an influential factor in differential outcomes for children regarding intake decisions. As expected, internal parental attributions were higher for families in cases of removal. However, these internal attributions were also higher for two-parent and mid-SES families. Results also highlighted the role played by CPS history in decisions to screen in for investigation and remove the child from his home. Ultimately, more exploration of the issue of possible bias in decision making is needed, as this is a very complex issue that is even more compounded by the complexities of each professional's and each family's circumstances. 


\section{REFERENCES}

Anderson, D. (2000). Coping strategies and burnout among veteran child protection workers. Child Abuse \& Neglect, 24(6), 839-848.

Aosved, A. C., \& Long, P. J. (2006). Co-occurrence of rape myth acceptance, sexism, racism, homophobia, ageism, classism, and religious intolerance, Sex Roles, 55, 481-492

Asawa, L. E., Hansen, D. J., \& Flood, M. F. (2008). Early childhood intervention programs: Opportunities and challenges for preventing child maltreatment. Education and Treatment of Children, 31(1), 74-110.

Barbee, A. P. (1988). The effects of positive and negative moods on cheering up processes in close relationships: How can I help you when I'm feeling blue? University of Georgia. Dissertation.

Barth, R. (2005). Child welfare and race: Models of Disproportionality. In D. M. Derezotes, J. Poertner, \& M. F. Testa (Eds.). Race matters in child welfare: The overrepresentation of African American children in the system, pp. 25-46. Washington, DC: Child Welfare League of America.

Barth, R. P., Wildfire, J., \& Green, R. L. (2006). Placement Into foster care and the interplay of urbanicity, child behavior problems, and poverty. American Journal of Orthopsychiatry, 76(3), 358-366.

Berger, L. M. (2005). Income, family characteristics, and physical violence toward children. Child Abuse and Neglect, 29(2), 107-133. 
Berger, L. M. (2006). Children living out-of-home: Effects of family and environmental characteristics. Children and Youth Services Review, 28, $158-179$.

Berger, L. M., McDaniel, M., \& Paxon, C. (2006). How does race influence judgments about parenting? Focus, 24(2), 24-30.

Billingsley, A., \& Giovannoni, J. M. (1972). Children of the storm. New York: Harcourt Brace Jovanivich.

Britner, P. A., \& Mossler, D. G. (2002). Professionals' decision-making about outof-home placements following incidents of child abuse. Child Abuse and Neglect, 26, 317-332.

Bullock, H. E. (1995). Class acts: Middle-class responses to the poor. In B. Lott \& D. Maluso (Eds.), The Social Psychology of Interpersonal Discrimination (pp. 118-159). New York: The Guilford Press.

Carter, V., \& Meyers, M. R. (2007). Exploring the risks of substantiated physical neglect related to poverty and parental characteristics: A national sample. Children and Youth Services Review, 29, 110-121.

Center for the Study of Social Policy. (2004, March 16). Fact Sheet $2-$ Stateby-State Statistical Profile of Racial Over-Representation in Foster Care. Retrieved November 15, 2008 from http://www.cssp.org/uploadFiles/statORFactSheet2.pdf Child Welfare League of America. (2009). 2009 State Fact Sheets. Retrieved June 23, 2009 from http://www.cwla.org/advocacy/statefactsheets/statefactsheets09.htm 
Cohen, E. (2003). Framework for culturally competent decision making in child welfare. Child Welfare, 82(2), 143-155.

The Consultation Center of the Yale University School of Medicine. (April 2004). Rhode Island Data Analytic Center Research Brief \#2. Risk factors for the recurrence of substantiated abuse or neglect. Providence, Rl: Rhode Island Department of Children, Youth, \& Families. Retrieved June 23, 2009, from http://www.dcyf.state.ri.us/docs/reports/recurrence_substantiated_abuse.p df

Cook, C., Heath, F., \& Thompson, R. L. (2000). A meta-analysis of response rates in Web- or Internet-based surveys. Educational and Psychological Measurement, 60(6), 821-836.

Courtney, M. E., \& Barth, R. P. (1996). Race and child welfare services: Past research and future directions. Child Welfare, 75(2), pp. 99-137.

Daly, M. \& Wilson, M. I. (1994). Some differential attributes of lethal assaults on small children by stepfathers versus genetic fathers. Ethology and Sociobiology, 15, 207-217.

Derezotes, D. M. (2002). Examining child maltreatment and the impact of race in receipt of child welfare services in the United States. Champaign-Urbana, IL: Children and Family Research Center.

Derezotes, D. M., Poertner, J., \& Testa, M. F. (2005). Race matters in child welfare: The overrepresentation of African American children in the system. Washington, DC: Child Welfare League of America. 
Dill, K. (2007). Impact of stressors on front-line child welfare supervisors. The Clinical Supervisor, 26(1/2), 177-193

Dillman, D. A. (2000). Mail and Internet surveys: The Tailored Design Method ( $2^{\text {nd }}$ ed.). New York: John Wiley \& Sons, Inc.

Downs, S. W., Costin, L. B., \& McFadden, E. J. (1996). Child welfare and family services: Policies and practice. White Plains, NY: Longman.

Dufour, Lavergne, Larrivée, \& Trocmé. (2007). Who are these parents involved in child neglect? A differential analysis by parent gender and family structure. Children and Youth Services Review, 30, 141-156.

Elliott, K., \& Urquiza, A. (2006). Ethnicity, culture, and child maltreatment. Journal of Social Issues, 62(4), 787-809.

English, D. J., Marshall, D. B., Burmmel, S., \& Orme, M. (1999). Characteristics of repeated referrals to child protective services in Washington State. Child Maltreatment, 4(4), 297-308.

English, D. J., Marshall, D. B., Coghlan, L., Brummel, S., \& Orme, M. (2002). Causes and consequences of the substantiation decision in Washington State child protective services. Children and Youth Services Review, 24(11), 817-851.

Finch, J. (1987). The vignette technique in survey research. Sociology, 21(1),105-114.

Finn, J. (2006). An exploratory study of email use by direct service social workers. Journal of Technology in Human Services, 24(4), 1-20.

Fiske, S. T. (1998). Stereotyping, prejudice, and discrimination. In D. T. Gilbert, 
S. T. Fiske, \& G. Lindzey (Eds.), The Handbook of Social Psychology (pp. $357-414 ; 4^{\text {th }}$ ed.). Boston: McGraw-Hill.

Fluke, J. D., Shusterman, G., Hollinshead, D., Yuan, Y.T. (July 2005). Reporting and recurrence of child maltreatment: Findings from NCANDS.

Washington, DC: U.S. Department of Health and Human Services, Office of the Assistant Secretary for Planning and Evaluation. Retrieved June 22, 2009, from http://aspe.hhs.gov/hsp/05/child-maltreat-rereporting/

Forslund, M., Jergeby, U., Soydan, H., \& Williams C. (2002) Responding to ethnicity:A cross-national evaluation of social work responses in child protection cases. Social Work in Europe, 9(3), 1-13.

Galante, L. M. C. (1999). Subtle racism in child welfare decision making. University of Nebraska. Lincoln, Nebraska. Dissertation.

Gammon, R. (2000). Racial and socioeconomic bias in social workers' decisions regarding family reunification. California School of Professional Psychology at Alameda. Dissertation.

Garland, A. F., \& Besinger, B. A. (1997). Racial/ethnic difference in court referred pathways to mental health services for children in foster care. Children and Youth Services Review, 19(8), 651-666.

Garland, A. F., Hough, R. L., Landsverk, J. A., McCabe, K. M., Yeh, M., Ganger, W. C., \& Reynolds, B. J. (2000). Racial and ethnic variations in mental health care utilization among children in foster care. Children's Services: Social Policy, Research and Practice, 3(3), 133-146.

Gilbert, D. T. (1998). Ordinary personology. In D. T. Gilbert, S. T. Fiske, \& G. 
Lindzey (Eds.), The Handbook of Social Psychology (pp. 89-150; $4^{\text {th }}$ ed.). Boston: McGraw-Hill.

Gilbert, D. T., Pelham, B. W., \& Krull, D. S. (1988). On cognitive busyness: When person perceivers meet persons perceived. Journal of Personality and Social Psychology, 54, 733-740.

Gosling, S. D., Vazire, S., Srivastava, S., \& John, O. P. (2004).Should we trust Web-based studies? A comparative analysis of six preconceptions about Internet questionnaires. American Psychologist, 59(2), 93-104.

Green, R. G., Kiernan-Stern, M., \& Baskind, F. R. (2005). White social workers' attitudes about people of color. Journal of Ethnic \& Cultural Diversity in Social Work, 14(1/2), 47-68.

Gryzlak, B., Wells, S., \& Johnson, M. (2005). The role of race in child protective services screening decisions. In D. M. Derezotes, J. Poertner, \& M. F. Testa (Eds.). Race matters in child welfare: The overrepresentation of African American children in the system (pp.63-96). Washington, DC: Child Welfare League of America.

Hammond, K. R. (1996). Human judgment and social policy. New York: Oxford University Press.

Hansen, D. J., Bumby, K. M., Lundquist, L. M., Chandler, R. M., Le, P. T., and Futa, K. T. (1997). The influence of case and professional variables on the identification and reporting of child maltreatment: A study of licensed psychologists and certified masters social workers. Journal of Family Violence, 12(3), 313-332. 
Harris, M. S., \& Courtney, M. E. (2003). The interaction of, race, ethnicity, and family structure with respect to the timing of family reunification. Children and Youth Services Review, 25(5/6), 409-429.

Harris, M. S., \& Hackett, W. (2008). Decision points in child welfare: An action research model to address disproportionality. Children and Youth Services Review, 30, 199-215.

Heider, F. (1958). The psychology of interpersonal relations. New York: Wiley. Heineman Pieper, M. (1989). The heuristic paradigm: A unifying and comprehensive approach to social work research. Smith College Studies in Social Work, 60(1), 8-29.

Hewstone, M. (Ed.). (1983). Attribution theory: Social and functional extensions. Oxford: Basil Blackwell.

Hill, R. B. (2005). The role of race in foster care placements. In D. M. Derezotes, J. Poertner, \& M. F. Testa (Eds.). Race matters in child welfare: The overrepresentation of African American children in the system (pp.187200). Washington, DC: Child Welfare League of America.

Hill, R. B. (2006). Synthesis of research on disproportionality in child welfare: An update. Seattle, WA: Casey Family Programs.

Hines, A. M., Lemon, K., Wyatt, P., \& Merdinger, J. (2004). Factors related to the disproportionate involvement of children of color in the child welfare system: A review and emerging themes. Children and Youth Services Review, 26, 507-527.

Jenkins, S., \& Diamond, B. (1985). Ethnicity and foster care: Census data as 
predictors of placement variables. American Journal of Orthopsychiatry, $55,267-276$.

Johnson, L. M., Antle, B. F., \& Barbee, A. P. (2009). Addressing disproportionality and disparity in child welfare: Evaluation of an antiracism training for community service providers. Children and Youth Services Review, 31(6), 688-696.

Jones, E. E., \& Davis, K. E. (1965). From acts to dispositions: The attribution process in person perception. In L. Berkowitz Ed.), Adventures in experimental social psychology (Vol. 2, pp. 219-266). New York: Academic Press.

Karski, R. L. (1999). Key decisions in child protective services: report investigation and court referral. Children and Youth Services Review, 21(8), 643-656.

Kelley, H. H. (1967). Attribution theory in social psychology. In D. Levine (Ed.), Nebraska Symposium on Motivation (Vol. 15, pp. 192-238). Lincoln: University of Nebraska Press.

Korbin, J. E., Coulton, C. J., Chard, S., Platt-Houston, C., \& Su, M. (1998). Impoverishment and child maltreatment in African American and European American neighborhoods. Development and Psychopathology, $10,215-233$.

Landsman, M. J., \& Hartley, C. C. (2007). Attributing responsibility for child maltreatment whendomestic violence is present. Child Abuse \& Neglect, $31,445-461$. 
Lane, W. G., Rubin, D. M., Monteith, R., \& Christian, C. W. (2002). Racial differences in the evaluation of pediatric fractures for physical abuse. Journal of the American Medical Association, 288(13), 1603-1609.

Lazar, A. (2006). Determinants of child protection officers' decisions in emergency situations: An experimental study. Child Youth Care Forum, $35,263-276$.

Lindsey, D. (1992). Adequacy of income and the foster care placement decision: Using an odds ratio approach to examine client variables. Social Work Research \& Abstracts, 28(3).

Lu, Y. E., Landsverk, J., Ellis-Macleod, E., Newton, R., Ganger, W., \& Johnson, I. (2004). Race, ethnicity, and case outcomes in child protective services. Children and Youth Services Review, 26, 447-461.

McConnell, D., Llewellyn, G., \& Ferronato, L. (2006). Context-contingent decision-making in child protection practice. International Journal of Social Welfare, 15, 230-239.

McDaniel, M. (2006). In the eye of the beholder: The role of reporters in bringing families to the attention of child protective services. Children and Youth Services Review, 28, 306-324.

McRoy, R. (April 29, 2002). Color of child welfare policy: Racial disparities in child welfare services. Hunter College School of Social Work Child Welfare Lecture Series.

Morton, T. D. (1999). The increasing colorization of American's child welfare 
system: The overrepresentation of African American children. Policy \& Practice of Public Human Services, 57(4), 23-30.

Munro, E. (1999). Common errors of reasoning in child protection work. Child Abuse and Neglect, 23(8), 745-758.

Neville, H. A., Lilly, R. L., Duran, G., Lee, R. M., \& Browne, L. V. (2000).

Construction and initial validation of the Color-Blind Racial Attitudes Scale (CoBRAS). Journal of Counseling Psychology,47(1), 59-70.

The Nielsen Company. (2008). Television, internet, and mobile usage in the U.S.: A2/M2 three screen report. Third Quarter 2008.

Nobes, G., \& Smith, M. (2002). Family structure and the physical punishment of children. Journal of Family Issues, 23(3), 349-373.

Noble, C. L., Eby, L. T., Lockwood, A., \& Allen, T. D. (2004). Attitudes toward working single parents: Initial development of a measure. Educational and Psychological Measurement, 64(6), 1030-1052.

Oliver, W. J., Kuhns, L. R., \& Pomeranz, E. S. (2006). Family structure and child abuse. Clinical Pediatrics, 45, 111-118.

Orasanu, J., \& Connolly, T. (1993). The reinvention of decision making. In G. A. Klein, J. Orasanu, R. Calderwood, \& C. E. Zsambok (Eds.), Decision making in action: Models and methods (3-20). Norwood, NJ: Ablex.

Parada, H., Barnoff, L., \& Coleman, B. (2007). Negotiating 'professional agency': Social work and decision-making within the Ontario child welfare system. Journal of Sociology \& Social Welfare, 34(4), 35-56.

Payne, J. W., Bettman, J. R., \& Johnson, E. R. (1993). The adaptive decision 
maker. Cambridge, MA: Cambridge University Press.

Platt, D. (2006). Threshold decisions: How social workers prioritize referrals of child concern. Child Abuse Review 15, 4-18.

Poulter, J. (2006). The two embedded research functions of heuristic case practice. Australian Social Work, 59(3), 328-341.

Quattrone, G. A. (1982). Overattribution and unit formation: When behavior engulfs the person. Journal of Personality and Social Psychology, 42, 593607.

The Race Matters Consortium. (2005). Introduction. In D. M. Derezotes, J. Poertner, \& M. F. Testa (Eds.). Race matters in child welfare: The overrepresentation of African American children in the system (pp. v-vii). Washington, DC: Child Welfare League of America.

Regehr, C., Chau, S., Leslie, B., \& Howe, P. (2002). An exploration of supervisors' and managers' responses to child welfare reform. Administration in Social Work, 26(3), 17.

Rehner, T., Ishee, J., Salloum, M., \& Velasues, D. (1997). Mississippi social workers attitudes toward poverty and the poor. Journal of Social Work Education, 33(1).

Rivaux, S. L., James, J., Wittenstrom, K., Baumann, D., Sheets, J., Henry, J., \& Jeffries, V. (2008). The intersection of race, poverty, and risk: Understanding the decision to provide services to clients and to remove children. Child Welfare, 87(2), 151-168.

Roberts, D. (2002). Shattered bonds: The color of child welfare. New York: Basic 
Civitas Books.

Rodenborg, N. A. (2004). Services to African American children in poverty: Institutional discrimination in child welfare? Journal of Poverty, 8(3), 109130.

Rossi, P. H., Schuerman, J., \& Budde, S. (1999). Understanding decisions about child maltreatment. Evaluation Review, 23(6), 579-598.

Scannapieco, M., \& Carrick, K. C. (2003). Families in poverty: Those who maltreat their infants and toddlers and those who do not. Journal of Family Social Work, 7(3), 49-70.

Sedlak, A. J., \& Broadhurst, D. D. (1996). Executive Summary of the Third National Incidence Study of Child Abuse and Neglect. U.S. Department of Health and Human Services, Administration for Children and Families, Administration on Children, Youth and Families, National Center on Child Abuse and Neglect. Retrieved September 22, 2008 from, http://www.childwelfare.gov/pubs/statsinfo/nis3.cfm\#child

Silver, P. T., Poulin, J. E., \& Manning, R. C. (1997). Surviving the bureaucracy: The predictors of job satisfaction for the public agency supervisor. The Clinical Supervisor, 15(1), 1-20.

Simsek, Z. \& Veiga, J. F. (2001). A primer on internet organizational surveys. Organizational Research Methods, 4, 200-217.

Sledjeski, E.M., Dierker, L.C., Brigham, R., \& Breslin, E. (2008). The use of risk assessment to predict recurrent maltreatment: A classification and regression tree analysis (CART). Prevention Science, 9(1), 28-37. 
Smith, C. J., \& Devore, W. (2004). African American children in the child welfare and kinship system: from exclusion to over inclusion. Children and Youth Services Review, 26, 427-446.

Stevens, L. R. (1998). Decision making during investigation: Factors that influence child protection service workers. Rutgers University. Dissertation.

Stevenson, M. R., \& Medler, B. R. (1995). Is homophobia a weapon of sexism? Journal of Men's Studies, 4(1).

Tabachnick, B. G. \& Fidell, L. S. (2001). Using multivariate statistics ( $4^{\text {th }}$ ed.). Boston: Allyn \& Bacon.

Taylor, B. J. (2006). Factorial surveys: Using vignettes to study professional judgment. British Journal of Social Work, 36, 1187-1207.

Taylor, S. E. (1998). The social being in social psychology. In D. T. Gilbert, S. T. Fiske, \& G. Lindzey (Eds.), The Handbook of Social Psychology (pp. 5898; $4^{\text {th }}$ ed.). Boston: McGraw-Hill.

Trope, Y. (1986). Identification and inferential processes in dispositional attribution. Psychological Review, 93, 239-257.

Turner, H. A., Finkelhor, D., \& Ormrod, R. (2007). Family structure variations in patterns and predictors of child victimization. American Journal of Orthopsychiatry, 77(2), 282-295.

Tversky, A., \& Kahneman, D. (1974). Judgment under uncertainty: Heuristics and biases. Science, 185. 1124-1131.

United States Census Bureau. (August 2007). Income, poverty, and health 
insurance coverage in the United States: 2006. U.S. Department of Commerce, Economics and Statistics Administration. Retrieved February 25, 2008, from http://www.census.gov/prod/2007pubs/p60-233.pdf United States Census Bureau. (2008a). Table C3: Living Arrangements of Children Under 18 Years and Marital Status of Parents, by Age, Gender, Race, and Hispanic Origin of the Child for All Children: 2007. America's Families and Living Arrangements: 2007. Retrieved September 22, 2008 from, http://www.census.gov/population/www/socdemo/hhfam/cps2007.html

United States Census Bureau (2008b). Current Population Survey. Annual Social and Economic Supplement. FINC-03. Presence of Related Children Under 18 Years Old--All Families by Total Money Income in 2007, Type of Family, Work Experience in 2007, Race and Hispanic Origin of Reference Person. Retrieved September 22, 2008 from http://pubdb3.census.gov/macro/032008/faminc/new03_001.htm United States Department of Health and Human Services, Administration for Children and Families, Children's Bureau. (1997). National study of protective, preventive and reunification services delivered to children and their families (1994). Retrieved, February 2, 2009 from http://www.acf.hhs.gov/programs/cb/pubs/97natstudy/index.htm United States Department of Health and Human Services, Administration for Children and Families/Children's Bureau and Office of the Assistant Secretary for Planning and Evaluation. (2003). National study of child 
protective services systems and reform efforts: Review of state CPS policy. Washing, DC: U.S. Government Printing Office.

United States Department of Health and Human Services, Administration for Children and Families, Children's Bureau. (2006a). Table 2-7 Child Protective Services Workforce, 2006. Child Maltreatment 2006. Retrieved, November 22, 2008 from http://www.acf.hhs.gov/programs/cb/pubs/cm06/table2_7.htm

United States Department of Health and Human Services, Administration for Children and Families, Office of Planning, Research, and Evaluation. (2006b, September). National Survey of Child and Adolescent Well-Being (NSCAW): CPS Sample Component Wave 1 Data Analysis Report. Retrieved February 25, 2007, from http://www.acf.hhs.gov/programs/opre/abuse_neglect/nscaw/reports/cps_ sample/cps_toc.html (Retrieved September 22, 2008 from http://www.acf.hhs.gov/programs/opre/abuse_neglect/nscaw/reports/cps_ sample/cps_ch6.html)

US Department of Health and Human Services, Administration on Children, Youth, and Families, (2008a). Child maltreatment 2006. Washington, DC: US Government Printing Office.

US Department of Health and Human Services, Administration on Children, Youth, and Families. (2008b). The AFCARS report: Preliminary FY 2006 estimates as of January 2008 (14). Retrieved January 23, 2009, from 
http://www.acf.hhs.gov/programs/cb/stats_research/afcars/tar/report14.ht $\mathrm{m}$

United States Government Accountability Office. (2007). African American Children in Foster Care. (GAO-07-816)

United States Government Accountability Office. (2008). African American Children in Foster Care: HHS and Congressional Actions Could Help Reduce Proportion in Care. (GAO-08-1064T)

Waldfogel, J. (2005). Income and child maltreatment. Child Abuse and Neglect, 29(2), 101-102.

Williams, C., \& Soydan, H. (2005). When and how does ethnicity matter? A cross-national study of social work responses to ethnicity in child protection cases. British Journal of Social Work, 35, 901-920. 


\section{Appendix A: Professional Decision Making Survey Questionnaire and Preamble Consent}

PROFESSIONAL DECISION MAKING IN CHILD PROTECTIVE SERVICES

April 2008

Dear Child Protection Professional:

You are being invited to participate in a research study by responding to the attached anonymous survey about decision making in child protection. This study is being conducted by Bibhuti Sar, Ph.D. and Lisa Johnson, MSW, researchers at the University of Louisville, Kent School of Social Work. The purpose of this research is to find out more about how intake, investigation, and ongoing workers and supervisors make decisions in child protection cases. In this study you will be asked to complete an on-line survey. The information you provide will be used to inform best practices in child protection. The survey will take approximately 20 minutes to complete. Approximately 1500 protection and permanency workers and supervisors in three states will be invited to complete this survey. It is expected that around 400 individuals will complete the survey. Information will be collected through surveys for approximately eight weeks.

Taking part in this study is completely voluntary. You may choose not to take part at all. If you decide to be in this study, you may stop taking part at any time. If you decide not to be in this study or if you stop taking part at any time, this will involve no penalty, and will not reflect negatively on your employment evaluations or affect your employment status in any way. Furthermore, participating in the study will also have no bearing on your employment evaluations or status. There are no foreseeable risks for your participation in this study other than possible minor discomfort in answering some questions. The information collected may not benefit you directly; however, the information learned in this study may be helpful to others.

Information from your completed survey will be stored electronically on a password-protected survey website (PsychData.com) and downloaded to a password-protected computer at the University of Louisville, Kent School of Social Work. Individuals from the Kent School of Social Work, the Institutional Review Board (IRB), the Human Subjects Protection Program Office (HSPPO), and other regulatory agencies may inspect these records. In all other respects, however, the data will be held in confidence to the extent permitted by law. Although absolute anonymity and confidentiality cannot be guaranteed, the data will be kept under lock and key and will be protected to the full extent of the law. Should the data be published, your identity will not be disclosed. 
If you have any questions, concerns, or complaints about the research study, please contact Dr. Bibhuti K. Sar at (502) 852-3932 or b.k.sar@louisville.edu. You may also contact Lisa M. Johnson, MSW, at (502) 852-8009 or Imjohn15@louisville.edu.

If you have any questions about your rights as a research participant, you may call the University of Louisville Human Subjects Protection Program Office at (502) 852-5188. You can discuss any questions about your rights as a research subject, in private, with a member of the IRB. You may also call this number if you have other questions about the research, and you cannot reach the research staff, or want to talk to someone else. The IRB is an independent committee made up of people from the University community, staff of the institution, as well as people from the community not connected with this institution. The University IRB and your state IRB have reviewed this research study.

If you have concerns or complaints about the research or research staff and you do not wish to give your name, you may call 1-877-852-1167. This is a 24 hour hotline answered by people who do not work at the University of Louisville.

Sincerely,

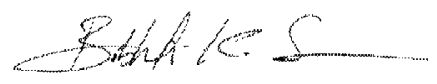

Bibhuti K. Sar, Ph.D.

Principal Investigator

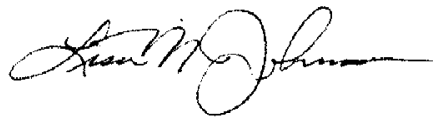

Lisa M. Johnson, MSW

Co-Investigator 


\section{PROFESSIONAL DECISION-MAKING IN CHILD PROTECTION}

This survey is designed to gather your views about how intake and investigation decisions are made.

To begin, please provide a brief description of your professional role by answering the following questions about your employment.

In what state are you located?

Please write in:

How would you describe the area in which you work?

$\square$ Urban (metropolitan area with a population of 50,000 or more)

$\square$ Rural (geographic area with a population of less than 50,000 )

What program area is your primary responsibility in your current position? If your position includes responsibilities in several areas, please check all that apply.

$\square$ Child Protection Intake/Screening

$\square$ Child Protection Investigations

$\square$ Child Protection Ongoing Casework (provision of in-home services)

$\square$ Other-Please specify:

What is your current position in your child welfare agency?

$\square$ Frontline/Direct Services Worker

$\square$ Supervisor

Other-Please specify:

How many years, to the nearest half year (e.g., 3.5), have you been employed in your current position at your agency?

Please write in:

How many years, to the nearest half year (e.g., 3.5), of professional child welfare practice experience do you have?

Please write in: 
Next, you will be presented with two brief hypothetical situations that are based on actual child welfare cases. Each situation contains two parts. Please read them carefully, as you will be asked to answer a brief set of questions after each one. Please answer all questions in terms of what you think you would do if you were making a decision regarding the situation described.

\section{Situation 1a}

You receive a child protection hotline report from Ms. Jones, a teacher at a local elementary school. She is calling to report the suspected maltreatment of 6-year-old Jamal, a student in her class. Ms. Jones reports that Jamal wet his pants today during lunch. As she was helping him change into another pair of pants, she noticed deep purple bruising on his buttocks and legs. When she asked Jamal how he got the bruises, Jamal only said that he got in trouble at home. Ms. Jones knows that Jamal lives with his mother and father in a public housing project. A case history search reveals that the family has had some past child protection involvement.

Based solely on this information, which of the following actions would you take?

Screen the report in and refer the case for investigation

Screen the report out and take no further action

Briefly describe how you came to the decision regarding the situation described above. In other words, what was the reasoning behind your decision? 
For the situation just presented, please rate your level of agreement with the following statements about the parents.

\begin{tabular}{|l|c|c|c|c|c|}
\hline & $\begin{array}{c}\text { Strongly } \\
\text { Disagree }\end{array}$ & & & & $\begin{array}{c}\text { Strongly } \\
\text { Agree }\end{array}$ \\
\hline $\begin{array}{l}\text { It is the parents' fault that the } \\
\text { family is in this situation. }\end{array}$ & 1 & 2 & 3 & 4 & 5 \\
\hline $\begin{array}{l}\text { The parents alone were } \\
\text { responsible for causing a } \\
\text { potentially negative situation. }\end{array}$ & 1 & 2 & 3 & 4 & 5 \\
\hline $\begin{array}{l}\text { Other factors, besides the } \\
\text { parents' actions, caused a } \\
\text { potentially negative situation. }\end{array}$ & 1 & 2 & 3 & 4 & 5 \\
\hline $\begin{array}{l}\text { The parents had control over } \\
\text { their behavior. }\end{array}$ & 1 & 2 & 3 & 4 & 5 \\
\hline $\begin{array}{l}\text { The parents' circumstances } \\
\text { were to blame for potential } \\
\text { risk to the child. }\end{array}$ & 1 & 2 & 3 & 4 & 5 \\
\hline $\begin{array}{l}\text { The parents' behavior } \\
\text { angered me. }\end{array}$ & 1 & 2 & 3 & 4 & 5 \\
\hline $\begin{array}{l}\text { This situation makes me feel } \\
\text { sympathetic toward the } \\
\text { parents. }\end{array}$ & 1 & 2 & 3 & 4 & 5 \\
\hline $\begin{array}{l}\text { The parents' situation makes } \\
\text { me feel distressed. }\end{array}$ & 1 & 2 & 3 & 4 & 5 \\
\hline
\end{tabular}

How important were the following issues in your decision making process for this particular situation?

\begin{tabular}{|c|c|c|c|c|c|}
\hline & $\begin{array}{l}\text { Not at all } \\
\text { important }\end{array}$ & & & & $\begin{array}{l}\text { Extremely } \\
\text { important }\end{array}$ \\
\hline $\begin{array}{l}\text { Parent risk factors (e.g., } \\
\text { substance abuse, mental } \\
\text { illness, limited cognitive } \\
\text { ability) }\end{array}$ & 1 & 2 & 3 & 4 & 5 \\
\hline Social supports available & 1 & 2 & 3 & 4 & 5 \\
\hline $\begin{array}{l}\text { Family history of CPS } \\
\text { involvement }\end{array}$ & 1 & 2 & 3 & 4 & 5 \\
\hline $\begin{array}{l}\text { Parents' compliance with past } \\
\text { services }\end{array}$ & 1 & 2 & 3 & 4 & 5 \\
\hline $\begin{array}{l}\text { Who is living in the home at } \\
\text { the time of the incident }\end{array}$ & 1 & 2 & 3 & 4 & 5 \\
\hline Family's financial situation & 1 & 2 & 3 & 4 & 5 \\
\hline Neighborhood safety/risks & 1 & 2 & 3 & 4 & 5 \\
\hline $\begin{array}{l}\text { Policy guidelines } \\
\text { (organizational, federal, state) }\end{array}$ & 1 & 2 & 3 & 4 & 5 \\
\hline
\end{tabular}




\begin{tabular}{|l|c|c|c|c|c|}
\hline Family's ethnic background & 1 & 2 & 3 & 4 & 5 \\
\hline $\begin{array}{l}\text { Quality of the parent/child } \\
\text { relationship }\end{array}$ & 1 & 2 & 3 & 4 & 5 \\
\hline
\end{tabular}




\section{Situation 1b}

An investigation of Jamal's situation reveals the following information: Jamal lives with his mother and father in a two-bedroom apartment in a public housing project. Both of Jamal's parents are employed part-time at a fast food restaurant. During an interview at school, Jamal disclosed that his mother hit him with a belt because he drew on the wall with crayons. The marks and bruises on Jamal's legs are consistent with his account of being hit with a belt. Jamal's mother denies hitting him. Jamal's father was not present during the alleged incident, but does not believe Jamal's story. The family has been the focus of three prior investigations: both parents denied hitting the child in first two; the mother admitted doing so in the third. Jamal's parents were then mandated to attend parenting classes and cooperate with periodic home visits. They both complied with these mandates.

\section{Based solely on this information, which of the following actions would you take?}

Remove the child from his home and place him in out-of-home care

$\square$ Set up in-home services for the child and family

Briefly describe how you came to the decision regarding the situation described above. In other words, what was the reasoning behind your decision? 
For the situation just presented, please rate your level of agreement with the following statements about the parents.

\begin{tabular}{|l|c|c|c|c|c|}
\hline & $\begin{array}{c}\text { Strongly } \\
\text { Disagree }\end{array}$ & & & & $\begin{array}{c}\text { Strongly } \\
\text { Agree }\end{array}$ \\
\hline $\begin{array}{l}\text { It is the parents' fault that the } \\
\text { family is in this situation. }\end{array}$ & 1 & 2 & 3 & 4 & 5 \\
\hline $\begin{array}{l}\text { The parents alone were } \\
\text { responsible for causing a } \\
\text { potentially negative situation. }\end{array}$ & 1 & 2 & 3 & 4 & 5 \\
\hline $\begin{array}{l}\text { Other factors, besides the } \\
\text { parents' actions, caused a } \\
\text { potentially negative situation. }\end{array}$ & 1 & 2 & 3 & 4 & 5 \\
\hline $\begin{array}{l}\text { The parents had control over } \\
\text { their behavior. }\end{array}$ & 1 & 2 & 3 & 4 & 5 \\
\hline $\begin{array}{l}\text { The parents' circumstances } \\
\text { were to blame for potential } \\
\text { risk to the child. }\end{array}$ & 1 & 2 & 3 & 4 & 5 \\
\hline $\begin{array}{l}\text { The parents' behavior } \\
\text { angered me. }\end{array}$ & 1 & 2 & 3 & 4 & 5 \\
\hline $\begin{array}{l}\text { This situation makes me feel } \\
\text { sympathetic toward the } \\
\text { parents. }\end{array}$ & 1 & 2 & 3 & 4 & 5 \\
\hline $\begin{array}{l}\text { The parents' situation makes } \\
\text { me feel distressed. }\end{array}$ & 1 & 2 & 3 & 4 & 5 \\
\hline
\end{tabular}

How important were the following issues in your decision making process for this particular situation?

\begin{tabular}{|l|c|c|c|c|c|}
\hline & $\begin{array}{c}\text { Not at all } \\
\text { important }\end{array}$ & & & & $\begin{array}{c}\text { Extremely } \\
\text { important }\end{array}$ \\
\hline $\begin{array}{l}\text { Parent risk factors (e.g., } \\
\text { substance abuse, mental } \\
\text { illness, limited cognitive } \\
\text { ability) }\end{array}$ & 1 & 2 & 3 & 4 & 5 \\
\hline Social supports available & 1 & 2 & 3 & 4 & 5 \\
\hline $\begin{array}{l}\text { Family history of CPS } \\
\text { involvement }\end{array}$ & 1 & 2 & 3 & 4 & 5 \\
\hline $\begin{array}{l}\text { Parents' compliance with past } \\
\text { services }\end{array}$ & 1 & 2 & 3 & 4 & 5 \\
\hline $\begin{array}{l}\text { Who is living in the home at } \\
\text { the time of the incident }\end{array}$ & 1 & 2 & 3 & 4 & 5 \\
\hline Family's financial situation & 1 & 2 & 3 & 4 & 5 \\
\hline Neighborhood safety/risks & 1 & 2 & 3 & 4 & 5 \\
\hline $\begin{array}{l}\text { Policy guidelines } \\
\text { (organizational, federal, state) }\end{array}$ & 1 & 2 & 3 & 4 & 5 \\
\hline
\end{tabular}




\begin{tabular}{|l|c|c|c|c|c|}
\hline Family's ethnic background & 1 & 2 & 3 & 4 & 5 \\
\hline $\begin{array}{l}\text { Quality of the parent/child } \\
\text { relationship }\end{array}$ & 1 & 2 & 3 & 4 & 5 \\
\hline
\end{tabular}




\section{Situation 2a}

You receive a child protection report regarding 7-year-old Dustin from a nurse who works in a pediatrician's office. The nurse states that Dustin's mother brought him to see the doctor because Dustin was complaining of wrist and arm pain. Dustin's mother reported that he hurt his arm when he fell off his bike. When asked about this, Dustin became sullen and refused to answer any questions. Preliminary assessment indicates that Dustin has a sprained wrist and bruised elbow. The nurse reported that according to Dustin's file, he lives with his mother who works as an accountant. The nurse remembers Dustin's mother once saying that the child's father lives in another state and doesn't see Dustin very often. A case history search shows that the family was involved with child protection on one occasion.

Based solely on this information, which of the following actions would you take?

Screen the report in and refer the case for investigation

Screen the report out and take no further action

Briefly describe how you came to the decision regarding the situation described above. In other words, what was the reasoning behind your decision? 
For the situation just presented, please rate your level of agreement with the following statements about the parent.

\begin{tabular}{|l|c|c|c|c|c|}
\hline & $\begin{array}{c}\text { Strongly } \\
\text { Disagree }\end{array}$ & & & & $\begin{array}{c}\text { Strongly } \\
\text { Agree }\end{array}$ \\
\hline $\begin{array}{l}\text { It is the parent's fault that the } \\
\text { family is in this situation. }\end{array}$ & 1 & 2 & 3 & 4 & 5 \\
\hline $\begin{array}{l}\text { The parent alone was } \\
\text { responsible for causing a } \\
\text { potentially negative situation. }\end{array}$ & 1 & 2 & 3 & 4 & 5 \\
\hline $\begin{array}{l}\text { Other factors, besides the } \\
\text { parent's actions, caused a } \\
\text { potentially negative situation. }\end{array}$ & 1 & 2 & 3 & 4 & 5 \\
\hline $\begin{array}{l}\text { The parent had control over } \\
\text { her behavior. }\end{array}$ & 1 & 2 & 3 & 4 & 5 \\
\hline $\begin{array}{l}\text { The parent's circumstances } \\
\text { were to blame for potential } \\
\text { risk to the child. }\end{array}$ & 1 & 2 & 3 & 4 & 5 \\
\hline $\begin{array}{l}\text { The parent's behavior } \\
\text { angered me. }\end{array}$ & 1 & 2 & 3 & 4 & 5 \\
\hline $\begin{array}{l}\text { This situation makes me feel } \\
\text { sympathetic toward the } \\
\text { parent. }\end{array}$ & 1 & 2 & 3 & 4 & 5 \\
\hline $\begin{array}{l}\text { The parent's situation makes } \\
\text { me feel distressed. }\end{array}$ & 1 & 2 & 3 & 4 & 5 \\
\hline
\end{tabular}

How important were the following issues in your decision making process for this particular situation?

\begin{tabular}{|c|c|c|c|c|c|}
\hline & $\begin{array}{l}\text { Not at all } \\
\text { important }\end{array}$ & & & & $\begin{array}{l}\text { Extremely } \\
\text { important }\end{array}$ \\
\hline $\begin{array}{l}\text { Parent risk factors (e.g., } \\
\text { substance abuse, mental } \\
\text { illness, limited cognitive } \\
\text { ability) }\end{array}$ & 1 & 2 & 3 & 4 & 5 \\
\hline Social supports available & 1 & 2 & 3 & 4 & 5 \\
\hline $\begin{array}{l}\text { Family history of CPS } \\
\text { involvement }\end{array}$ & 1 & 2 & 3 & 4 & 5 \\
\hline $\begin{array}{l}\text { Parent's compliance with past } \\
\text { services }\end{array}$ & 1 & 2 & 3 & 4 & 5 \\
\hline $\begin{array}{l}\text { Who is living in the home at } \\
\text { the time of the incident }\end{array}$ & 1 & 2 & 3 & 4 & 5 \\
\hline Family's financial situation & 1 & 2 & 3 & 4 & 5 \\
\hline Neighborhood safety/risks & 1 & 2 & 3 & 4 & 5 \\
\hline $\begin{array}{l}\text { Policy guidelines } \\
\text { (organizational, federal, state) }\end{array}$ & 1 & 2 & 3 & 4 & 5 \\
\hline
\end{tabular}




\begin{tabular}{|l|c|c|c|c|c|}
\hline Family's ethnic background & 1 & 2 & 3 & 4 & 5 \\
\hline $\begin{array}{l}\text { Quality of the parent/child } \\
\text { relationship }\end{array}$ & 1 & 2 & 3 & 4 & 5 \\
\hline
\end{tabular}




\section{Situation $\mathbf{2 b}$}

An investigation of Dustin's case yields the following information: Dustin and his mother live in a comfortable home in a middle-class neighborhood. During a private interview, Dustin discloses that he didn't get hurt by falling off of his bike. He says that his mother got mad and pushed him down. Dustin's mother reports that she sometimes spanks Dustin, but denies ever pushing him. The family's previous child protection involvement was due to an allegation that Dustin's mother left marks when she spanked Dustin with her hand. She complied with the investigation and treatment plan of parenting classes and individual counseling.

Based solely on this information, which of the following actions would you take?

Remove the child from his home and place him in out-of-home care

Set up in-home services for the child and family

Briefly describe how you came to the decision regarding the situation described above. In other words, what was the reasoning behind your decision? 
For the situation just presented, please rate your level of agreement with the following statements about the parent.

\begin{tabular}{|l|c|c|c|c|c|}
\hline & $\begin{array}{c}\text { Strongly } \\
\text { Disagree }\end{array}$ & & & & $\begin{array}{c}\text { Strongly } \\
\text { Agree }\end{array}$ \\
\hline $\begin{array}{l}\text { It is the parent's fault that the } \\
\text { family is in this situation. }\end{array}$ & 1 & 2 & 3 & 4 & 5 \\
\hline $\begin{array}{l}\text { The parent alone was } \\
\text { responsible for causing a } \\
\text { potentially negative situation. }\end{array}$ & 1 & 2 & 3 & 4 & 5 \\
\hline $\begin{array}{l}\text { Other factors, besides the } \\
\text { parent's actions, caused a } \\
\text { potentially negative situation. }\end{array}$ & 1 & 2 & 3 & 4 & 5 \\
\hline $\begin{array}{l}\text { The parent had control over } \\
\text { her behavior. }\end{array}$ & 1 & 2 & 3 & 4 & 5 \\
\hline $\begin{array}{l}\text { The parent's circumstances } \\
\text { were to blame for potential } \\
\text { risk to the child. }\end{array}$ & 1 & 2 & 3 & 4 & 5 \\
\hline $\begin{array}{l}\text { The parent's behavior } \\
\text { angered me. }\end{array}$ & 1 & 2 & 3 & 4 & 5 \\
\hline $\begin{array}{l}\text { This situation makes me feel } \\
\text { sympathetic toward the } \\
\text { parent. }\end{array}$ & 1 & 2 & 3 & 4 & 5 \\
\hline $\begin{array}{l}\text { The parent's situation makes } \\
\text { me feel distressed. }\end{array}$ & 1 & 2 & 3 & 4 & 5 \\
\hline
\end{tabular}

How important were the following issues in your decision making process for this particular situation?

\begin{tabular}{|c|c|c|c|c|c|}
\hline & $\begin{array}{l}\text { Not at all } \\
\text { important }\end{array}$ & & & & $\begin{array}{l}\text { Extremely } \\
\text { important }\end{array}$ \\
\hline $\begin{array}{l}\text { Parent risk factors (e.g., } \\
\text { substance abuse, mental } \\
\text { illness, limited cognitive } \\
\text { ability) }\end{array}$ & 1 & 2 & 3 & 4 & 5 \\
\hline Social supports available & 1 & 2 & 3 & 4 & 5 \\
\hline $\begin{array}{l}\text { Family history of CPS } \\
\text { involvement }\end{array}$ & 1 & 2 & 3 & 4 & 5 \\
\hline $\begin{array}{l}\text { Parent's compliance with past } \\
\text { services }\end{array}$ & 1 & 2 & 3 & 4 & 5 \\
\hline $\begin{array}{l}\text { Who is living in the home at } \\
\text { the time of the incident }\end{array}$ & 1 & 2 & 3 & 4 & 5 \\
\hline Family's financial situation & 1 & 2 & 3 & 4 & 5 \\
\hline Neighborhood safety/risks & 1 & 2 & 3 & 4 & 5 \\
\hline $\begin{array}{l}\text { Policy guidelines } \\
\text { (organizational, federal, state) }\end{array}$ & 1 & 2 & 3 & 4 & 5 \\
\hline
\end{tabular}




\begin{tabular}{|l|c|c|c|c|c|}
\hline Family's ethnic background & 1 & 2 & 3 & 4 & 5 \\
\hline $\begin{array}{l}\text { Quality of the parent/child } \\
\text { relationship }\end{array}$ & 1 & 2 & 3 & 4 & 5 \\
\hline
\end{tabular}


You will now be asked to respond to a list of statements about your attitudes toward social conditions that may be relevant to child protection cases. Please check the appropriate box for each item to indicate your level of agreement with the statement.

\begin{tabular}{|c|c|c|c|c|c|c|}
\hline & $\begin{array}{l}\text { Strongly } \\
\text { Disagree }\end{array}$ & $\begin{array}{c}\text { Moderately } \\
\text { Disagree }\end{array}$ & $\begin{array}{c}\text { Mildly } \\
\text { Disagree }\end{array}$ & $\begin{array}{l}\text { Mildly } \\
\text { Agree }\end{array}$ & $\begin{array}{c}\text { Moderately } \\
\text { Agree }\end{array}$ & $\begin{array}{c}\text { Strongly } \\
\text { Agree }\end{array}$ \\
\hline $\begin{array}{l}\text { Everyone who works } \\
\text { hard, no matter what } \\
\text { race they are, has an } \\
\text { equal chance to become } \\
\text { rich. }\end{array}$ & 1 & 2 & 3 & 4 & 5 & 6 \\
\hline $\begin{array}{l}\text { Race plays a major role } \\
\text { in the type of social } \\
\text { services (such as type of } \\
\text { health care or day care) } \\
\text { that people receive in } \\
\text { the U.S. }\end{array}$ & 1 & 2 & 3 & 4 & 5 & 6 \\
\hline $\begin{array}{l}\text { Too many of my tax } \\
\text { dollars are spent to take } \\
\text { care of those who are } \\
\text { unwilling to take care of } \\
\text { themselves. }\end{array}$ & 1 & 2 & 3 & 4 & 5 & 6 \\
\hline $\begin{array}{l}\text { If every individual would } \\
\text { carry his/her own } \\
\text { weight, there would be } \\
\text { no poverty. }\end{array}$ & 1 & 2 & 3 & 4 & 5 & 6 \\
\hline $\begin{array}{l}\text { There are more poor } \\
\text { people than wealthy } \\
\text { people in prisons } \\
\text { because poor people } \\
\text { commit more crimes. }\end{array}$ & 1 & 2 & 3 & 4 & 5 & 6 \\
\hline $\begin{array}{l}\text { A child is more likely to } \\
\text { struggle in life if raised } \\
\text { by a single parent. }\end{array}$ & 1 & 2 & 3 & 4 & 5 & 6 \\
\hline $\begin{array}{l}\text { It is important that } \\
\text { people begin to think of } \\
\text { themselves as American } \\
\text { and not African } \\
\text { American, Mexican } \\
\text { American, or Italian } \\
\text { American. }\end{array}$ & 1 & 2 & 3 & 4 & 5 & 6 \\
\hline $\begin{array}{l}\text { English should be the } \\
\text { only official language in } \\
\text { the U.S. }\end{array}$ & 1 & 2 & 3 & 4 & 5 & 6 \\
\hline
\end{tabular}




\begin{tabular}{|c|c|c|c|c|c|c|}
\hline & $\begin{array}{l}\text { Strongly } \\
\text { Disagree }\end{array}$ & $\begin{array}{l}\text { Moderately } \\
\text { Disagree }\end{array}$ & $\begin{array}{c}\text { Mildly } \\
\text { Disagree }\end{array}$ & $\begin{array}{l}\text { Mildly } \\
\text { Agree }\end{array}$ & $\begin{array}{c}\text { Moderately } \\
\text { Agree }\end{array}$ & $\begin{array}{c}\text { Strongly } \\
\text { Agree }\end{array}$ \\
\hline $\begin{array}{l}\text { White people are more } \\
\text { to blame for racial } \\
\text { discrimination than racial } \\
\text { and ethnic minorities. }\end{array}$ & 1 & 2 & 3 & 4 & 5 & 6 \\
\hline $\begin{array}{l}\text { Single-parent families } \\
\text { are as capable of } \\
\text { providing for children's } \\
\text { wellbeing as two-parent } \\
\text { families. }\end{array}$ & 1 & 2 & 3 & 4 & 5 & 6 \\
\hline $\begin{array}{l}\text { Homeless people should } \\
\text { get their acts together } \\
\text { and become productive } \\
\text { members of society. }\end{array}$ & 1 & 2 & 3 & 4 & 5 & 6 \\
\hline Poor people are lazy. & 1 & 2 & 3 & 4 & 5 & 6 \\
\hline $\begin{array}{l}\text { Racism may have been a } \\
\text { problem in the past, but } \\
\text { it is not an important } \\
\text { problem today. }\end{array}$ & 1 & 2 & 3 & 4 & 5 & 6 \\
\hline $\begin{array}{l}\text { Racial and ethnic } \\
\text { minorities do not have } \\
\text { the same opportunities } \\
\text { as White people in the } \\
\text { U.S. }\end{array}$ & 1 & 2 & 3 & 4 & 5 & 6 \\
\hline $\begin{array}{l}\text { White people in the U.S. } \\
\text { are discriminated against } \\
\text { because of the color of } \\
\text { their skin. }\end{array}$ & 1 & 2 & 3 & 4 & 5 & 6 \\
\hline $\begin{array}{l}\text { It is important for public } \\
\text { schools to teach about } \\
\text { the history and } \\
\text { contributions of racial } \\
\text { and ethnic minorities. }\end{array}$ & 1 & 2 & 3 & 4 & 5 & 6 \\
\hline $\begin{array}{l}\text { Equal educational } \\
\text { opportunities exist for all } \\
\text { people in our society. }\end{array}$ & 1 & 2 & 3 & 4 & 5 & 6 \\
\hline $\begin{array}{l}\text { Most poor people should } \\
\text { not have children until } \\
\text { they can afford to take } \\
\text { care of them. }\end{array}$ & 1 & 2 & 3 & 4 & 5 & 6 \\
\hline
\end{tabular}




\begin{tabular}{|c|c|c|c|c|c|c|}
\hline & $\begin{array}{l}\text { Strongly } \\
\text { Disagree }\end{array}$ & $\begin{array}{c}\text { Moderately } \\
\text { Disagree }\end{array}$ & $\begin{array}{c}\text { Mildly } \\
\text { Disagree }\end{array}$ & $\begin{array}{l}\text { Mildly } \\
\text { Agree }\end{array}$ & $\begin{array}{c}\text { Moderately } \\
\text { Agree }\end{array}$ & $\begin{array}{c}\text { Strongly } \\
\text { Agree }\end{array}$ \\
\hline $\begin{array}{l}\text { Most poor people are in } \\
\text { debt because they can't } \\
\text { manage their money. }\end{array}$ & 1 & 2 & 3 & 4 & 5 & 6 \\
\hline $\begin{array}{l}\text { It is almost impossible } \\
\text { for a single, working } \\
\text { parent to raise a child as } \\
\text { effectively as two } \\
\text { parents. }\end{array}$ & 1 & 2 & 3 & 4 & 5 & 6 \\
\hline $\begin{array}{l}\text { Talking about racial } \\
\text { issues causes } \\
\text { unnecessary tensions. }\end{array}$ & 1 & 2 & 3 & 4 & 5 & 6 \\
\hline $\begin{array}{l}\text { It is important for } \\
\text { political leaders to talk } \\
\text { about racism to help } \\
\text { work through or solve } \\
\text { society's problems. }\end{array}$ & 1 & 2 & 3 & 4 & 5 & 6 \\
\hline $\begin{array}{l}\text { White people in the U.S. } \\
\text { have certain advantages } \\
\text { because of the color of } \\
\text { their skin. }\end{array}$ & 1 & 2 & 3 & 4 & 5 & 6 \\
\hline $\begin{array}{l}\text { Racial problems in the } \\
\text { U.S. are rare, isolated } \\
\text { situations. }\end{array}$ & 1 & 2 & 3 & 4 & 5 & 6 \\
\hline $\begin{array}{l}\text { Race plays an important } \\
\text { role in who gets sent to } \\
\text { prison. }\end{array}$ & 1 & 2 & 3 & 4 & 5 & 6 \\
\hline $\begin{array}{l}\text { People who stay on } \\
\text { welfare have no desire to } \\
\text { work. }\end{array}$ & 1 & 2 & 3 & 4 & 5 & 6 \\
\hline $\begin{array}{l}\text { Welfare keeps the nation } \\
\text { in debt. }\end{array}$ & 1 & 2 & 3 & 4 & 5 & 6 \\
\hline $\begin{array}{l}\text { People who don't make } \\
\text { much money are } \\
\text { generally unmotivated. }\end{array}$ & 1 & 2 & 3 & 4 & 5 & 6 \\
\hline $\begin{array}{l}\text { Racism is a major } \\
\text { problem in the U.S. }\end{array}$ & 1 & 2 & 3 & 4 & 5 & 6 \\
\hline $\begin{array}{l}\text { If given the chance, a } \\
\text { poor person would be } \\
\text { able to keep a job. }\end{array}$ & 1 & 2 & 3 & 4 & 5 & 6 \\
\hline
\end{tabular}




\begin{tabular}{|c|c|c|c|c|c|c|}
\hline & $\begin{array}{l}\text { Strongly } \\
\text { Disagree }\end{array}$ & $\begin{array}{l}\text { Moderately } \\
\text { Disagree }\end{array}$ & $\begin{array}{c}\text { Mildly } \\
\text { Disagree }\end{array}$ & $\begin{array}{l}\text { Mildly } \\
\text { Agree }\end{array}$ & $\begin{array}{c}\text { Moderately } \\
\text { Agree }\end{array}$ & $\begin{array}{c}\text { Strongly } \\
\text { Agree }\end{array}$ \\
\hline $\begin{array}{l}\text { People who live in } \\
\text { poverty could benefit } \\
\text { from educational } \\
\text { opportunities. }\end{array}$ & 1 & 2 & 3 & 4 & 5 & 6 \\
\hline $\begin{array}{l}\text { Due to racial } \\
\text { discrimination, programs } \\
\text { such as affirmative } \\
\text { action are necessary to } \\
\text { help create equality. }\end{array}$ & 1 & 2 & 3 & 4 & 5 & 6 \\
\hline $\begin{array}{l}\text { Race is very important in } \\
\text { determining who is } \\
\text { successful and who is } \\
\text { not. }\end{array}$ & 1 & 2 & 3 & 4 & 5 & 6 \\
\hline $\begin{array}{l}\text { Immigrants should try to } \\
\text { fit into the culture and } \\
\text { values of the U.S. }\end{array}$ & 1 & 2 & 3 & 4 & 5 & 6 \\
\hline $\begin{array}{l}\text { Most poor people aren't } \\
\text { very smart. }\end{array}$ & 1 & 2 & 3 & 4 & 5 & 6 \\
\hline $\begin{array}{l}\text { Single parents and their } \\
\text { children develop closer } \\
\text { relationships than } \\
\text { children with two } \\
\text { parents. }\end{array}$ & 1 & 2 & 3 & 4 & 5 & 6 \\
\hline $\begin{array}{l}\text { To be well adjusted, a } \\
\text { child needs two parents } \\
\text { (a mom and a dad) who } \\
\text { both live at home. }\end{array}$ & 1 & 2 & 3 & 4 & 5 & 6 \\
\hline $\begin{array}{l}\text { Social policies, such as } \\
\text { affirmative action, } \\
\text { discriminate unfairly } \\
\text { against White people. }\end{array}$ & 1 & 2 & 3 & 4 & 5 & 6 \\
\hline $\begin{array}{l}\text { Racial and ethnic } \\
\text { minorities in the U.S. } \\
\text { have certain advantages } \\
\text { because of the color of } \\
\text { their skin. }\end{array}$ & 1 & 2 & 3 & 4 & 5 & 6 \\
\hline
\end{tabular}


Please respond to the following demographic questions.

What is your gender?

$\square$ Female

$\square$ Male

$\square$ Other (please specify):

What is your age?

Please write in:

Do you self-identify as Latino/Hispanic?

$\square$ Yes

$\square$ No

What is your self-identified race/ethnicity?

$\square$ Black/African American

$\square$ Caucasian

$\square$ Asian

Native American

Biracial/Multiracial

Other (please specify):

What is the highest level (and type) of education you have completed?

$\square$ High School Diploma / GED

Professional Certification

Associate's Degree

Bachelor's Degree in Social Work (BSW)

$\square$ Bachelor's Degree in another field

$\square$ Master's Degree in Social Work (MSW)

$\square$ Master's Degree in another field

$\square$ Doctoral Degree

$\square$ Other-Please specify: 
Finally, please take a few more moments to respond to questions about your work environment.

In your opinion, how much emphasis does your agency place on promoting culturally competent practice?

\begin{tabular}{|c|c|c|c|c|c|c|}
\hline $\begin{array}{c}\text { Very little } \\
\text { emphasis }\end{array}$ & & & & & & $\begin{array}{c}\text { A lot of } \\
\text { emphasis }\end{array}$ \\
\hline 1 & 2 & 3 & 4 & 5 & 6 & 7 \\
\hline
\end{tabular}

Based on your best estimate, please write in the percentages of children currently on your caseload by race/ethnicity. (The numbers should add up to 100. .)

Hispanic/Latino of any race:

Black or African American:

Caucasian:

Asian/Pacific Islander:

Native American:

Biracial/Multiracial:

Other:

As of today, what is your caseload (number of FAMILIES you are serving)?

Please write in:

On average, how much work-related stress have you experienced in the past month?

\begin{tabular}{|c|c|c|c|c|c|c|}
\hline No stress & & & & & & $\begin{array}{c}\text { Extreme } \\
\text { stress }\end{array}$ \\
\hline 1 & 2 & 3 & 4 & 5 & 6 & 7 \\
\hline
\end{tabular}

You may write any other comments you have in the space below.

Thank you for completing this survey. 


\title{
Appendix B: Vignettes Randomly Assigned in Survey
}

\section{Situation1: Jamal/Garth}

\section{1: Black/low-SES/two-parent}

\author{
Situation 1a
}

You receive a child protection hotline report from Ms. Jones, a teacher at a local elementary school. She is calling to report the suspected maltreatment of 6 -yearold Jamal, a student in her class. Ms. Jones reports that Jamal wet his pants today during lunch. As she was helping him change into another pair of pants, she noticed deep purple bruising on his buttocks and legs. When she asked Jamal how he got the bruises, Jamal only said that he got in trouble at home. Ms. Jones knows that Jamal lives with his mother and father in a public housing project. A case history search reveals that the family has had some past child protection involvement.

Situation $1 b$

An investigation of Jamal's situation reveals the following information: Jamal lives with his mother and father in a two-bedroom apartment in a public housing project. Both of Jamal's parents are employed part-time at a fast food restaurant. During an interview at school, Jamal disclosed that his mother hit him with a belt because he drew on the wall with crayons. The marks and bruises on Jamal's legs are consistent with his account of being hit with a belt. Jamal's mother denies hitting him. Jamal's father was not present during the alleged incident, but does not believe Jamal's story. The family has been the focus of three prior investigations: both parents denied hitting the child in first two; the mother admitted doing so in the third. Jamal's parents were then mandated to attend parenting classes and cooperate with periodic home visits. They both complied with these mandates.

\section{2: Black/low-SES/single parent}

\section{Situation 1a}

You receive a child protection hotline report from Ms. Jones, a teacher at a local elementary school. She is calling to report the suspected maltreatment of 6-yearold Jamal, a student in her class. Ms. Jones reports that Jamal wet his pants today during lunch. As she was helping him change into another pair of pants, she noticed deep purple bruising on his buttocks and legs. When she asked Jamal how he got the bruises, Jamal only said that he got in trouble at home. Ms. 
Jones knows that Jamal lives with his mother only in a public housing project. A case history search reveals that the family has had some past child protection involvement.

\section{Situation 1b}

An investigation of Jamal's situation reveals the following information: Jamal lives with his mother in a two-bedroom apartment in a public housing project. His father is estranged and has not been present since Jamal was 3 years old. Jamal's mother is employed part-time at a fast food restaurant. During an interview at school, Jamal disclosed that his mother hit him with a belt because he drew on the wall with crayons. The marks and bruises on Jamal's legs are consistent with his account of being hit with a belt. Jamal's mother denies hitting him. The family has been the focus of three prior investigations: Jamal's mother denied hitting the child in first two, but admitted doing so in the third. Jamal's mother was then mandated to attend parenting classes and cooperate with periodic home visits. She complied with these mandates.

\section{3: Black/mid-SES/two-parent}

\section{Situation 1a}

You receive a child protection hotline report from Ms. Jones, a teacher at a local elementary school. She is calling to report the suspected maltreatment of 6 -yearold Jamal, a student in her class. Ms. Jones reports that Jamal wet his pants today during lunch. As she was helping him change into another pair of pants, she noticed deep purple bruising on his buttocks and legs. When she asked Jamal how he got the bruises, Jamal only said that he got in trouble at home. Ms. Jones knows that Jamal lives with his mother and father and that the parents are employed as an occupational therapist and grocery store manager, respectively. A case history search reveals that the family has had some past child protection involvement.

\section{Situation $1 b$}

An investigation of Jamal's situation reveals the following information: Jamal lives with his mother and father in a three-bedroom house in a middle-class neighborhood just outside of town. Jamal's mother is employed as an occupational therapist and his father is the manager of a local grocery store. During an interview at school, Jamal disclosed that his mother hit him with a belt because he drew on the wall with crayons. The marks and bruises on Jamal's legs are consistent with his account of being hit with a belt. Jamal's mother denies hitting him. Jamal's father was not present during the alleged incident, but does not believe Jamal's story. The family has been the focus of three prior investigations: both parents denied hitting the child in first two; the mother admitted doing so in the third. Jamal's parents were then mandated to attend 
parenting classes and cooperate with periodic home visits. They both complied with these mandates.

\section{4: Black/mid-SES/single parent}

\section{Situation 1a}

You receive a child protection hotline report from Ms. Jones, a teacher at a local elementary school. She is calling to report the suspected maltreatment of 6-yearold Jamal, a student in her class. Ms. Jones reports that Jamal wet his pants today during lunch. As she was helping him change into another pair of pants, she noticed deep purple bruising on his buttocks and legs. When she asked Jamal how he got the bruises, Jamal only said that he got in trouble at home. Ms. Jones knows that Jamal lives with his mother only and she works as a dental hygienist. A case history search reveals that the family has had some past child protection involvement.

\section{Situation $1 b$}

An investigation of Jamal's situation reveals the following information: Jamal lives with his mother in a three-bedroom house in a middle-class neighborhood just outside of town. His father is estranged and has not been present since Jamal was 3 years old. Jamal's mother is employed as a dental hygienist. During an interview at school, Jamal disclosed that his mother hit him with a belt because he drew on the wall with crayons. The marks and bruises on Jamal's legs are consistent with his account of being hit with a belt. Jamal's mother denies hitting him. The family has been the focus of three prior investigations: Jamal's mother denied hitting the child in first two, but admitted doing so in the third. Jamal's mother was then mandated to attend parenting classes and cooperate with periodic home visits. She complied with these mandates.

\section{5: White/low-SES/two-parent}

Situation 1a

You receive a child protection hotline report from Ms. Jones, a teacher at a local elementary school. She is calling to report the suspected maltreatment of 6-yearold Garth, a student in her class. Ms. Jones reports that Garth wet his pants today during lunch. As she was helping him change into another pair of pants, she noticed deep purple bruising on his buttocks and legs. When she asked Garth how he got the bruises, Garth only said that he got in trouble at home. Ms. Jones knows that Garth lives with his mother and father in a public housing project. A case history search reveals that the family has had some past child protection involvement. 
An investigation of Garth's situation reveals the following information: Garth lives with his mother and father in a two-bedroom apartment in a public housing project. Both of Garth's parents are employed part-time at a fast food restaurant. During an interview at school, Garth disclosed that his mother hit him with a belt because he drew on the wall with crayons. The marks and bruises on Garth's legs are consistent with his account of being hit with a belt. Garth's mother denies hitting him. Garth's father was not present during the alleged incident, but does not believe Garth's story. The family has been the focus of three prior investigations: both parents denied hitting the child in first two; the mother admitted doing so in the third. Garth's parents were then mandated to attend parenting classes and cooperate with periodic home visits. They both complied with these mandates.

\section{6: White/low-SES/single parent}

\section{Situation 1a}

You receive a child protection hotline report from Ms. Jones, a teacher at a local elementary school. She is calling to report the suspected maltreatment of 6-yearold Garth, a student in her class. Ms. Jones reports that Garth wet his pants today during lunch. As she was helping him change into another pair of pants, she noticed deep purple bruising on his buttocks and legs. When she asked Garth how he got the bruises, Garth only said that he got in trouble at home. Ms. Jones knows that Garth lives with his mother only in a public housing project. A case history search reveals that the family has had some past child protection involvement.

\section{Situation $1 b$}

An investigation of Garth's situation reveals the following information: Garth lives with his mother in a two-bedroom apartment in a public housing project. His father is estranged and has not been present since Garth was 3 years old. Garth's mother is employed part-time at a fast food restaurant. During an interview at school, Garth disclosed that his mother hit him with a belt because he drew on the wall with crayons. The marks and bruises on Garth's legs are consistent with his account of being hit with a belt. Garth's mother denies hitting him. The family has been the focus of three prior investigations: Garth's mother denied hitting the child in first two, but admitted doing so in the third. Garth's mother was then mandated to attend parenting classes and cooperate with periodic home visits. She complied with these mandates. 


\section{7: White/mid-SES/two-parent}

Situation 1a

You receive a child protection hotline report from Ms. Jones, a teacher at a local elementary school. She is calling to report the suspected maltreatment of 6-yearold Garth, a student in her class. Ms. Jones reports that Garth wet his pants today during lunch. As she was helping him change into another pair of pants, she noticed deep purple bruising on his buttocks and legs. When she asked Garth how he got the bruises, Garth only said that he got in trouble at home. Ms. Jones knows that Garth lives with his mother and father and that the parents are employed as an occupational therapist and grocery store manager, respectively. A case history search reveals that the family has had some past child protection involvement.

\section{Situation $1 b$}

An investigation of Garth's situation reveals the following information: Garth lives with his mother and father in a three-bedroom house in a middle-class neighborhood just outside of town. Garth's mother is employed as an occupational therapist and his father is the manager of a local grocery store. During an interview at school, Garth disclosed that his mother hit him with a belt because he drew on the wall with crayons. The marks and bruises on Garth's legs are consistent with his account of being hit with a belt. Garth's mother denies hitting him. Garth's father was not present during the alleged incident, but does not believe Garth's story. The family has been the focus of three prior investigations: both parents denied hitting the child in first two; the mother admitted doing so in the third. Garth's parents were then mandated to attend parenting classes and cooperate with periodic home visits. They both complied with these mandates.

\section{8: White/mid-SES/single parent}

\section{Situation 1a}

You receive a child protection hotline report from Ms. Jones, a teacher at a local elementary school. She is calling to report the suspected maltreatment of 6-yearold Garth, a student in her class. Ms. Jones reports that Garth wet his pants today during lunch. As she was helping him change into another pair of pants, she noticed deep purple bruising on his buttocks and legs. When she asked Garth how he got the bruises, Garth only said that he got in trouble at home. Ms. Jones knows that Garth lives with his mother only and she works as an occupational therapist. A case history search reveals that the family has had some past child protection involvement.

Situation $1 b$ 
An investigation of Garth's situation reveals the following information: Garth lives with his mother in a three-bedroom house in a middle-class neighborhood just outside of town. His father is estranged and has not been present since Garth was 3 years old. Garth's mother is employed as an occupational therapist. During an interview at school, Garth disclosed that his mother hit him with a belt because he drew on the wall with crayons. The marks and bruises on Garth's legs are consistent with his account of being hit with a belt. Garth's mother denies hitting him. The family has been the focus of three prior investigations: Garth's mother denied hitting the child in first two, but admitted doing so in the third. Garth's mother was then mandated to attend parenting classes and cooperate with periodic home visits. She complied with these mandates.

\section{Situation 2: Tyrone/Dustin}

\section{1: Black/low-SES/two-parent}

\section{Situation 2a}

You receive a child protection report regarding 7-year-old Tyrone from a nurse who works in a pediatrician's office. The nurse states that Tyrone's mother brought him to see the doctor because Tyrone was complaining of wrist and arm pain. Tyrone's mother reported that he hurt his arm when he fell off his bike. When asked about this, Tyrone became sullen and refused to answer any questions. Preliminary assessment indicates that Tyrone has a sprained wrist and bruised elbow. The nurse reported that according to Tyrone's file, he lives with his mother and father. A case history search shows that the family was involved with child protection on one occasion. At the time, Tyrone and his parents were living in a homeless shelter.

\section{Situation $2 b$}

An investigation of Tyrone's case yields the following information: Tyrone and his parents no longer reside at the homeless shelter and have been living in public housing for a year. Tyrone's mother works part-time as a clerk at a convenience store. His father works as a day laborer. During a private interview, Tyrone discloses that he didn't get hurt by falling off of his bike. He says that his mother got mad and pushed him down. Tyrone's mother reports that she sometimes spanks Tyrone, but denies ever pushing him. Tyrone's father also denies that he or the mother pushed Tyrone. The family's previous child protection involvement was due to an allegation that Tyrone's mother left marks when she spanked Tyrone with her hand. She complied with the investigation and treatment plan of parenting classes and individual counseling. 


\section{2: Black/low-SES/single parent}

\section{Situation $2 a$}

You receive a child protection report regarding 7-year-old Tyrone from a nurse who works in a pediatrician's office. The nurse states that Tyrone's mother brought him to see the doctor because Tyrone was complaining of wrist and arm pain. Tyrone's mother reported that he hurt his arm when he fell off his bike. When asked about this, Tyrone became sullen and refused to answer any questions. Preliminary assessment indicates that Tyrone has a sprained wrist and bruised elbow. The nurse reported that according to Tyrone's file, he lives with his mother. The nurse remembers Tyrone's mother once saying that the child's father lives in another state and doesn't see Tyrone very often. A case history search shows that the family was involved with child protection on one occasion. At the time, Tyrone and his mother were living in a homeless shelter.

Situation $2 b$

An investigation of Tyrone's case yields the following information: Tyrone and his mother no longer reside at the homeless shelter and have been living in public housing for a year. Tyrone's mother works part-time as a clerk at a convenience store. During a private interview, Tyrone discloses that he didn't get hurt by falling off of his bike. He says that his mother got mad and pushed him down. Tyrone's mother reports that she sometimes spanks Tyrone, but denies ever pushing him. The family's previous child protection involvement was due to an allegation that Tyrone's mother left marks when she spanked Tyrone with her hand. She complied with the investigation and treatment plan of parenting classes and individual counseling.

\section{3: Black/mid-SES/two-parent}

\section{Situation $2 a$}

You receive a child protection report regarding 7-year-old Tyrone from a nurse who works in a pediatrician's office. The nurse states that Tyrone's mother brought him to see the doctor because Tyrone was complaining of wrist and arm pain. Tyrone's mother reported that he hurt his arm when he fell off his bike. When asked about this, Tyrone became sullen and refused to answer any questions. Preliminary assessment indicates that Tyrone has a sprained wrist and bruised elbow. The nurse reported that according to Tyrone's file, he lives with his mother and father. Both parents are accountants. A case history search shows that the family was involved with child protection on one occasion.

\section{Situation $2 b$}

An investigation of Tyrone's case yields the following information: Tyrone and his parents live in a comfortable home in a middle-class neighborhood. During a private interview, Tyrone discloses that he didn't get hurt by falling off of his bike. 
He says that his mother got mad and pushed him down. Tyrone's mother reports that she sometimes spanks Tyrone, but denies ever pushing him. Tyrone's father also denies that he or the mother pushed Tyrone. The family's previous child protection involvement was due to an allegation that Tyrone's mother left marks when she spanked Tyrone with her hand. She complied with the investigation and treatment plan of parenting classes and individual counseling.

\section{4: Black/mid-SES/single parent}

\section{Situation $2 a$}

You receive a child protection report regarding 7-year-old Tyrone from a nurse who works in a pediatrician's office. The nurse states that Tyrone's mother brought him to see the doctor because Tyrone was complaining of wrist and arm pain. Tyrone's mother reported that he hurt his arm when he fell off his bike. When asked about this, Tyrone became sullen and refused to answer any questions. Preliminary assessment indicates that Tyrone has a sprained wrist and bruised elbow. The nurse reported that according to Tyrone's file, he lives with his mother who works as an accountant. The nurse remembers Tyrone's mother once saying that the child's father lives in another state and doesn't see Tyrone very often. A case history search shows that the family was involved with child protection on one occasion.

Situation $2 b$

An investigation of Tyrone's case yields the following information: Tyrone and his mother live in a comfortable home in a middle-class neighborhood. During a private interview, Tyrone discloses that he didn't get hurt by falling off of his bike. He says that his mother got mad and pushed him down. Tyrone's mother reports that she sometimes spanks Tyrone, but denies ever pushing him. The family's previous child protection involvement was due to an allegation that Tyrone's mother left marks when she spanked Tyrone with her hand. She complied with the investigation and treatment plan of parenting classes and individual counseling.

\section{5: White/low-SES/two-parent}

\section{Situation $2 \mathrm{a}$}

You receive a child protection report regarding 7-year-old Dustin from a nurse who works in a pediatrician's office. The nurse states that Dustin's mother brought him to see the doctor because Dustin was complaining of wrist and arm pain. Dustin's mother reported that he hurt his arm when he fell off his bike. When asked about this, Dustin became sullen and refused to answer any questions. Preliminary assessment indicates that Dustin has a sprained wrist and bruised elbow. The nurse reported that according to Dustin's file, he lives with his mother and father. A case history search shows that the family was involved with 
child protection on one occasion. At the time, Dustin and his parents were living in a homeless shelter.

\section{Situation $2 b$}

An investigation of Dustin's case yields the following information: Dustin and his parents no longer reside at the homeless shelter and have been living in public housing for a year. Dustin's mother works part-time as a clerk at a convenience store. His father works as a day laborer. During a private interview, Dustin discloses that he didn't get hurt by falling off of his bike. He says that his mother got mad and pushed him down. Dustin's mother reports that she sometimes spanks Dustin, but denies ever pushing him. Dustin's father also denies that he or the mother pushed Dustin. The family's previous child protection involvement was due to an allegation that Dustin's mother left marks when she spanked Dustin with her hand. She complied with the investigation and treatment plan of parenting classes and individual counseling.

\section{6: White/low-SES/single parent}

\section{Situation2a}

You receive a child protection report regarding 7-year-old Dustin from a nurse who works in a pediatrician's office. The nurse states that Dustin's mother brought him to see the doctor because Dustin was complaining of wrist and arm pain. Dustin's mother reported that he hurt his arm when he fell off his bike. When asked about this, Dustin became sullen and refused to answer any questions. Preliminary assessment indicates that Dustin has a sprained wrist and bruised elbow. The nurse reported that according to Dustin's file, he lives with his mother. The nurse remembers Dustin's mother once saying that the child's father lives in another state and doesn't see Dustin very often. A case history search shows that the family was involved with child protection on one occasion. At the time, Dustin and his mother were living in a homeless shelter.

\section{Situation $2 b$}

An investigation of Dustin's case yields the following information: Dustin and his mother no longer reside at the homeless shelter and have been living in public housing for a year. Dustin's mother works part-time as a clerk at a convenience store. During a private interview, Dustin discloses that he didn't get hurt by falling off of his bike. He says that his mother got mad and pushed him down. Dustin's mother reports that she sometimes spanks Dustin, but denies ever pushing him. The family's previous child protection involvement was due to an allegation that Dustin's mother left marks when she spanked Dustin with her hand. She complied with the investigation and treatment plan of parenting classes and individual counseling. 


\section{7: White/mid-SES/two-parent}

\section{Situation $2 a$}

You receive a child protection report regarding 7-year-old Dustin from a nurse who works in a pediatrician's office. The nurse states that Dustin's mother brought him to see the doctor because Dustin was complaining of wrist and arm pain. Dustin's mother reported that he hurt his arm when he fell off his bike. When asked about this, Dustin became sullen and refused to answer any questions. Preliminary assessment indicates that Dustin has a sprained wrist and bruised elbow. The nurse reported that according to Dustin's file, he lives with his mother and father. Both parents are accountants. A case history search shows that the family was involved with child protection on one occasion.

\section{Situation $2 b$}

An investigation of Dustin's case yields the following information: Dustin and his parents live in a comfortable home in a middle-class neighborhood. During a private interview, Dustin discloses that he didn't get hurt by falling off of his bike. He says that his mother got mad and pushed him down. Dustin's mother reports that she sometimes spanks Dustin, but denies ever pushing him. Dustin's father also denies that he or the mother pushed Dustin. The family's previous child protection involvement was due to an allegation that Dustin's mother left marks when she spanked Dustin with her hand. She complied with the investigation and treatment plan of parenting classes and individual counseling.

\section{8: White/mid-SES/single parent}

\section{Situation $2 \mathrm{a}$}

You receive a child protection report regarding 7-year-old Dustin from a nurse who works in a pediatrician's office. The nurse states that Dustin's mother brought him to see the doctor because Dustin was complaining of wrist and arm pain. Dustin's mother reported that he hurt his arm when he fell off his bike. When asked about this, Dustin became sullen and refused to answer any questions. Preliminary assessment indicates that Dustin has a sprained wrist and bruised elbow. The nurse reported that according to Dustin's file, he lives with his mother who works as an accountant. The nurse remembers Dustin's mother once saying that the child's father lives in another state and doesn't see Dustin very often. A case history search shows that the family was involved with child protection on one occasion.

\section{Situation $2 b$}

An investigation of Dustin's case yields the following information: Dustin and his mother live in a comfortable home in a middle-class neighborhood. During a private interview, Dustin discloses that he didn't get hurt by falling off of his bike. He says that his mother got mad and pushed him down. Dustin's mother reports 
that she sometimes spanks Dustin, but denies ever pushing him. The family's previous child protection involvement was due to an allegation that Dustin's mother left marks when she spanked Dustin with her hand. She complied with the investigation and treatment plan of parenting classes and individual counseling. 
Appendix C: Factorial Vignette Matrices

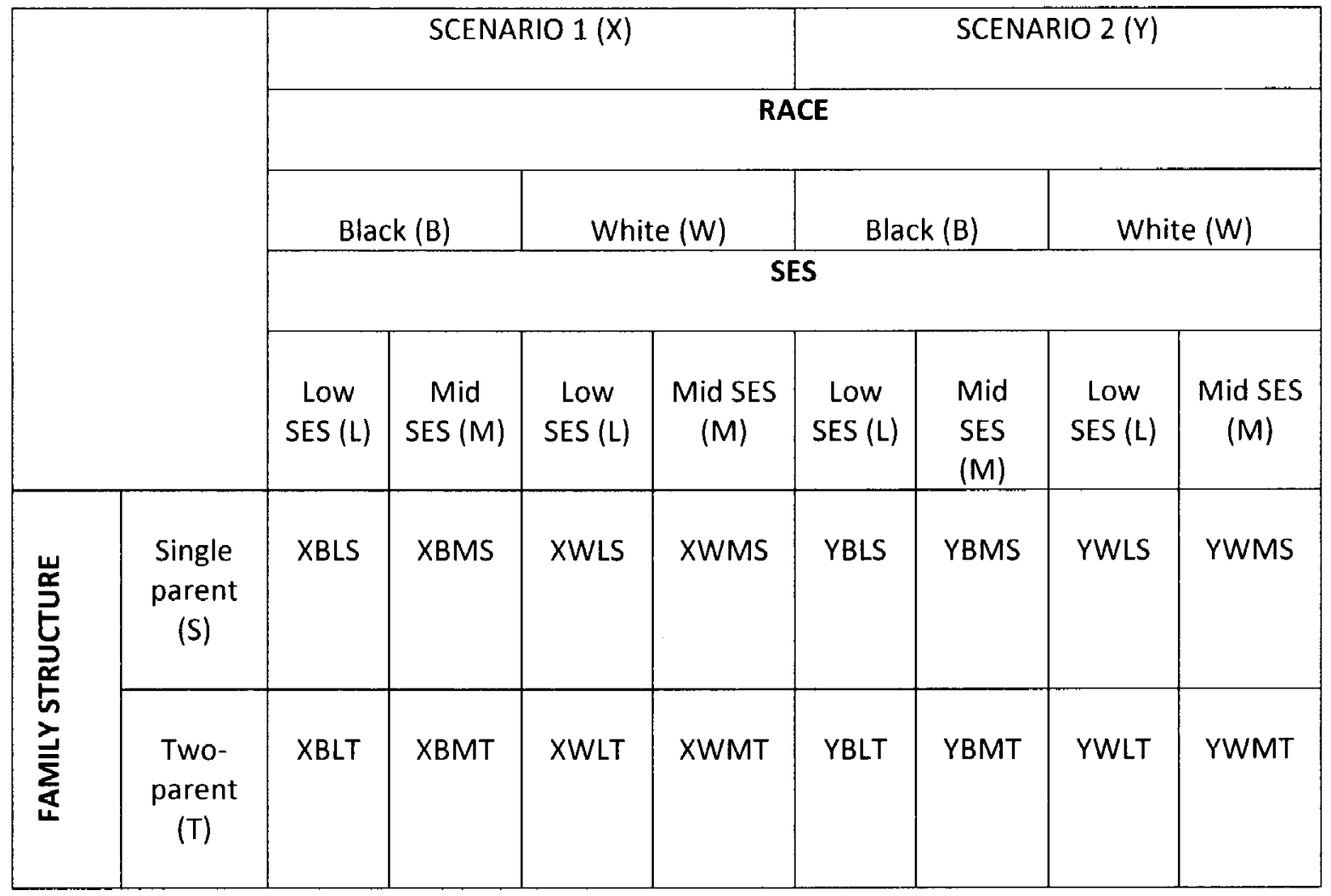

Target $\mathrm{N}$ (of respondents) $=30$ per cell for eight possible combinations of three factors (race, SES, family structure) $\rightarrow N=240$ total

$N=30$ per scenario pairing $\rightarrow N=240$ total 
Example pairings:

\begin{tabular}{|c|c|c|}
\hline $\mathbf{1}$ & $\mathbf{2}$ & $\mathbf{N}$ \\
\hline XBLS & YWMT & 30 \\
\hline XBLT & YWMS & 30 \\
\hline XBMS & YWLT & 30 \\
\hline XBMT & YWLS & 30 \\
\hline XWLS & YBMT & 30 \\
\hline XWLT & YBMS & 30 \\
\hline XWMS & YBLT & 30 \\
\hline XWMT & YBLS & 30 \\
\hline \multicolumn{2}{|c|}{ TOTAL } & $\mathbf{2 4 0}$ \\
\hline
\end{tabular}

Total of 64 possible combinations of randomly assigned Scenario $1+$ randomly assigned Scenario 2

\begin{tabular}{|c|c|c|c|c|c|c|c|}
\hline $\begin{array}{l}\text { XBLS- } \\
\text { YWMT }\end{array}$ & $\begin{array}{l}\text { XBLS- } \\
\text { YWMS }\end{array}$ & $\begin{array}{l}\text { XBLS- } \\
\text { YWLT }\end{array}$ & $\begin{array}{l}\text { XBLS- } \\
\text { YWLS }\end{array}$ & $\begin{array}{l}\text { XBLS- } \\
\text { YBMT }\end{array}$ & $\begin{array}{l}\text { XBLS- } \\
\text { YBMS }\end{array}$ & $\begin{array}{l}\text { XBLS- } \\
\text { YBLT }\end{array}$ & $\begin{array}{l}\text { XBLS- } \\
\text { YBLS }\end{array}$ \\
\hline $\begin{array}{l}\text { XBLT- } \\
\text { YWMS }\end{array}$ & $\begin{array}{l}\text { XBLT- } \\
\text { YWMT }\end{array}$ & $\begin{array}{l}\text { XBLT- } \\
\text { YWLT }\end{array}$ & $\begin{array}{l}\text { XBLT- } \\
\text { YWLS }\end{array}$ & $\begin{array}{l}\text { XBLT- } \\
\text { YBMT }\end{array}$ & $\begin{array}{l}\text { XBLT- } \\
\text { YBMS }\end{array}$ & $\begin{array}{l}\text { XBLT- } \\
\text { YBLT }\end{array}$ & $\begin{array}{l}\text { XBLT- } \\
\text { YBLS }\end{array}$ \\
\hline $\begin{array}{l}\text { XBMS- } \\
\text { YWLT }\end{array}$ & $\begin{array}{l}\text { XBMS- } \\
\text { YWMT }\end{array}$ & $\begin{array}{l}\text { XBMS- } \\
\text { YWMS }\end{array}$ & $\begin{array}{l}\text { XBMS- } \\
\text { YWLS }\end{array}$ & $\begin{array}{l}\text { XBMS- } \\
\text { YBMT }\end{array}$ & $\begin{array}{l}\text { XBMS- } \\
\text { YBMS }\end{array}$ & $\begin{array}{l}\text { XBMS- } \\
\text { YBLT }\end{array}$ & $\begin{array}{l}\text { XBMS- } \\
\text { YBLS }\end{array}$ \\
\hline $\begin{array}{l}\text { XBMT- } \\
\text { YWLS }\end{array}$ & $\begin{array}{l}\text { XBMT- } \\
\text { YWMT }\end{array}$ & $\begin{array}{l}\text { XBMT- } \\
\text { YWMS }\end{array}$ & $\begin{array}{l}\text { XBMT- } \\
\text { YWLT }\end{array}$ & $\begin{array}{l}\text { XBMT- } \\
\text { YBMT }\end{array}$ & $\begin{array}{l}\text { XBMT- } \\
\text { YBMS }\end{array}$ & $\begin{array}{c}\text { XBMT- } \\
\text { YBLT }\end{array}$ & $\begin{array}{l}\text { XBMT- } \\
\text { YBLS }\end{array}$ \\
\hline $\begin{array}{l}\text { XWLS- } \\
\text { YBMT }\end{array}$ & $\begin{array}{l}\text { XWLS- } \\
\text { YWMT }\end{array}$ & $\begin{array}{l}\text { XWLS- } \\
\text { YWMS }\end{array}$ & $\begin{array}{l}\text { XWLS- } \\
\text { YWLT }\end{array}$ & $\begin{array}{l}\text { XWLS- } \\
\text { YWLS }\end{array}$ & $\begin{array}{l}\text { XWLS- } \\
\text { YBMS }\end{array}$ & $\begin{array}{c}\text { XWLS- } \\
\text { YBLT }\end{array}$ & $\begin{array}{l}\text { XWLS- } \\
\text { YBLS }\end{array}$ \\
\hline $\begin{array}{l}\text { XWLT- } \\
\text { YBMS }\end{array}$ & $\begin{array}{l}\text { XWLT- } \\
\text { YWMT }\end{array}$ & $\begin{array}{l}\text { XWLT- } \\
\text { YWMS }\end{array}$ & $\begin{array}{l}\text { XWLT- } \\
\text { YWLT }\end{array}$ & $\begin{array}{l}\text { XWLT- } \\
\text { YWLS }\end{array}$ & $\begin{array}{l}\text { XWLT- } \\
\text { YBMT }\end{array}$ & $\begin{array}{c}\text { XWLT- } \\
\text { YBLT }\end{array}$ & $\begin{array}{l}\text { XWLT- } \\
\text { YBLDS }\end{array}$ \\
\hline $\begin{array}{c}\text { XWMS- } \\
\text { YBLT }\end{array}$ & $\begin{array}{l}\text { XWMS- } \\
\text { YWMT }\end{array}$ & $\begin{array}{l}\text { XWMS- } \\
\text { YWMS }\end{array}$ & $\begin{array}{l}\text { XWMS- } \\
\text { YWLT }\end{array}$ & $\begin{array}{l}\text { XWMS- } \\
\text { YWLS }\end{array}$ & $\begin{array}{c}\text { XWMS- } \\
\text { YBMT }\end{array}$ & $\begin{array}{l}\text { XWMS- } \\
\text { YBMS }\end{array}$ & $\begin{array}{c}\text { XWMS- } \\
\text { YBLS }\end{array}$ \\
\hline $\begin{array}{l}\text { XWMT- } \\
\text { YBLS }\end{array}$ & $\begin{array}{l}\text { XWMT- } \\
\text { YWMT }\end{array}$ & $\begin{array}{l}\text { XWMT- } \\
\text { YWMS }\end{array}$ & $\begin{array}{l}\text { XWMT- } \\
\text { YWLT }\end{array}$ & $\begin{array}{l}\text { XWMT- } \\
\text { YWLS }\end{array}$ & $\begin{array}{l}\text { XWMT- } \\
\text { YBMT }\end{array}$ & $\begin{array}{l}\text { XWMT- } \\
\text { YBMS }\end{array}$ & $\begin{array}{c}\text { XWMT- } \\
\text { YBLT }\end{array}$ \\
\hline
\end{tabular}

Target $N=240 \rightarrow N=3-4$ per cell 
Breakdown by Intake and Investigation

Total number still 240 since same respondents receive $V / X$ and $Y / Z$

\begin{tabular}{|c|c|c|c|c|c|c|c|c|}
\hline & \multicolumn{4}{|c|}{$\begin{array}{l}\text { SCENARIO 1a (V) } \\
\text { Intake }\end{array}$} & \multicolumn{4}{|c|}{$\begin{array}{c}\text { SCENARIO } 1 \mathrm{~b}(\mathrm{X}) \\
\text { Investigation/Ongoing }\end{array}$} \\
\hline & \multicolumn{2}{|c|}{ Black (B) } & \multicolumn{2}{|c|}{ White (W) } & \multicolumn{2}{|c|}{ Black (B) } & \multicolumn{2}{|c|}{ White (W) } \\
\hline & $\begin{array}{l}\text { Low } \\
\text { SES (L) }\end{array}$ & $\begin{array}{l}\text { Mid SES } \\
\text { (M) }\end{array}$ & $\begin{array}{l}\text { Low SES } \\
\text { (L) }\end{array}$ & $\begin{array}{l}\text { Mid SES } \\
\text { (M) }\end{array}$ & $\begin{array}{l}\text { Low } \\
\text { SES (L) }\end{array}$ & $\begin{array}{l}\text { Mid SES } \\
\text { (M) }\end{array}$ & $\begin{array}{c}\text { Low SES } \\
\text { (L) }\end{array}$ & $\begin{array}{l}\text { Mid SES } \\
(\mathrm{M})\end{array}$ \\
\hline $\begin{array}{l}\text { Single } \\
\text { parent }\end{array}$ & $\begin{array}{l}\text { VBLS } \\
30 a\end{array}$ & $\begin{array}{l}\text { VBMS } \\
30 \mathrm{~b}\end{array}$ & $\begin{array}{l}\text { VWLS } \\
30 c\end{array}$ & $\begin{array}{l}\text { VWMS } \\
\text { 30d }\end{array}$ & $\begin{array}{c}\text { XBLS } \\
30 a\end{array}$ & $\begin{array}{c}\text { XBMS } \\
30 \mathrm{~b}\end{array}$ & $\begin{array}{l}X W L S \\
30 c\end{array}$ & $\begin{array}{l}\text { XWMS } \\
\text { 30d }\end{array}$ \\
\hline $\begin{array}{l}\text { Two- } \\
\text { parent } \\
\text { (T) }\end{array}$ & $\begin{array}{c}\text { VBLT } \\
30 \mathrm{e}\end{array}$ & $\begin{array}{l}\text { VBMT } \\
30 f\end{array}$ & $\begin{array}{l}\text { VWLT } \\
30 \mathrm{~g}\end{array}$ & $\begin{array}{l}\text { VWMT } \\
30 \mathrm{~h}\end{array}$ & $\begin{array}{l}\text { XBLT } \\
30 e\end{array}$ & $\begin{array}{l}\text { XBMT } \\
30 f\end{array}$ & $\begin{array}{c}X W L T \\
30 \mathrm{~g}\end{array}$ & $\begin{array}{l}\text { XWMT } \\
30 \mathrm{~h}\end{array}$ \\
\hline
\end{tabular}

\begin{tabular}{|c|c|c|c|c|c|c|c|c|}
\hline & \multicolumn{4}{|c|}{$\begin{array}{l}\text { SCENARIO 2a }(\mathrm{Y}) \\
\text { Intake }\end{array}$} & \multicolumn{4}{|c|}{$\begin{array}{c}\text { SCENARIO } 2 \mathrm{~b}(\mathrm{Z}) \\
\text { Investigation/Ongoing }\end{array}$} \\
\hline & \multicolumn{2}{|c|}{ Black (B) } & \multicolumn{2}{|c|}{ White (W) } & \multicolumn{2}{|c|}{ Black (B) } & \multicolumn{2}{|c|}{ White (W) } \\
\hline & $\begin{array}{l}\text { Low } \\
\text { SES (L) }\end{array}$ & $\begin{array}{l}\text { Mid SES } \\
\text { (M) }\end{array}$ & $\begin{array}{c}\text { Low SES } \\
(\mathrm{L})\end{array}$ & $\begin{array}{l}\text { Mid SES } \\
(\mathrm{M})\end{array}$ & $\begin{array}{l}\text { Low } \\
\text { SES (L) }\end{array}$ & $\begin{array}{l}\text { Mid SES } \\
\text { (M) }\end{array}$ & $\begin{array}{c}\text { Low SES } \\
(\mathrm{L})\end{array}$ & $\begin{array}{l}\text { Mid SES } \\
\text { (M) }\end{array}$ \\
\hline $\begin{array}{c}\text { Single } \\
\text { parent } \\
\text { (S) }\end{array}$ & $\begin{array}{l}\text { YBLS } \\
30 \mathrm{~h}\end{array}$ & $\begin{array}{l}\text { YBMS } \\
30 \mathrm{~g}\end{array}$ & $\begin{array}{l}\text { YWLS } \\
30 f\end{array}$ & $\begin{array}{l}\text { YWMS } \\
30 \mathrm{e}\end{array}$ & $\begin{array}{l}\text { ZBLS } \\
30 \mathrm{~h}\end{array}$ & $\begin{array}{c}\text { ZBMS } \\
30 \mathrm{~g}\end{array}$ & $\begin{array}{l}\text { ZWLS } \\
30 f\end{array}$ & $\begin{array}{l}\text { ZWMS } \\
30 \mathrm{e}\end{array}$ \\
\hline $\begin{array}{l}\text { Two- } \\
\text { parent } \\
\text { (T) }\end{array}$ & $\begin{array}{l}\text { YBLT } \\
\text { 30d }\end{array}$ & $\begin{array}{l}\text { YBMT } \\
30 c\end{array}$ & $\begin{array}{l}\text { YWLT } \\
30 \mathrm{~b}\end{array}$ & $\begin{array}{l}\text { YWMT } \\
30 a\end{array}$ & $\begin{array}{l}\text { ZBLT } \\
30 \mathrm{~d}\end{array}$ & $\begin{array}{l}\text { ZBMT } \\
30 \mathrm{c}\end{array}$ & $\begin{array}{c}\text { ZWLT } \\
30 \mathrm{~b}\end{array}$ & $\begin{array}{l}\text { ZWMT } \\
30 a\end{array}$ \\
\hline
\end{tabular}


Example pairings of scenarios by group:

\begin{tabular}{|c|c|c|c|}
\hline Group & $\mathbf{1}$ & $\mathbf{2}$ & $\mathbf{N}$ \\
\hline a & V/XBLS & Y/ZWMT & 30 \\
\hline b & V/XBMS & Y/ZWLT & 30 \\
\hline c & V/XWLS & Y/ZBMT & 30 \\
\hline d & V/XWMS & Y/ZBLT & 30 \\
\hline e & V/XBLT & Y/ZWMS & 30 \\
\hline f & V/XBMT & Y/ZWLS & 30 \\
\hline g & V/XWLT & Y/ZBMS & 30 \\
\hline h & V/XWMT & Y/ZBLS & 30 \\
\hline \multicolumn{3}{|c|}{ TOTAL } & $\mathbf{2 4 0}$ \\
\hline
\end{tabular}




\section{Appendix D: Participant Communications}

\section{Pre-notice e-mail}

Subject: Professional Decision Making Survey to follow

Dear Child Protection Professional:

In one week you will receive an e-mail message inviting you to participate in a research study by completing a brief on-line survey about decision making in child protection. This study is being conducted by researchers at the University of Louisville, Kent School of Social Work. The purpose of this research is to find out more about how intake, investigation, and ongoing workers and supervisors make decisions in child maltreatment cases. The information you provide will be used to inform best practices in ensuring equitable outcomes for children. The survey will take approximately 20 minutes to complete.

Participation in this study is voluntary and survey participation will be anonymous. Choosing not to participate in this study will involve no penalty and will not reflect negatively on your employment evaluations or status. Furthermore, participating in the study will also have no bearing on your employment evaluations or status.

If you have any questions about the research study, please contact Dr. Bibhuti K. Sar at (502) 852-3932 or b.k.sar @ louisville.edu. You may also contact Lisa M. Johnson, MSW, at (502) 852-8009 or Imjohn15 @louisville.edu.

Sincerely,

Bibhuti K. Sar, Ph.D.

Principal Investigator

Lisa M. Johnson, MSW

Co-Investigator 


\section{Survey e-mail}

Subject: Professional Decision Making Survey

Dear Child Protection Professional:

As mentioned in an e-mail message sent earlier this week, you are being invited to participate in a research study by completing a brief on-line survey about decision making in child protection. This study is being conducted by researchers at the University of Louisville, Kent School of Social Work. The purpose of this research is to find out more about how intake, investigation, and ongoing workers and supervisors make decisions in child maltreatment cases. The information you provide will be used to inform best practices in ensuring equitable outcomes for children. The survey will take approximately 20 minutes to complete.

Participation in this study is voluntary.

You may access the survey by clicking on the following link or pasting it in the address bar of your web browser:

https://www.psychdata.com/s.asp?SID=127074. Before you begin the survey, you will be asked to create your own nickname and password so that you may complete the survey anonymously. This nickname and password will also allow you to stop, save your progress, and resume the survey at a later time if needed.

Comprehensive informed consent information is below. This same information will also be available for your review at the beginning of the survey. By completing the survey, you agree to take part in the research study.

If you have any questions, comments, or concerns about the research study, please contact Dr. Bibhuti K. Sar at (502) 852-3932 or b.k.sar@louisville.edu. You may also contact Lisa M. Johnson, MSW, at (502) 852-8009 or Imjohn15@louisville.edu.

\section{COMPLETE INFORMED CONSENT INFORMATION}

\section{Dear Child Protection Professional:}

You are being invited to participate in a research study by responding to the attached anonymous survey about decision making in child protection. This study is being conducted by Bibhuti Sar, Ph.D. and Lisa Johnson, MSW, researchers at the University of Louisville, Kent School of Social Work. The purpose of this research is to find out more about how intake, investigation, and ongoing workers and supervisors make decisions in child protection cases. In this study you will be asked to complete an on-line survey. The information you provide will be used to inform best practices in child protection. The survey will take approximately 20 
minutes to complete. Approximately 1500 protection and permanency workers and supervisors in three states will be invited to complete this survey. It is expected that around 400 individuals will complete the survey. Information will be collected through surveys for approximately eight weeks.

Taking part in this study is completely voluntary. You may choose not to take part at all. If you decide to be in this study, you may stop taking part at any time. If you decide not to be in this study or if you stop taking part at any time, this will involve no penalty, and will not reflect negatively on your employment evaluations or affect your employment status in any way. Furthermore, participating in the study will also have no bearing on your employment evaluations or status. There are no foreseeable risks for your participation in this study other than possible minor discomfort in answering some questions. The information collected may not benefit you directly; however, the information learned in this study may be helpful to others.

Information from your completed survey will be stored electronically on a password-protected survey website (PsychData.com) and downloaded to a password-protected computer at the University of Louisville, Kent School of Social Work. Individuals from the Kent School of Social Work, the Institutional Review Board (IRB), the Human Subjects Protection Program Office (HSPPO), and other regulatory agencies may inspect these records. In all other respects, however, the data will be held in confidence to the extent permitted by law. Although absolute anonymity and confidentiality cannot be guaranteed, the data will be kept under lock and key and will be protected to the full extent of the law. Should the data be published, your identity will not be disclosed.

If you have any questions, concerns, or complaints about the research study, please contact Dr. Bibhuti K. Sar at (502) 852-3932 or b.k.sar@louisville.edu. You may also contact Lisa M. Johnson, MSW, at (502) 852-8009 or Imjohn15@louisville.edu.

If you have any questions about your rights as a research participant, you may call the University of Louisville Human Subjects Protection Program Office at (502) 852-5188. You can discuss any questions about your rights as a research subject, in private, with a member of the IRB. You may also call this number if you have other questions about the research, and you cannot reach the research staff, or want to talk to someone else. The IRB is an independent committee made up of people from the University community, staff of the institution, as well as people from the community not connected with this institution. The University IRB and your state IRB have reviewed this research study. 
If you have concerns or complaints about the research or research staff and you do not wish to give your name, you may call 1-877-852-1167. This is a 24 hour hotline answered by people who do not work at the University of Louisville.

Sincerely,

Bibhuti K. Sar, Ph.D.

Principal Investigator

Lisa M. Johnson, MSW

Co-Investigator 


\section{Follow-up e-mail \#1}

Subject: Friendly reminder regarding decision making survey

Dear Child Protection Professional:

Two weeks ago, you received an invitation to participate in a research study by completing a brief on-line survey about decision making in child protection. If you have already completed the survey, thank you very much for your participationyou may disregard the remainder of this message. If you have not yet completed the survey, we invite you to do so at your earliest convenience. The survey will be open for approximately six more weeks.

This study is being conducted by researchers at the University of Louisville, Kent School of Social Work. The purpose of this research is to find out more about how intake, investigation, and ongoing workers and supervisors make decisions in child maltreatment cases.

You may access the survey by clicking on the following link or pasting it in the address bar of your web browser:

https://www.psychdata.com/s.asp?SID=127074. Before you begin the survey, you will be asked to create your own nickname and password so that you may complete the survey anonymously. This nickname and password will also allow you to stop, save your progress, and resume the survey at a later time if needed. The survey will take approximately 20 minutes to complete.

Comprehensive informed consent information will be available for your review at the beginning of the survey. By completing the survey, you agree to take part in the research study.

If you have any questions, comments, or concerns about the research study, please contact Dr. Bibhuti K. Sar at (502) 852-3932 or b.k.sar@louisville.edu. You may also contact Lisa M. Johnson, MSW, at (502) 852-8009 or Imjohn15@louisville.edu.

Sincerely,

Bibhuti K. Sar, Ph.D.

Principal Investigator

Lisa M. Johnson, MSW

Co-Investigator 


\section{Follow-up e-mail \#2 (sent six weeks after survey e-mail)}

Subject: Final reminder regarding decision making survey

Dear Child Protection Professional:

Several weeks ago, you received an invitation to participate in a research study by completing a brief on-line survey about decision making in child protection. If you have already completed the survey, thank you very much for your participation-you may disregard the remainder of this message. If you have not yet completed the survey, we invite you to do so at your earliest convenience. The survey will be open for completion for approximately two more weeks.

This study is being conducted by researchers at the University of Louisville, Kent School of Social Work. The purpose of this research is to find out more about how intake, investigation, and ongoing workers and supervisors make decisions in child maltreatment cases.

You may access the survey by clicking on the following link or pasting it in the address bar of your web browser:

https://www.psychdata.com/s.asp?SID=127074. Before you begin the survey, you will be asked to create your own nickname and password so that you may complete the survey anonymously. This nickname and password will also allow you to stop, save your progress, and resume the survey at a later time if needed. The survey will take approximately 20 minutes to complete.

Comprehensive informed consent information will be available for your review at the beginning of the survey. By completing the survey, you agree to take part in the research study.

If you have any questions, comments, or concerns about the research study, please contact Dr. Bibhuti K. Sar at (502) 852-3932 or b.k.sar@louisville.edu. You may also contact Lisa M. Johnson, MSW, at (502) 852-8009 or Imjohn15@louisville.edu.

Sincerely,

Bibhuti K. Sar, Ph.D.

Principal Investigator

Lisa Johnson, MSW

Co-Investigator 
Appendix E: Study Codebook

\begin{tabular}{|c|c|c|c|c|}
\hline$=$ & Name & Type & Label & Values \\
\hline 1 & $\overline{\text { DATE }}$ & String & Date completed & None \\
\hline 2 & CASEID & Numeric & Unique Respondent ID & None \\
\hline 3 & STATE & String & $\begin{array}{l}\text { In what state are you } \\
\text { located? (please write) }\end{array}$ & None \\
\hline 4 & GEO & Numeric & $\begin{array}{l}\text { How would you describe } \\
\text { the area in which you } \\
\text { work? }\end{array}$ & $1=$ Urban, $2=$ Rural \\
\hline 5 & PGM_INTAKE & Numeric & $\begin{array}{l}\text { What program area is your } \\
\text { primary responsibility in } \\
\text { your current position? If } \\
\text { your position includes } \\
\text { responsibilities in several } \\
\text { areas, please check all that } \\
\text { apply.: Child Protection } \\
\text { Intake/Screening }\end{array}$ & $\begin{array}{l}1=\text { Yes/Checked, } 0= \\
\text { No/Unchecked }\end{array}$ \\
\hline 6 & PGM_CPS & Numeric & $\begin{array}{l}\text { Child Protection } \\
\text { Investigations }\end{array}$ & $\begin{array}{l}1=\text { Yes } / \text { Checked, } 0= \\
\text { No/Unchecked }\end{array}$ \\
\hline 7 & PGM_ONGOING & Numeric & $\begin{array}{l}\text { Child Protection Ongoing } \\
\text { Casework (provision of in- } \\
\text { home services) }\end{array}$ & $\begin{array}{l}1=\text { Yes } / \text { Checked, } 0= \\
\text { No/Unchecked }\end{array}$ \\
\hline 8 & PGM_OTHER & Numeric & Other (Please specify) & $\begin{array}{l}1=\text { Yes } / \text { Checked, } 0= \\
\text { No/Unchecked }\end{array}$ \\
\hline 9 & PGM_OTHER2 & String & Other & None \\
\hline 10 & POS & Numeric & $\begin{array}{l}\text { What is your current } \\
\text { position in your child } \\
\text { welfare agency? }\end{array}$ & $\begin{array}{l}1=\text { Frontline/Direct } \\
\text { services worker, } 2= \\
\text { Supervisor, } 3=\text { Other }\end{array}$ \\
\hline 11 & POS_OTHER & String & Other & None \\
\hline 12 & YRSCPS & String & $\begin{array}{l}\text { How many years, to the } \\
\text { nearest half year (e.g., } \\
\text { 3.5), have you been } \\
\text { employed in your current } \\
\text { position at your agency? }\end{array}$ & None \\
\hline 13 & YRSEXP & String & $\begin{array}{l}\text { How many years, to the } \\
\text { nearest half year (e.g., } \\
\text { 3.5), of professional child } \\
\text { welfare practice } \\
\text { experience do you have? }\end{array}$ & None \\
\hline 14 & RSA1 & Numeric & $\begin{array}{l}\text { Random Stimulus } \\
\text { Assignment } 1\end{array}$ & $\begin{array}{l}1=\mathrm{B} / \mathrm{L} / \mathrm{T}, 2=\mathrm{B} / \mathrm{L} / \mathrm{S}, 3= \\
\mathrm{B} / \mathrm{M} / \mathrm{T}, 4=\mathrm{B} / \mathrm{M} / \mathrm{S}, 5= \\
\mathrm{W} / \mathrm{L} / \mathrm{T}, 6=\mathrm{W} / \mathrm{L} / \mathrm{S}, 7= \\
\mathrm{W} / \mathrm{M} / \mathrm{T}, 8=\mathrm{W} / \mathrm{M} / \mathrm{S}\end{array}$ \\
\hline
\end{tabular}




\begin{tabular}{|c|c|c|c|c|}
\hline 15 & RSA2 & Numeric & $\begin{array}{l}\text { Random Stimulus } \\
\text { Assignment } 2\end{array}$ & $\begin{array}{l}1=\mathrm{B} / \mathrm{L} / \mathrm{T}, 2=\mathrm{B} / \mathrm{L} / \mathrm{S}, 3= \\
\mathrm{B} / \mathrm{M} / \mathrm{T}, 4=\mathrm{B} / \mathrm{M} / \mathrm{S}, 5= \\
\mathrm{W} / \mathrm{L} / \mathrm{T}, 6=\mathrm{W} / \mathrm{L} / \mathrm{S}, 7= \\
\mathrm{W} / \mathrm{M} / \mathrm{T}, 8=\mathrm{W} / \mathrm{M} / \mathrm{S}\end{array}$ \\
\hline 16 & DECISION_A & Numeric & $\begin{array}{l}\text { Based solely on this } \\
\text { information, which of the } \\
\text { following actions would } \\
\text { you take? }\end{array}$ & $\begin{array}{l}1=\text { Screen in/refer for } \\
\text { investigation, } 2=\text { Screen } \\
\text { out/no further action }\end{array}$ \\
\hline 17 & REASON_A & String & $\begin{array}{l}\text { Briefly describe how you } \\
\text { came to the decision } \\
\text { regarding the situation } \\
\text { described above. In other } \\
\text { words, what was the } \\
\text { reasoning behind your } \\
\text { decision? }\end{array}$ & None \\
\hline 18 & PAR_FAULT_A & Numeric & $\begin{array}{l}\text { It is the parents' fault that } \\
\text { the family is in this } \\
\text { situation. }\end{array}$ & $\begin{array}{l}1=\text { Strongly Disagree, } 5= \\
\text { Strongly Agree }\end{array}$ \\
\hline 19 & PAR_NEG_A & Numeric & $\begin{array}{l}\text { The parents alone were } \\
\text { responsible for causing a } \\
\text { potentially negative } \\
\text { situation. }\end{array}$ & $\begin{array}{l}1=\text { Strongly Disagree, } 5= \\
\text { Strongly Agree }\end{array}$ \\
\hline 20 & PAR_OTHER_A & Numeric & $\begin{array}{l}\text { Other factors, besides the } \\
\text { parents' actions, caused a } \\
\text { potentially negative } \\
\text { situation. }\end{array}$ & $\begin{array}{l}1=\text { Strongly Disagree, } 5= \\
\text { Strongly Agree }\end{array}$ \\
\hline 21 & PAR_CONTROL_A & Numeric & $\begin{array}{l}\text { The parents had control } \\
\text { over their behavior. }\end{array}$ & $\begin{array}{l}1=\text { Strongly Disagree, } 5= \\
\text { Strongly Agree }\end{array}$ \\
\hline 22 & PAR_CIRCUM_A & Numeric & $\begin{array}{l}\text { The parents' } \\
\text { circumstances were to } \\
\text { blame for potential risk to } \\
\text { the child. }\end{array}$ & $\begin{array}{l}1=\text { Strongly Disagree, } 5= \\
\text { Strongly Agree }\end{array}$ \\
\hline 23 & PAR_ANGER_A & Numeric & $\begin{array}{l}\text { The parents' behavior } \\
\text { angered me. }\end{array}$ & $\begin{array}{l}1=\text { Strongly Disagree, } 5= \\
\text { Strongly Agree }\end{array}$ \\
\hline 24 & PAR_SYMP_A & Numeric & $\begin{array}{l}\text { This situation makes me } \\
\text { feel sympathetic toward } \\
\text { the parents. }\end{array}$ & $\begin{array}{l}1=\text { Strongly Disagree, } 5= \\
\text { Strongly Agree }\end{array}$ \\
\hline 25 & PAR_DISTR_A & Numeric & $\begin{array}{l}\text { The parents' situation } \\
\text { makes me feel distressed. }\end{array}$ & $\begin{array}{l}1=\text { Strongly Disagree, } 5= \\
\text { Strongly Agree }\end{array}$ \\
\hline 26 & DMFAC_RISK_A & Numeric & $\begin{array}{l}\text { Parent risk factors (e.g,, } \\
\text { substance abuse, mental } \\
\text { illness, limited cognitive } \\
\text { ability) }\end{array}$ & $\begin{array}{l}1=\text { Not at all important, } 5= \\
\text { Extremely important }\end{array}$ \\
\hline 27 & DMFAC_SUPPORT_A & Numeric & Social supports available & $\begin{array}{l}1=\text { Not at all important, } 5= \\
\text { Extremely important }\end{array}$ \\
\hline 28 & DMFAC_HX_A & Numeric & $\begin{array}{l}\text { Family history of CPS } \\
\text { involvement }\end{array}$ & $\begin{array}{l}1=\text { Not at all important, } 5= \\
\text { Extremely important }\end{array}$ \\
\hline 29 & DMFAC_SVCS_A & Numeric & $\begin{array}{l}\text { Parents' compliance with } \\
\text { past services }\end{array}$ & $\begin{array}{l}1=\text { Not at all important, } 5= \\
\text { Extremely important }\end{array}$ \\
\hline 30 & DMFAC_FAMILY_A & Numeric & $\begin{array}{l}\text { Who is living in the home } \\
\text { at the time of the incident }\end{array}$ & $\begin{array}{l}1=\text { Not at all important, } 5= \\
\text { Extremely important }\end{array}$ \\
\hline
\end{tabular}




\begin{tabular}{|c|c|c|c|c|}
\hline 31 & DMFAC_FIN_A & Numeric & Family's financial situation & $\begin{array}{l}1=\text { Not at all important, } 5= \\
\text { Extremely important }\end{array}$ \\
\hline 32 & DMFAC_SAFETY_A & Numeric & Neighborhood safety/risks & $\begin{array}{l}1=\text { Not at all important, } 5= \\
\text { Extremely important }\end{array}$ \\
\hline 33 & DMFAC_POLICY_A & Numeric & $\begin{array}{l}\text { Policy guidelines } \\
\text { (organizational, federal, } \\
\text { state) }\end{array}$ & $\begin{array}{l}1=\text { Not at all important, } 5= \\
\text { Extremely important }\end{array}$ \\
\hline 34 & DMFAC_ETHNIC_A & Numeric & $\begin{array}{l}\text { Family's ethnic } \\
\text { background }\end{array}$ & $\begin{array}{l}1=\text { Not at all important, } 5= \\
\text { Extremely important }\end{array}$ \\
\hline 35 & DMFAC_REL_A & Numeric & $\begin{array}{l}\text { Quality of the parent/child } \\
\text { relationship }\end{array}$ & $\begin{array}{l}1=\text { Not at all important, } 5= \\
\text { Extremely important }\end{array}$ \\
\hline 36 & DECISION_B & Numeric & $\begin{array}{l}\text { Based solely on this } \\
\text { information, which of the } \\
\text { following actions would } \\
\text { you take? }\end{array}$ & $\begin{array}{l}1=\text { Remove from } \\
\text { home/place in } \mathrm{OOH} \text { care, } 2 \\
=\text { Set up in-home services }\end{array}$ \\
\hline 37 & REASON_B & String & $\begin{array}{l}\text { Briefly describe how you } \\
\text { came to the decision } \\
\text { regarding the situation } \\
\text { described above. In other } \\
\text { words, what was the } \\
\text { reasoning behind your } \\
\text { decision?<br> }\end{array}$ & None \\
\hline 38 & PAR_FAULT_B & Numeric & $\begin{array}{l}\text { It is the parents' fault that } \\
\text { the family is in this } \\
\text { situation. }\end{array}$ & $\begin{array}{l}1=\text { Strongly Disagree, } 5= \\
\text { Strongly Agree }\end{array}$ \\
\hline 39 & PAR_NEG_B & Numeric & $\begin{array}{l}\text { The parents alone were } \\
\text { responsible for causing a } \\
\text { potentially negative } \\
\text { situation. }\end{array}$ & $\begin{array}{l}1=\text { Strongly Disagree, } 5= \\
\text { Strongly Agree }\end{array}$ \\
\hline 40 & PAR_OTHER_B & Numeric & $\begin{array}{l}\text { Other factors, besides the } \\
\text { parents' actions, caused a } \\
\text { potentially negative } \\
\text { situation. }\end{array}$ & $\begin{array}{l}1=\text { Strongly Disagree, } 5= \\
\text { Strongly Agree }\end{array}$ \\
\hline 41 & PAR_CONTROL_B & Numeric & $\begin{array}{l}\text { The parents had control } \\
\text { over their behavior. }\end{array}$ & $\begin{array}{l}1=\text { Strongly Disagree, } 5= \\
\text { Strongly Agree }\end{array}$ \\
\hline 42 & PAR_CIRCUM_B & Numeric & $\begin{array}{l}\text { The parents' } \\
\text { circumstances were to } \\
\text { blame for potential risk to } \\
\text { the child. }\end{array}$ & $\begin{array}{l}1=\text { Strongly Disagree, } 5= \\
\text { Strongly Agree }\end{array}$ \\
\hline 43 & PAR_ANGER_B & Numeric & $\begin{array}{l}\text { The parents' behavior } \\
\text { angered me. }\end{array}$ & $\begin{array}{l}1=\text { Strongly Disagree, } 5= \\
\text { Strongly Agree }\end{array}$ \\
\hline 44 & PAR_SYMP_B & Numeric & $\begin{array}{l}\text { This situation makes me } \\
\text { feel sympathetic toward } \\
\text { the parents. }\end{array}$ & $\begin{array}{l}1=\text { Strongly Disagree, } 5= \\
\text { Strongly Agree }\end{array}$ \\
\hline 45 & PAR_DISTR_B & Numeric & $\begin{array}{l}\text { The parents' situation } \\
\text { makes me feel distressed. }\end{array}$ & $\begin{array}{l}1=\text { Strongly Disagree, } 5= \\
\text { Strongly Agree }\end{array}$ \\
\hline 46 & DMFAC_RISK_B & Numeric & $\begin{array}{l}\text { Parent risk factors (e.g., } \\
\text { substance abuse, mental } \\
\text { illness, limited cognitive } \\
\text { ability) }\end{array}$ & $\begin{array}{l}1=\text { Not at all important, } 5= \\
\text { Extremely important }\end{array}$ \\
\hline
\end{tabular}




\begin{tabular}{|c|c|c|c|c|}
\hline 47 & DMFAC_SUPPORT_B & Numeric & Social supports available & $\begin{array}{l}1=\text { Not at all important, } 5= \\
\text { Extremely important }\end{array}$ \\
\hline 48 & DMFAC_HX_B & Numeric & $\begin{array}{l}\text { Family history of CPS } \\
\text { involvement }\end{array}$ & $\begin{array}{l}1=\text { Not at all important, } 5= \\
\text { Extremely important }\end{array}$ \\
\hline 49 & DMFAC_SVCS_B & Numeric & $\begin{array}{l}\text { Parents' compliance with } \\
\text { past services }\end{array}$ & $\begin{array}{l}1=\text { Not at all important, } 5= \\
\text { Extremely important }\end{array}$ \\
\hline 50 & DMFAC_FAMILY_B & Numeric & $\begin{array}{l}\text { Who is living in the home } \\
\text { at the time of the incident }\end{array}$ & $\begin{array}{l}1=\text { Not at all important, } 5= \\
\text { Extremely important }\end{array}$ \\
\hline 51 & DMFAC_FIN_B & Numeric & Family's financial situation & $\begin{array}{l}1=\text { Not at all important, } 5= \\
\text { Extremely important }\end{array}$ \\
\hline 52 & DMFAC_SAFETY_B & Numeric & Neighborhood safety/risks & $\begin{array}{l}1=\text { Not at all important, } 5= \\
\text { Extremely important }\end{array}$ \\
\hline 53 & DMFAC_POLICY_B & Numeric & $\begin{array}{l}\text { Policy guidelines } \\
\text { (organizational, federal, } \\
\text { state) }\end{array}$ & $\begin{array}{l}1=\text { Not at all important, } 5= \\
\text { Extremely important }\end{array}$ \\
\hline 54 & DMFAC_ETHNIC_B & Numeric & $\begin{array}{l}\text { Family's ethnic } \\
\text { background }\end{array}$ & $\begin{array}{l}1=\text { Not at all important, } 5= \\
\text { Extremely important }\end{array}$ \\
\hline 55 & DMFAC_REL_B & Numeric & $\begin{array}{l}\text { Quality of the parent/child } \\
\text { relationship }\end{array}$ & $\begin{array}{l}1=\text { Not at all important, } 5= \\
\text { Extremely important }\end{array}$ \\
\hline 56 & COBRAS1 & Numeric & $\begin{array}{l}\text { Everyone who works hard, } \\
\text { no matter what race they } \\
\text { are, has an equal chance } \\
\text { to become rich. }\end{array}$ & $\begin{array}{l}1=\text { Strongly Disagree, } 2= \\
\text { Moderately Disagree, } 3= \\
\text { Mildly Disagree, } 4=\text { Mildly } \\
\text { Agree, } 5=\text { Moderately } \\
\text { Agree, } 6=\text { Strongly Agree }\end{array}$ \\
\hline 57 & COBRAS2* & Numeric & $\begin{array}{l}\text { Race plays a major role in } \\
\text { the type of social services } \\
\text { (such as type of health } \\
\text { care or day care) that } \\
\text { people receive in the U.S. }\end{array}$ & $\begin{array}{l}1=\text { Strongly Disagree, } 2= \\
\text { Moderately Disagree, } 3= \\
\text { Mildly Disagree, } 4=\text { Mildly } \\
\text { Agree, } 5=\text { Moderately } \\
\text { Agree, } 6=\text { Strongly Agree }\end{array}$ \\
\hline 58 & MEBS1** & Numeric & $\begin{array}{l}\text { Too many of my tax dollars } \\
\text { are spent to take care of } \\
\text { those who are unwilling to } \\
\text { take care of themselves. }\end{array}$ & $\begin{array}{l}1=\text { Strongly Disagree, } 2= \\
\text { Moderately Disagree, } 3= \\
\text { Mildly Disagree, } 4=\text { Mildly } \\
\text { Agree, } 5=\text { Moderately } \\
\text { Agree, } 6=\text { Strongly Agree }\end{array}$ \\
\hline 59 & MEBS2** & Numeric & $\begin{array}{l}\text { If every individual would } \\
\text { carry his/her own weight, } \\
\text { there would be no } \\
\text { poverty. }\end{array}$ & $\begin{array}{l}1=\text { Strongly Disagree, } 2= \\
\text { Moderately Disagree, } 3= \\
\text { Mildly Disagree, } 4=\text { Mildly } \\
\text { Agree, } 5=\text { Moderately } \\
\text { Agree, } 6=\text { Strongly Agree }\end{array}$ \\
\hline 60 & MEBS3** & Numeric & $\begin{array}{l}\text { There are more poor } \\
\text { people than wealthy } \\
\text { people in prisons because } \\
\text { poor people commit more } \\
\text { crimes. }\end{array}$ & $\begin{array}{l}1=\text { Strongly Disagree, } 2= \\
\text { Moderately Disagree, } 3= \\
\text { Mildly Disagree, } 4=\text { Mildly } \\
\text { Agree, } 5=\text { Moderately } \\
\text { Agree, } 6=\text { Strongly Agree }\end{array}$ \\
\hline 61 & FAMST1 & Numeric & $\begin{array}{l}\text { A child is more likely to } \\
\text { struggle in life if raised by } \\
\text { a single parent. }\end{array}$ & $\begin{array}{l}1=\text { Strongly Disagree, } 2= \\
\text { Moderately Disagree, } 3= \\
\text { Mildly Disagree, } 4=\text { Mildly } \\
\text { Agree, } 5=\text { Moderately } \\
\text { Agree, } 6=\text { Strongly Agree }\end{array}$ \\
\hline
\end{tabular}




\begin{tabular}{|c|c|c|c|c|}
\hline 62 & COBRAS3 & Numeric & $\begin{array}{l}\text { It is important that people } \\
\text { begin to think of } \\
\text { themselves as American } \\
\text { and not African American, } \\
\text { Mexican American, or } \\
\text { Italian American. }\end{array}$ & $\begin{array}{l}1=\text { Strongly Disagree, } 2= \\
\text { Moderately Disagree, } 3= \\
\text { Mildly Disagree, } 4=\text { Mildly } \\
\text { Agree, } 5=\text { Moderately } \\
\text { Agree, } 6=\text { Strongly Agree }\end{array}$ \\
\hline 63 & COBRAS4 & Numeric & $\begin{array}{l}\text { English should be the only } \\
\text { official language in the } \\
\text { U.S. }\end{array}$ & $\begin{array}{l}1=\text { Strongly Disagree, } 2= \\
\text { Moderately Disagree, } 3= \\
\text { Mildly Disagree, } 4=\text { Mildly } \\
\text { Agree, } 5=\text { Moderately } \\
\text { Agree, } 6=\text { Strongly Agree }\end{array}$ \\
\hline 64 & COBRAS5* & Numeric & $\begin{array}{l}\text { White people are more to } \\
\text { blame for racial } \\
\text { discrimination than racial } \\
\text { and ethnic minorities. }\end{array}$ & $\begin{array}{l}1=\text { Strongly Disagree, } 2= \\
\text { Moderately Disagree, } 3= \\
\text { Mildly Disagree, } 4=\text { Mildly } \\
\text { Agree, } 5=\text { Moderately } \\
\text { Agree, } 6=\text { Strongly Agree }\end{array}$ \\
\hline 65 & FAMST2* & Numeric & $\begin{array}{l}\text { Single-parent families are } \\
\text { as capable of providing for } \\
\text { children's wellbeing as } \\
\text { two-parent families. }\end{array}$ & $\begin{array}{l}1=\text { Strongly Disagree, } 2= \\
\text { Moderately Disagree, } 3= \\
\text { Mildly Disagree, } 4=\text { Mildly } \\
\text { Agree, } 5=\text { Moderately } \\
\text { Agree, } 6=\text { Strongly Agree }\end{array}$ \\
\hline 66 & MEBS4** & Numeric & $\begin{array}{l}\text { Homeless people should } \\
\text { get their acts together and } \\
\text { become productive } \\
\text { members of society. }\end{array}$ & $\begin{array}{l}1=\text { Strongly Disagree, } 2= \\
\text { Moderately Disagree, } 3= \\
\text { Mildly Disagree, } 4=\text { Mildly } \\
\text { Agree, } 5=\text { Moderately } \\
\text { Agree, } 6=\text { Strongly Agree }\end{array}$ \\
\hline 67 & MEBS5 & Numeric & Poor people are lazy. & $\begin{array}{l}1=\text { Strongly Disagree, } 2= \\
\text { Moderately Disagree, } 3= \\
\text { Mildly Disagree, } 4=\text { Mildly } \\
\text { Agree, } 5=\text { Moderately } \\
\text { Agree, } 6=\text { Strongly Agree }\end{array}$ \\
\hline 68 & $\begin{array}{c}\text { COBRAS6 } \\
.\end{array}$ & Numeric & $\begin{array}{l}\text { Racism may have been a } \\
\text { problem in the past, but it } \\
\text { is not an important } \\
\text { problem today. }\end{array}$ & $\begin{array}{l}1=\text { Strongly Disagree, } 2= \\
\text { Moderately Disagree, } 3= \\
\text { Mildly Disagree, } 4=\text { Mildly } \\
\text { Agree, } 5=\text { Moderately } \\
\text { Agree, } 6=\text { Strongly Agree }\end{array}$ \\
\hline 69 & COBRAS7* & Numeric & $\begin{array}{l}\text { Racial and ethnic } \\
\text { minorities do not have the } \\
\text { same opportunities as } \\
\text { White people in the U.S. }\end{array}$ & $\begin{array}{l}1=\text { Strongly Disagree, } 2= \\
\text { Moderately Disagree, } 3= \\
\text { Mildly Disagree, } 4=\text { Mildly } \\
\text { Agree, } 5=\text { Moderately } \\
\text { Agree, } 6=\text { Strongly Agree }\end{array}$ \\
\hline 70 & COBRAS8 & Numeric & $\begin{array}{l}\text { White people in the U.S. } \\
\text { are discriminated against } \\
\text { because of the color of } \\
\text { their skin. }\end{array}$ & $\begin{array}{l}1=\text { Strongly Disagree, } 2= \\
\text { Moderately Disagree, } 3= \\
\text { Mildly Disagree, } 4=\text { Mildly } \\
\text { Agree, } 5=\text { Moderately } \\
\text { Agree, } 6=\text { Strongly Agree }\end{array}$ \\
\hline 71 & COBRAS9 & Numeric & $\begin{array}{l}\text { It is important for public } \\
\text { schools to teach about the } \\
\text { history and contributions } \\
\text { of racial and ethnic } \\
\text { minorities. }\end{array}$ & $\begin{array}{l}1=\text { Strongly Disagree, } 2= \\
\text { Moderately Disagree, } 3= \\
\text { Mildly Disagree, } 4=\text { Mildly } \\
\text { Agree, } 5=\text { Moderately } \\
\text { Agree, } 6=\text { Strongly Agree }\end{array}$ \\
\hline
\end{tabular}




\begin{tabular}{|c|c|c|c|c|}
\hline 72 & MEBS6** & Numeric & $\begin{array}{l}\text { Equal educational } \\
\text { opportunities exist for all } \\
\text { people in our society. }\end{array}$ & $\begin{array}{l}1=\text { Strongly Disagree, } 2= \\
\text { Moderately Disagree, } 3= \\
\text { Mildly Disagree, } 4=\text { Mildly } \\
\text { Agree, } 5=\text { Moderately } \\
\text { Agree, } 6=\text { Strongly Agree }\end{array}$ \\
\hline 73 & MEBS7 & Numeric & $\begin{array}{l}\text { Most poor people should } \\
\text { not have children until } \\
\text { they can afford to take } \\
\text { care of them. }\end{array}$ & $\begin{array}{l}1=\text { Strongly Disagree, } 2= \\
\text { Moderately Disagree, } 3= \\
\text { Mildly Disagree, } 4=\text { Mildly } \\
\text { Agree, } 5=\text { Moderately } \\
\text { Agree, } 6=\text { Strongly Agree }\end{array}$ \\
\hline 74 & MEBS8 & Numeric & $\begin{array}{l}\text { Most poor people are in } \\
\text { debt because they can't } \\
\text { manage their money. }\end{array}$ & $\begin{array}{l}1=\text { Strongly Disagree, } 2= \\
\text { Moderately Disagree, } 3= \\
\text { Mildly Disagree, } 4=\text { Mildly } \\
\text { Agree, } 5=\text { Moderately } \\
\text { Agree, } 6=\text { Strongly Agree }\end{array}$ \\
\hline 75 & FAMST3 & Numeric & $\begin{array}{l}\text { It is almost impossible for } \\
\text { a single, working parent to } \\
\text { raise a child as effectively } \\
\text { as two parents. }\end{array}$ & $\begin{array}{l}1=\text { Strongly Disagree, } 2= \\
\text { Moderately Disagree, } 3= \\
\text { Mildly Disagree, } 4=\text { Mildly } \\
\text { Agree, } 5=\text { Moderately } \\
\text { Agree, } 6=\text { Strongly Agree }\end{array}$ \\
\hline 76 & COBRAS10 & Numeric & $\begin{array}{l}\text { Talking about racial issues } \\
\text { causes unnecessary } \\
\text { tensions. }\end{array}$ & $\begin{array}{l}1=\text { Strongly Disagree, } 2= \\
\text { Moderately Disagree, } 3= \\
\text { Mildly Disagree, } 4=\text { Mildly } \\
\text { Agree, } 5=\text { Moderately } \\
\text { Agree, } 6=\text { Strongly Agree }\end{array}$ \\
\hline 77 & COBRAS11* & Numeric & $\begin{array}{l}\text { It is important for political } \\
\text { leaders to talk about } \\
\text { racism to help work } \\
\text { through or solve society's } \\
\text { problems. }\end{array}$ & $\begin{array}{l}1=\text { Strongly Disagree, } 2= \\
\text { Moderately Disagree, } 3= \\
\text { Mildly Disagree, } 4=\text { Mildly } \\
\text { Agree, } 5=\text { Moderately } \\
\text { Agree, } 6=\text { Strongly Agree }\end{array}$ \\
\hline 78 & COBRAS12* & Numeric & $\begin{array}{l}\text { White people in the U.S. } \\
\text { have certain advantages } \\
\text { because of the color of } \\
\text { their skin. }\end{array}$ & $\begin{array}{l}1=\text { Strongly Disagree, } 2= \\
\text { Moderately Disagree, } 3= \\
\text { Mildly Disagree, } 4=\text { Mildly } \\
\text { Agree, } 5=\text { Moderately } \\
\text { Agree, } 6=\text { Strongly Agree }\end{array}$ \\
\hline 79 & COBRAS13 & Numeric & $\begin{array}{l}\text { Racial problems in the U.S. } \\
\text { are rare, isolated } \\
\text { situations. }\end{array}$ & $\begin{array}{l}1=\text { Strongly Disagree, } 2= \\
\text { Moderately Disagree, } 3= \\
\text { Mildly Disagree, } 4=\text { Mildly } \\
\text { Agree, } 5=\text { Moderately } \\
\text { Agree, } 6=\text { Strongly Agree }\end{array}$ \\
\hline 80 & COBRAS14* & Numeric & $\begin{array}{l}\text { Race plays an important } \\
\text { role in who gets sent to } \\
\text { prison. }\end{array}$ & $\begin{array}{l}1=\text { Strongly Disagree, } 2= \\
\text { Moderately Disagree, } 3= \\
\text { Mildly Disagree, } 4=\text { Mildly } \\
\text { Agree, } 5=\text { Moderately } \\
\text { Agree, } 6=\text { Strongly Agree }\end{array}$ \\
\hline 81 & MEBS9** & Numeric & $\begin{array}{l}\text { People who stay on } \\
\text { welfare have no desire to } \\
\text { work. }\end{array}$ & $\begin{array}{l}1=\text { Strongly Disagree, } 2= \\
\text { Moderately Disagree, } 3= \\
\text { Mildly Disagree, } 4=\text { Mildly } \\
\text { Agree, } 5=\text { Moderately } \\
\text { Agree, } 6=\text { Strongly Agree }\end{array}$ \\
\hline
\end{tabular}




\begin{tabular}{|c|c|c|c|c|}
\hline 82 & MEBS10** & Numeric & $\begin{array}{l}\text { Welfare keeps the nation } \\
\text { in debt. }\end{array}$ & $\begin{array}{l}1=\text { Strongly Disagree, } 2= \\
\text { Moderately Disagree, } 3= \\
\text { Mildly Disagree, } 4=\text { Mildly } \\
\text { Agree, } 5=\text { Moderately } \\
\text { Agree, } 6=\text { Strongly Agree }\end{array}$ \\
\hline 83 & MEBS11** & Numeric & $\begin{array}{l}\text { People who don't make } \\
\text { much money are generally } \\
\text { unmotivated. }\end{array}$ & $\begin{array}{l}1=\text { Strongly Disagree, } 2= \\
\text { Moderately Disagree, } 3= \\
\text { Mildly Disagree, } 4=\text { Mildly } \\
\text { Agree, } 5=\text { Moderately } \\
\text { Agree, } 6=\text { Strongly Agree }\end{array}$ \\
\hline 84 & COBRAS15* & Numeric & $\begin{array}{l}\text { Racism is a major problem } \\
\text { in the U.S. }\end{array}$ & $\begin{array}{l}1=\text { Strongly Disagree, } 2= \\
\text { Moderately Disagree, } 3= \\
\text { Mildly Disagree, } 4=\text { Mildly } \\
\text { Agree, } 5=\text { Moderately } \\
\text { Agree, } 6=\text { Strongly Agree }\end{array}$ \\
\hline 85 & MEBS12 & Numeric & $\begin{array}{l}\text { If given the chance, a poor } \\
\text { person would be able to } \\
\text { keep a job. }\end{array}$ & $\begin{array}{l}1=\text { Strongly Disagree, } 2= \\
\text { Moderately Disagree, } 3= \\
\text { Mildly Disagree, } 4=\text { Mildly } \\
\text { Agree, } 5=\text { Moderately } \\
\text { Agree, } 6=\text { Strongly Agree }\end{array}$ \\
\hline 86 & MEBS13 & Numeric & $\begin{array}{l}\text { People who live in poverty } \\
\text { could benefit from } \\
\text { educational opportunities. }\end{array}$ & $\begin{array}{l}1=\text { Strongly Disagree, } 2= \\
\text { Moderately Disagree, } 3= \\
\text { Mildly Disagree, } 4=\text { Mildly } \\
\text { Agree, } 5=\text { Moderately } \\
\text { Agree, } 6=\text { Strongly Agree }\end{array}$ \\
\hline 87 & COBRAS16* & Numeric & $\begin{array}{l}\text { Due to racial } \\
\text { discrimination, programs } \\
\text { such as affirmative action } \\
\text { are necessary to help } \\
\text { create equality. }\end{array}$ & $\begin{array}{l}1=\text { Strongly Disagree, } 2= \\
\text { Moderately Disagree, } 3= \\
\text { Mildly Disagree, } 4=\text { Mildly } \\
\text { Agree, } 5=\text { Moderately } \\
\text { Agree, } 6=\text { Strongly Agree }\end{array}$ \\
\hline 88 & COBRAS17* & Numeric & $\begin{array}{l}\text { Race is very important in } \\
\text { determining who is } \\
\text { successful and who is not. }\end{array}$ & $\begin{array}{l}1=\text { Strongly Disagree, } 2= \\
\text { Moderately Disagree, } 3= \\
\text { Mildly Disagree, } 4=\text { Mildly } \\
\text { Agree, } 5=\text { Moderately } \\
\text { Agree, } 6=\text { Strongly Agree }\end{array}$ \\
\hline 89 & COBRAS18 & Numeric & $\begin{array}{l}\text { Immigrants should try to } \\
\text { fit into the culture and } \\
\text { values of the U.S. }\end{array}$ & $\begin{array}{l}1=\text { Strongly Disagree, } 2= \\
\text { Moderately Disagree, } 3= \\
\text { Mildly Disagree, } 4=\text { Mildly } \\
\text { Agree, } 5=\text { Moderately } \\
\text { Agree, } 6=\text { Strongly Agree }\end{array}$ \\
\hline 90 & MEBS14 & Numeric & $\begin{array}{l}\text { Most poor people aren't } \\
\text { very smart. }\end{array}$ & $\begin{array}{l}1=\text { Strongly Disagree, } 2= \\
\text { Moderately Disagree, } 3= \\
\text { Mildly Disagree, } 4=\text { Mildly } \\
\text { Agree, } 5=\text { Moderately } \\
\text { Agree, } 6=\text { Strongly Agree }\end{array}$ \\
\hline 91 & FAMST4* & Numeric & $\begin{array}{l}\text { Single parents and their } \\
\text { children develop closer } \\
\text { relationships than children } \\
\text { with two parents. }\end{array}$ & $\begin{array}{l}1=\text { Strongly Disagree, } 2= \\
\text { Moderately Disagree, } 3= \\
\text { Mildly Disagree, } 4=\text { Mildly } \\
\text { Agree, } 5=\text { Moderately } \\
\text { Agree, } 6=\text { Strongly Agree }\end{array}$ \\
\hline
\end{tabular}




\begin{tabular}{|c|c|c|c|c|}
\hline 92 & FAMST5 & Numeric & $\begin{array}{l}\text { To be well adjusted, a } \\
\text { child needs two parents (a } \\
\text { mom and a dad) who both } \\
\text { live at home. }\end{array}$ & $\begin{array}{l}1=\text { Strongly Disagree, } 2= \\
\text { Moderately Disagree, } 3= \\
\text { Mildly Disagree, } 4=\text { Mildly } \\
\text { Agree, } 5=\text { Moderately } \\
\text { Agree, } 6=\text { Strongly Agree }\end{array}$ \\
\hline 93 & COBRAS19 & Numeric & $\begin{array}{l}\text { Social policies, such as } \\
\text { affirmative action, } \\
\text { discriminate unfairly } \\
\text { against White people. }\end{array}$ & $\begin{array}{l}1=\text { Strongly Disagree, } 2= \\
\text { Moderately Disagree, } 3= \\
\text { Mildly Disagree, } 4=\text { Mildly } \\
\text { Agree, } 5=\text { Moderately } \\
\text { Agree, } 6=\text { Strongly Agree }\end{array}$ \\
\hline 94 & COBRAS20 & Numeric & $\begin{array}{l}\text { Racial and ethnic } \\
\text { minorities in the U.S. have } \\
\text { certain advantages } \\
\text { because of the color of } \\
\text { their skin. }\end{array}$ & $\begin{array}{l}1=\text { Strongly Disagree, } 2= \\
\text { Moderately Disagree, } 3= \\
\text { Mildly Disagree, } 4=\text { Mildly } \\
\text { Agree, } 5=\text { Moderately } \\
\text { Agree, } 6=\text { Strongly Agree }\end{array}$ \\
\hline 95 & MEBS15 & Numeric & $\begin{array}{l}\text { People living in poverty } \\
\text { would rather commit } \\
\text { crimes for financial gain } \\
\text { than work for a living } \\
\text { (mean score substitution) }\end{array}$ & $\begin{array}{l}1=\text { Strongly Disagree, } 2= \\
\text { Moderately Disagree, } 3= \\
\text { Mildly Disagree, } 4=\text { Mildly } \\
\text { Agree, } 5=\text { Moderately } \\
\text { Agree, } 6=\text { Strongly Agree }\end{array}$ \\
\hline 96 & GENDER & Numeric & What is your gender? & $\begin{array}{l}1=\text { Female, } 2=\text { Male, } 3= \\
\text { Other }\end{array}$ \\
\hline 97 & GENDER_OTHER & String & Other & None \\
\hline 98 & $\overline{A G E}$ & String & What is your age? & None \\
\hline 99 & LATHISP & Numeric & $\begin{array}{l}\text { Do you self-identify as } \\
\text { Latino/Hispanic? }\end{array}$ & $1=$ Yes, $0=$ No \\
\hline 100 & RACE & Numeric & $\begin{array}{l}\text { What is your self-identified } \\
\text { race/ethnicity? }\end{array}$ & $\begin{array}{l}1=\text { Black } / \text { AA, } 2= \\
\text { White/Caucasian, } 3= \\
\text { Asian, } 4=\text { Native American, } \\
5=\text { Biracial/Multiracial, } 6= \\
\text { Other }\end{array}$ \\
\hline 101 & RACE_OTHER & String & Other & None \\
\hline 102 & EDU & Numeric & $\begin{array}{l}\text { What is the highest level } \\
\text { and type of education you } \\
\text { have COMPLETED? }\end{array}$ & $\begin{array}{l}1=\text { HS Diploma } / \text { GED, } 2= \\
\text { Professional Certification, } 3 \\
=\text { Associate's Degree, } 4= \\
\text { BSW, } 5=\text { Bachelor's in } \\
\text { another field, } 6=\text { MSW, } 7= \\
\text { Master's in another field, } 8 \\
=\text { Doctoral Degree, } 9= \\
\text { Other }\end{array}$ \\
\hline 103 & EDU_OTHER & String & Other & None \\
\hline 104 & CULCOMP & Numeric & $\begin{array}{l}\text { In your opinion, how much } \\
\text { emphasis does your } \\
\text { agency place on } \\
\text { promoting culturally } \\
\text { competent practice? }\end{array}$ & $\begin{array}{l}1=\text { Very little emphasis, } 7= \\
\text { A lot of emphasis }\end{array}$ \\
\hline
\end{tabular}




\begin{tabular}{|c|c|c|c|c|}
\hline 105 & PCT_HISP & String & $\begin{array}{l}\text { Based on your best } \\
\text { estimate, please write in } \\
\text { the percentages of } \\
\text { children currently on your } \\
\text { caseload by race/ethnicity. } \\
\text { (The numbers should add } \\
\text { up to } 100 \text {.): } \\
\text { Hispanic/Latino of any } \\
\text { race }\end{array}$ & None \\
\hline 106 & PCT_BLK & String & Black or African American & None \\
\hline 107 & PCT_WHT & String & Caucasian & None \\
\hline 108 & PCT_ASIAN & String & Asian/Pacific Islander & None \\
\hline 109 & PCT_NA & String & Native American & None \\
\hline 110 & PCT_BIRACIAL & String & Biracial/Multiracial & None \\
\hline 111 & PCT_OTHER & String & Other & None \\
\hline 112 & CASELOAD & String & $\begin{array}{l}\text { As of today, what is your } \\
\text { caseload (number of } \\
\text { FAMILIES you are serving)? }\end{array}$ & None \\
\hline 113 & STRESS & Numeric & $\begin{array}{l}\text { On average, how much } \\
\text { work-related stress have } \\
\text { you experienced in the } \\
\text { past month? }\end{array}$ & $\begin{array}{l}1=\text { No stress, } 7=\text { Extreme } \\
\text { stress }\end{array}$ \\
\hline 114 & COMMENT & String & $\begin{array}{l}\text { You may write any other } \\
\text { comments you have in the } \\
\text { space below. }\end{array}$ & None \\
\hline 115 & SCENARIO & Numeric & Scenario Number & $\begin{array}{l}1=\text { Scenarios } 1 \text { thru } 8,2= \\
\text { Scenarios } 9 \text { thru } 16\end{array}$ \\
\hline 116 & VIG_RACE1 & Numeric & $\begin{array}{l}\text { Vignette Race (Scenarios } \\
1-8 \text { ) }\end{array}$ & $1=$ Black, $2=$ White \\
\hline 117 & VIG_RACE2 & Numeric & $\begin{array}{l}\text { Vignette Race (Scenarios } \\
9-16)\end{array}$ & $1=$ Black, $2=$ White \\
\hline 118 & VIG_SES1 & Numeric & $\begin{array}{l}\text { Vignette SES (Scenarios 1- } \\
\text { 8) }\end{array}$ & $1=$ Low-SES, $2=$ Mid-SES \\
\hline 119 & VIG_SES2 & Numeric & $\begin{array}{l}\text { Vignettes SES (Scenarios 9- } \\
\text { 16) }\end{array}$ & $1=$ LoW - SES, $2=$ Mid-SES \\
\hline 120 & VIG_FAMST1 & Numeric & $\begin{array}{l}\text { Vignette Family Structure } \\
\text { (Scenarios 1-8) }\end{array}$ & $\begin{array}{l}1=\text { Two-parent, } 2=\text { Single- } \\
\text { parent }\end{array}$ \\
\hline 121 & VIG_FAMST2 & Numeric & $\begin{array}{l}\text { Vignette Family Structure } \\
\text { (Scenarios 9-16) }\end{array}$ & $\begin{array}{l}1=\text { Two-parent, } 2=\text { Single- } \\
\text { parent }\end{array}$ \\
\hline
\end{tabular}

*Items reverse scored

${ }^{* *}$ Eight-item Economic Beliefs Scale (Stevenson \& Medler, 1995) 


\section{Appendix F: Informal Name Questionnaire}

The purpose of this document is to find out what some people think about the association of a certain name with a certain racial category. This is not a survey and your responses will not be shared in individual or aggregate form. This information will remain with me (Lisa Johnson) and help me determine which names to use in case examples for a research project. Completion of the form below is voluntary.

Questions may be directed to Lisa Johnson at Imjohn15@louisville.edu

For each of the following names, please indicate your opinion about whether the name would be associated with a Black or White child by checking the appropriate box. If you think the name could be easily associated with a child of either race, please indicate this by checking the "neutral" box.

\begin{tabular}{|l|l|l|l|l|l|l|l|}
\hline NAME & BLACK & WHITE & NEUTRAL & NAME & BLACK & WHITE & NEUTRAL \\
\hline Liam & & & & Connor & & & \\
\hline Landon & & & & DeShawn & & & \\
\hline Tyrone & & & & Holt & & & \\
\hline Aidan & & & & Dustin & & & \\
\hline Jamal & & & & Tanner & & & \\
\hline Darius & & & & Wyatt & & & \\
\hline Marquis & & & & Malik & & & \\
\hline Garth & & & & DeAndre & & & \\
\hline Cody & & & & Trevon & & & \\
\hline Darnell & & & & Alfred & & & \\
\hline
\end{tabular}




\section{Appendix G: Demographics for Final Sample}

\begin{tabular}{|c|c|c|c|c|}
\hline VARIABLE & FREQUENCY & $\begin{array}{l}\text { VALID } \\
\text { PERCENT }\end{array}$ & $\begin{array}{l}\text { MEASURES OF CENTRAL } \\
\text { TENDENCY }\end{array}$ & $\begin{array}{l}\text { NUMBER } \\
\text { MISSING }\end{array}$ \\
\hline Practice Area & 28 & $\quad$ & & 2 \\
\hline Intake only & 5 & 1.3 & & \\
\hline Investigation only & 45 & 11.3 & & \\
\hline Ongoing only & 178 & 44.5 & & \\
\hline Combination of CPS duties & 148 & 37 & & \\
\hline CPS and other & 24 & 6 & & \\
\hline Position & & & & 3 \\
\hline Frontline/Direct Services & 297 & 74.8 & & \\
\hline Supervisor & 73 & 18.4 & & \\
\hline Other & 27 & 6.8 & & \\
\hline Yrs in Current Position & $\begin{array}{l}\text { Range: } \\
0-40\end{array}$ & & $\begin{array}{l}\text { Mean: } 3.99, \text { Median: } 2 \text {, Mode: } \\
\text { 1.50, SD: } 5.231 \\
\text { Positively skewed, positive } \\
\text { kurtosis (leptokurtic) }\end{array}$ & 9 \\
\hline Yrs in $\mathrm{CW}$ & $\begin{array}{l}\text { Range: } \\
0-40\end{array}$ & & $\begin{array}{l}\text { Mean: } 6.52, \text { Median: } 3.50 \text {, } \\
\text { Mode: } 1.50, \text { SD: } 6.893 \\
\text { Positively skewed }\end{array}$ & 9 \\
\hline Gender & & & & 35 \\
\hline Female & 312 & 85.5 & & \\
\hline Male & 52 & 14.2 & & \\
\hline Other & 1 & 0.3 & & \\
\hline AGE & $\begin{array}{l}\text { Range: } \\
23-63\end{array}$ & & $\begin{array}{l}\text { Mean: } 35.89 \text {, Median: } 32 \text {, Mode: } \\
\text { 26, SD: } 10.436 \\
\text { Positively skewed }\end{array}$ & 35 \\
\hline LATINO? & 1 yes & & & 35 \\
\hline RACE & & & & 36 \\
\hline AA/Black & 21 & 5.8 & & \\
\hline Caucasian/White & 320 & 87.8 & & \\
\hline Asian & 1 & 0.3 & & \\
\hline Native American & 6 & 1.7 & & \\
\hline Biracial/Multiracial & 7 & 1.9 & & \\
\hline Other & 9 & 2.5 & & \\
\hline
\end{tabular}




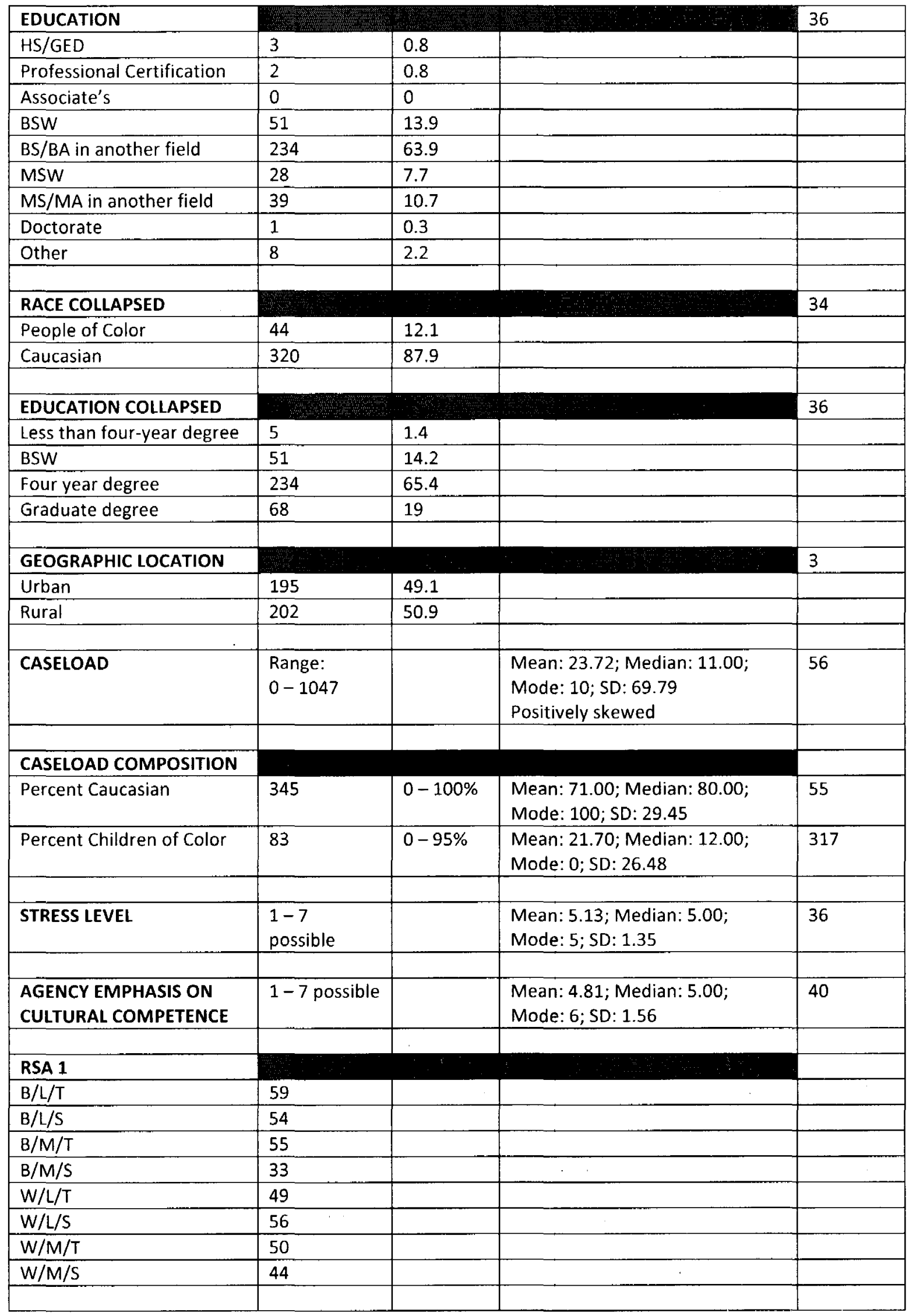




\begin{tabular}{|c|c|c|c|c|}
\hline RSA 2 & & & & \\
\hline $\mathrm{B} / \mathrm{L} / \mathrm{T}$ & 54 & & & \\
\hline $\mathrm{B} / \mathrm{L} / \mathrm{S}$ & 54 & & & \\
\hline $\mathrm{B} / \mathrm{M} / \mathrm{T}$ & 53 & & & \\
\hline $\mathrm{B} / \mathrm{M} / \mathrm{S}$ & 57 & & & \\
\hline $\mathrm{W} / \mathrm{L} / \mathrm{T}$ & 45 & & & \\
\hline$W / L / S$ & 56 & & & \\
\hline $\mathrm{W} / \mathrm{M} / \mathrm{T}$ & 42 & & & \\
\hline $\mathrm{W} / \mathrm{M} / \mathrm{S}$ & 39 & & & \\
\hline DECISION A & & & $\ldots$ & \\
\hline Screen in & 395 & 98.8 & & \\
\hline Screen out & 5 & 1.3 & & \\
\hline DECISION B & & & & 2 \\
\hline Remove & 172 & 43.2 & & \\
\hline Provide in-home services & 226 & 56.8 & & \\
\hline DECISION A2 & & & & \\
\hline Screen in & 247 & 61.8 & & \\
\hline Screen out & 153 & 38.3 & & \\
\hline DECISION B2 & & & & 18 \\
\hline Remove & 108 & 28.3 & & \\
\hline Provide in-home services & 274 & 71.7 & & \\
\hline COBRAS & $\begin{array}{l}\text { Range: } \\
27-114 \\
\end{array}$ & & $\begin{array}{l}\text { Mean: } 67.97 \text {; Median: } 69 ; \text { Mode: } \\
\text { 76; SD: } 14.00\end{array}$ & 51 \\
\hline EBS & $\begin{array}{l}\text { Range: } \\
8-43\end{array}$ & & $\begin{array}{l}\text { Mean: 22.24; Median: 22; Mode: } \\
\text { 22; SD: 7.14 }\end{array}$ & 41 \\
\hline FAMST & $\begin{array}{l}\text { Range: } \\
4-22\end{array}$ & & $\begin{array}{l}\text { Mean: 9.8; Median: 10; Mode: } 4 \text {; } \\
\text { SD: } 3.82\end{array}$ & 37 \\
\hline
\end{tabular}




\section{Appendix H: Results of Qualitative Analysis}

Reasons for decisions (frequencies)

\begin{tabular}{|c|c|c|c|}
\hline$A$ - screen in & A-screen out & B-remove & B - in-home services \\
\hline $\begin{array}{l}\text { 1. Bruising/marks (38) } \\
\text { 2. Past CPS } \\
\text { involvement (16) } \\
\text { 3. Child statement } \\
\text { (14) } \\
\text { 4. Assumption of } \\
\text { "trouble at home" } \\
\text { meaning } \\
\text { punishment/spanki } \\
\text { ng or hitting (14) } \\
\text { Need to gather } \\
\text { more information } \\
\text { (3) } \\
\text { Source of report } \\
\text { (teacher) (2) } \\
\text { 7. Single mother (1) } \\
\text { 8. Economic issues (1) } \\
\text { 9. Wetting pants may } \\
\text { indicate other } \\
\text { issues (1) } \\
\text { 10. No reason not to } \\
\text { screen in/"better } \\
\text { safe than sorry" (1) }\end{array}$ & 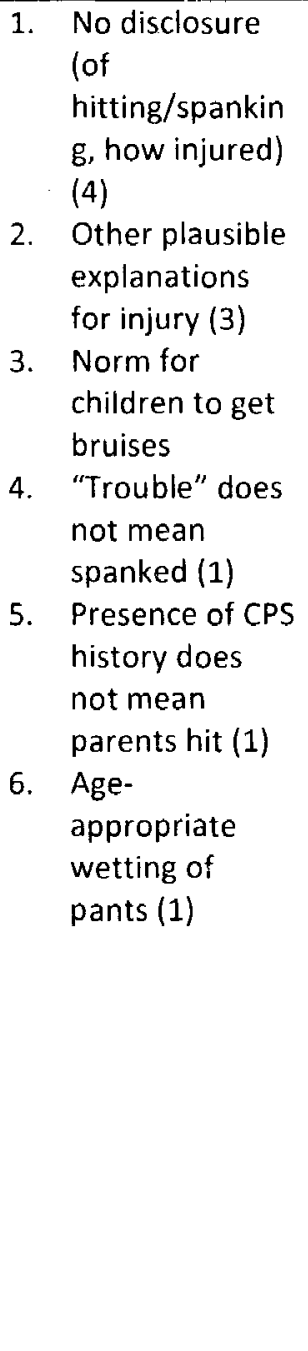 & $\begin{array}{l}\text { 1. Child } \\
\text { safety/protection } \\
\text { (11) } \\
\text { 2. Failure of previous } \\
\text { interventions (7) } \\
\text { 3. History of CPS } \\
\text { involvement (5) } \\
\text { 4. Fourth } \\
\text { incident/pattern (5) } \\
\text { 5. Consistency of } \\
\text { child's report and } \\
\text { injury/inconsistency } \\
\text { of parents' report } \\
\text { and injury (4) } \\
\text { 6. No admit, remorse, } \\
\text { denial (4) } \\
\text { 7. Nature of } \\
\text { incident/maltreatme } \\
\text { nt present (2) } \\
\text { Services not } \\
\text { assurance of safety } \\
\text { (1) }\end{array}$ & $\begin{array}{l}\text { 1. } \begin{array}{l}\text { Compliance } \\
\text { (previous/current) } \\
\text { (10) } \\
\text { 2. Benefits of services to } \\
\text { parent/family of skill- } \\
\text { building (10) }\end{array} \\
\text { 3. Monitoring - further } \\
\text { assessment (7) } \\
\text { Chance/opportunity } \\
\text { to utilize services this } \\
\text { time (may remove if } \\
\text { unsuccessful) (5) } \\
\text { Stress of } \\
\text { situation/circumstanc } \\
\text { es (3) } \\
\text { No immediate } \\
\text { danger/injuries not } \\
\text { severe enough for } \\
\text { removal (3) } \\
\text { Current cooperation/ } \\
\text { acknowledgement (3) } \\
\text { Limited } \\
\text { information/need } \\
\text { more information } \\
\text { (speak with } \\
\text { supervisor) ( } 2 \text { ) } \\
\text { Removal as last resort } \\
\text { (1) } \\
\text { 10. Nature of injury } \\
\text { (worse if elsewhere on } \\
\text { body) (1) } \\
\text { NS = } 2\end{array}$ \\
\hline
\end{tabular}




\begin{tabular}{|c|c|c|c|}
\hline$A 2$ - screen in & A2 - screen out & B2-remove: & B2 - in-home services \\
\hline $\begin{array}{l}\text { 1. Child not being } \\
\text { willing to talk/his } \\
\text { behavior (11) } \\
\text { 2. Past history of CPS } \\
\text { (7) } \\
\text { 3. Seriousness of } \\
\text { injury (5) } \\
\text { 4ack of } \\
\text { information/need } \\
\text { more information } \\
\text { (5) } \\
\text { Unexplained } \\
\text { injuries/cause of } \\
\text { injury still in } \\
\text { question (5) } \\
\text { Child safety (3) } \\
\text { 7. Follow-up } \\
\text { (investigation to } \\
\text { gather information) } \\
\text { (3) } \\
\text { 8. To be safe/better } \\
\text { safe than sorry (3) } \\
\text { 9. Medical personnel } \\
\text { has concerns ( } 2 \text { ) } \\
\text { 10. Single mother (1) } \\
\text { 11. Possible stress (1) } \\
\text { 12. Source of report } \\
\text { (MD's office) (1) } \\
\text { 13. Supervision } \\
\text { concerns (1) }\end{array}$ & $\begin{array}{l}\text { 1. Injury } \\
\text { consistent with } \\
\text { explanation/no } \\
\text { indication of } \\
\text { parental } \\
\text { involvement } \\
\text { with the injury } \\
\text { (4) } \\
\text { No reason not } \\
\text { to believe } \\
\text { story/lack of } \\
\text { information } \\
\text { contradicting } \\
\text { mother's story } \\
\text { (3) } \\
\text { No allegation } \\
\text { (of } \\
\text { maltreatment) } \\
\text { from child or } \\
\text { medical staff } \\
\text { (no medical } \\
\text { proof) (1) } \\
\text { Lack of } \\
\text { statement from } \\
\text { child does not } \\
\text { necessarily } \\
\text { mean abuse (1) } \\
\text { Mother took } \\
\text { child to MD (1) } \\
\text { Depends on last } \\
\text { report (type of } \\
\text { allegation) ( } 1 \text { ) }\end{array}$ & $\begin{array}{l}\text { 1. Child safety (4) } \\
\text { 2. Past services not } \\
\text { successful (4) } \\
\text { 3. History of CPS } \\
\text { involvement (4) } \\
\text { 4. Nature of injury - } \\
\text { required medical } \\
\text { attention (pushed) } \\
\text { (3) } \\
\text { 5. Physical abuse } \\
\text { occurring (or } \\
\text { potential of abuse) } \\
\text { (2) } \\
\text { 6. Parental denial (1) } \\
\text { 7. Put services in place } \\
\text { and work toward } \\
\text { reunification - look } \\
\text { for improvements } \\
\text { (1) } \\
\text { NS = } 1\end{array}$ & $\begin{array}{l}\text { 1. Opportunity to serve } \\
\text { family in the home - } \\
\text { parenting supports - } \\
\text { benefit to family - } \\
\text { Professionals in home } \\
\text { allow for assessment } \\
\text { and dealing with } \\
\text { stressors - ensure } \\
\text { safety - prevent } \\
\text { removal (18) } \\
\text { Previous compliance } \\
\text { with services (6) } \\
\text { Injuries not life } \\
\text { threatening/no } \\
\text { immediate danger (5) } \\
\text { Parent did not } \\
\text { purposely cause injury } \\
\text { (2) } \\
\text { Importance of leaving } \\
\text { child in home when } \\
\text { possible/keep family } \\
\text { together (2) } \\
\text { Need more } \\
\text { information before } \\
\text { removal ( } 2 \text { ) } \\
\text { No proof of } \\
\text { maltreatment (1) } \\
\text { NS = } 6 \text { (no decision = 3) }\end{array}$ \\
\hline
\end{tabular}

NS = no statement/left blank 


\section{Appendix I: Test Statistics for Logistic Regression Models Based on Theoretical Constructs}

Note: Cohen and ADM - 1; ADM - 2; attribution theories - 3

\begin{tabular}{|c|c|c|c|c|}
\hline$=$ Step & $\begin{array}{c}\% \\
\text { Variance } \\
\text { Explained }\end{array}$ & $\begin{array}{l}\text { \% Correctly } \\
\text { Identified } \\
\text { Cases }\end{array}$ & Significant Variables $(p)$ & $\begin{array}{l}\text { Odds } \\
\text { Ratio }\end{array}$ \\
\hline \multicolumn{5}{|c|}{ B: Remove } \\
\hline $\begin{array}{l}\text { 1- Professional, } \\
\text { personal, case, } \\
\text { environmental } \\
\text { factors; attitudes }\end{array}$ & 13.8 & 67 & $\begin{array}{l}\text { Agency emphasis on cultural } \\
\text { competence }(.042) \\
\text { Level of work-related stress }(.024) \\
\text { Economic Beliefs Scale score }(.010)\end{array}$ & $\begin{array}{r}1.191 \\
1.247 \\
.940 \\
\end{array}$ \\
\hline $\begin{array}{l}2-\text { Decision } \\
\text { making factors }\end{array}$ & 25.4 & 70.6 & $\begin{array}{l}\text { Emphasis on cultural competence } \\
(.006) \\
\text { Importance of family's CPS history } \\
\text { in decision making (.001) }\end{array}$ & $\begin{array}{l}1.291 \\
2.498\end{array}$ \\
\hline $\begin{array}{l}3 \text {-Attributions } \\
\text { for parental } \\
\text { behaviors }\end{array}$ & 26.3 & 71.5 & $\begin{array}{l}\text { Emphasis on cultural competence } \\
(.010) \\
\text { Importance of CPS history (.001) }\end{array}$ & $\begin{array}{l}1.276 \\
2.491\end{array}$ \\
\hline \multicolumn{5}{|c|}{ A2: Screen In } \\
\hline $\begin{array}{l}1 \text { - Professional, } \\
\text { personal, case, } \\
\text { environmental } \\
\text { factors; attitudes }\end{array}$ & 7 & 66.2 & Low-SES family (.023) & .566 \\
\hline $\begin{array}{l}2-\text { Decision } \\
\text { making factors }\end{array}$ & 27.9 & 72.4 & $\begin{array}{l}\text { Position - supervisor (.045) } \\
\text { Low-SES family }(.037) \\
\text { Importance of CPS history }(.000) \\
\text { Importance of family structure in } \\
\text { decision making }(.001)\end{array}$ & $\begin{array}{l}.243 \\
.556 \\
2.324 \\
1.876\end{array}$ \\
\hline $\begin{array}{l}3 \text { - Attributions } \\
\text { for parental } \\
\text { behaviors }\end{array}$ & 36.9 & 76 & $\begin{array}{l}\text { Low-SES family (.033) } \\
\text { Importance of CPS history }(.000) \\
\text { Importance of family structure } \\
(.004) \\
\text { Internal parental attributions } \\
(.001)\end{array}$ & $\begin{array}{l}.527 \\
2.188 \\
1.755 \\
1.393\end{array}$ \\
\hline
\end{tabular}




\begin{tabular}{|c|c|c|c|c|}
\hline \multicolumn{5}{|c|}{ B2: Remove } \\
\hline $\begin{array}{l}\text { 1-Professional, } \\
\text { personal, case, } \\
\text { environmental } \\
\text { factors; attitudes }\end{array}$ & 12 & 70.2 & No Significant Items & \\
\hline $\begin{array}{l}2 \text { - Decision } \\
\text { making factors }\end{array}$ & 27.7 & 76.7 & $\begin{array}{l}\text { Less than 4-year degree }(.029) \\
\text { Importance of CPS history }(.000) \\
\text { Importance of family's compliance } \\
\text { with past services }(.001)\end{array}$ & $\begin{array}{c}.068 \\
4.576 \\
.420\end{array}$ \\
\hline $\begin{array}{l}3 \text { - Attributions } \\
\text { for parental } \\
\text { behaviors }\end{array}$ & 30.3 & 77 & $\begin{array}{l}\text { Female }(.040) \\
\text { Less than } 4 \text {-yr degree }(.017) \\
\text { Importance of social supports } \\
\text { being available to family }(.037) \\
\text { Importance of CPS history }(.000) \\
\text { Importance of compliance with } \\
\text { past services (.001) } \\
\text { Feeling attributions for parental } \\
\text { behaviors }(.043)\end{array}$ & $\begin{array}{c}.407 \\
.046 \\
.608 \\
\\
4.748 \\
.402 \\
\\
1.152\end{array}$ \\
\hline
\end{tabular}




\section{Appendix J: Summary of Research Regarding Factors Contributing to Disproportionality/Disparity}

\begin{tabular}{|c|c|c|}
\hline Author(s)/Year & Method & Key Findings \\
\hline $\begin{array}{l}\text { Korbin, } \\
\text { Coulton, } \\
\text { Chard, Platt- } \\
\text { Houston, \& Su } \\
\text { (1998) }\end{array}$ & 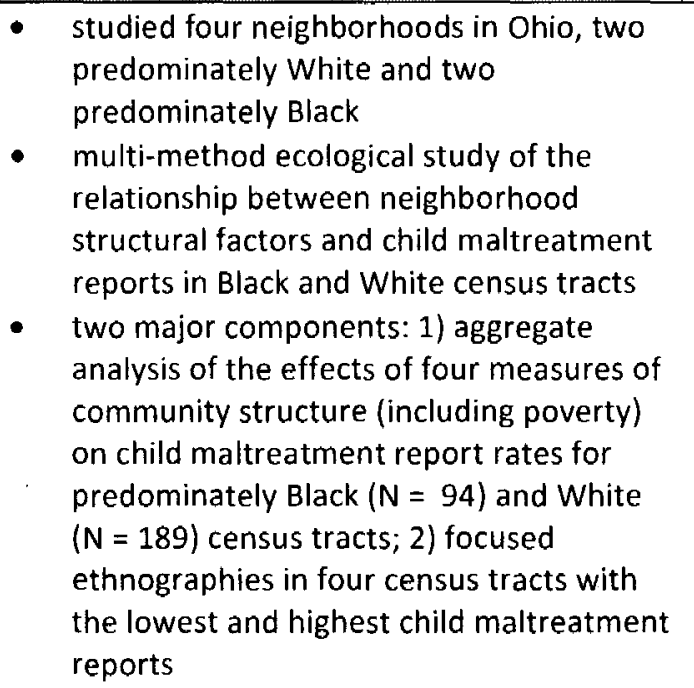 & $\begin{array}{l}\text { found lower rates of } \\
\text { maltreatment among families in } \\
\text { the Black neighborhoods, even } \\
\text { when poverty was greater in } \\
\text { these communities } \\
\text { community protective factors } \\
\text { (e.g., social cohesion and } \\
\text { extended family ties) may serve } \\
\text { as mediators of maltreatment, } \\
\text { even in the presence of } \\
\text { environmental risk factors such } \\
\text { as poverty }\end{array}$ \\
\hline $\begin{array}{l}\text { US DHHS, } \\
\text { Children's } \\
\text { Bureau (1997) }\end{array}$ & 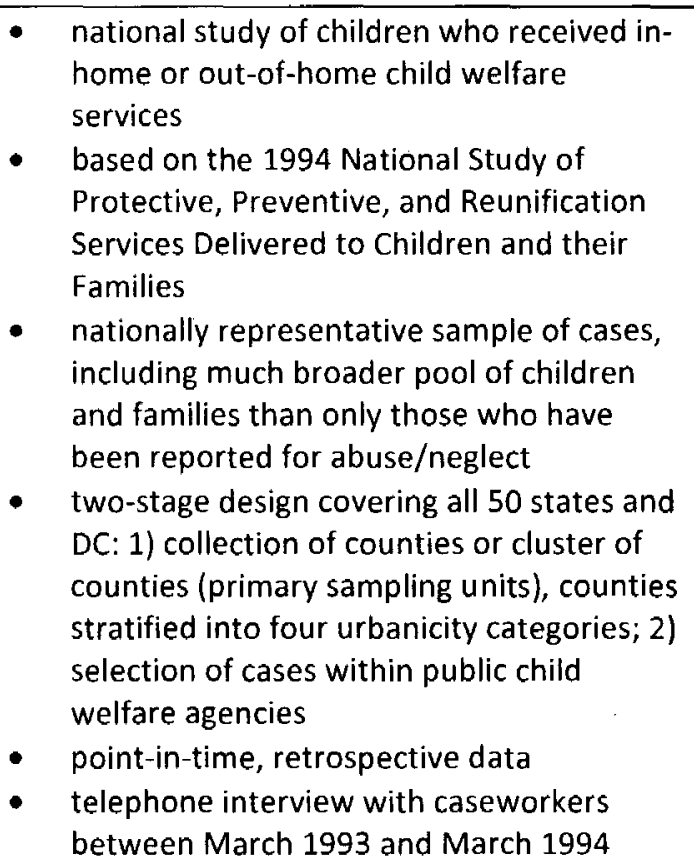 & $\begin{array}{l}\text { Black children were less likely } \\
\text { than White children to have } \\
\text { certain advantaged } \\
\text { characteristics (e.g., they lived in } \\
\text { two-parent families, neither } \\
\text { parent abused drugs, the family } \\
\text { relied on earnings and not } \\
\text { welfare, and they lived in low- } \\
\text { crime neighborhoods) } \\
\text { the less advantaged Black } \\
\text { children were more likely to be } \\
\text { placed in out-of-home care than } \\
\text { White children }\end{array}$ \\
\hline
\end{tabular}




\begin{tabular}{|c|c|c|}
\hline Hill (2005) & $\begin{array}{l}\text { - } \\
\text { Decondary analysis of the data from US } \\
\text { Protective, Preventive, and Reunification } \\
\text { Services Delivered to Children and their } \\
\text { Families } \\
1994 \text { study: N = 2,109 children who } \\
\text { received child welfare services in-home or } \\
\text { out-of-home from March } 1993 \text { to March } \\
\text { 1994 } \\
\text { cross-sectional comparison between Black } \\
\text { and White children/families } \\
\text { analysis: logistic regression models }\end{array}$ & $\begin{array}{l}\text { Black children in advantaged } \\
\text { circumstances were still more } \\
\text { likely to be placed in out-of- } \\
\text { home care than their White } \\
\text { counterparts }\end{array}$ \\
\hline US GAO 2007 & $\begin{array}{l}\text { comprehensive analysis of the social } \\
\text { problem of differences among children and } \\
\text { families of different races in the child } \\
\text { welfare system } \\
\text { study included: administering a nationwide } \\
\text { survey of state child welfare } \\
\text { administrators, conducting site visits to six } \\
\text { states, interviewing researchers and } \\
\text { federal agency officials, reviewing AFCARS } \\
\text { data, and analyzing federal legislation and } \\
\text { policies }\end{array}$ & $\begin{array}{l}\text { - found several factors that may } \\
\text { affect Black children's } \\
\text { disproportional representation in } \\
\text { foster care, including (a) higher } \\
\text { rates of poverty among Black } \\
\text { families, (b) families' difficulties } \\
\text { in accessing services that are } \\
\text { instrumental in creating safe } \\
\text { home environments and } \\
\text { preventing removal of children, } \\
\text { and (c) racial bias and cultural } \\
\text { misunderstanding among child } \\
\text { welfare decision makers }\end{array}$ \\
\hline \multicolumn{3}{|c|}{ POVERTY } \\
\hline $\begin{array}{l}\text { Sedlack \& } \\
\text { Broadhurst } \\
(1996) \\
\text { NIS-3 }\end{array}$ & $\begin{array}{l}\text { - NIS-3 includes data regarding children not } \\
\text { reported or reported and screened out } \\
\text { without investigation } \\
\text { - } \text { nationally representative sample of } 42 \\
\text { counties } \\
\text { - } \quad \text { three-month study period - September to } \\
\text { December } 1993 \\
\text { - } \\
\text { sentinel survey methodology - community } \\
\text { professionals serving children and families } \\
\text { (5,612 professionals in } 800 \text { non-CPS } \\
\text { agencies) } \\
\text { also surveyed public child welfare } \\
\text { employees } \\
\text { collected total of } 50,729 \text { data forms }\end{array}$ & $\begin{array}{l}\text { family income is significantly } \\
\text { related to incidence rates in } \\
\text { nearly every category of } \\
\text { maltreatment }\end{array}$ \\
\hline $\begin{array}{l}\text { USDHHS, ACF, } \\
\text { OPRE, } 2006\end{array}$ & $\begin{array}{l}\text { National Survey of Child and Adolescent } \\
\text { Well Being (NSCAW) } \\
\text { sample selected from children and families } \\
\text { who entered the child welfare system } \\
\text { between October } 1999 \text { and December } \\
2000 \\
\text { - } N=5,500+\text { children ( } 0-14 \text { years) from } 97 \\
\text { child welfare agencies nationwide }\end{array}$ & $\begin{array}{l}\text { approximately one-quarter of } \\
\text { households who have been } \\
\text { investigated for child } \\
\text { maltreatment had a total } \\
\text { household income under } \\
\$ 10,000 \text {, and } 65 \% \text { had a total } \\
\text { income under } \$ 25,000\end{array}$ \\
\hline
\end{tabular}




\begin{tabular}{|c|c|c|}
\hline $\begin{array}{l}\text { Barth, Wildfire, } \\
\& \text { Green } \\
\text { (2006) }\end{array}$ & $\begin{array}{l}\text { - data from National Survey of Child and } \\
\text { Adolescent Wellbeing } \\
\text { - } \quad \text { random selection of cases } \\
\text { - } \quad \mathrm{N}=3,798 \text { children ages } 2 \text { and above }\end{array}$ & $\begin{array}{l}\text { - effects of poverty may be } \\
\text { mitigated by factors such as } \\
\text { geography (e.g., rural vs. urban) }\end{array}$ \\
\hline $\begin{array}{l}\text { Scannapieco \& } \\
\text { Carrick (2003) }\end{array}$ & $\begin{array}{l}\text { - studied differences among poor families } \\
\text { who maltreat their children and those who } \\
\text { do not maltreat their children } \\
\text { data collected from administrative case } \\
\text { records in Dallas County, TX from March to } \\
\text { December } 2000 \text { using a case abstraction } \\
\text { form } \\
\text { - } \quad \mathrm{random} \text { sample of families living in poverty } \\
\text { - } N=248 \text { families }\end{array}$ & $\begin{array}{l}\text { - poor families who were } \\
\text { substantiated were more likely } \\
\text { to expose children to unsanitary } \\
\text { conditions within the home, as } \\
\text { well as hazards and other } \\
\text { dangers } \\
\text { maltreating caregivers had fewer } \\
\text { parenting skills and a decreased } \\
\text { capacity as a parent due to } \\
\text { substance abuse and mental } \\
\text { illness }\end{array}$ \\
\hline $\begin{array}{l}\text { Carter \& } \\
\text { Meyers (2007) }\end{array}$ & $\begin{array}{l}\text { - used data from the } 1994 \text { National Study of } \\
\text { Protective, Preventive, and Reunification } \\
\text { Services Delivered to Children and Their } \\
\text { Families (stratified two-stage random } \\
\text { sample) to consider the influence of } \\
\text { poverty indicators and parental } \\
\text { characteristics on physical neglect } \\
\text { analyzed subset of } 1994 \text { study cases where } \\
\text { physical neglect was found to be } \\
\text { substantiated ( } N=431)\end{array}$ & $\begin{array}{l}\text { high correlation between } \\
\text { substantiated physical neglect } \\
\text { and indicators of poverty such as } \\
\text { unemployment and receipt of } \\
\text { social welfare assistance, these } \\
\text { indicators were not found to be } \\
\text { predictive of substantiated } \\
\text { physical neglect } \\
\text { the factors that were strong } \\
\text { predictors of physical neglect } \\
\text { were substance abuse problems } \\
\text { and mental illness among } \\
\text { primary caretakers }\end{array}$ \\
\hline $\begin{array}{l}\text { Jenkins \& } \\
\text { Diamond } \\
\text { (1985) }\end{array}$ & $\begin{array}{l}\text { - data collected in } 1980 \text { from } 2,439 \text { public } \\
\text { welfare departments regarding children in } \\
\text { care (by ethnic group) for over } 3.000 \\
\text { counties in the U.S. ( } N=301,943 \text { children) } \\
25 \% \text { of reporting units ( } 80 \% \text { counties) were } \\
\text { randomly selected; sample drawn from } \\
\text { each state, representing approximately } \\
25 \% \text { of all children in placement ( } N=565 \\
\text { units) } \\
\text { counties selected in which Black child (0- } \\
15 \text { years) population was either } 5-10 \% \text { ( } N= \\
46 \text { counties) or } 30-50 \% \text { ( } N=48 \text { counties) } \\
\text { analysis: } t \text {-test (significant difference mean } \\
\text { levels of placement between counties with } \\
\text { different population statistics) }\end{array}$ & $\begin{array}{l}\text { support for the visibility } \\
\text { hypothesis: Black children were } \\
\text { more likely to enter foster care } \\
\text { when Black people comprised } \\
\text { only } 5-10 \% \text { of the local } \\
\text { population versus } 30-50 \%\end{array}$ \\
\hline
\end{tabular}




\begin{tabular}{|c|c|c|}
\hline \multicolumn{3}{|c|}{ FAMILY STRUCTURE } \\
\hline Berger (2005) & $\begin{array}{l}\text { analyzed data from the } 1985 \text { National } \\
\text { Family Violence Survey (NFVS) in an effort } \\
\text { to estimate the effects of income and } \\
\text { other factors on physical violence toward } \\
\text { children } \\
\text { NFVS includes a nationally representative } \\
\text { sample of } 6,002 \text { families self-reporting } \\
\text { parenting behavior } \\
\text { random selection of } 2,760 \text { cases from the } \\
\text { NFVS } \\
\text { analysis: probit and ordered probit models } \\
\text { used to explore relationships between } \\
\text { income, family characteristics, state } \\
\text { characteristics, and physical violence }\end{array}$ & $\begin{array}{l}\text { - income likely has a more } \\
\text { substantial impact on parental } \\
\text { violence in single-parent families } \\
\text { than two-parent families }\end{array}$ \\
\hline $\begin{array}{l}\text { Nobes \& Smith } \\
(2002)\end{array}$ & $\begin{array}{l}\text { - compared the extent of physical } \\
\text { punishment of children in one-parent (lone } \\
\text { mother) and two-parent (mother and } \\
\text { father) families } \\
\text { families with children } 1-11 \text { years } \\
\text { randomly selected from UK health } \\
\text { authority lists in an urban area outside } \\
\text { London; stratified by gender of child } \\
\text { face-to-face, semi-structured interviews; } \\
\text { interviewed a total of } 498 \text { parents from } \\
399 \text { families in the U.K., asking them about } \\
\text { the nature, severity, and frequency of their } \\
\text { punishment of their children }\end{array}$ & $\begin{array}{l}\text { - } \quad \text { the frequency of lone mothers' } \\
\text { and partnered mothers' use of } \\
\text { physical punishment did not } \\
\text { differ significantly; however, } \\
\text { inclusion of fathers showed that } \\
\text { children in two-parent families } \\
\text { were punished more frequently } \\
\text { than children in one-parent } \\
\text { families } \\
\text { also explored confounding } \\
\text { factors that might influence } \\
\text { associations between family } \\
\text { structure and use of physical } \\
\text { punishment; found that } \\
\text { regarding measures of social } \\
\text { deprivation, including poverty, } \\
\text { lone parents were, on average, } \\
\text { worse off than partnered parents } \\
\text { among families with higher } \\
\text { incomes, lone parents were } \\
\text { more likely to have used severe } \\
\text { punishments, but this difference } \\
\text { was not significant among those } \\
\text { in lower income groups } \\
\text { lone mothers were no more } \\
\text { punitive than partnered } \\
\text { mothers, despite (or maybe } \\
\text { because of) their exposure to } \\
\text { social disadvantages and their } \\
\text { children experience less frequent } \\
\text { and less severe physical } \\
\text { punishment than do those in } \\
\text { two-parent families }\end{array}$ \\
\hline
\end{tabular}




\begin{tabular}{|c|c|c|}
\hline $\begin{array}{l}\text { Sedlack \& } \\
\text { Broadhurst } \\
\text { (1996) } \\
\text { NIS-3 }\end{array}$ & $\begin{array}{l}\text { - NIS-3 includes data regarding children not } \\
\text { reported or reported and screened out } \\
\text { without investigation } \\
\text { nationally representative sample of } 42 \\
\text { counties } \\
\text { three-month study period - September to } \\
\text { December } 1993 \\
\text { sentinel survey methodology - community } \\
\text { professionals serving children and families } \\
\text { (5,612 professionals in } 800 \text { non-CPS } \\
\text { agencies) } \\
\text { also surveyed public child welfare } \\
\text { employees } \\
\text { collected total of } 50,729 \text { data forms }\end{array}$ & $\begin{array}{l}\text { children in single-parent families } \\
\text { are at higher risk of physical } \\
\text { abuse and severe neglect than } \\
\text { children in two-parent families }\end{array}$ \\
\hline $\begin{array}{l}\text { Turner, } \\
\text { Finkelhor, \& } \\
\text { Ormrod (2007) }\end{array}$ & $\begin{array}{l}\text { - examined differences in victimization } \\
\text { among those living in biological or } \\
\text { adoptive, two-parent households, } \\
\text { stepfamily households, and single-parent } \\
\text { households } \\
\text { data from Developmental Victimization } \\
\text { Survey (DVS) - national probability sample } \\
\text { of } 1,000 \text { children aged } 10 \text { to } 17 \\
\text { telephone surveys: random digital dial } \\
\text { methodology; December } 2002 \text { to February } \\
2003 \text {; interviews with one adult and one } \\
\text { child in each household } \\
\text { sample somewhat underrepresented Black } \\
\text { and Hispanic families }\end{array}$ & $\begin{array}{l}\text { - youth in single-parent families } \\
\text { and stepfamilies experience } \\
\text { greater victimization than youth } \\
\text { living with two biological or } \\
\text { adoptive parents; however, } \\
\text { youth in stepfamilies reported } \\
\text { the greatest exposure to } \\
\text { individual forms of victimization, } \\
\text { such as child maltreatment } \\
\text { youth in single-parent families } \\
\text { were more likely to be exposed } \\
\text { to victimization outside of the } \\
\text { family context, as a result of } \\
\text { lower socio-economic status and } \\
\text { residence in more violent } \\
\text { neighborhoods and schools }\end{array}$ \\
\hline $\begin{array}{l}\text { Dufour, } \\
\text { Lavergne, } \\
\text { Larrivée, \& } \\
\text { Trocmé (2007) }\end{array}$ & $\begin{array}{l}\text { - explored the differences between fathers } \\
\text { and mothers with regard to family } \\
\text { structure and child neglect } \\
\text { data from the } 2003 \text { Canadian Incidence } \\
\text { Study of Reported Child Abuse and Neglect } \\
\text { (CIS); } N=11,562 \text { child maltreatment } \\
\text { investigations between October and } \\
\text { December } 2003 \text {; representative sample of } \\
63 \text { child welfare service areas; four-stage } \\
\text { stratified cluster sampling process } \\
\text { secondary data analysis; } N=1,266 \\
\text { almost half of the cases studied were } \\
\text { single-parent families; many of these were } \\
\text { families whose female heads were } \\
\text { extremely vulnerable, due to issues such as } \\
\text { little education, mental illness, and no } \\
\text { employment income }\end{array}$ & $\begin{array}{l}\text { situations of neglect often } \\
\text { include men, whether they } \\
\text { reside with their children in a } \\
\text { two-parent family ( } 38 \% \text { of } \\
\text { neglectful families) or they } \\
\text { maintain a link with their } \\
\text { children, but live outside the } \\
\text { home (approximately } 35 \% \text { of } \\
\text { child neglect situations) }\end{array}$ \\
\hline
\end{tabular}




\begin{tabular}{|c|c|c|}
\hline $\begin{array}{l}\text { Harris \& } \\
\text { Courtney } \\
(2003)\end{array}$ & $\begin{array}{l}\text { - considered a key point in the child welfare } \\
\text { process, family reunification, and its } \\
\text { association with race/ethnicity and family } \\
\text { structure } \\
\text { data from extract of the Foster Care } \\
\text { Information System, which was the } \\
\text { administrative child welfare data system of } \\
\text { California } \\
10 \% \text { random sample of White, Black, and } \\
\text { Hispanic children in } 57 \text { of } 58 \text { counties who } \\
\text { experienced a first spell of out-of-home } \\
\text { care from } 1992 \text { to } 1996 ; N=9,162\end{array}$ & $\begin{array}{l}\text { children from two-parent } \\
\text { families were returned home } \\
\text { faster than children from single- } \\
\text { parent homes, regardless of the } \\
\text { parent's gender } \\
\text { reunification for African- } \\
\text { American children from single- } \\
\text { parent families was the slowest } \\
\text { and Hispanic children in two- } \\
\text { parent families were reunified at } \\
\text { the fastest rates }\end{array}$ \\
\hline $\begin{array}{l}\text { Garland, } \\
\text { Hough, } \\
\text { Landsverk, } \\
\text { McCabe, Yeh, } \\
\text { Ganger, \& } \\
\text { Reynolds } \\
(2000)\end{array}$ & $\begin{array}{l}\text { study of mental health service utilization } \\
\text { among children in foster care } \\
\text { - } \mathrm{N}=659 \text { White, Black, and Latino youth } \\
\text { ages 2-17 years who entered foster care in } \\
\text { San Diego, CA between May } 1990 \text { and } \\
\text { October } 1991 \text { and remained in placement } \\
\text { for at least five months } \\
\text { - sample drawn from a larger cohort } \\
\text { - measurement: assessment scales, } \\
\text { caregiver interviews, administrative data } \\
\text { for demographics } \\
\text { analysis: bivariate/chi square, multivariate } \\
\text { logistic regression }\end{array}$ & $\begin{array}{l}\text { found a significant difference in } \\
\text { utilization rates across racial and } \\
\text { ethnic groups } \\
\text { even when controlling for the } \\
\text { confounding effects of age, } \\
\text { severity of behavior problems, } \\
\text { and type of maltreatment, Black } \\
\text { children were still significantly } \\
\text { less likely to receive mental } \\
\text { health services than White } \\
\text { children }\end{array}$ \\
\hline $\begin{array}{l}\text { Rodenborg } \\
(2004)\end{array}$ & $\begin{array}{l}\text { - considered outcomes for African American } \\
\text { children and children in poverty } \\
\text { examined provision of services, such as } \\
\text { housing assistance, to address the poverty- } \\
\text { related needs of families involved in the } \\
\text { child welfare system } \\
\text { secondary data taken from large national } \\
\text { sample of case file data collected in the } \\
1994 \text { National Study of Protective, } \\
\text { Preventive, and Reunification Services } \\
\text { Delivered to Children and Families } \\
\text { analyzed cases opened between March } 1, \\
1993 \text { and February } 28,1994 \\
\text { - } \mathrm{N}=725 \text { cases }\end{array}$ & $\begin{array}{l}\text { Black children and families' } \\
\text { poverty-related needs were } \\
\text { more likely to go unmet than } \\
\text { White children and families' } \\
\text { needs }\end{array}$ \\
\hline
\end{tabular}




\begin{tabular}{|c|c|c|}
\hline $\begin{array}{l}\text { Lu, Landsverk, } \\
\text { Ellis-Macleod, } \\
\text { Newton, } \\
\text { Ganger, \& } \\
\text { Johnson (2004) }\end{array}$ & $\begin{array}{l}\text { - secondary data analysis; chart file review; } \\
\text { administrative data analysis } \\
\text { reviewed the records of nearly 4,000 } \\
\text { children who were referred to a public } \\
\text { receiving home for suspected } \\
\text { maltreatment } \\
\text { cohort gathered between May } 1990 \text { and } \\
\text { October } 1991 \text { for the Foster Care Mental } \\
\text { Health Project, a longitudinal study of } \\
\text { children placed in out-of-home care in San } \\
\text { Diego County, CA } \\
\text { - examined correlation between background } \\
\text { characteristics and case outcome decisions } \\
\text { - bivariate and multivariate analysis }\end{array}$ & $\begin{array}{l}\text { African American children are } \\
\text { overrepresented in the child } \\
\text { protective system, are most } \\
\text { likely to be placed out-of-home, } \\
\text { and are less likely to be reunited } \\
\text { with their family of origin than } \\
\text { any other racial group in the } \\
\text { study }\end{array}$ \\
\hline $\begin{array}{l}\text { Lane, Rubin, } \\
\text { Monteith, and } \\
\text { Christian } \\
\text { (2002) }\end{array}$ & $\begin{array}{l}\text { - } \text { review of the medical records of Black and } \\
\text { White toddlers who were seen for bone } \\
\text { injuries } \\
\text { retrospective chart review conducted at an } \\
\text { urban U.S. academic children's hospital } \\
\text { among } 388 \text { children younger than three } \\
\text { years old who had been hospitalized for } \\
\text { treatment of an acute primary skull or } \\
\text { long-bone fracture between } 1994 \text { and } \\
2000 \\
\text { children with perpetrator-admitted abuse, } \\
\text { bone disease, trauma, or injury cause by } \\
\text { vehicle crash were excluded } \\
\text { main outcome measures: ordering of } \\
\text { skeletal surveys and filing reports of } \\
\text { suspected abuse }\end{array}$ & $\begin{array}{l}\text { more than } 65 \% \text { of children of } \\
\text { color had skeletal surveys } \\
\text { performed, while only } 31 \% \text { of } \\
\text { White children underwent this } \\
\text { same test } \\
\text { CPS reports were filed for } 22.5 \% \\
\text { of White children versus } 52.9 \% \\
\text { of children of color }\end{array}$ \\
\hline $\begin{array}{l}\text { Garland \& } \\
\text { Besinger } \\
\text { (1997) }\end{array}$ & 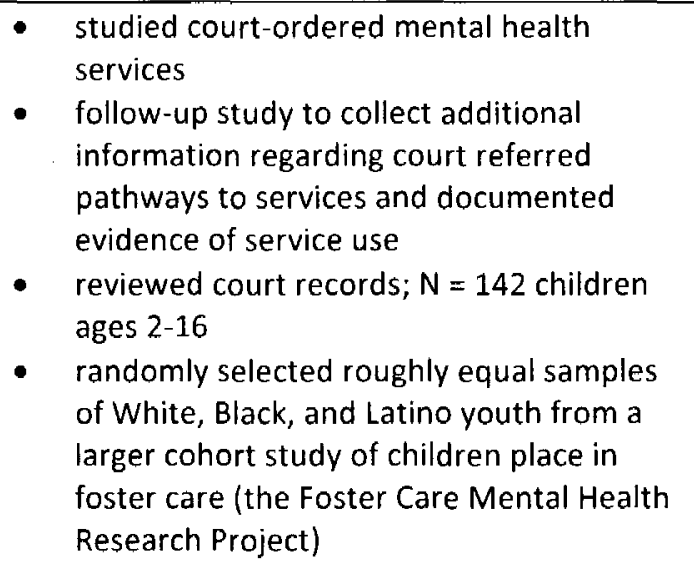 & $\begin{array}{l}\text { - Black children were less likely to } \\
\text { receive court orders for services } \\
\text { than white children }\end{array}$ \\
\hline
\end{tabular}




\begin{tabular}{|c|c|c|}
\hline $\begin{array}{l}\text { Garland, } \\
\text { Hough, } \\
\text { Landsverk, } \\
\text { McCabe, Yeh, } \\
\text { Ganger, \& } \\
\text { Reynolds } \\
(2000)\end{array}$ & $\begin{array}{l}\text { - } 5 \text { tudy of mental health service utilization } \\
\text { among children in foster care } \\
\mathrm{N}=659 \text { White, Black, and Latino youth } \\
\text { ages 2-17 years who entered foster care in } \\
\text { San Diego, CA between May } 1990 \text { and } \\
\text { October } 1991 \text { and remained in placement } \\
\text { for at least five months } \\
\text { - } \quad \text { ample drawn from a larger cohort } \\
\text { measurement: assessment scales, } \\
\text { caregiver interviews, administrative data } \\
\text { for demographics } \\
\text { analysis: bivariate/chi square, multivariate } \\
\text { logistic regression }\end{array}$ & $\begin{array}{l}\text { - even when services were } \\
\text { ordered, Black children had } \\
\text { lower levels of service provision } \\
\text { and utilization than White } \\
\text { children }\end{array}$ \\
\hline $\begin{array}{l}\text { Berger, } \\
\text { McDaniel, \& } \\
\text { Paxon (2006) }\end{array}$ & 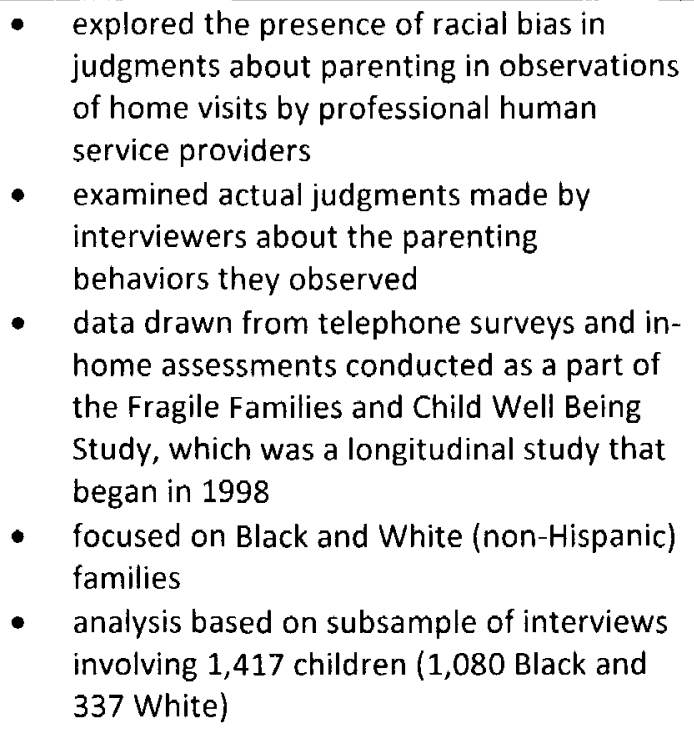 & $\begin{array}{l}\text { - Black parents were judged more } \\
\text { harshly by the professionals on } \\
\text { subjective measures of parenting } \\
\text { such as annoyance, criticism, and } \\
\text { hostility } \\
\text { there was no racial bias found, } \\
\text { however, in judgments of more } \\
\text { objective measures such as } \\
\text { spanking }\end{array}$ \\
\hline $\begin{array}{l}\text { Hansen, } \\
\text { Bumby, } \\
\text { Lundquist, } \\
\text { Chandler, Le, \& } \\
\text { Futa (1997) }\end{array}$ & 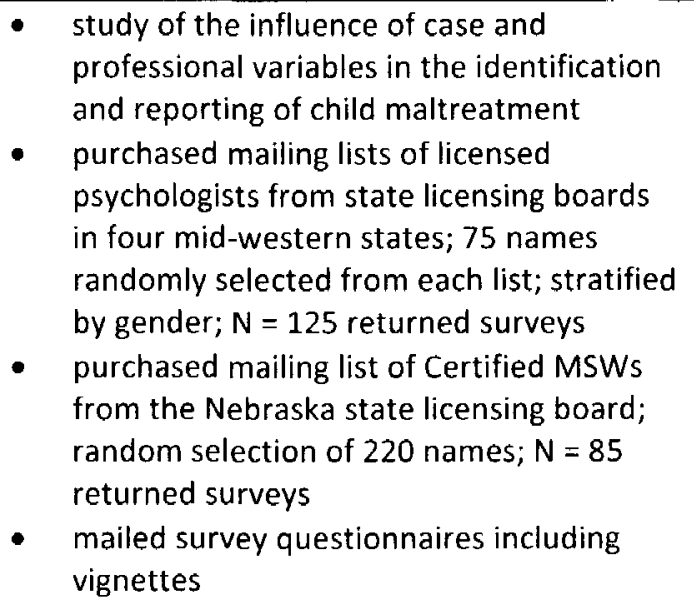 & $\begin{array}{l}\text { - } \\
\text { psace had the most impact on } \\
\text { workers' ratings of severity of } \\
\text { maltreatment and the need to } \\
\text { report } \\
\text { professionals were more likely to } \\
\text { rate vignettes describing possible } \\
\text { maltreatment among African } \\
\text { American families as less severe } \\
\text { and less likely to be reported } \\
\text { than similar vignettes including } \\
\text { White families }\end{array}$ \\
\hline
\end{tabular}




\begin{tabular}{|l|l|l|}
\hline $\begin{array}{l}\text { Green, } \\
\text { Kiernan-Stern, } \\
\text { (2005) }\end{array}$ & $\begin{array}{l}\text { studied agency-based social workers' } \\
\text { attitudes about ethnic and cultural } \\
\text { diversity } \\
\text { data collection instruments for this study } \\
\text { nested within a larger survey that } \\
\text { compared more general professional } \\
\text { attitudes and competencies of members of } \\
\text { a state chapter of NASW (N = 157) with } \\
\text { those of the national membership (135); } \\
\text { comparable demographics } \\
\text { anonymous mail survey questionnaire; } \\
\text { utilized the Cognitive and Affective Racial } \\
\text { Attitudes scales of the Quick } \\
\text { Discrimination Index completed } \\
\text { sample of 257 White members of NASW }\end{array}$ & $\begin{array}{l}\text { social workers expressed some } \\
\text { ambivalence regarding a desire } \\
\text { for more interaction with people } \\
\text { of color } \\
12 \% \text { of those surveyed believed } \\
\text { that racism is no longer a major } \\
\text { problem in the U.S., indicating a } \\
\text { lack of racial awareness }\end{array}$ \\
\hline $\begin{array}{l}\text { Rehner, Ishee, } \\
\text { Salloum, \& } \\
\text { Velasu (1997) }\end{array}$ & $\begin{array}{l}\text { studied social workers' attitudes toward } \\
\text { the poor } \\
\text { data collected at the NASW Mississippi } \\
\text { chapter's annual conference in 1995 } \\
\text { 20\% of conference attendees completed } \\
\text { surveys; N = 186 } \\
\text { majority of sample relatively young White } \\
\text { women } \\
\text { collected demographic data and responses } \\
\text { to the Attitudes toward Poverty scale }\end{array}$ & $\begin{array}{l}\text { social workers had relatively } \\
\text { positive attitudes toward the } \\
\text { poor overall } \\
\text { age and years of experience } \\
\text { correlated with ATP scores; } \\
\text { older, more experienced social } \\
\text { workers had more favorable } \\
\text { attitudes toward the poor }\end{array}$ \\
\hline
\end{tabular}




\section{Appendix K: Summary of Decision Making Literature}

Note: Findings preceded by an asterisk (*) are related to either race, SES, or family structure, which are the case characteristics of interest in the present study.

\begin{tabular}{|c|c|c|c|}
\hline $\begin{array}{l}\text { Author } \\
\text { s }\end{array}$ & Method/Design & Key Findings & Limitations/Gaps \\
\hline $\begin{array}{l}\text { Munro } \\
\text { (1999) }\end{array}$ & $\begin{array}{l}\text { content analysis on all } \\
\text { available child fatality reports } \\
(N=45) \text { published in Britain } \\
\text { between } 1973 \text { and } 1994\end{array}$ & $\begin{array}{l}\text { in many instances, once a } \\
\text { decision had been made } \\
\text { regarding a case, social } \\
\text { workers were slow to revise } \\
\text { their judgment, even in the } \\
\text { presence of new information; } \\
\text { social workers were making } \\
\text { decisions without the benefit } \\
\text { of extensive information } \\
\text { about the families they were } \\
\text { serving }\end{array}$ & $\begin{array}{l}\text { The child fatality reports } \\
\text { were not prepared } \\
\text { specifically for this } \\
\text { research project. They } \\
\text { vary greatly in size, } \\
\text { structure, and the } \\
\text { amount of detail they } \\
\text { include and in their } \\
\text { coverage of the issues of } \\
\text { interest to this research } \\
\text { project. This affects the } \\
\text { precision of the analysis. } \\
\text { Data not gathered } \\
\text { recently. }\end{array}$ \\
\hline \multicolumn{4}{|c|}{ Intake/Screening } \\
\hline $\begin{array}{l}\text { Karski } \\
\text { (1999) }\end{array}$ & $\begin{array}{l}\text { analysis of maltreatment } \\
\text { reports and agency response } \\
\text { to allegations in a public CW } \\
\text { agency in California; chart file } \\
\text { review of random sample of } \\
557 \text { reports made to a county } \\
\text { CPS agency from } 1993-1994 \\
\text { and interviews of all } 23 \\
\text { intake and assessment } \\
\text { workers in the county; } \\
\text { bivariate and multivariate } \\
\text { analyses, logistic regression }\end{array}$ & $\begin{array}{l}\text {--case characteristics do } \\
\text { influence screening decisions } \\
\text { (did not consider race) } \\
\text {--sexual abuse reports more } \\
\text { likely to be investigated than } \\
\text { physical abuse reports } \\
\text {--drug use and lack of } \\
\text { support increased likelihood } \\
\text { of court referral } \\
\text { * families who have AFDC are } \\
\text { more likely to be investigated }\end{array}$ & $\begin{array}{l}\text { Sampling was made by } \\
\text { family member, so larger } \\
\text { families are } \\
\text { oversampled. } \\
\text { Part of the missing data } \\
\text { (18-25\% of the three } \\
\text { case sets) included many } \\
\text { active cases, so the } \\
\text { findings may understate } \\
\text { the problems of many } \\
\text { families with extensive } \\
\text { experience of the child } \\
\text { protective system. } \\
\text { The analysis reflects } \\
\text { workers' observations } \\
\text { noted in case files (no an } \\
\text { independent measure) } \\
\text { Data not gathered } \\
\text { recently }\end{array}$ \\
\hline
\end{tabular}




\begin{tabular}{|c|c|c|c|}
\hline $\begin{array}{l}\text { Gryzlak } \\
\text {, Wells, } \\
\& \\
\text { Johnso } \\
\text { n } \\
(2005)\end{array}$ & $\begin{array}{l}\text { examination of decision } \\
\text { making at intake; chart file } \\
\text { review of } 960 \text { CPS intake } \\
\text { contacts from five sites in } \\
\text { four states (purposive } \\
\text { sampling) gathered by US } \\
\text { DHHS until 1991; data } \\
\text { collection form completed } \\
\text { for each case by social } \\
\text { workers; forms included } \\
\text { report characteristics, child } \\
\text { characteristics, family } \\
\text { structure, worker decision, } \\
\text { and reasoning; survey of } \\
\text { caseworkers who completed } \\
\text { the data collection forms and } \\
\text { their supervisors, which } \\
\text { provided some demographic } \\
\text { and contextual data }\end{array}$ & $\begin{array}{l}\text {--predictors of screening } \\
\text { decisions: the CPS site, } \\
\text { allegation, type of injury, } \\
\text { source of the report, } \\
\text { completeness of the data } \\
\text { recording form, gender of } \\
\text { child, age of youngest child, } \\
\text { and type of parental } \\
\text { problems } \\
\text { *interaction of race/ethnicity } \\
\text { and type of maltreatment } \\
\text { alleged affected screening } \\
\text { decisions } \\
\text { *workers of color screened in } \\
\text { half of cases involving } \\
\text { children of color and three- } \\
\text { quarters of cases involving } \\
\text { White children; White } \\
\text { workers screened in half of } \\
\text { cases involving White } \\
\text { children and about } 40 \\
\text { percent of cases involving } \\
\text { children of color }\end{array}$ & $\begin{array}{l}\text { - Data not gathered } \\
\text { recently. } \\
\text { - Focus on intake } \\
\text { decisions. }\end{array}$ \\
\hline $\begin{array}{l}\text { Platt } \\
(2006)\end{array}$ & $\begin{array}{l}\text { examined decision making at } \\
\text { initial referral stage; } \\
\text { qualitative interviews and } \\
\text { chart file review; } N=23 \text { cases } \\
\text { and } 14 \text { workers (interviews } \\
\text { with worker and parents in } \\
\text { each case); UK }\end{array}$ & $\begin{array}{l}{ }^{*} \text { CPS referrals evaluated on } \\
\text { the basis of } 5 \text { key factors: } \\
\text { severity, specificity, risk, } \\
\text { parental accountability, and } \\
\text { corroboration (did not } \\
\text { consider race, SES, or family } \\
\text { structure) }\end{array}$ & $\begin{array}{l}\text { Only a small number of } \\
\text { cases in the present } \\
\text { study proceeded to } \\
\text { investigation, so this } \\
\text { interpretation is relying } \\
\text { to a significant degree on } \\
\text { social workers' general } \\
\text { opinions, expressed in } \\
\text { the interviews, about } \\
\text { how alleged child abuse } \\
\text { referrals were handled. } \\
\text { Small sample size. }\end{array}$ \\
\hline $\begin{array}{l}\text { Parada, } \\
\text { Barnoff } \\
\text { \& } \\
\text { Colema } \\
\text { n } \\
(2007)\end{array}$ & $\begin{array}{l}\text { explored "professional } \\
\text { agency"; qualitative; } \\
\text { institutional ethnography } \\
\text { method; documentation } \\
\text { review and interview with } \\
\text { social workers }(\mathrm{N}=10) \text {; } \\
\text { Canada }\end{array}$ & $\begin{array}{l}{ }^{*} \text { SW's exhibited complex } \\
\text { decision making (beyond } \\
\text { protocol) } \\
{ }^{*} \text { more experience } \rightarrow \text { more } \\
\text { DM comfort }\end{array}$ & $\begin{array}{l}\text { Small sample size. } \\
\text { - Focus on professional } \\
\text { agency; not linked to } \\
\text { particular decision point. }\end{array}$ \\
\hline
\end{tabular}




\begin{tabular}{|c|c|c|c|}
\hline \multicolumn{4}{|c|}{ Investigation/Assessment } \\
\hline $\begin{array}{l}\text { Stevens } \\
\text { (1998) }\end{array}$ & $\begin{array}{l}\text { attempted to identify factors } \\
\text { that influence CPS worker } \\
\text { decisions regarding case } \\
\text { disposition following the } \\
\text { initial maltreatment } \\
\text { investigation; secondary data } \\
\text { analysis; case record review } \\
(\mathrm{N}=336) \text { of reports to } \mathrm{NJ} \\
\text { public child welfare agency } \\
\text { from } 1988-1989 ; \text { worker } \\
\text { questionnaire ( } \mathrm{N}=180) \text {; } \\
\text { retrospective case control } \\
\text { approach to ensure sufficient } \\
\text { numbers of occurrence under } \\
\text { investigation }\end{array}$ & $\begin{array}{l}\text {--case and worker } \\
\text { characteristics impacted } \\
\text { decisions, but context did not } \\
\text { *Black children had a lower } \\
\text { possibility of a case being } \\
\text { opened }\end{array}$ & $\begin{array}{l}\text { - Secondary data analysis. } \\
\text { - Data not gathered } \\
\text { recently. }\end{array}$ \\
\hline $\begin{array}{l}\text { English, } \\
\text { Marsha } \\
\text { II, } \\
\text { Coghla } \\
\text { n, } \\
\text { Brumm } \\
\text { el, \& } \\
\text { Orme } \\
(2002)\end{array}$ & $\begin{array}{l}\text { examination of factors used } \\
\text { in decision making; analysis } \\
\text { of existing data from 12,871 } \\
\text { referrals in Washington } \\
\text { State; } 37 \text { variables (e.g., } \\
\text { history of DV, disability, } \\
\text { hazardous home, } \\
\text { cooperation with agency) } \\
\text { highlighted from Washington } \\
\text { Risk Model (defined from } \\
0=\text { no risk to } 5=\text { high risk); } \\
\text { qualitative interviews of } 200 \\
\text { CPS workers regarding what } \\
\text { factors they used in reaching } \\
\text { their decisions; used neural } \\
\text { network analysis }\end{array}$ & $\begin{array}{l}\text { *Native American children } \\
\text { had a higher rate of neglect } \\
\text { substantiation } \\
\text { *no significant racial } \\
\text { difference for abuse } \\
\text { *White children had a } \\
\text { significantly lower } \\
\text { substantiation rate for } \\
\text { neglect than all other races } \\
\text { combined } \\
\text {--chronicity important }\end{array}$ & $\begin{array}{l}\text { Children's Administration } \\
\text { Management } \\
\text { Information System } \\
\text { reports contain data } \\
\text { integrity issues that may } \\
\text { affect the accuracy of } \\
\text { data and/or conclusions } \\
\text { drawn from the data. } \\
\text { No information provided } \\
\text { re: sample demographics } \\
\text { for data set or workers. }\end{array}$ \\
\hline $\begin{array}{l}\text { William } \\
\text { s \& } \\
\text { Soydan } \\
\text { (2005) }\end{array}$ & $\begin{array}{l}\text { analysis was part of a cross- } \\
\text { national study of CPS } \\
\text { decision making in which } \\
\text { questionnaires were mailed } \\
\text { and administered face-to- } \\
\text { face to } 713 \text { CPS social } \\
\text { workers in comparable cities } \\
\text { in Denmark, Germany, } \\
\text { Sweden, the U.S. and the UK } \\
\text { from 1998-2002; } \\
\text { questionnaire included one } \\
\text { of two case vignettes } \\
\text { developing in three stages, }\end{array}$ & $\begin{array}{l}\text { *quantitative analysis: no } \\
\text { significant difference in DM } \\
\text { by ethnicity (Forslund, } \\
\text { Jergeby, Soydan, \& Williams, } \\
2002 \text { ) } \\
{ }^{*} \text { qualitative analysis: of those } \\
\text { who considered vignette with } \\
\text { ethnic cue, evidence of } \\
\text { stereotyping, use of cultural } \\
\text { deficit models, } \\
\text { ethnocentrism, use of } \\
\text { universalist and color-blind } \\
\text { approaches }\end{array}$ & $\begin{array}{l}\text { Possible cultural } \\
\text { differences due to } \\
\text { gathering data from } \\
\text { several cultures. }\end{array}$ \\
\hline
\end{tabular}




\begin{tabular}{|c|c|c|c|}
\hline & $\begin{array}{l}\text { ethnicity manipulated; } \\
\text { between subjects design; half } \\
\text { of respondents were given } \\
\text { vignette with name common } \\
\text { to country and other half } \\
\text { were given vignette with the } \\
\text { name Ali Habib }\end{array}$ & & \\
\hline $\begin{array}{l}\text { Mccon } \\
\text { nell, } \\
\text { Llewell } \\
\text { yn, \& } \\
\text { Ferrona } \\
\text { to } \\
(2006)\end{array}$ & $\begin{array}{l}\text { focus of study was on } \\
\text { decisions to take court action } \\
\text { in cases of parents with an } \\
\text { intellectual disability; } \\
\text { reviewed } 285 \text { court files and } \\
\text { conducted } 17 \text { focus groups } \\
\text { involving } 155 \text { workers, } \\
\text { majority ( } 85 \%) \text { of the group } \\
\text { participants were frontline } \\
\text { child protection workers; } \\
\text { content analysis of the court } \\
\text { files and a thematic analysis } \\
\text { of the transcripts from the } \\
\text { group interviews }\end{array}$ & $\begin{array}{l}\text {--found parental compliance } \\
\text { to be the "bottom line" for } \\
\text { the child protection workers } \\
\text { in the study; parental } \\
\text { compliance was found to be } \\
\text { a significant determinant of } \\
\text { court action }\end{array}$ & - Focus on court action. \\
\hline $\begin{array}{l}\text { Landsm } \\
\text { an \& } \\
\text { Hartley } \\
(2007)\end{array}$ & $\begin{array}{l}\text { examined factors influencing } \\
\text { how child welfare workers } \\
\text { attribute responsibility for } \\
\text { child maltreatment and } \\
\text { safety in domestic violence } \\
\text { cases; factorial survey } \\
\text { approach; mailed } \\
\text { questionnaire including } 5 \\
\text { vignettes; vignettes } \\
\text { constructed by randomly } \\
\text { assigning characteristics to } \\
\text { vignettes believed to be } \\
\text { related to assessments about } \\
\text { responsibility for child } \\
\text { maltreatment; within- } \\
\text { subjects design; } \\
\text { systematically sampled } 200 \\
\text { workers in the state; final } \\
\mathrm{N}=87 ; \text { variables: presence or } \\
\text { absence of DV, maltreatment } \\
\text { type, degree of responsibility } \\
\text { for three types of } \\
\text { maltreatment, professional } \\
\text { demographics; analysis: least } \\
\text { squares regression }\end{array}$ & $\begin{array}{l}\text {--the presence of DV } \\
\text { heightens workers } \\
\text { assessments of responsibility } \\
\text { for CM and concerns for child } \\
\text { safety } \\
\text { * concern predicted by race } \\
\text { (AA - decreased concerns } \\
\text { about child safety) and } 6 \\
\text { other variables, including } \\
\text { prior referral }\end{array}$ & $\begin{array}{l}\text { The sample size, though } \\
\text { respectable, is not large } \\
\text { relative to the number of } \\
\text { parameters in each } \\
\text { model. } \\
\text { A caveat to interpreting } \\
\text { the results is that in } \\
\text { those case vignettes } \\
\text { involving domestic } \\
\text { violence, both the child } \\
\text { maltreatment and } \\
\text { domestic violence } \\
\text { incident were occurring } \\
\text { simultaneously. } \\
\text { Findings not readily } \\
\text { generalizable. }\end{array}$ \\
\hline
\end{tabular}




\begin{tabular}{|c|c|c|c|}
\hline \multicolumn{4}{|c|}{ Removal/Placement } \\
\hline $\begin{array}{l}\text { Rossi, } \\
\text { Scheur } \\
\text { man, \& } \\
\text { Budde } \\
\text { (1999) }\end{array}$ & $\begin{array}{l}\text { analysis was part of a study } \\
\text { designed to explore the } \\
\text { degree of agreement } \\
\text { between experts and front- } \\
\text { line workers on decisions to } \\
\text { place children in out-of-home } \\
\text { care or refer them to family } \\
\text { preservation services; mailed } \\
\text { and face-to-face } \\
\text { questionnaire including } \\
\text { either } 70 \text { case summaries for } \\
\text { experts or } 18 \text { case summaries } \\
\text { for workers ( } 4 \text { same for all } \\
\text { workers, } 14 \text { randomly } \\
\text { assigned) in } 1994 \text { and } 1995 ; \\
\text { within-subjects; } N=27 \\
\text { experts, } 103 \text { CPS } \\
\text { investigators; analysis } \\
\text { (multinominal logit } \\
\text { regression and calculated } \\
\text { Kish design effect measures) } \\
\text { based on } 1,890 \text { expert } \\
\text { decisions and } 1,854 \text { worker } \\
\text { decisions }\end{array}$ & $\begin{array}{l}\text {--most of the case variables } \\
\text { did not play a significant role } \\
\text { in decisions } \\
\text {--mental illness and } \\
\text { substance abuse was } \\
\text { associated with lower } \\
\text { likelihood of either } \\
\text { placement or services } \\
\text {--families in which support } \\
\text { and receptiveness to change } \\
\text { were present were likely to } \\
\text { have children placed, but } \\
\text { were also more likely receive } \\
\text { services than to have a child } \\
\text { placed } \\
\text {--prior complaint was the } \\
\text { most influential variable in } \\
\text { decision-making; families } \\
\text { with prior complaints much } \\
\text { more likely to have their } \\
\text { children taken into custody } \\
\text { *families who showed signs } \\
\text { of being interested in change } \\
\text { and in which there was some } \\
\text { income from employment } \\
\text { were less likely to have their } \\
\text { children taken into custody } \\
\text { and more likely to be } \\
\text { referred for family } \\
\text { preservation services }\end{array}$ & $\begin{array}{l}\text { Focus on degree of } \\
\text { agreement, not on } \\
\text { workers decisions. This } \\
\text { study combined samples } \\
\text { b/c workers and experts } \\
\text { demographically similar } \\
\text { and similar in decisions. }\end{array}$ \\
\hline $\begin{array}{l}\text { Galante } \\
\text { (1999) }\end{array}$ & $\begin{array}{l}\text { examined removal decisions } \\
\text { after substantiation; mailed } \\
\text { questionnaire including } 1 \text { of } \\
12 \text { vignettes; multivariate } \\
3 \text { (ambiguity level) } \times 2 \text { (race of } \\
\text { child) } \times 2 \text { (modern racism } \\
\text { score) between-groups } \\
\text { design; } N=903 \mathrm{CW} \text { workers } \\
\text { from NASW sample; } \\
\text { multivariate analyses } \\
\text { conducted independently for } \\
\text { both physical abuse and } \\
\text { neglect vignettes }\end{array}$ & $\begin{array}{l}\text { *White children were more } \\
\text { likely to be removed and thus } \\
\text { protected from high risk } \\
\text { situations than Black children } \\
\text {--decisions involved race, but } \\
\text { this information not used in a } \\
\text { discriminatory manner }\end{array}$ & $\begin{array}{l}\text { The study was designed } \\
\text { to focus on direct service } \\
\text { providers, but the survey } \\
\text { reached others who had } \\
\text { little to know direct } \\
\text { service responsibilities. } \\
\text { - Vast majority of } \\
\text { respondents had } \\
\text { Master's degrees, which } \\
\text { was not indicative of } \\
\text { front-line child welfare } \\
\text { workers-limits } \\
\text { generalizations. } \\
\text { Self selected sample. } \\
\text { Limitations re: scales and } \\
\text { brevity of vignettes. } \\
\text { Data not gathered } \\
\text { recently. }\end{array}$ \\
\hline
\end{tabular}




\begin{tabular}{|c|c|c|c|}
\hline & & & \\
\hline $\begin{array}{l}\text { Gamm } \\
\text { on } \\
(2000)\end{array}$ & $\begin{array}{l}\text { examined role of race and } \\
\text { SES on SW's decision making } \\
\text { regarding family } \\
\text { reunification; mailed } \\
\text { questionnaire including } 1 \text { of } 4 \\
\text { vignettes; varied race and SES } \\
\text { of child and family; between- } \\
\text { subjects; } N=534 \mathrm{CW} \text { workers } \\
\text { from random sample of } \\
\text { NASW members who } \\
\text { indicated } \mathrm{CW} \text { as primary field } \\
\text { of practice; chi square and } \\
\text { logistic regression }\end{array}$ & $\begin{array}{l}\text { *no significant difference in } \\
\text { reunification decisions by } \\
\text { race or SES } \\
\text {--SW characteristics } \\
\text { significant; male SWs were } \\
\text { more likely to have the child } \\
\text { remain in foster care and } \\
\text { more experienced workers } \\
\text { were more likely to reunify }\end{array}$ & $\begin{array}{l}\text { - Sample from NASW not } \\
\text { representative of child } \\
\text { welfare workers. } \\
\text { - Low response rate. } \\
\text { - Data not gathered } \\
\text { recently. }\end{array}$ \\
\hline $\begin{array}{l}\text { Britner } \\
\& \\
\text { Mossle } \\
r(2002)\end{array}$ & $\begin{array}{l}\text { examined role of } \\
\text { professionals' experiences in } \\
\text { foster care placement } \\
\text { decisions; mailed } \\
\text { questionnaire including } 4 \\
\text { vignettes; mixed between- } \\
\text { and within-subjects design; } \\
\text { manipulated race, age, and } \\
\text { pattern of abuse; } N=90 \text {; } \\
\text { various professionals } \\
\text { (judges/GAL's }(N=14), \text { CASA } \\
\text { ( } N=10), \text { SW's }(n=43) \text {, mental } \\
\text { health providers( } n=23) \text { ) in } \\
\text { five Virginia jurisdictions; } \\
\text { MANCOVAs and ANOVAs }\end{array}$ & $\begin{array}{l}\text { *race and chronicity do not } \\
\text { influence the importance of } \\
\text { kinds of information used in } \\
\text { DM } \\
\text {--importance of kinds of } \\
\text { information vary by } \\
\text { profession }\end{array}$ & $\begin{array}{l}\text { - The generalizability of } \\
\text { these findings is limited } \\
\text { by the study's sample } \\
\text { and methodology. } \\
\text { Statistical power to } \\
\text { detect real group } \\
\text { differences is weakened } \\
\text { by the small sample } \\
\text { sizes. } \\
\text { Sex and years of } \\
\text { education were } \\
\text { confounded with group } \\
\text { membership in this } \\
\text { sample. }\end{array}$ \\
\hline $\begin{array}{l}\text { Lazar } \\
(2006)\end{array}$ & $\begin{array}{l}\text { studied effects of Israeli CPS } \\
\text { workers' demographic and } \\
\text { personality variables in } \\
\text { emergency situations; mailed } \\
\text { questionnaire including } 1 \text { of } 4 \\
\text { randomly assigned vignettes; } \\
\text { between-subjects designs; } \\
\mathrm{N}=145 ; \text { IV: SES, age, gender, } \\
\text { ethnicity, family status, } \\
\text { authoritarianism of worker; } \\
\text { analysis: ANOVA, hierarchal } \\
\text { multiple regression, bivariate } \\
\text { correlation }\end{array}$ & $\begin{array}{l}\text {-- more authoritarian workers } \\
\text { tended to choose less severe } \\
\text { intervening decisions for boys } \\
\text { than for girls } \\
\text {--in the battered girl } \\
\text { situation, female workers } \\
\text { tended to choose a less } \\
\text { severe form of intervention } \\
\text { than male workers }\end{array}$ & $\begin{array}{l}\text { - One may argue that the } \\
\text { gender differences } \\
\text { reported here are due to } \\
\text { the differences in the } \\
\text { nature of the situations } \\
\text { and thus reflect the } \\
\text { workers' objective } \\
\text { judgment. However, a } \\
\text { closer examination of } \\
\text { the vignettes reveals } \\
\text { that the abused boys are } \\
\text { younger than the girls } \\
\text { and that one of them is } \\
\text { depicted as a victim of } \\
\text { sexual abuse. }\end{array}$ \\
\hline $\begin{array}{l}\text { Rivaux, } \\
\text { James, } \\
\text { Wittens } \\
\text { trom, } \\
\text { Bauma }\end{array}$ & $\begin{array}{l}\text { considered interaction of } \\
\text { race, poverty, and risk; } \\
\text { analysis of existing data; } \\
\mathrm{N}=123,621 \text { public child } \\
\text { welfare cases in TX; analysis: }\end{array}$ & $\begin{array}{l}\text { *risk scores higher for White } \\
\text { children } \\
\text { * risk scores higher for lower } \\
\text { income families } \\
{ }^{*} \text { Black children more likely to }\end{array}$ & $\begin{array}{l}\text { Did not use analyses that } \\
\text { control for hierarchical } \\
\text { effects that may exist in } \\
\text { this study due to } \\
\text { assessing multiple cases }\end{array}$ \\
\hline
\end{tabular}




\begin{tabular}{|c|c|c|c|}
\hline $\begin{array}{l}\text { nn, } \\
\text { Sheets, } \\
\text { Henry, } \\
\& \\
\text { Jeffries } \\
(2008)\end{array}$ & $\begin{array}{l}\text { examined mean differences } \\
\text { in risk scores as a function of } \\
\text { race and income (ANOVA, } \\
\text { bivariate logistic regression) }\end{array}$ & $\begin{array}{l}\text { have case acted upon; other } \\
\text { contributors include marital } \\
\text { status } \\
\text { *Black children more likely to } \\
\text { be removed } \\
\text { * findings not due to racial } \\
\text { bias, but to racial differences } \\
\text { in the risk threshold used to } \\
\text { make case decisions; this } \\
\text { threshold is higher for White } \\
\text { children }\end{array}$ & $\begin{array}{l}\text { from the same family. } \\
\text { Poverty is situational and } \\
\text { perhaps should be a part } \\
\text { of how we understand } \\
\text { risk. The difference is } \\
\text { that our response to } \\
\text { poverty also needs to be } \\
\text { situational. Poverty, risk, } \\
\text { and race may be related } \\
\text { due to the fundamental } \\
\text { attribution error through } \\
\text { which decisions may be } \\
\text { made based on an } \\
\text { underestimation of } \\
\text { situational forces such as } \\
\text { poverty. Should explore } \\
\text { more on this error in } \\
\text { thinking. }\end{array}$ \\
\hline \multicolumn{4}{|c|}{ Multiple Decision Points } \\
\hline $\begin{array}{l}\text { Harris } \\
\& \\
\text { Hackett } \\
(2008)\end{array}$ & $\begin{array}{l}\text { mixed methods; secondary } \\
\text { analysis of data from King } \\
\text { County Washington research } \\
\text { study ( } \mathrm{N}=6518 \text { ) regarding the } \\
\text { trajectories of Black, White, } \\
\text { and Native American youth at } \\
\text { five decision points in the } \\
\text { child welfare continuum; } \\
\text { focus groups to provide } \\
\text { context for quantitative } \\
\text { findings ( } \mathrm{N}=66 \text { ); various } \\
\text { professionals and clients } \\
\text { interviewed at each stage of } \\
\text { the process, asked: "how do } \\
\text { you make decisions at this } \\
\text { point in the process?" }\end{array}$ & $\begin{array}{l}\text {--decisions influenced by } \\
\text { attitudinal and structural } \\
\text { factors } \\
\text { *subjective factors in risk } \\
\text { assessment may open the } \\
\text { door for racial bias } \\
\text { *administrative data } \\
\text { demonstrated that children } \\
\text { of color were more likely to } \\
\text { have a different set of } \\
\text { experiences at each decision } \\
\text { point than their White } \\
\text { counterparts }\end{array}$ & $\begin{array}{l}\text { Quantitative data were } \\
\text { collected from Children's } \\
\text { Administration } \\
\text { Management } \\
\text { Information System } \\
\text { (CAMIS) reports, which } \\
\text { contain data integrity } \\
\text { issues that may affect } \\
\text { the accuracy of data } \\
\text { and/or conclusions } \\
\text { drawn from the data. } \\
\text { Relatively small number } \\
\text { of informants from any } \\
\text { one professional } \\
\text { category (e.g., two } \\
\text { judges), which may be } \\
\text { offset by } \\
\text { representativeness of } \\
\text { cW decision makers and } \\
\text { multiple responses for } \\
\text { each question. }\end{array}$ \\
\hline
\end{tabular}




\section{Appendix L: Factors Impacting Decision Making in Protection Grouped by Design}

Note: Several studies used mixed methods. Studies were grouped by the design that was the primary focus of the study and/or yielded the most data.

\begin{tabular}{|c|c|c|c|}
\hline AUTHOR ? & METHOD & No. & YES \\
\hline \multicolumn{4}{|c|}{ Secondary Data Collection - Quantitative analysis } \\
\hline Karski (1999) & $\begin{array}{l}\text { chart file review; } N=557 \\
\text { cases/reports and } 23 \\
\text { intake and assessment } \\
\text { workers }\end{array}$ & & $\begin{array}{l}\text { case characteristics influence } \\
\text { screening decisions: reports } \\
\text { where family received AFDC, } \\
\text { parental drug use was } \\
\text { alleged, there was a female } \\
\text { primary victim, or sexual } \\
\text { abuse was alleged (more } \\
\text { likely to be screened in) }\end{array}$ \\
\hline $\begin{array}{l}\text { Gryzlak, } \\
\text { Wells, \& } \\
\text { Johnson } \\
(2005)\end{array}$ & $\begin{array}{l}\text { chart file review of } 960 \\
\text { cases from five sites in } \\
\text { four states; data } \\
\text { collected for each case } \\
\text { included report } \\
\text { characteristics, child } \\
\text { characteristics, family } \\
\text { structure, worker } \\
\text { decision, and reasoning; } \\
\text { survey of caseworkers } \\
\text { and their supervisors }\end{array}$ & race alone & $\begin{array}{l}\text { predictors of screening } \\
\text { decisions: the CPS site, } \\
\text { allegation, type of injury, } \\
\text { source of the report, } \\
\text { completeness of the data } \\
\text { recording form, gender of } \\
\text { child, age of youngest child, } \\
\text { and type of parental } \\
\text { problems } \\
\text { interaction of race/ethnicity } \\
\text { and type of maltreatment } \\
\text { alleged affected screening } \\
\text { decisions; difference in } \\
\text { screening decision by race of } \\
\text { worker }\end{array}$ \\
\hline
\end{tabular}




\begin{tabular}{|c|c|c|c|}
\hline $\begin{array}{l}\text { Stevens } \\
(1998)\end{array}$ & $\begin{array}{l}\text { case record review } \\
(\mathrm{N}=336) ; \text { worker } \\
\text { questionnaire }(\mathrm{N}=180)\end{array}$ & $\begin{array}{l}\text { contextual variables (office } \\
\text { and caseload) }\end{array}$ & $\begin{array}{l}\text { case characteristics (parental } \\
\text { cooperation, parental } \\
\text { problems, child problems) } \\
\text { and individual worker traits } \\
\text { and activities (contact with } \\
\text { the child, judged severity of } \\
\text { maltreatment, worker } \\
\text { education) were predictors } \\
\text { of case decisions; race (cases } \\
\text { more likely to be opened in } \\
\text { situations where child was } \\
\text { not Black) }\end{array}$ \\
\hline $\begin{array}{l}\text { English, } \\
\text { Marshall, } \\
\text { Coghlan, } \\
\text { Brummel, \& } \\
\text { Orme (2002) }\end{array}$ & $\begin{array}{l}\text { analysis of existing data; } \\
\text { qualitative interviews; } \\
\mathrm{N}=12,871 \text { cases and } 200 \\
\text { CPS workers }\end{array}$ & race re: abuse & $\begin{array}{l}\text { race re: neglect (Native } \\
\text { Americans had higher } \\
\text { substantiation rate than } \\
\text { others and Whites had lower } \\
\text { rate than others combined), } \\
\text { gender (females higher rate } \\
\text { for sexual abuse, males } \\
\text { higher rate for neglect); } \\
\text { chronicity is the only risk } \\
\text { factor with a large effect and } \\
\text { used in a consistent manner }\end{array}$ \\
\hline $\begin{array}{l}\text { Rivaux, } \\
\text { James, } \\
\text { Wittenstrom, } \\
\text { Baumann, } \\
\text { Sheets, } \\
\text { Henry, \& } \\
\text { Jeffries } \\
\text { (2008) }\end{array}$ & $\begin{array}{l}\text { analysis of existing data; } \\
\mathrm{N}=123,621 \text { public child } \\
\text { welfare cases in } \mathrm{TX} \text {; } \\
\text { considered interaction } \\
\text { of race, poverty, and risk }\end{array}$ & & $\begin{array}{l}\text { race (Whites rated higher risk } \\
\text { than Blacks; Blacks more } \\
\text { likely to have case acted } \\
\text { upon, be removed), income } \\
\text { (lower income rated higher } \\
\text { risk), child's age, parent's } \\
\text { marital status, report source, } \\
\text { allegation type, number of } \\
\text { children in the family, teen } \\
\text { parents, and family living in } \\
\text { certain regions of the state }\end{array}$ \\
\hline \multicolumn{4}{|c|}{ Primary Data Collection - Qualitative analysis } \\
\hline Platt (2006) & $\begin{array}{l}\text { qualitative interviews } \\
\text { and chart file review; } \\
\mathrm{N}=23 \text { cases and } 14 \\
\text { workers (interviews with } \\
\text { worker and parents in } \\
\text { each case); UK }\end{array}$ & & $\begin{array}{l}\text { severity, specificity, risk, } \\
\text { parental accountability, and } \\
\text { corroboration }\end{array}$ \\
\hline $\begin{array}{l}\text { Parada, } \\
\text { Barnoff, \& } \\
\text { Coleman } \\
(2007)\end{array}$ & $\begin{array}{l}\text { qualitative; } \\
\text { documentation review } \\
\text { and interview with social } \\
\text { workers }(N=10) \text {; Canada; } \\
\text { explored "professional } \\
\text { agency" }\end{array}$ & & $\begin{array}{l}\text { professional's level of } \\
\text { experience }\end{array}$ \\
\hline $\begin{array}{l}\text { Williams \& } \\
\text { Soydan }\end{array}$ & $\begin{array}{l}\text { qualitative review of } \\
\text { original study, which }\end{array}$ & $\begin{array}{l}\text { ethnicity (quantitative } \\
\text { findings); though did find that }\end{array}$ & $\begin{array}{l}\text { among those responding to } \\
\text { vignette with ethnic cue: }\end{array}$ \\
\hline
\end{tabular}




\begin{tabular}{|c|c|c|c|}
\hline $\begin{array}{l}\text { (2005) } \\
\text { (Forslund, } \\
\text { Jergeby, } \\
\text { Soydan, \& } \\
\text { Williams, } \\
2002 \text { ) }\end{array}$ & $\begin{array}{l}\text { included mailed and } \\
\text { face-to-face } \\
\text { questionnaire including } \\
1 \text { of two vignettes, } \\
\text { ethnicity manipulated; } \\
\text { between subjects; } \\
\mathrm{N}=713 \text {; CPS social } \\
\text { workers; cross-national } \\
\text { study }\end{array}$ & $\begin{array}{l}\text { ethnic minorities were } \\
\text { generally afforded the more } \\
\text { punitive end of the } \\
\text { care/control axis } \rightarrow\end{array}$ & $\begin{array}{l}\text { evidence of stereotyping, use } \\
\text { of cultural deficit models, } \\
\text { ethnocentrism, use of } \\
\text { universalist and color-blind } \\
\text { approaches }\end{array}$ \\
\hline $\begin{array}{l}\text { Mcconnell, } \\
\text { Llewellyn, \& } \\
\text { Ferronato } \\
(2006)\end{array}$ & $\begin{array}{l}\text { reviewed } 285 \text { court files } \\
\text { and conducted } 17 \text { focus } \\
\text { groups involving } 155 \\
\text { workers, majority ( } 85 \%) \\
\text { of the group participants } \\
\text { were frontline child } \\
\text { protection workers; } \\
\text { content analysis of the } \\
\text { court files and a } \\
\text { thematic analysis of the } \\
\text { transcripts from the } \\
\text { group interviews }\end{array}$ & & parental compliance \\
\hline $\begin{array}{l}\text { Harris \& } \\
\text { Hackett } \\
(2008)\end{array}$ & $\begin{array}{l}\text { qualitative; focus } \\
\text { groups; } N=66 ; \text { various } \\
\text { professionals and clients }\end{array}$ & & $\begin{array}{l}\text { administrative data } \\
\text { demonstrated different } \\
\text { experiences by race; } \\
\text { decisions result of } \\
\text { independent process from } \\
\text { multiple systems; decision } \\
\text { outcomes influenced by both } \\
\text { attitudinal and structural } \\
\text { factors }\end{array}$ \\
\hline \multicolumn{4}{|c|}{ Primary Data Collection - Quantitative analysis } \\
\hline $\begin{array}{l}\text { Landsman \& } \\
\text { Hartley } \\
\text { (2007) }\end{array}$ & $\begin{array}{l}\text { mailed questionnaire } \\
\text { including } 5 \text { vignettes; } \\
\text { within-subjects; } N=87 \text {; } \\
\text { public } C W \text { workers }\end{array}$ & & $\begin{array}{l}\text { domestic violence, substance } \\
\text { use, race, prior referrals to } \\
\text { CPS, female told batterer to } \\
\text { leave, police involvement } \\
\text { (AA, more than one prior } \\
\text { referral, and batterer told to } \\
\text { leave decreased concerns } \\
\text { about child safety - see } \\
\text { Hansen 1997) }\end{array}$ \\
\hline $\begin{array}{l}\text { Rossi, } \\
\text { Scheurman, } \\
\text { \& Budde } \\
(1999)\end{array}$ & $\begin{array}{l}\text { mailed and face-to-face } \\
\text { questionnaire including } \\
\text { either } 70 \text { (experts) or } 18 \\
\text { (workers) case } \\
\text { summaries; within- } \\
\text { subjects; } N=27 \text { experts, } \\
103 \text { CPS investigators }\end{array}$ & $\begin{array}{l}\text { most of the } 70 \text { coded } \\
\text { variables played no role in } \\
\text { experts' or workers' decisions } \\
\text { (e.g., gender, number of } \\
\text { victims, referral source, type } \\
\text { of complaint) }\end{array}$ & $\begin{array}{l}\text { family receptiveness to } \\
\text { change and support for } \\
\text { caretaker associated with } \\
\text { placement, but also more } \\
\text { likely to receive services than } \\
\text { have a child placed; scenarios } \\
\text { involving mentally ill } \\
\text { caregivers and substance- } \\
\text { exposed infants seen as less }\end{array}$ \\
\hline
\end{tabular}




\begin{tabular}{|c|c|c|c|}
\hline & & & $\begin{array}{l}\text { serious and lower likelihood } \\
\text { of placement (SA) or services } \\
\text { (MI-both); when family } \\
\text { preservation services are } \\
\text { available, prior complaints } \\
\text { and caretaker criminal } \\
\text { records become more } \\
\text { important in decision- } \\
\text { making; families with prior } \\
\text { complaint records were much } \\
\text { more likely to have their } \\
\text { children taken into custody; } \\
\text { families who were interested } \\
\text { in changing and in which } \\
\text { there was income from } \\
\text { employment were less likely } \\
\text { to have children placed and } \\
\text { more likely to be referred for } \\
\text { services }\end{array}$ \\
\hline $\begin{array}{l}\text { Galante } \\
\text { (1999) }\end{array}$ & $\begin{array}{l}\text { mailed questionnaire } \\
\text { including } 1 \text { of } 12 \\
\text { vignettes; between- } \\
\text { subjects; } \mathrm{N}=903 \mathrm{CW} \\
\text { workers from NASW } \\
\text { sample }\end{array}$ & & $\begin{array}{l}\text { type of maltreatment; race } \\
\text { (White children more likely to } \\
\text { be removed, thus protected, } \\
\text { than Black children) }\end{array}$ \\
\hline $\begin{array}{l}\text { Gammon } \\
(2000)\end{array}$ & $\begin{array}{l}\text { mailed questionnaire } \\
\text { including } 1 \text { of } 4 \\
\text { vignettes; between- } \\
\text { subjects; N=534 CW } \\
\text { workers from NASW } \\
\text { sample }\end{array}$ & $\begin{array}{l}\text { race and SES (re: } \\
\text { reunification decisions) }\end{array}$ & $\begin{array}{l}\text { worker gender (male more } \\
\text { likely to have child remain in } \\
\text { FC), years in the field (more } \\
\text { experienced workers more } \\
\text { likely to reunify) }\end{array}$ \\
\hline $\begin{array}{l}\text { Britner \& } \\
\text { Mossler } \\
(2002)\end{array}$ & $\begin{array}{l}\text { mailed questionnaire } \\
\text { including } 4 \text { vignettes; } \\
\text { within-subjects; } N=90 \text {; } \\
\text { various professionals } \\
\text { (judges, GAL's, CASA, } \\
\text { SW's, mental health } \\
\text { providers) }\end{array}$ & $\begin{array}{l}\text { professional rating of } \\
\text { importance of various kinds } \\
\text { of information not impacted } \\
\text { by race, age, or chronicity }\end{array}$ & professional affiliation \\
\hline Lazar (2006) & $\begin{array}{l}\text { mailed questionnaire } \\
\text { including } 1 \text { of } 4 \\
\text { vignettes; between } \\
\text { subjects; } N=145 ; \text { CPS } \\
\text { social workers; Israel }\end{array}$ & & $\begin{array}{l}\text { decision regarding severity of } \\
\text { intervention associated with } \\
\text { child's gender (more severe } \\
\text { reaction for girls), worker } \\
\text { gender (females chose less } \\
\text { severe interventions), and } \\
\text { worker authoritarianism } \\
\text { (more authoritarian chose } \\
\text { more severe interventions) }\end{array}$ \\
\hline
\end{tabular}




\section{Appendix M: Factors Impacting Decision Making in Child Protection - Checklist}

Note: An empty cell indicates that the factor was not included as a study variable or the author(s) did not report specific findings related to this variable.

$Y=$ Yes $\quad N=$ No 


\begin{tabular}{|c|c|c|c|c|c|c|c|c|c|c|c|c|c|}
\hline & \multicolumn{13}{|c|}{ Case Characteristics } \\
\hline & $\begin{array}{l}\text { Race } \\
\text { Alone }\end{array}$ & \begin{tabular}{|l|} 
Race \& \\
Maltreat- \\
ment \\
Type
\end{tabular} & \begin{tabular}{|l|} 
Family \\
Structure
\end{tabular} & SES & Risk & \begin{tabular}{|l|} 
Parental \\
Compliance
\end{tabular} & \begin{tabular}{|l|} 
Maltreatment/Injury \\
Type or Severity
\end{tabular} & \begin{tabular}{|l|} 
Gender \\
\end{tabular} & Age & $\begin{array}{l}\text { Parental } \\
\text { Problems } \\
\text { (DV, SA, } \\
\text { MH) }\end{array}$ & $\begin{array}{l}\text { Chronicity/Prior } \\
\text { Complaints }\end{array}$ & \begin{tabular}{|l|} 
Marital \\
Status
\end{tabular} & \begin{tabular}{|l|} 
Report \\
Source
\end{tabular} \\
\hline INTAKE & 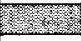 & & & & If & & 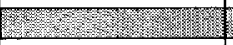 & 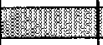 & 20 & & 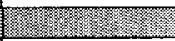 & 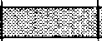 & 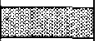 \\
\hline Karski (1999) & & & $\mathrm{N}$ & 4 & & 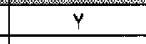 & $\mathrm{Y}$ & $\mathrm{Y}$ & & Y & & & \\
\hline Gryzlak et al. (2005) & $\mathrm{N}$ & $Y$ & & & & & $y$ & $\mathrm{Y}$ & $Y$ & $y$ & & & $Y$ \\
\hline Platt (2006) & & & & & $r$ & $\bar{\varphi}$ & $Y$ & & & & & & \\
\hline Parada et al. (2007) & & & & & & & & & & & & & \\
\hline INVESTIGATION & & 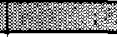 & 2 & (1.) & 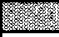 & 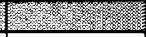 & 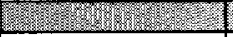 & 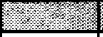 & 2 & 0 & 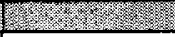 & 4 प्रा & 28 \\
\hline Stevens (1998) & Y & & & & & Y & & & & $Y$ & & & \\
\hline English et al. (2002) & & $\begin{array}{c}Y \\
\text { (neglect) } \\
N \\
\text { (abuse) }\end{array}$ & & & $\bar{y}$ & & & Y & & & Y & & \\
\hline $\begin{array}{l}\text { Williams \& Soydan } \\
(2005)\end{array}$ & $\mathrm{N}$ & & & & & & & & & & & & \\
\hline Forslund et al. (2002) & & & & & & & & & & & & & \\
\hline McConnell et al. $\{2006\}$ & & & & & & Y & & & & & & & \\
\hline $\begin{array}{l}\text { Landsman \& Hartley } \\
\text { (2007) }\end{array}$ & & & & & & & & & & y & y & & \\
\hline REMOVAL/PLACEMENT & 12 & 2 & & (2) & & & $z^{2}$ & 2 & 2 & en & & & $\sqrt{125 e}$ \\
\hline Rossiet al. (1999) & & & & $y$ & & $r$ & $\mathrm{~N}$ & $\mathrm{~N}$ & 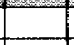 & y & $y$ & & $\mathrm{~N}$ \\
\hline Galante (1999) & $\bar{Y}$ & & & & & & $\mathrm{Y}$ & & & & & & \\
\hline Gammon $(2000)$ & $\mathrm{N}$ & & & $\mathrm{N}$ & & & & & & & & & \\
\hline $\begin{array}{l}\text { Britner \& Mossler } \\
(2002)\end{array}$ & $\mathrm{N}$ & & & & & & & & $\mathrm{N}$ & & $\mathrm{N}$ & & \\
\hline Lazar (2006) & & & & & & & & Y & & & & & \\
\hline Rivaux et al. (2008) & $y$ & & & $y$ & & & $y$ & & $r$ & & & प्रेशि? & $Y$ \\
\hline MULTIPLE DM POINIS & $\sqrt{21}$ & & & & & 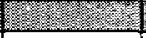 & 20 & 210 & 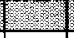 & $2 \pi$ & 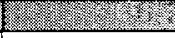 & 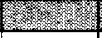 & DIII: \\
\hline $\begin{array}{l}\text { Harris \& Hackett } \\
\text { (2008) }\end{array}$ & Y & & & & & & & & & & & & \\
\hline
\end{tabular}




\begin{tabular}{|c|c|c|c|c|c|c|c|c|c|}
\hline & \multicolumn{9}{|c|}{ Professional Characteristics } \\
\hline & Race & Gender & $\begin{array}{l}\text { Years of } \\
\text { Experience }\end{array}$ & $\begin{array}{l}\text { Contextual } \\
\text { Variables (CPS } \\
\text { Site, Office, } \\
\text { Caseload) }\end{array}$ & $\begin{array}{l}\text { Completeness } \\
\text { of Data } \\
\text { Recarding }\end{array}$ & \begin{tabular}{|l|} 
Education \\
\end{tabular} & $\begin{array}{l}\text { Professional } \\
\text { Affiliation }\end{array}$ & Authoritarianism & Stereotyping \\
\hline INTAKE & 8 & 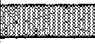 & A & 20 & & ateme & 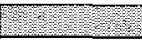 & & 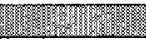 \\
\hline Karski (1999) & & & & & & & & & \\
\hline Gryzlaket al. (2005) & Y & & & & $\bar{Y}$ & & & & \\
\hline Platt (2006) & & & & & & & & & \\
\hline Parada et al. (2007) & & & $y$ & & & & & & \\
\hline INVESTIGATION & & & & 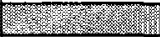 & 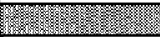 & & 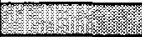 & & 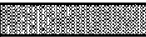 \\
\hline Stevens (1998) & & & & $\mathrm{N}$ & & Y & & & \\
\hline English et al. (2002) & & & & & & & & & \\
\hline Williams \& Soydan \{2005) & & & & & & & & & Y \\
\hline Forslund et al. $\{2002\}$ & & & & & & & & & \\
\hline McConnell et af. (2006) & & & & & & & & & \\
\hline Landsman \& Hartley $\{2007\}$ & & & & & & & & & \\
\hline REMOVAL/PLACEMENT & 3 & 12 & 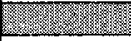 & 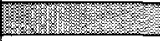 & 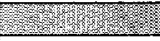 & 18020 & 20 & 15. never? & $10-2$ \\
\hline Rossietal. (1999) & & & & & & & & & \\
\hline Galante (1999) & & & & & & & & & \\
\hline Gammon $(2000)$ & & $\bar{Y}$ & $y$ & & & & & & \\
\hline Britner \& Mossler \{2002) & & & & & & & Y & & \\
\hline Lazar (2006) & & 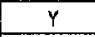 & & & & & & 4 & \\
\hline Rivaux et al. $[2008\}$ & & & & & & & & & \\
\hline MULTIPLE DM POINTS & 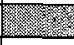 & 7 & 20: & 2 & 25 & 2a & 2010 & H & 4 \\
\hline Harris \& Hackett (2008) & & & & Y & & & & & \\
\hline
\end{tabular}




\title{
CURRICULUM VITAE
}

\section{LISA MICHELE JOHNSON}

\author{
1120 Cherokee Road \\ Apartment 4 \\ Louisville, KY 40204 \\ 828.777 .0059 \\ Imjohn15@louisville.edu
}

\section{EDUCATION}

Doctor of Philosophy in Social Work, August 2009

University of Louisville

Dissertation: Correlates of Intake and Disposition Decisions by Child Protective Services

Professionals

Master of Social Work, January 2001

University of Illinois at Urbana-Champaign

Specialization: Child Welfare, Concentration: Policy, Planning, Administration

Bachelor of Science, May 1999

University of North Carolina at Greensboro

Major: Social Work, Minor: African American Studies

\section{RESEARCH INTERESTS}

Child welfare, professional decision-making, cultural diversity and competency, training and program evaluation, social work education 


\section{TEACHING EXPERIENCE}

Lecturer, University of Louisville, Kent School of Social Work

January 2009 - April 2009

Social Work 669: Advanced Research Practice II

This course prepares students to disseminate best practices information to micro and macro practice settings, and evaluate the impact of their dissemination efforts via use of quantitative and qualitative methods and analysis.

August 2008 - December 2008

Social Work 668: Advanced Research Practice I

This course prepares students to evaluate information gathered through literature reviews, practice wisdom, and consumer perspectives to inform best practices in social work. A plan to incorporate critically appraised information into current micro and/or macro social work practice is developed.

Teaching Practicum, University of Louisville, Kent School of Social Work August 2007 - December 2007

Social Work 603: Human Diversity

This foundation course is designed to provide students with the knowledge and skills for social work practice with people who are subject to various forms of oppression (e.g., racism, sexism, heterosexism, classism, ageism, and ableism) operating at the individual, community and institutional levels of society. Cultural diversity and strengths are emphasized. Development of greater professional and personal awareness about the impacts of various forms of oppression is addressed.

\section{RESEARCH EXPERIENCE}

Research Practicum, University of Louisville, Kent School of Social Work June 2007 - present Evaluation of a Graduate Human Diversity Course

Evaluating the extent to which human diversity education influences students' knowledge about, attitudes toward, and practice with culturally diverse populations. Designed the study, developed the survey instrument, and administered the survey to students and their field placement supervisors (with support from a faculty mentor). Entering the data analysis phase of the study. 
Research Practicum, University of Louisville, Kent School of Social Work April 2007 - August 2008

Evaluation of an Anti-Racism Training

Evaluated effectiveness of an anti-racism training in impacting the following participant outcomes: training satisfaction, knowledge about and attitudes towards race and racism, and anticipated transfer of skills learned in the training to professional practice. Responsible for the following project elements (with support from faculty mentors): designing the study, developing the survey instrument, working collaboratively with community partners, administering the survey, analyzing the data, synthesizing literature and documenting findings, writing and submitting a report to the public child welfare agency, presenting findings to colleagues and community members, and submitting a manuscript to a peer-reviewed journal for publication.

Graduate Research Assistant, University of Louisville Kent School of Social Work August 2006 - present

Contribute to publication of research findings and facilitate trainings for professionals and community members in connection with the following grants: Department for Health and Human Services, Administration on Children, Youth and Families, Children's Bureau (funded). 2003-2008, $\$ 1,000,000$. The Prevention of Child Maltreatment through Child Welfare Training on Healthy Marriage and Family Formation. PI: Becky Antle; Co-PI: Bibhuti Sar. Consultant: Anita Barbee.

Department for Health and Human Services, Administration on Children, Youth and Families, Children's Bureau (funded). 2005-2008. $\$ 960,000$. Evidence-Based Supervisor-Team Independent Living Training. PI: Anita Barbee, Co-PI: Becky Antle.

Department for Health and Human Services, Administration on Children, Youth and Families, Office of Family Assistance (funded). 2006-2011. \$2.5 million. Promoting Healthy Relationships for At-Risk Adults and Youth through Community-Based Training and Collaboration. PI: Becky Antle, Co-PI: Bibhuti Sar, Evaluator: Anita Barbee.

Eastern Kentucky University and the Cabinet for Families and Children (funded). \$175,714. Child Welfare Training Assessment Project.

PI: Anita Barbee.

Undergraduate Research Assistant, UNCG Social Work Department August 1998 - May 1999

Assisted professor in a study of homeless and runaway youth. Coded and analyzed data. Completed individual data analysis as part of a larger study. Completed qualitative research study. 


\section{PROFESSIONAL EXPERIENCE}

Contract Employee, Center for Participatory Change

March 2005 - July 2006

Partnered with CPC staff to build the capacities of local nonprofit organizations. Facilitated meetings and retreats with nonprofit staff and boards focusing on planning, development, and organizational structure.

Social Worker, Mission Hospitals

December 2003 - July 2006

Worked in the Emergency Department. Assessed risk to vulnerable populations. Provided supportive intervention to patients and families, including referral to community service agencies.

Social Worker III, Buncombe County Department of Social Services January 2002 - December 2003

Worked in Child Protective Services. Provided case planning and case management services to children who were placed at risk by abuse, neglect and/or dependency and their families.

Social Worker III, Forsyth County Department of Social Services March 2001 - December 2001

Worked in Child Protective Services. Provided investigative social work services to children who were identified as victims/potential victims of abuse, neglect, and/or dependency and their families.

Intern, National Association of Social Workers Illinois Chapter June 2000 - December 2000

Planned committee meetings and events. Served as staff liaison to committees. Assisted in lobbying and political action efforts.

Graduate Assistant, UIUC School of Social Work Admissions Office January 2000 - May 2000

Prepared prospective student files for admissions review. Communicated with students concerning graduate school and related issues. Facilitated student visits.

Intern and Resident Manager, Mary's House, Inc.

August 1998 - May 1999

Worked with mothers in substance abuse recovery and their children. Performed case management duties. Assisted in grant-writing and fundraising activities. 


\section{PEER-REVIEWED PUBLICATIONS}

Johnson, L. M., Antle, B. F., \& Barbee, A. P. (2009). Addressing disproportionality and disparity in child welfare: Evaluation of an anti-racism training for community service providers. Children and Youth Services Review, 31(6), 688-696.

Barney, R. J., Buckingham, S. L., Friedrich, J. M., Johnson, L. M., \& Robinson, M. A. (in press). The ethics of the President's Emergency Plan for AIDS Relief (PEPFAR): A social work analysis and call to action. Journal of Sociology and Social Welfare.

Antle, B. F., Barbee, A. P., Sullivan, D. J., Taylor, J., \& Johnson, L., (in press).

Matrix of twelve independent living curricula. Special Issue on Independent Living in Training and Development in Human Services, 9. and Child and Youth Care Work.

Antle, B. F., Johnson, L., Barbee, A., \& Sullivan, D. (2009). Fostering interdependent versus independent living in youth aging out of care through healthy relationships. Families in Society, 90(3), 309-315.

Christensen, D. N., Antle, B. F., \& Johnson, L. (2008). Practice Skills for Couple Teamwork Conversations in Child Welfare. Journal of Family Social Work,11(3), 303-322.

Antle, B. F., Barbee, A. P., Sullivan, D., Yankeelov, P., Johnson, L., \& Cunningham, M. R. (2007). The relationship between domestic violence and child neglect. Brief Treatment and Crisis Intervention, 7(4), 364-382.

\section{OTHER PUBLICATIONS}

Johnson, L., M., Barbee, A. P. \& Antle, B. F. (2009). Addressing disproportionality and disparity in child welfare: Preliminary results from an evaluation of an anti-racism training for community service providers. Proceedings of the Eleventh Annual National Human Services Training Evaluation Symposium: 2008. Berkeley, CA: CalSWEC.

Johnson, L. (2001, February). African American chapter leaders discuss diversity in social work. Social Work Networker: National Association of Social Workers Illinois Chapter, 40(1), 1-7.

\section{MANUSCRIPTS UNDER REVIEW}

Sar, B. K., Antle, B. F., \& Johnson, L. M. "Fostering" healthy couple relationships of foster parents. Child \& Family Social Work. 


\section{MANUSCRIPTS IN PREPARATION}

Barbee, A. P., Antle, B. F., \& Johnson, L. M. Kinship care as a part of the family preservation continuum: Relevance of attachment theory.

\section{PROFESSIONAL PRESENTATIONS}

Johnson, L. M. (2009, November 6 - 9). Using the Internet as a Tool for Discussion of Heterosexism. Electronic poster accepted for presentation at the $55^{\text {th }}$ Annual Program Meeting (November 6-9, 2009), sponsored by the Council on Social Work Education, San Antonio, TX.

Johnson, L. M., Barbee, A. P., \& Antle, B. F. (2009, April 1). Fostering interdependent versus independent living in youth aging out of care through healthy relationships. Presentation made at the $17^{\text {th }}$ National Conference on Child Abuse and Neglect (March 30 - April 4, 2009), sponsored by the Children's Bureau, Atlanta, GA.

Johnson, L. M., \& Taylor, J. (2008, September 10). Time is Ticking: Tools for Transitioning Youth - Cultural Competence and Youth Development. Presentation made at the Louisville Youth Summit (September 10-11, 2008), sponsored by the University of Louisville Kent School of Social Work, Louisville, KY.

Johnson, L. M., \& Taylor, J. (2008, September 11). Time is Ticking: Tools for Transitioning Youth - Healthy Relationships. Presentation made at the Louisville Youth Summit (September 10-11, 2008), sponsored by the University of Louisville Kent School of Social Work, Louisville, KY.

Michalczyk, L., \& Johnson, L. M. (2008, September 10). Overview of the Race, Community, and Child Welfare Initiative. Presentation made at the Louisville Youth Summit (September 10-11, 2008), sponsored by the University of Louisville Kent School of Social Work, Louisville, KY.

Barney, R., Buckingham, S., \& Johnson, L. (2008, May 25). The Ethics of the President's Emergency Plan for AIDS Relief (PEPFAR): A Social Work Analysis and Call to Action. Presentation made at the $20^{\text {th }}$ Annual National Conference on Social Work and HIV/AIDS (May 22-25, 2008), sponsored by the Boston College School of Social Work, Washington, DC.

Johnson, L. M., \& Barbee, A. P. (2008, May 23). Evaluation of the Undoing Racism Training in Kentucky. Presentation made at the $11^{\text {th }}$ Annual National Human Services Training Evaluation Symposium (May 21-23, 2008), sponsored by the University of California, Berkeley School of Social Welfare, Berkeley, CA. 
Barney, R., Buckingham, S., Friedrich, J., Johnson, L., \& Robinson, M. (2007, May 26). HIV/AIDS Research and Education: A Proposed Model for Doctoral Students.

Presentation made at the $19^{\text {th }}$ Annual National Conference on Social Work and HIV/AIDS (May 24-27, 2007), sponsored by the Boston College School of Social Work, Albuquerque, NM.

Antle, B. F., Ratcliffe, P., \& Johnson, L. (2006, November 7). Building Couple Teams for Child Protection. Presentation made at the National Parent Advocacy Conference, sponsored by the Annie E. Casey Foundation, Louisville, KY.

Antle, B. F., Sar, B., \& Johnson, L. (2006, October 23). Conflict Resolution and Healthy Communication. Presentation made at the Neighborhood Place Annual Meeting, Louisville, KY.

Antle, B. F., Sar, B., \& Johnson, L. (2006, October 23). Engaging Fathers and Keeping Kids Safe. Presentation made at the Neighborhood Place Annual Meeting, Louisville, KY.

Williams, N. R., Lindsey, E., Kurtz, D., Jarvis, S., \& Johnson, L. M. (2000, January 7). From trauma to resiliency: Lessons from runaway and homeless youth. Presentation made at the QUIG 2000 Conference on Qualitative Research in Education (January $6-8,2000$ ), sponsored by the University of Georgia College of Education, Athens, GA.

\section{COMMITTEE AND PROFESSIONAL MEMBERSHIPS}

Jefferson County Race, Community, and Child Welfare Initiative Advisory Board Evaluation Committee Chair

March 2008 - June 2009

Kent School of Social Work, Faculty Search Committee

September 2007 - February 2008

Race, Community, and Child Welfare Conference Planning Committee

February 2007 - December 2007

Casey Family Programs, Breakthrough Series Collaborative, Jefferson County Extended Community Team

February 2007 - July 2007

Council on Social Work Education

October 2006 - present 


\section{HONORS AND AWARDS}

Southern Regional Education Board Dissertation Year Fellowship (2008 - 2009)

UIUC Graduate School Fellowship (1999 - 2000)

UNCG Katherine Smith Reynolds Scholar (1995 - 1999)

UNCG Scholastic Achievement Award (1995 - 1999)

UNCG Undergraduate Research Assistantship (1998 - 1999)

Completed UNCG Honors Program (1999)

UNCG Outstanding Senior (1999)

Human Environmental Sciences Outstanding Senior in Social Work (1999)

Alpha Delta Mu Social Work Honor Society $(1999,2001)$

UNCG Golden Chain Honor Society (1997)

UNCG University Marshal (1997 - 1999)

\section{COMMUNITY SERVICE}

Citizens of Louisville Organized and United Together (CLOUT)

Treasurer

March 2007 - August 2009

Serve as Treasurer, Research Committee member, and Justice Ministry Team member. Participate in community organizing and fundraising activities to promote social justice and systemic change.

\section{Project Women}

December 2007

Created a brief curriculum and facilitated a staff development session on professional boundaries.

Blue Apple Players

January, June, July 2007, November 2008

Provided consultation to actors employed for training social workers to complete effective child protection interviews.

Center for Participatory Change

September 2004 - July 2006

Coordinated a qualitative evaluation and inquiry project. Planned the evaluation (with a CPC staff member). Conducted qualitative interviews or focus groups with 11 grassroots groups and CPC staff. Analyzed transcribed interviews.

United Way of McDowell County

January 2001 - March 2001

Assisted in an evaluation of services by interviewing several United Way-funded agencies in the county, transcribing the information, and writing a report of the findings. 